\author{
UNIVERSIDADE DE SÃO PAULO \\ INSTITUTO DE ENERGIA E AMBIENTE \\ PROGRAMA DE PÓS-GRADUAÇÃO EM ENERGIA
}

RICARDO DA SILVA BENEDITO

ANÁLISE DE UM MECANISMO DE COMPENSAÇÃO DE REATIVOS INCORPORADO AOS INVERSORES DE UM SISTEMA FOTOVOLTAICO CONECTADO À REDE ELÉTRICA 
RICARDO DA SILVA BENEDITO

\section{ANÁLISE DE UM MECANISMO DE COMPENSAÇÃO DE REATIVOS INCORPORADO AOS INVERSORES DE UM SISTEMA FOTOVOLTAICO CONECTADO À REDE ELÉTRICA}

Tese apresentada ao Programa de PósGraduação em Energia do Instituto de Energia e Ambiente da Universidade de São Paulo para a obtenção do título de Doutor em Ciências.

Orientador: Prof. Dr. Roberto Zilles

Versão Corrigida

(Versão original disponível na Biblioteca da Unidade que aloja o Programa e na Biblioteca Digital de Teses e Dissertações da USP)

SÃO PAULO 
AUTORIZO A REPRODUÇÃO E DIVULGAÇÃO TOTAL OU PARCIAL DESTE TRABALHO, POR QUALQUER MEIO CONVENCIONAL OU ELETRÔNICO, PARA FINS DE ESTUDO E PESQUISA, DESDE QUE CITADA A FONTE.

FICHA CATALOGRÁFICA

Benedito, Ricardo da Silva.

Análise de um mecanismo de compensação de reativos incorporado aos inversores de um sistema fotovoltaico conectado à rede elétrica./ Ricardo da Silva Benedito; orientador : Roberto Zilles. - São Paulo, 2014.

130 f.: il.; $30 \mathrm{~cm}$.

Tese (Doutorado em Ciência) - Programa de Pós-Graduação em Energia - Instituto de Energia e Ambiente da Universidade de São Paulo

1. Redes de distribuição elétrica. 2. Sistemas fotovoltaicos. 3. Geração de distribuída. I. Título 
RICARDO DA SILVA BENEDITO

ANÁLISE DE UM MECANISMO DE COMPENSAÇÃO DE REATIVOS INCORPORADO AOS INVERSORES DE UM SISTEMA FOTOVOLTAICO CONECTADO À REDE ELÉTRICA

TESE DEFENDIDA E APROVADA, EM 14/11/2014, PELA COMISSÃO JULGADORA:

Prof. Dr. Roberto Zilles (Orientador e presidente) - Universidade de São Paulo (USP)

Prof. Dr. Eduardo Lorenzo Pigueiras - Universidade Politécnica de Madrid (UPM)

Dr. Hélio Eiji Sueta - Universidade de São Paulo (USP)

Prof. Dr. João Tavares Pinho - Universidade Federal do Pará (UFPA)

Prof. Dr. Wilson Negrão Macêdo - Universidade Federal do Pará (UFPA) 


\section{DEDICATÓRIA}

Dedico este trabalho a todos os estudantes que, assim como eu, precisaram ou precisam trabalhar durante o Doutorado e aos respectivos orientadores e empregadores que os apoiaram ou os apoiam durante sua jornada. É difícil mas não impossível! 


\section{AGRADECIMENTOS}

Primeiramente agradeço a meu orientador, o professor Roberto Zilles, pelas excelentes oportunidades que me concedeu nos campos acadêmico, profissional e pessoal, nos quase oito anos entre o Mestrado e o Doutorado.

Em seguida, quero agradecer ao apoio incondicional recebido de minha esposa Paula, meus filhos Luana e Henrique e minha querida mãe Maria Alice. Eles tiveram compreensão nos momentos em que estive ausente por conta das obrigações acadêmicas e profissionais.

Também gostaria de agradecer as empresas CTEEP e CESP, que viabilizaram os recursos financeiros do projeto de P\&D denominado "Desenvolvimento de Competências e Avaliação de Arranjos Técnicos e Comerciais em Geração Distribuída com Sistemas Fotovoltaicos Conectados à Rede", no âmbito do qual este doutorado foi desenvolvido.

Eu não poderia jamais deixar de agradecer a todos os colegas do Laboratório de Sistemas Fotovoltaicos (somos em muitos!), mas quero citar os nomes de alguns que foram determinantes na minha jornada, seja pelo apoio emocional, técnico ou logístico, que são o Aimé, o Alex, o André, a Cristina, o Gilberto, o Givaldo, o Lourival e o Teddy.

Além dessas pessoas, há uma enorme legião de colaboradores deste trabalho. Fatalmente vou me esquecer de citar alguém (que me perdoem se isso ocorrer!), mas vou tentar agradecer a todos. Do IEE-USP: Andressa, Fátima, Lourdes e Penha (biblioteca), Fernandes e Gustavo (laboratório de metrologia), Dr. Welson Bassi, Alcântaro, Paulo Dantas e Sr. Rogério Grosche. Da empresa Sindustrial os funcionários Cícero e Valdir. Da empresa WEG os funcionários Ismael, Flávio e Luiz. Da empresa Landis+Gyr o funcionário José Scallete. Da Universidade Nove de Julho os professores Antônio Manuel Alves de Morais e Carlos Berto. Da Universidade São Judas Tadeu os professores Robson Colantonio, Romildo de Campos e Sandro Martini.

Estendo meus agradecimentos aos colegas Leonardo Testoni, sem o apoio do qual eu não teria tomado a decisão que mudou o rumo do meu doutorado e ao Ricardo Barros Fiziotto, ambos companheiros de longa data lá do Instituto de Física da USP que, junto com suas esposas Andréia e Elaine (respectivamente!), têm proporcionado a mim e à minha esposa Paula momentos de descontração, de reflexão e crescimento pessoal e profissional.

Finalmente, obrigado a todos os familiares, colegas e conhecidos que me apoiaram de qualquer maneira que puderam! 


\section{RESUMO}

BENEDITO, Ricardo da Silva. Análise de um mecanismo de compensação de reativos incorporado aos inversores de um sistema fotovoltaico conectado à rede elétrica, 2014, 130 f. Tese (Doutorado em Ciências) - Programa de Pós-Graduação em Energia da Universidade de São Paulo, São Paulo, 2014.

No Brasil, quando uma unidade consumidora (UC) sob regime de microgeração ou de minigeração distribuída tem parte ou a totalidade da sua demanda por potência ativa suprida pela planta geradora, mas sua demanda por potência reativa é atendida exclusivamente pela rede elétrica, verifica-se uma aparente deterioração do fator de potência dessa UC, sob a ótica da concessionária. Esse efeito decorre do fato de que o fator de potência, de acordo com a regulamentação vigente, é determinado apenas a partir das medições dos fluxos de potência ativa e reativa trocados entre a $\mathrm{UC}$ e a rede elétrica e não também entre a planta geradora e UC. Para consumidores do Grupo A (tensão de fornecimento igual ou superior a 2,3 kV) nessa situação, de acordo com o perfil da carga, pode haver cobrança por excedentes de reativos, constituindo-se assim uma barreira. Especificamente no caso de sistemas fotovoltaicos conectados à rede, existe a possibilidade de se utilizar os próprios inversores c.c.-c.a para suprir a demanda de reativos da UC e, dessa forma, minimizar o problema apresentado. Com o objetivo de se avaliar essa alternativa no contexto brasileiro, tendo-se em vista condições reais de operação e os limites normativos de injeção de potência reativa para inversores de sistemas fotovoltaicos, foi realizado um estudo de caso de uma planta fotovoltaica instalada no telhado do prédio da Administração do Instituto de Energia e Ambiente da Universidade de São Paulo. O estudo mostrou que a compensação realizada por meio do inversor selecionado evitou a cobrança de excedentes de reativos sem afetar de forma significativa a produtividade do sistema fotovoltaico. Do ponto de vista elétrico, verificou-se que a injeção de reativos pelo inversor não provocou variações significativas de tensão no ponto de acoplamento ou no alimentador e, ainda, se verificou considerável liberação de capacidade do sistema supridor da concessionária. Dessa forma, a análise dos resultados indica uma tendência a se considerar a compensação de reativos proporcionada pelo próprio inversor a opção mais viável para se lidar com os excedentes de reativos, comparativamente a métodos convencionais de compensação ou à situação em que nenhuma ação compensatória seja implementada.

Palavras-chave: geração distribuída, sistemas fotovoltaicos conectados à rede, compensação de reativos. 


\begin{abstract}
BENEDITO, Ricardo da Silva. Analysis of a reactive power compensation mechanism incorporated into inverters of a grid-connected photovoltaic system, 2014, $126 \mathrm{f}$. Thesis (Ph.D.) - São Paulo University Graduate Program on Energy, São Paulo, 2014.
\end{abstract}

In Brazil, when a consumer unit (CU) under a distributed microgeneration or minigeneration scheme has part or all of its demand for active power supplied by the generating plant, but its demand for reactive power is served exclusively by the grid, the power factor of this CU appears deteriorated, from the perspective of the utility. This effect is due to the fact the power factor, according to the current regulations, is determined only from measurements of the flows of active and reactive power exchanged between the UC and the grid and not also between the generating plant and UC. Users of group A (supply voltage equal to or greater than $2.3 \mathrm{kV}$ ) in this situation, according to the $\mathrm{CU}$ load profile, may be charged due the reactive power excess, thus constituting a barrier. Specifically in the case of grid-connected photovoltaic systems, there is the possibility of using the d.c.- a.c. inverters to suply the CU reactive power demand and, thus, minimizing the presented problem. In order to evaluate this alternative in the Brazilian context, keeping in view real operating conditions and regulatory limits for the reactive power injection for photovoltaic inverters, we conducted a case study with a photovoltaic plant installed on the roof of the University of São Paulo Institute for Energy and Environment administration building. The study showed that the compensation performed by the selected inverter prevented the reactive power excess charging without affecting significantly the photovoltaic system productivity. From an electrical point of view, it was found that the injection of reactive power by the inverter did not cause significant voltage variations at the coupling point or at the transformer and, additionally, there was a significant release in the utility suply system capacity. Thus, the analysis results indicates a tendency to consider the compensation provided by the inverter itself the most viable option for dealing with the surplus of reactive power compared to conventional compensation methods or to the situation in which no compensatory action is implemented.

Keywords: distributed generation, grid-connected photovoltaic systems, reactive power compensation. 


\section{LISTA DE FIGURAS}

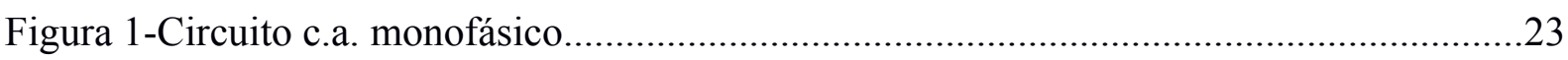

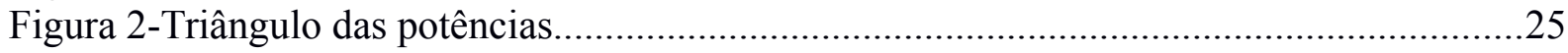

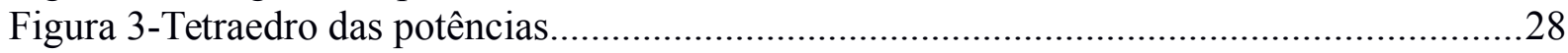

Figura 4-Circuito trifásico com ligação da carga em Y......................................................29

Figura 5-Esquema para medição de potência ativa com a carga ligada em Y.........................32

Figura 6-Esquema para medição de potência reativa com a carga ligada em Y......................33

Figura 7- Correção do fator de potência para cargas lineares...............................................37

Figura 8- Correção do fator de potência para cargas não-lineares..........................................38

Figura 9- Representação fasorial da tensão e das correntes em um circuito LC.......................41

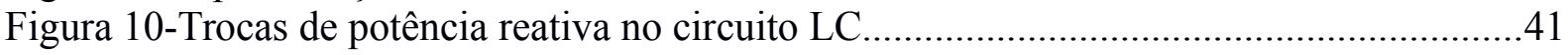

Figura 11- Irradiância para céu nublado e céu limpo..........................................................46

Figura 12- Diferença entre as irradiações de céu limpo e de céu nublado...............................48

Figura 13-Topologia básica de um inversor monofásico sem transformador..........................51

Figura 14-Circuito equivalente no acoplamento do inversor à rede......................................51

Figura 15-Topologia básica de um inversor trifásico sem transformador...............................52

Figura 16- Diagrama unifilar das instalações elétricas do sistema CRPV ..............................57

Figura 17 - Gerador fotovoltaico de $78 \mathrm{kWp}$ sobre o edifício da Administração do IEE - USP

Figura 18- Detalhes da fixação dos arranjos de módulos fotovoltaicos ao telhado.....................58

Figura 19-Inversor AURORA TRIO PVI 12.5-TL-OUTDS.................................................59

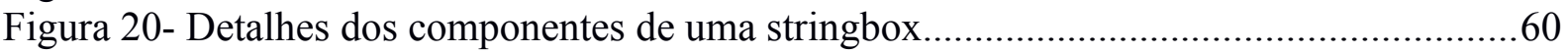

Figura 21-Diagrama de blocos do inversor AURORA PVI 12.5-TL-OUTD-S.........................61

Figura 22- Abrigo contendo transformador de $75 \mathrm{kVA}(380 \mathrm{~V} / 220 \mathrm{~V})$ e painel de proteção.....63

Figura 23-Detalhes do painel de proteção do sistema CRPV .................................................63

Figura 24- Vistas superior e traseira do transformador de $380 \mathrm{~V} / 220 \mathrm{~V}$...............................64

Figura 25-Diagramas elétrico e vetorial do transformador de $380 \mathrm{~V} / 220 \mathrm{~V}$.......................64

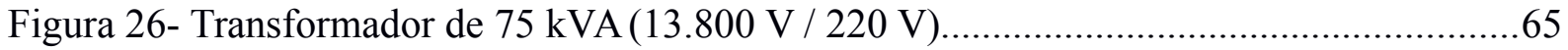

Figura 27-Quadro geral do prédio da Administração do IEE-USP..........................................66

Figura 28- Canaletas metálicas com circuitos independentes seguindo para o quadro geral...67

Figura 29- Circuitos de comunicação e de energia provenientes dos 5 inversores...................67

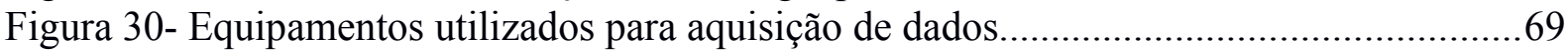

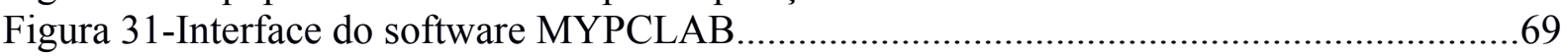

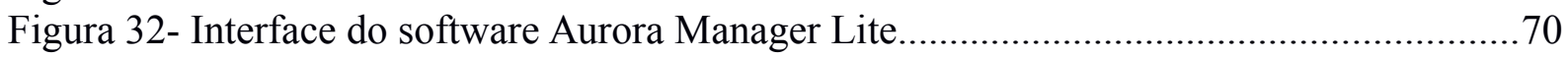

Figura 33- Interface do software Aurora Communicator..................................................... 70

Figura 34- Sistema de aquisição dados dos inversores, de irradiância e de temperatura...........71

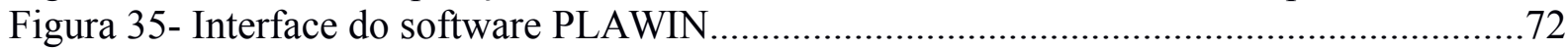

Figura 36-Ligação dos medidores de energia elétrica no quadro geral....................................73

Figura 37- Demanda de potência ativa do prédio da Administração.......................................76

Figura 38- Demanda de potência reativa do prédio da Administração...................................76

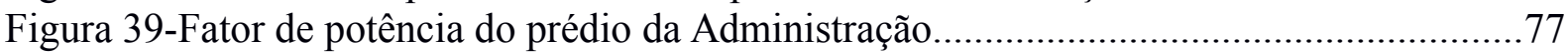

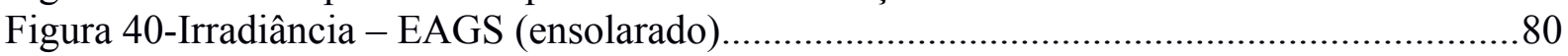

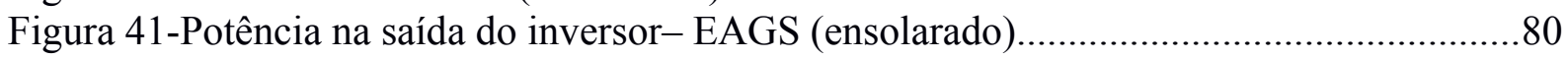

Figura 42- Sombreamento das fileiras 2 a 5 no período da tarde - estação inverno..................81

Figura 43- Disposição das células dos módulos SUNMODULE 260 ....................................82

Figura 44-Sombreamento com o módulo disposto na horizontal............................................82

Figura 45- Sombreamento com o módulo disposto na vertical............................................ 83

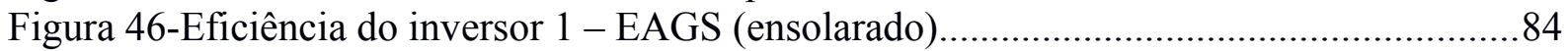




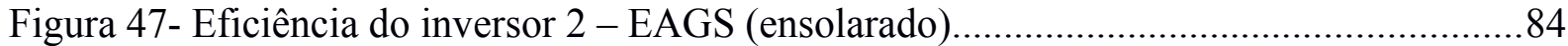

Figura 48- Curva de eficiência do inversor Aurora PVI 12.5 TL-OUTD...............................85

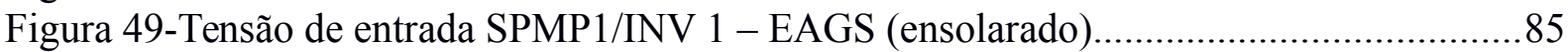

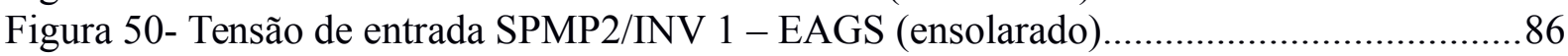

Figura 51- Tensão de entrada SPMP1/INV 2 - EAGS (ensolarado) ........................................ 86

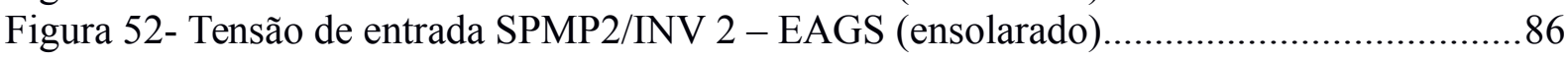

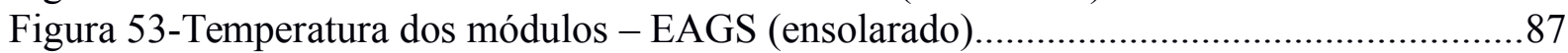

Figura 54- Cópia da figura 40- Irradiância - EAGS (ensolarado)...........................................87

Figura 55-Potências medida (P) e calculada (PC) para o inversor 1 EAGS (ensolarado)........88

Figura 56-Potências medida (P) e calculada (PC) para o inversor 2 EAGS (ensolarado)........89

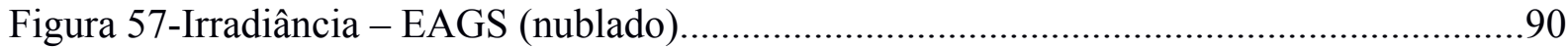

Figura 58- Potência na saída do inversor - EAGS (nublado)..................................................90

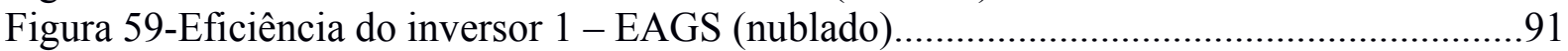

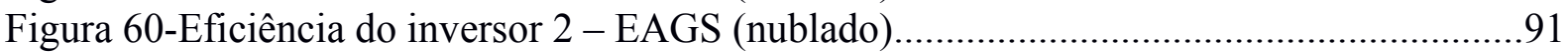

Figura 61- Tensão de entrada SPMP1/INV 1-EAGS (nublado).............................................92

Figura 62-Tensão de entrada SPMP2/INV 1 - EAGS (nublado).........................................92

Figura 63-Tensão de entrada SPMP1/INV 2 - EAGS (nublado)...........................................92

Figura 64-Tensão de entrada SPMP2/INV 2 - EAGS (nublado)..........................................93

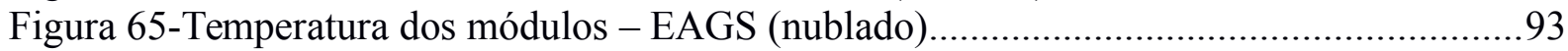

Figura 66- Cópia da figura 57 - Irradiância - EAGS (nublado)..............................................94

Figura 67-Potências medida (P) e calculada (PC) para o inversor 1 EAGS (nublado)...........94

Figura 68-Potências medida (P) e calculada (PC) para o inversor 2 EAGS (nublado)............95

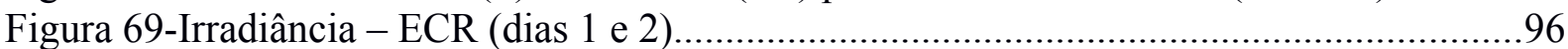

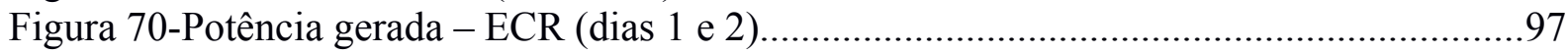

Figura 71-Curva de demanda ativa da carga - ECR (dias 1 e 2)...........................................97

Figura 72-Curva de demanda ativa líquida - ECR (dias 1 e 2) .........................................98

Figura 73-Consumo líquido horário de energia ativa - ECR (dias 1 e 2)..............................98

Figura 74-Curva de demanda reativa líquida - ECR (dias 1 e 2)..........................................99

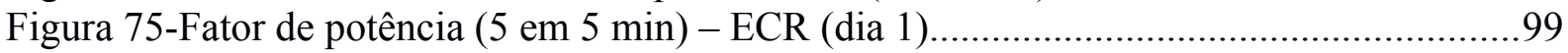

Figura 76-Fator de potência (5 em 5 min) - ECR (dia 2)....................................................... 100

Figura 77- Fator de potência (1 em 1 hora) - ECR (dias 1 e 2) ..............................................100

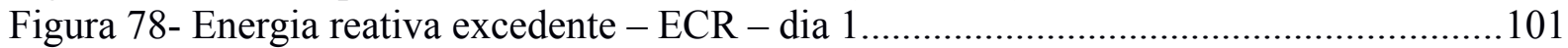

Figura 79-Potência aparente - ECR (dias 1 e 2) ................................................................... 102

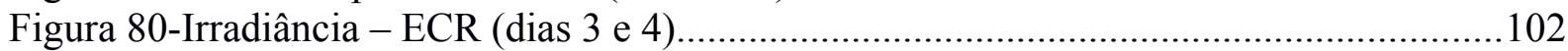

Figura 81-Potência gerada e entregue à carga- ECR (dias 3 e 4),........................................103

Figura 82-Curva de demanda ativa da carga - ECR (dias 3 e 4) ......................................... 103

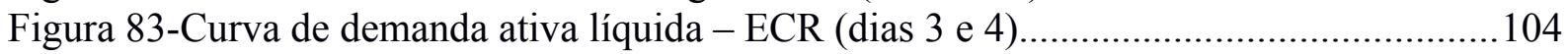

Figura 84-Consumo líquido horário de energia ativa - ECR (dias 3 e 4).............................104

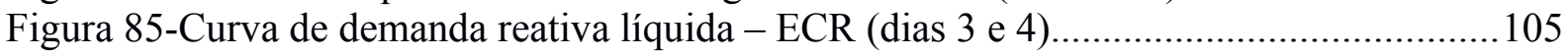

Figura 86-Fator de potência (5 em 5 min) - ECR (dia 3)...................................................... 105

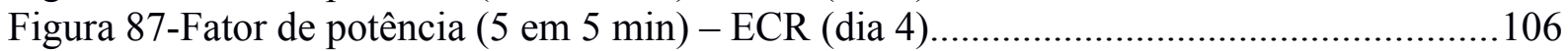

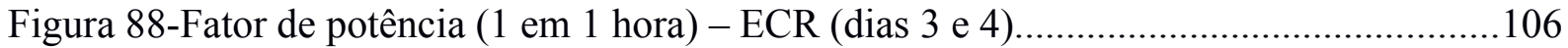

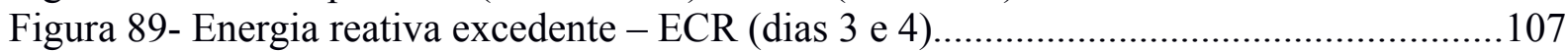

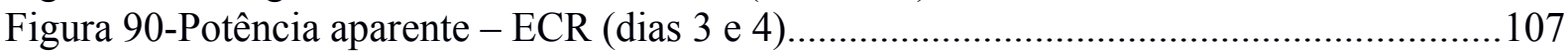

Figura 91-Irradiância - EAMCI (normal versus capacitivo)...............................................109

Figura 92- Potência ativa na saída do inversor- EAMCI (normal versus capacitivo)............109

Figura 93-Temperatura dos módulos - EAMCI (normal versus capacitivo).........................110

Figura 94-Potências medida (Pfv) e calculada (PC) - EAMCI (normal)................................111

Figura 95-Potências medida (Pfv) e calculada (PC) - EAMCI (capacitivo)..........................111

Figura 96- Potência reativa na saída do inversor - EAMCI (normal versus capacitivo)........112 
Figura 97-Potência aparente na saída do inversor - EAMCI (normal versus capacitivo)......112

Figura 98- Fator de potência do sistema fotovoltaico no modo normal................................113

Figura 99-Fator de potência do sistema fotovoltaico no modo capacitivo............................113

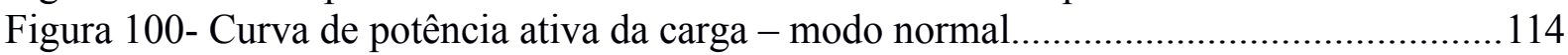

Figura 101-Curva de potência ativa da carga - modo capacitivo..........................................114

Figura 102-Curva de potência ativa da carga - SFV desligado.........................................114

Figura 103- Curva de potência reativa da carga -modo normal............................................115

Figura 104-Curva de potência reativa da carga -modo capacitivo.......................................115

Figura 105-Curva de potência reativa da carga - SFV desligado.........................................115

Figura 106- Tensão fase A/neutro no ponto de conexão - (normal versus capacitivo)...........116

Figura 107-Tensão fase B/neutro no ponto de conexão - (normal versus capacitivo)...........116

Figura 108-Tensão fase C/neutro no ponto de conexão - (normal versus capacitivo)...........117

Figura 109-Tensão fase $\mathrm{A} /$ neutro no transformador - (normal versus capacitivo)...................117

Figura 110-Tensão fase B/neutro no transformador - (normal versus capacitivo)..................118

Figura 111-Tensão fase C/neutro no transformador - (normal versus capacitivo)..................118

Figura 112-Irradiância - EAMCI (normal versus indutivo)..............................................119

Figura 113-Potência ativa na saída do inversor- EAMCI (normal versus indutivo)..............119

Figura 114-Temperatura dos módulos - EAMCI (normal versus indutivo)..........................120

Figura 115-Potências medida (Pfv) e calculada (PC) - EAMCI (indutivo)...........................120

Figura 116-Potência reativa na saída do inversor - EAMCI (normal versus indutivo)..........121

Figura 117-Potência aparente na saída do inversor - EAMCI (normal versus indutivo).......121

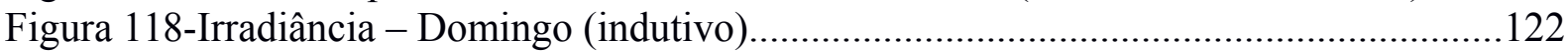

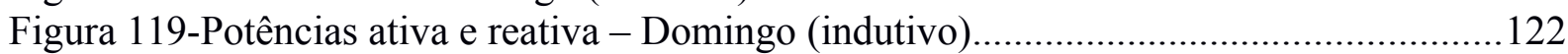

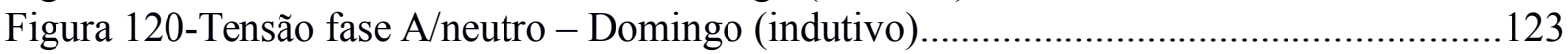

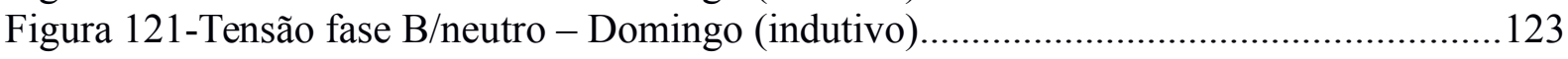

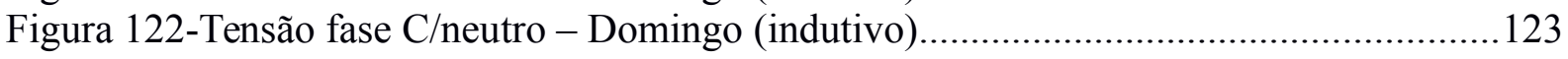




\section{LISTA DE TABELAS}

Tabela 1- Descrição do conjunto de ensaios realizados. .54

Tabela 2-Especificações do inversor AURORA PVI 12.5-TL-OUTD-S................................62

Tabela 3-Equipamentos elétricos do prédio da Administração do IEE-USP..........................75

Tabela 4-Resumo dos indicadores de desempenho - EAGS (ensolarado).............................89

Tabela 5-Resumo dos indicadores de desempenho - EAGS (ensolarado)............................95

Tabela 6-Resumo dos indicadores de desempenho - EAMCI (normal versus capacitivo).....110

Tabela 7-Resumo dos indicadores de desempenho - EAMCI (normal versus indutivo)........119 


\section{LISTA DE ABREVIATURAS E SIGLAS}

ABNT

ANEEL

BAPV

BT

c.a.

c.c.

CCEE

CESP

CTEEP

EAGS

EAMCI

ECR

IEC

IEE-USP

IGBT

INMETRO

MT

NBR

ONS

P\&D

PRODIST

PUFE

PVC

PWM

RN

SFCR

SPMP

TC

THDi

$\mathrm{UC}$

VSI
Associação Brasileira de Normas Técnicas

Agência Nacional de Energia Elétrica

Building Adapted PV (Sistema fotovoltaico adaptado à edificação)

Baixa tensão

Corrente alternada

Corrente contínua

Câmara Comercializadora de Energia Elétrica

Companhia Energética de São Paulo

Companhia de Transmissão Elétrica Paulista

Ensaios de avaliação geral do sistema

Ensaios de avaliação dos modos capacitivo e indutivo

Ensaios de compensação de reativos

International Electrotechnical Commission

Instituto de Energia e Ambiente da Universidade de São Paulo)

Insulated Gate Bipolar Transistor (Transistor bipolar de porta isolada)

Instituto Nacional de Metrologia, Qualidade e Tecnologia

Média tensão

Norma Brasileira

Operador Nacional do Sistema

Pesquisa e Desenvolvimento

Procedimentos de Distribuição de Energia Elétrica

Programa Usos Finais de Energia

Policloreto de vinila

Pulse-Width Modulation (Modulação por largura de pulso)

Resolução Normativa

Sistema(s) Fotovoltaico(s) Conectado(s) à Rede

Seguidor do ponto de máxima potência

Transformador de corrente

Distorção harmônica de corrente

Unidade Consumidora

Voltage Source Inverter (Inversor com fonte de tensão) 


\section{LISTA DE SÍMBOLOS}

\begin{tabular}{|c|c|}
\hline$u(t)$ & Tensão instantânea \\
\hline$i(t)$ & Corrente instantânea \\
\hline$U$ & Valor eficaz da tensão \\
\hline$I$ & Valor eficaz da corrente \\
\hline$\omega$ & Frequência angular \\
\hline$\varphi$ & Ângulo da impedância \\
\hline$p(t)$ & Potência instantânea \\
\hline$P$ & Potência ativa \\
\hline$Q$ & Potência reativa \\
\hline$\hat{U}$ & Fasor da tensão \\
\hline$\hat{I}$ & Fasor da corrente \\
\hline$\dot{S}$ & Potência complexa \\
\hline$S$ & Potência aparente \\
\hline$\dot{Z}$ & Impedância \\
\hline$R$ & Resistência elétrica \\
\hline$X$ & Reatância \\
\hline $\cos \varphi$ & Fator de potência de deslocamento \\
\hline $\cos \lambda$ & Fator de distorção \\
\hline$T H D_{i}$ & Distorção harmônica total de corrente \\
\hline$D$ & Potência de distorção \\
\hline FP & Fator de potência global \\
\hline$L$ & Indutância \\
\hline C & Capacitância \\
\hline$E_{\mathrm{RE}}$ & Energia elétrica reativa excedente \\
\hline EEAM & Montante de energia elétrica ativa \\
\hline$V R_{\mathrm{ERE}}$ & Valor de referência da tarifa de energia \\
\hline$D_{\mathrm{RE}}$ & Demanda de potência reativa excedente \\
\hline$P A M$ & Demanda de potência ativa medida \\
\hline $\mathrm{f}_{R}$ & Fator de potência de referência \\
\hline $\mathrm{f}_{T}$ & Fator de potência medido \\
\hline$P A F$ & Potência ativa faturável \\
\hline$V R_{\mathrm{DRE}}$ & Valor de referência da demanda \\
\hline$G$ & Irradiância \\
\hline$A$ & Área \\
\hline$H$ & Irradiação \\
\hline$E_{\text {IN }}$ & Energia incidente no plano do gerador \\
\hline$Y_{F}$ & Produtividade do sistema \\
\hline$C_{F}$ & Fator de capacidade \\
\hline$P R$ & Rendimento global do sistema \\
\hline$G_{0}$ & Irradiância de referência \\
\hline$C_{G}$ & Custo de geração \\
\hline$r$ & Taxa de desconto \\
\hline$O \& M$ & Taxa de operação e manutenção \\
\hline$P_{m p}$ & Máxima potência do gerador fotovoltaico \\
\hline
\end{tabular}




$\begin{array}{cc}P_{F V}^{0} & \text { Potência nominal do gerador fotovoltaico } \\ \gamma_{\mathrm{mp}} & \text { Coeficiente de temperatura do ponto de máxima potência } \\ T_{C} & \text { Temperatura de célula } \\ \eta_{\mathrm{SPMP}} & \text { Eficiência de seguimento do ponto de máxima potência } \\ \eta_{\mathrm{CONV}} & \text { Eficiência de conversão de c.c. para c.a. } \\ \eta_{\mathrm{TR}} & \text { Eficiência de transformação de tensão e transporte } \\ \mathrm{A} & \text { ampere } \\ \mathrm{V} & \text { volt } \\ \mathrm{VA} & \text { volt-ampere } \\ \mathrm{kVA} & \text { quilovolt-ampere } \\ \mathrm{var} & \text { volt-ampere reativo } \\ \mathrm{kvar} & \text { quilovolt-ampere reativo } \\ \mathrm{kvarh} & \text { quilovolt-ampere reativo-hora } \\ \mathrm{W} & \text { watt } \\ \mathrm{kW} & \text { quilowatt } \\ \mathrm{kWh} & \text { quilowatt-hora }\end{array}$




\section{SUMÁRIO}

INTRODUÇÃO

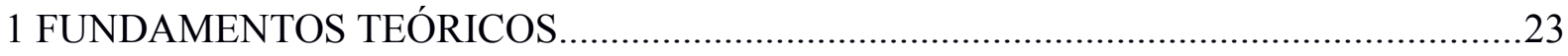

1.1 Potência elétrica e fator de potência................................................................................23

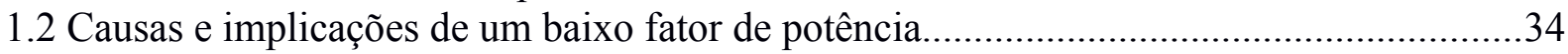

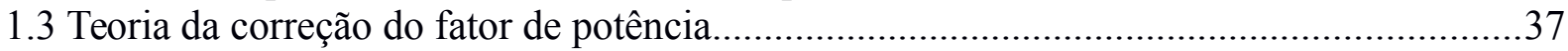

1.4 Técnicas convencionais de correção do fator de potência...............................................40

1.5 Regulamentação dos excedentes de reativos no Brasil.......................................................44

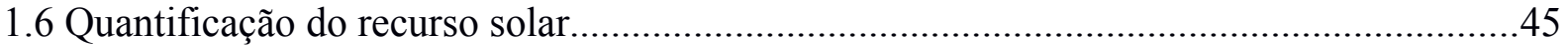

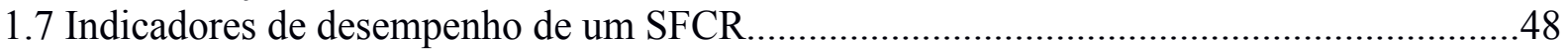

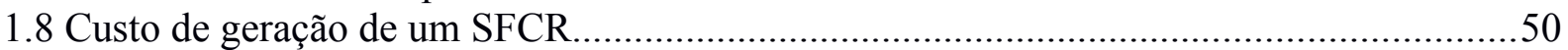

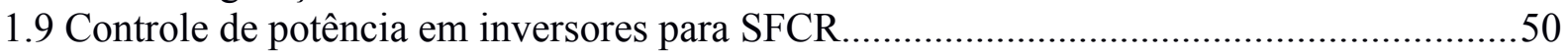

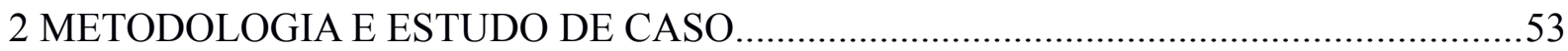

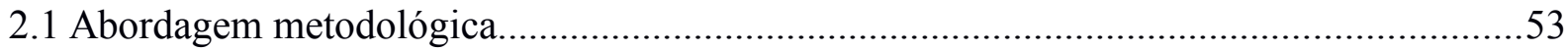

2.2 Sistema fotovoltaico de $78 \mathrm{kWp}$ sobre o prédio da Administração do IEE - USP............56

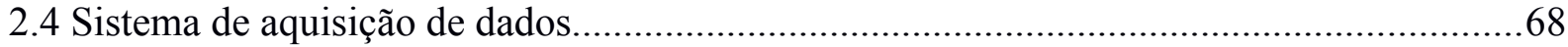

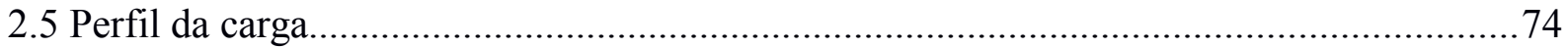

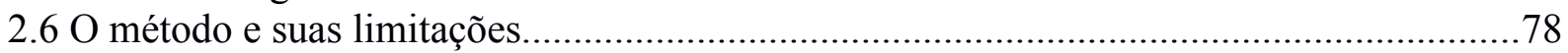

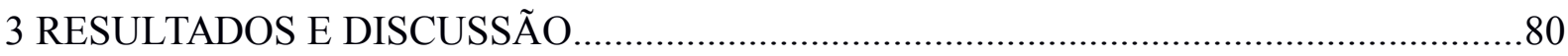

3.1 Resultados dos ensaios de avaliação geral do sistema (EAGS) ........................................80

3.2 Resultados dos ensaios de compensação de reativos (ECR) .............................................96

3.3 Resultados dos ensaios de avaliação dos modos capacitivo e indutivo (EAMCI)............108

CONCLUSÕES

SUGESTÕES PARA TRABALHOS FUTUROS..........................................................126

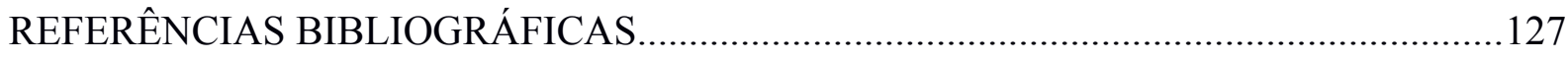




\section{INTRODUÇÃO}

\section{Organização do texto}

Inicialmente, ainda na Introdução, são apresentados o problema motivador, a pergunta a ser respondida, os objetivos da pesquisa, uma síntese da revisão bibliográfica, a hipótese a ser avaliada e a contribuição esperada com este trabalho.

Em seguida, no Capítulo 1, são discutidos os conceitos utilizados com maior frequência no trabalho, especialmente aqueles inerentes aos fluxos de potência ativa e reativa em circuitos elétricos de corrente alternada e à análise de desempenho de sistemas fotovoltaicos.

A metodologia e o estudo de caso são descritos no Capítulo 2, enquanto os resultados experimentais são apresentados e discutidos Capítulo 03.

Os termos estrangeiros não foram traduzidos, mas aparecem em itálico ao longo do texto. Por exemplo, datalogger ou netmetering. O mesmo se aplica a modelos e nomes de fabricantes de equipamentos, como KR-174 ou KRON.

A sigla SFCR, que aparece com frequência ao longo do trabalho, pode significar Sistema Fotovoltaico Conectado à Rede (no singular) ou Sistemas Fotovoltaicos Conectados à Rede (no plural).

\section{Problema motivador}

As iniciativas de algumas universidades públicas comprovaram a viabilidade técnica dos sistemas fotovoltaicos conectados à rede elétrica pública brasileira no final da década de 1990 (BENEDITO, 2009).

Nessa época surgiu, na literatura, uma importante questão envolvendo os impactos da inserção desse tipo de fonte na matriz elétrica. Tratava-se da possível deterioração do fator de potência, no ponto de entrega, de unidades consumidoras que produzissem parte ou a totalidade de sua demanda de potência ativa, mas que tivessem como única fonte de potência reativa a rede elétrica pública (BARBOSA et al., 1998). Posteriormente, em meados dos anos 
2000, essa possibilidade foi demonstrada experimentalmente em uma instalação real (MACÊDO; ZILLES, 2009), utilizando-se um sistema fotovoltaico como fonte geradora.

Como explicitado no primeiro capítulo, a legislação brasileira estabelece o valor 0,92 como referência para o fator de potência de uma UC. Sempre que num determinado período, que pode ser horário ou mensal, o fator de potência medido no ponto de entrega for menor que o valor de referência, o proprietário da UC pode incorrer no pagamento da energia e da demanda reativas excedentes (tarifação binômia). Atualmente essa cobrança é restrita a consumidores do grupo A (tensão maior ou igual a $2,3 \mathrm{kV}$ ).

A justificativa clássica para essa cobrança teria relação com o uso ineficiente da energia pois, em tese, uma UC com determinada demanda de potência ativa que apresente fator de potência deteriorado demandaria da rede elétrica uma potência muito maior que o necessário para a alimentação da carga, comparativamente ao caso em que esse problema fosse corrigido. As consequências negativas para o sistema elétrico dos excedentes de reativos seriam, principalmente, o aumento das perdas por efeito Joule e gastos adicionais das concessionárias para fornecer e acomodar, nos condutores, a potência adicional requerida pela carga (BARRETO et al., 2012; STAROSTA, 2009; CREDER, 2007).

Esses argumentos são válidos para unidades consumidoras que têm como única fonte de potência ativa a rede elétrica. Para unidades consumidoras que possuem geração distribuída, porém, não se pode tomar o fator de potência medido no ponto de entrega como único indicador de um uso ineficiente da energia elétrica. O motivo é que muitas vezes o fator de potência efetivo da UC é até superior a 0,92, quando se utiliza no cálculo apenas as potências ativa e reativa de fato demandadas da rede pela carga. Porém, como a UC pode estar diminuindo sua demanda de potência ativa proveniente da rede, por possuir geração própria, o medidor da concessionária registrará, nesses casos, valores baixos de fator de potência, caso a potência reativa continue sendo provida pela concessionária.

A possibilidade de cobrança por excedentes de reativos de unidades consumidoras com esse perfil, mesmo que de forma equivocada, pode diminuir sobremaneira a taxa de atratividade de empreendimentos de geração distribuída, como já ficou demonstrado no caso específico dos sistemas fotovoltaicos (PINTO; ZILLES, 2014).

Uma das saídas para esse impasse seria uma mudança na legislação pertinente. Por exemplo, modificando-se a forma tradicional de medição do fator de potência. Outra medida regulatória mais radical seria isentar unidades consumidoras com geração distribuída do pagamento por excedentes de reativos. Essas soluções, porém, podem ser de difícil implementação, como detalhado em seguida. 
O PRODIST (Procedimentos de Distribuição de Energia Elétrica) prevê, para consumidores cativos do grupo A que possuam geração distribuída, a existência de um único medidor capaz de registrar os fluxos de potência ativa e reativa nos sentidos direto e reverso (da UC para a rede e vice-versa). Porém, esse equipamento sozinho não é suficiente para se determinar a demanda de potência ativa efetiva da carga, parâmetro importante na determinação de um fator de potência realista.

A referida demanda efetiva pode ser obtida algebricamente com a instalação de um medidor adicional para a geração, com base nas leituras dos dois medidores. No entanto, a necessidade desse segundo medidor, o local de sua instalação, os procedimentos adicionais de leitura e as fórmulas necessárias para a obtenção do fator de potência efetivo não estão contemplados na legislação atual.

Por sua vez, a isenção da cobrança de excedentes de reativos para uma dada UC com geração distribuída, sob o argumento de que uma possível deterioração de seu fator de potência se deve exclusivamente ao motivo já apresentado (não estaria sendo utilizada a demanda efetiva em seu cálculo), pode não ser uma medida adequada. Isso porque essa UC pode apresentar um fator de potência inferior ao de referência, mesmo que sua demanda de potência ativa seja totalmente suprida pela rede elétrica, indicando um uso realmente ineficiente da energia elétrica e, portanto, exigindo uma medida disciplinadora por parte da concessionária.

Enquanto a legislação não avança nessa questão, que parece ser de difícil solução, algumas alternativas técnicas encontram-se disponíveis. Todas elas baseiam-se no suprimento local das necessidades da carga por reativos, diminuindo-se ou zerando-se os fluxos de potência reativa trocados entre a rede elétrica e a UC. Por exemplo, utilizando-se técnicas consolidadas e vastamente citadas na literatura, como a instalação de bancos de capacitores e geradores síncronos (esses últimos apenas para grandes consumidores) (STAROSTA, 2009; HOFMANN; SCHLABBACH; JUST, 2012) e, no caso específico da geração distribuída com sistemas fotovoltaicos, utilizando-se mecanismos de compensação de reativos incorporados ao próprio inversor do sistema.

Essa última opção, a qual é investigada ao longo deste trabalho, tem sido avaliada teoricamente, através de simulações computadorizadas ou através de protótipos de inversores, em países como Alemanha (BRAUN, 2007), China (LIBO; ZHENGMING; JIANZHENG, 2007; YU; PAN; XIANG, 2005), Coréia do Sul (SEO et al., 2009), Estados Unidos (TURITSYN et al., 2011) e Itália (CAGNANO et al., 2011).

Boa parte dos inversores comerciais para conexão à rede disponíveis no mercado 
mundial com potência nominal igual ou superior a $5 \mathrm{~kW}$ já vêm com a funcionalidade de controle de reativos incorporada.

No Brasil, a norma NBR 16149:2013, que estabelece as recomendações específicas e os pré-requisitos para a interface de conexão entre os sistemas fotovoltaicos e a rede de distribuição, estipula como obrigatória a existência desse mecanismo para inversores de potência nominal maior que $3 \mathrm{~kW}$. Porém, por padrão os equipamentos devem sair de fábrica com fator de potência unitário, sendo que os parâmetros a serem transmitidos a eles, a fim de ativar o controle de reativos, devem ser fornecidos pelo operador de rede junto com a permissão de acesso (ASSOCIAÇÃO BRASILEIRA DE NORMAS TÉCNICAS, 2013).

Contudo, como detalhado no Capítulo 2, a escassez de trabalhos científicos que avaliem a utilização de mecanismos de controle de reativos incorporados a inversores para fotovoltaicos, em condições reais de operação, deixa dúvidas se essa medida é eficaz e benéfica ao proprietário da UC, à concessionária e ao sistema elétrico.

Por isso, esse trabalho se insere nesse contexto e pretende responder à pergunta seguinte.

\section{Pergunta a ser respondida}

A partir do problema levantado anteriormente, elaborou-se a seguinte pergunta que norteou a pesquisa:

"Tendo em vista aspectos financeiros e de qualidade da energia elétrica e considerando-se o estágio atual da legislação que regulamenta a cobrança por excedentes de reativos, qual a melhor estratégia para lidar com a possível deterioração do fator de potência em unidades consumidoras conectadas à rede elétrica pública brasileira que possuam geração distribuida por meio de sistemas fotovoltaicos: utilizar um mecanismo de controle de reativos incorporado ao próprio inversor, usar técnicas convencionais de compensação ou pagar às concessionárias pelos excedentes?". 


\section{Objetivo geral}

O objetivo geral desta pesquisa é avaliar a utilização de um mecanismo de controle de reativos incorporado a um modelo de inversor para conexão de um sistema fotovoltaico à rede elétrica, diminuindo a probabilidade da cobrança de excedentes de reativos, em função da deterioração do fator de potência medido na entrada da UC.

\section{Objetivos específicos}

Os objetivos específicos almejados na pesquisa são os seguintes:

- Compreender a formação das curvas de demanda de potência ativa e reativa de uma UC comercial com perfil de prédio público, em função das características das cargas presentes;

- Desenvolver procedimentos para medição dos fluxos de potência ativa e reativa no quadro geral da UC, tendo em vista que nele se conectam os cabos provenientes da geração fotovoltaica, da carga e da rede elétrica pública;

- Quantificar as perdas elétricas do sistema nas diferentes etapas de conversão da energia;

- Analisar possíveis impactos da injeção de potência reativa pelo inversor às instalações internas da UC e ao sistema elétrico;

- Analisar possíveis impactos da produção de potência reativa no desempenho do inversor, no que diz respeito à produção de energia ativa.

\section{Síntese da revisão bibliográfica}

Inicialmente, buscou-se na literatura trabalhos publicados no Brasil e no exterior que abordassem a questão da deterioração do fator de potência no ponto de entrega, devida à 
geração fotovoltaica local e que, de preferência, comparassem as diferentes estratégias de compensação existentes.

No total, foram encontrados e analisados 26 artigos científicos publicados entre 1996 e 2014, no que se constatou:

- Apenas 4 trabalhos citam a possibilidade da cobrança por excedente de reativos quando da utilização de geração fotovoltaica (PINTO; ZILLES, 2014; MACÊDO; ZILLES, 2009; BRAUN, 2007; BARBOSA et al., 1998), sendo que apenas um deles (BRAUN, 2007) realiza uma análise de custo-benefício sobre a utilização do inversor para compensar reativos, porém utilizando a realidade alemã como referência e cenários simulados;

- 22 trabalhos têm o objetivo específico de modelar inversores com a funcionalidade de compensação de reativos incorporada e demonstrar sua viabilidade técnica (HASSAINE et al., 2014; CHANG et al., 2014; RESHMA; RAJESH, 2013; MARTI et al., 2013; BELAIDI et al., 2013; NOROOZIAN; GHAREHPETIAN, 2013; LI et al., 2012; HAMZAOUI; BOUCHAFAA; HADJAMMAR, 2011; TURITSYN et al., 2011; LIU et al., 2011; SEO et al., 2009; ALBUQUERQUE et al., 2010; CAGNANO et al., 2011; TSENGENES; ADAMIDIS, 2011; TURITSYN et al., 2010; GHARAKHANY; MOHAMADIAN; VARJANI, 2009; CHUNLING et al., 2009; HAMROUNI; JRAIDI; CHÉRIF, 2008; HASSAINE et al., 2009; LIBO; ZHENGMING; JIANZHENG, 2007; YU; PAN; XIANG, 2005; BARBOSA et al., 1998; KIM; YOO; SONG, 1996);

- desses 22, 13 têm como base metodológica exclusivamente simulações computadorizadas e apenas 8 apresentam resultados experimentais (CHANG et al., 2014; HASSAINE et al., 2014; LIU et al., 2011; RESHMA; RAJESH, 2013; HASSAINE et al., 2009; LIBO; ZHENGMING; JIANZHENG, 2007; KIM; YOO; SONG, 1996; BARBOSA et al., 1998), ainda que os inversores construídos fossem protótipos laboratoriais de, no máximo, $600 \mathrm{~W}$.

Dessa forma, confirmou-se a inexistência de uma resposta consolidada à pergunta proposta nesta tese e justificou-se a necessidade da realização de um estudo para fazer avançar os conhecimentos a respeito da compensação de reativos em unidades consumidoras com geração fotovoltaica, passando-se do campo teórico-laboratorial para o campo teóricoprático. 


\section{Hipótese}

Tendo como base o contexto apresentado logo acima, desenvolveu-se, ao longo do trabalho, um estudo experimental para avaliar a seguinte hipótese:

"Considerando-se todas as vantagens ao sistema elétrico e o custo-beneficio das diferentes opções disponíveis, a compensação de reativos disponibilizada pelo próprio inversor do sistema fotovoltaico é a estratégia mais apropriada para lidar com a possibilidade da cobrança por excedentes de reativos em unidades consumidoras que possuam geração distribuída por meio de sistemas fotovoltaicos conectados à rede elétrica pública brasileira."

\section{Contribuição do trabalho}

A principal contribuição do trabalho para a linha de pesquisa na qual se insere é a avaliação de diferentes estratégias para se lidar com a deterioração do fator de potência de unidades consumidoras que possuam geração distribuída por meio de sistemas fotovoltaicos, visando encontrar a melhor solução técnica capaz de impedir que ela se torne uma barreira à inserção dessa tecnologia na matriz elétrica.

Cada uma delas pode acarretar algum tipo de impacto ao sistema elétrico e à taxa de retorno do empreendimento fotovoltaico e, dessa forma, necessitava-se conhecer a relação custo-benefício de cada opção, tendo em vista a realidade brasileira.

Uma estratégia em especial, que consiste na produção de potência reativa pelo próprio inversor do sistema fotovoltaico, é citada na literatura e prevista na norma brasileira de qualificação de inversores (NBR 16149:2013), mas ainda não havia sido estudada em condições reais de operação, no Brasil.

Dessa forma, os resultados apresentados nesta tese fornecem subsídios para a compreensão do comportamento do inversor com compensação de reativos. 


\section{FUNDAMENTOS TEÓRICOS}

\subsection{Potência elétrica e fator de potência}

\subsubsection{Potência elétrica em circuitos c.a. monofásicos}

Inicialmente, considere-se um circuito em corrente alternada (c.a.) com uma fonte monofásica puramente senoidal e uma impedância genérica de módulo $Z$, em regime permanente. Suponha-se, também, a ausência de distorções harmônicas devido a cargas não lineares. Tal circuito está representado esquematicamente na figura 1.

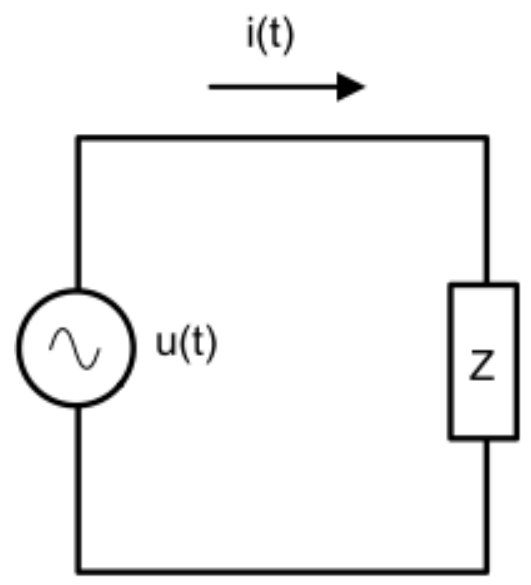

Figura 1-Circuito c.a. monofásico

No domínio do tempo, a tensão instantânea $u(t)$ na fonte e a corrente instantânea $i(t)$ fornecida ao circuito, em função de seus valores eficazes $U$ e $I$, respectivamente, são dadas pelas equações (1) e (2):

$$
\begin{gathered}
u(t)=\sqrt{2} U \sin (\omega t) \\
i(t)=\sqrt{2} I \sin (\omega t-\varphi)
\end{gathered}
$$

onde $\omega$ é a frequência angular de oscilação e $\varphi$ o ângulo da impedância (nesse caso $\varphi$ também 
pode ser interpretado como o ângulo de defasagem entre a tensão e a corrente).

A potência elétrica instantânea pode ser obtida através do produto das duas equações anteriores, cujo resultado está expresso na equação (3).

$$
p(t)=U I \cos \varphi(1-\cos 2 \omega t)-U I \sin \varphi \sin (2 \omega t)
$$

A primeira parcela da equação (3), denominada potência ativa instantânea, oscila em torno de um valor médio e nunca se torna negativa, indicando que ela é sempre utilizada integralmente pela carga, nunca retornando à fonte (COTRIM, 2009). O referido valor médio, expresso em watts (W), é denominado potência ativa $(P)$ e é dado pela equação (4).

$$
P=U I \cos \varphi
$$

Já a segunda parcela da equação (3) é denominada potência reativa instantânea. Seu valor médio é nulo e seu sinal ora é positivo ora negativo, indicando que esse termo representa a potência que vai da fonte para a carga e vice-versa, mas que não é consumida, sendo apenas trocada entre as reatâncias indutivas e capacitivas do circuito (COTRIM, 2009). O seu valor de pico, expresso em volt-ampere reativo (var), é denominado potência reativa $(Q)$ e é dado pela equação (5).

$$
Q=U I \sin \varphi
$$

Dessa forma, por conveniência, a equação (3), que representa a potência elétrica no domínio do tempo, pode ser reescrita como na equação (6).

$$
p(t)=P[1-\cos (2 \omega t)]-Q \sin (2 \omega t)
$$

Uma vez que as formas de onda e as frequências de oscilação das equações (1) e (2) são as mesmas, pode-se optar pela representação fasorial da tensão e da corrente, o que permite expressar a potência elétrica também no domínio dos números complexos (BARRETO et al., 2012), facilitando-se a análise dos fluxos de potência no circuito, por meio de argumentos geométricos.

Em notação fasorial, a tensão $\hat{U}$ e a corrente $\hat{I}$ podem ser expressas por meio das equações (7) e (8), respectivamente. 


$$
\begin{aligned}
& \hat{U}=U \angle 0^{\circ} \\
& \hat{I}=I \angle-\varphi
\end{aligned}
$$

Define-se como potência complexa o número complexo $\dot{S}$ dado pela equação (9):

$$
\dot{S}=\hat{U} \cdot \hat{I}^{*}=U I \cos \varphi+j . U I \sin \varphi
$$

e, com base nas equações (4) e (5), pode-se reescrevê-la de forma mais simples e definitiva por meio da equação (10) a seguir:

$$
\dot{S}=P+j \cdot Q=S \angle \varphi
$$

onde o termo S representa o módulo da potência complexa, denominado potência aparente e $\varphi$ o ângulo da impedância, como dito anteriormente.

Geometricamente, costuma-se representar as potências ativa, reativa e aparente através do triângulo das potências da figura 2 .

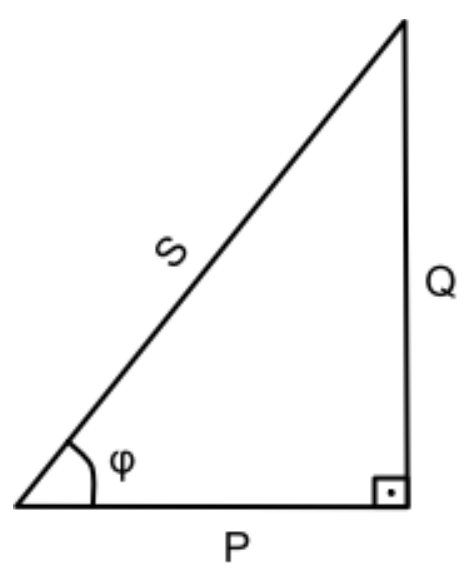

Figura 2-Triângulo das potências

Aplicando-se o Teorema de Pitágoras ao triângulo retângulo obtém-se a expressão que relaciona as três potências, dada pela equação (11).

$$
S=\sqrt{P^{2}+Q^{2}}
$$


Supondo-se que a impedância $\dot{Z}$ da carga seja composta pela soma da resistência $R$ e da reatância X equivalentes do circuito, ela pode ser expressa como na equação (12).

$$
\dot{Z}=R+j X
$$

A relação entre $\hat{U}, \quad \dot{Z}$ e $\hat{I}$, por sua vez, pode ser escrita como na equação (13).

$$
\hat{U}=\dot{Z} . \hat{I}
$$

Combinando-se as equações (9), (12) e (13), pode-se expressar as potências ativa P e reativa $Q$ de acordo com as equações (14) e (15), respectivamente.

$$
\begin{aligned}
& P=R . I^{2} \\
& Q=X . I^{2}
\end{aligned}
$$

Dessa forma, não resta dúvida de que $\mathrm{P}$ representa a potência dissipada pelos elementos resistivos do circuito e que Q expressa a potência trocada entre elementos com reatância. Quando a reatância equivalente for indutiva, diz-se que a carga demanda potência reativa $(\mathrm{Q}>0)$ e, quando for capacitiva, que ela fornece potência reativa $(\mathrm{Q}<0)$.

Assim, a orientação do triângulo das potências deve seguir o sinal de Q (a figura 2, por exemplo, foi concebida para uma carga indutiva, quando $\mathrm{Q}>0$ ).

\subsubsection{Cálculo do fator de potência em circuitos c.a. monofásicos}

Através de uma relação trigonométrica aplicada ao triângulo da figura 2, pode-se obter um importante parâmetro característico do circuito, chamado de fator de potência de deslocamento, dado pela equação (16).

$$
\cos \varphi=\frac{P}{S}
$$

Reescrevendo-se a última expressão na forma da equação (17), pode-se interpretar o 
fator de potência de deslocamento como sendo o percentual da potência aparente que é efetivamente demandada pela carga na forma de potência ativa.

$$
P=S \cos \varphi
$$

Portanto, é desejável que o ângulo $\varphi$ de defasagem entre as ondas de tensão e corrente (que equivale ao ângulo da impedância da carga) seja o menor possível em valor absoluto.

O ângulo $\varphi$ pode ser positivo ou negativo, dependendo da natureza da reatância da carga, mas o seu cosseno será sempre positivo, o que impede de se caracterizar completamente a carga apenas com o valor de $\cos \varphi$. Por isso, é importante que ele venha sempre acompanhado das expressões atrasado ou adiantado, conforme a carga seja indutiva ou capacitiva, respectivamente.

O tratamento dado ao circuito da figura 1 supôs uma carga linear, ou seja, que a corrente elétrica que alimenta o circuito não apresenta outras componentes de frequência além da fundamental (no Brasil, $60 \mathrm{~Hz}$ ).

Assim, o fator de potência global do circuito, designado por FP, estaria associado apenas ao ângulo $\varphi$ descrito anteriormente, podendo ser expresso através da equação (18).

$$
F P=\cos \varphi
$$

Porém, na maioria das instalações elétricas atuais, a carga é não linear e o modelo apresentado torna-se impreciso, na medida em que outras correntes de frequências múltiplas de $60 \mathrm{~Hz}$ se fazem presentes: os harmônicos de corrente (STAROSTA, 2009).

Isso implica que, se os harmônicos de corrente devido a cargas não lineares forem levados em conta, a potência aparente será maior que aquela que seria obtida caso as cargas fossem lineares, mas a potência ativa entregue à carga permanecerá a mesma. Consequentemente, será observada uma redução no fator de potência global FP, o qual fícará multiplicado por outro fator menor que 1 , designado por $\cos \lambda$, associado à distorção harmônica total de corrente $\left(\mathrm{THD}_{\mathrm{i}}\right)$, conforme a equação (19).

$$
F P=\cos \varphi \cos \lambda
$$

O valor de $\cos \lambda$ pode ser obtido por meio da equação (20), 


$$
\cos \lambda=\frac{1}{\sqrt{1+T H D_{i}^{2}}}
$$

onde o termo THDi pode ser escrito em função dos valores eficazes das correntes harmônicas de ordem $1,2,3 \ldots$, n por meio da equação (21).

$$
\operatorname{THD}_{i}=\frac{\sqrt{\sum_{i=1}^{n} I_{h i}^{2}}}{I_{h 1}}
$$

O análogo geométrico do triângulo das potências, utilizado para cargas exclusivamente lineares, é o tetraedro das potências da figura 3, no qual uma nova variável $\mathrm{D}$, chamada potência de distorção, passa a ser inserida nesse contexto. Fisicamente, D representa as perdas devidas à distorção harmônica de corrente e, matematicamente, está relacionada com o acréscimo da potência aparente quando existem componentes harmônicas na carga (STAROSTA, 2009).

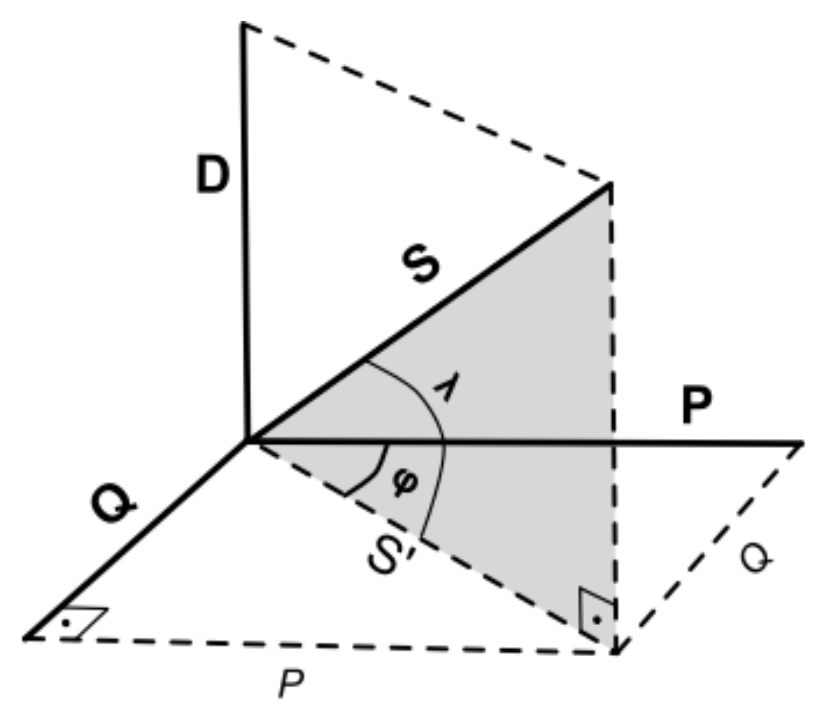

Figura 3-Tetraedro das potências

A relação entre as potências pode ser encontrada a partir dos triângulos retângulos destacados na figura 3 e pode ser expressa de acordo com a equação (22). 


$$
S=\sqrt{P^{2}+Q^{2}+D^{2}}
$$

\subsubsection{Potência elétrica e fator de potência em circuitos c.a. trifásicos em $\mathrm{Y}$}

A figura 4 ilustra um tipo específico de circuito elétrico trifásico, o qual é caracterizado pela presença de três fases A, B e C alimentadas simultaneamente pela fonte e um condutor neutro $\mathrm{N}$ aterrado. A carga é composta por três impedâncias, cujos módulos são $Z_{A}, Z_{B}$ e $Z_{c}$, percorridas pelas correntes de valores eficazes $I_{A}, I_{B}$ e $I_{C}$, respectivamente. As tensões entre as fases $A, B$ e $C$ e o neutro $N$ são dadas pelos valores eficazes $U_{A N}, U_{B N}$ e $U_{C N}$, respectivamente. Supõe-se um regime permanente e a ausência de harmônicos de corrente.

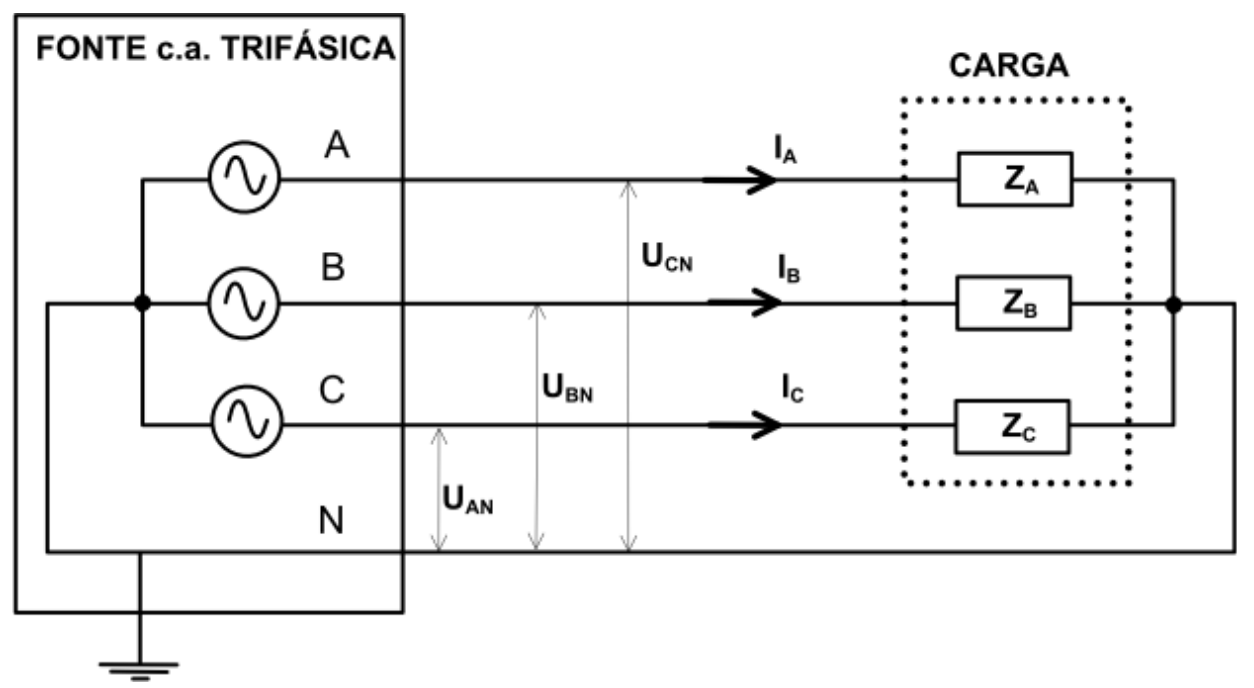

Figura 4-Circuito trifásico com ligação da carga em Y

Uma fonte trifásica como a da figura 4 pode ser entendida como a composição de três fontes monofásicas defasadas e conectadas eletricamente e, caso o valor eficaz da tensão faseneutro seja o mesmo para as três fases e o ângulo de defasagem seja igual a $120^{\circ}$, a fonte é dita equilibrada (BARRETO et al., 2012). A premissa para a abordagem a seguir é a de que a fonte satisfaz a última condição.

A carga presente neste circuito, por sua vez, não será necessariamente equilibrada, pois os módulos $Z_{A}, Z_{B}$ e $Z_{C}$ das impedâncias precisariam ser idênticos para que isso fosse 
possível. Em condições ideais, a carga deveria ser equilibrada e a a corrente no condutor neutro seria nula. Na prática, porém, os valores de $Z_{A}, Z_{B}$ e $Z_{C}$ são diferentes e é verificada uma corrente no condutor neutro.

A potência complexa total $\dot{S}_{T}$ entregue à carga é igual à soma das potências complexas em cada fase. Assim, com o auxílio da equação (10) e das propriedades dos números complexos, ela pode ser escrita como na equação (23):

$$
\dot{S}_{T}=P_{T}+j Q_{T}
$$

onde $P_{T}$ e $Q_{T}$ são as potências ativa e reativa totais demandadas pela carga, dadas pelas equações (24) e (25), respectivamente.

$$
\begin{gathered}
P_{T}=\left(P_{A}+P_{B}+P_{C}\right) \\
Q_{T}=\left(Q_{A}+Q_{B}+Q_{C}\right)
\end{gathered}
$$

Assim, a potência aparente total, ainda supondo-se a ausência de harmônicos de corrente, é igual ao módulo de $\dot{S}_{T}$ e pode ser expressa de acordo com a equação (26).

$$
S_{T}=\sqrt{P_{T}^{2}+Q_{T}^{2}}
$$

Caso houvesse a presença de harmônicos de corrente, a equação (27), que considera a potência de distorção D total, seria mais apropriada para se calcular $S_{T}$.

$$
S_{T}=\sqrt{P_{T}^{2}+Q_{T}^{2}+D_{T}^{2}}
$$

O fator de potência global da instalação, esteja $S_{T}$ expresso por meio das equações (26) ou (27), será sempre dado pela equação (28).

$$
F P=\frac{P_{T}}{S_{T}}
$$

Pode ser útil, para a compreensão do processo de medição de $\mathrm{P}$ e $\mathrm{Q}$, expressar as potências ativa e reativa presentes nas equações (24) e (25) em função dos valores eficazes 
das correntes ou dos módulos das impedâncias em cada fase e dos ângulos $\varphi_{\mathrm{A}}, \varphi_{\mathrm{B}} \mathrm{e} \varphi_{\mathrm{C}}$ das impedâncias. O termo U nas equações (29) a (32) é o valor eficaz da tensão fase-neutro, supostamente constante, pois foi considerada a premissa de que a fonte é equilibrada.

Em função dos valores eficazes das correntes:

$$
\begin{aligned}
& P_{T}=U\left(I_{A} \cos \varphi_{A}+I_{B} \cos \varphi_{B}+I_{C} \cos \varphi_{C}\right) \\
& Q_{T}=U\left(I_{A} \sin \varphi_{A}+I_{B} \sin \varphi_{B}+I_{C} \sin \varphi_{C}\right)
\end{aligned}
$$

Em função dos módulos das impedâncias:

$$
\begin{aligned}
& P_{T}=U^{2}\left(\frac{\cos \varphi_{A}}{Z_{A}}+\frac{\cos \varphi_{B}}{Z_{B}}+\frac{\cos \varphi_{C}}{Z_{C}}\right) \\
& Q_{T}=U^{2}\left(\frac{\sin \varphi_{A}}{Z_{A}}+\frac{\sin \varphi_{B}}{Z_{B}}+\frac{\sin \varphi_{C}}{Z_{C}}\right)
\end{aligned}
$$

\subsubsection{Medição da potência ativa em circuitos c.a. trifásicos com carga em $Y$}

A medição da potência ativa em um circuito trifásico com carga desequilibrada conectada em Y pode ser realizada com o auxílio de três wattímetros W1, W2 e W3 (BARRETO et al., 2012) e o esquema de ligações encontra-se na figura 5.

Cada aparelho mede apenas a parte real da potência complexa em cada fase, o que exige a obtenção da corrente associada à potência ativa em cada fase e a tensão entre essa fase e o neutro. As leituras $\mathrm{L}_{1}, \mathrm{~L}_{2}$ e $\mathrm{L}_{3}$ realizadas por cada aparelho, em watts, são dadas pelas equações (33) a (35):

$$
\begin{aligned}
& L_{1}=U_{A N} \cdot I_{A} \cdot \cos \varphi_{A} \\
& L_{2}=U_{B N} \cdot I_{B} \cdot \cos \varphi_{B} \\
& L_{3}=U_{C N} \cdot I_{C} \cdot \cos \varphi_{C}
\end{aligned}
$$


onde $U_{A N}, U_{B N}$ e $U_{C N}$ são os valores eficazes das tensões entre cada fase e o neutro, $I_{A}, I_{B}$ e $I_{C}$ são os valores eficazes das correntes em cada fase e $\varphi_{A}, \varphi_{B}$ e $\varphi_{C}$ são os ângulos das impedâncias em cada fase.

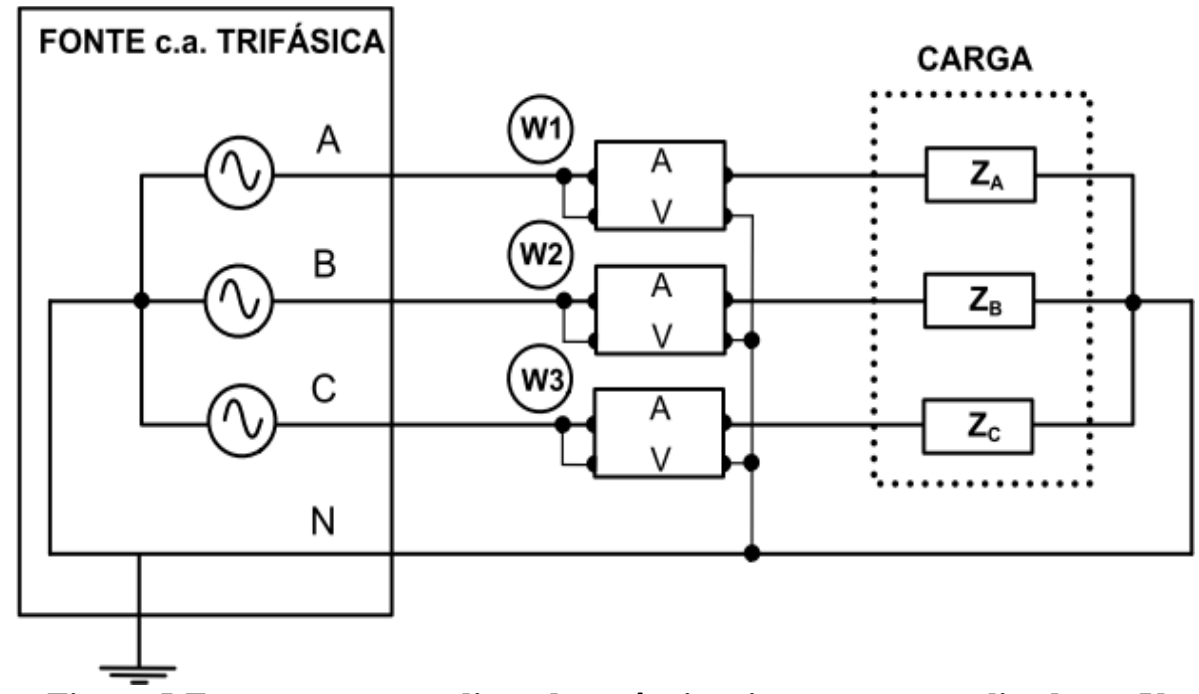

Figura 5-Esquema para medição de potência ativa com a carga ligada em Y

A potência ativa total, $P_{T}$, demandada pela carga é dada pela soma das três leituras, conforme a equação (36).

$$
P_{T}=L_{1}+L_{2}+L_{3}
$$

\subsubsection{Medição da potência reativa em circuitos c.a. trifásicos com carga em $Y$}

A medição da potência reativa pode ser obtida indiretamente através da utilização de wattímetros. O que fundamenta esse esquema é a expressão dada pela equação (37), a qual é válida para cargas equilibradas ou desequilibradas, ligadas tanto em Y quanto em delta, pois ela depende apenas de tensões e correntes de linha (BARRETO et al., 2012). A demonstração desta equação pode ser encontrada na referência citada logo acima.

$$
Q_{T}=\frac{1}{\sqrt{3}}\left[\Re\left\{\hat{U}_{B C} \cdot \hat{I}_{A}^{*}+\hat{U}_{C A} \cdot \hat{I}_{B}^{*}+\hat{U}_{A B} \cdot \hat{I}_{C}^{*}\right\}\right]
$$


A equação (37) denota que a potência reativa total pode ser obtida a partir da parte real da potência complexa destacada entre chaves, o que pode ser medido através dos wattímetros W1, W2 e W3, ligados conforme o esquema da figura 6.

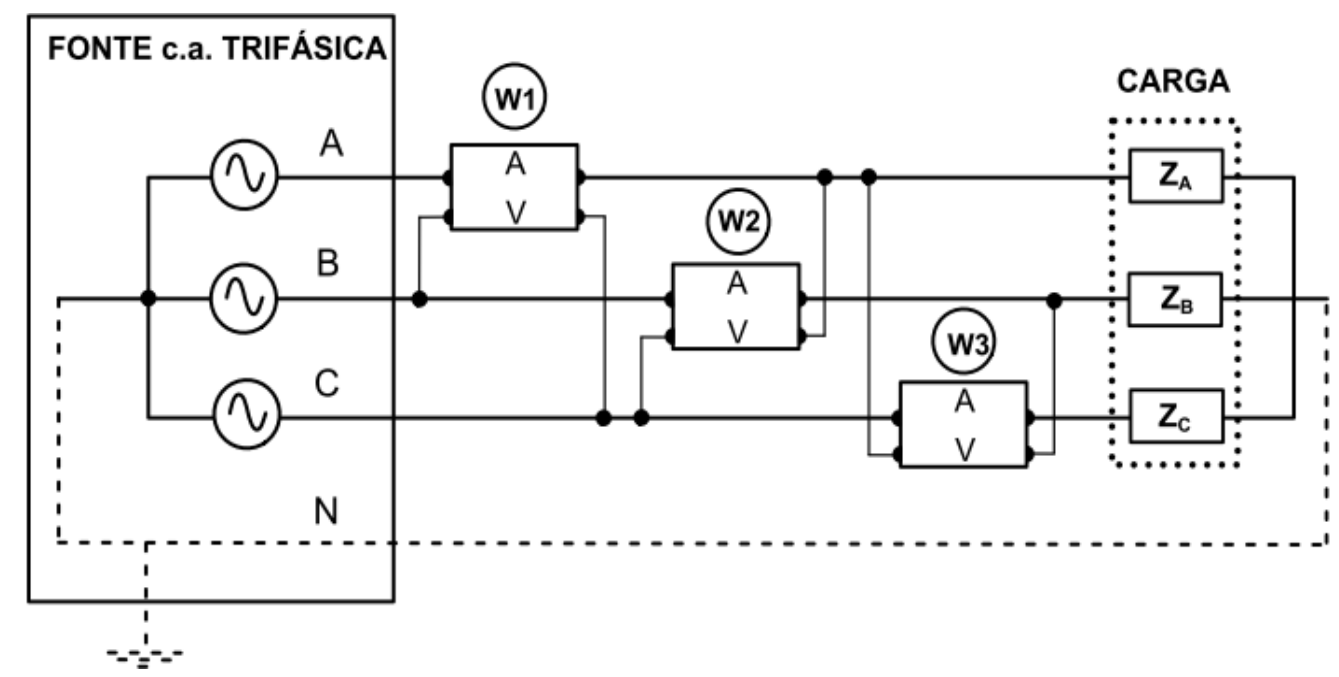

Figura 6-Esquema para medição de potência reativa com a carga ligada em $Y$

As leituras $L_{1}, L_{2}$ e $L_{3}$ de cada wattímetro são dadas pelas equações (38) a (40):

$$
\begin{aligned}
& L_{1}=U_{B C} \cdot I_{A} \cdot \cos \varphi_{1} \\
& L_{2}=U_{C A} \cdot I_{B} \cdot \cos \varphi_{2} \\
& L_{3}=U_{A B} \cdot I_{C} \cdot \cos \varphi_{3}
\end{aligned}
$$

onde $U_{B C}, U_{C A}$ e $U_{A B}$ são os valores eficazes das tensões entre as fases B-C, C-A e A-C, respectivamente. Já $I_{A}, I_{B}$ e $I_{C}$ são os valores eficazes da corrente em cada fase e $\varphi_{1}, \varphi_{2}$ e $\varphi_{3}$ são os respectivos ângulos entre as tensões e correntes presentes em cada equação.

A potência reativa total, $Q_{T}$, demandada pela carga é então dada pela equação (41).

$$
Q_{T}=\frac{1}{\sqrt{3}}\left(L_{1}+L_{2}+L_{3}\right)
$$




\subsection{Causas e implicações de um baixo fator de potência}

As principais causas que contribuem para a deterioração do fator de potência em uma instalação elétrica encontram-se amplamente divulgadas na literatura especializada e, para este trabalho, foram utilizadas duas referências em especial (CREDER, 2007; STAROSTA, 2009), que permitem sintetizá-las da seguinte forma:

- $\quad$ presença de motores de indução operando em vazio;

- $\quad$ presença de transformadores operando em vazio ou com pequenas cargas;

- tensão elétrica acima do valor nominal;

- $\quad$ utilização intensiva de aparelhos de ar condicionado;

- $\quad$ em edifícios, a presença de elevadores e bombas de água;

- na indústria, a presença de cargas típicas, como injetoras, extrusoras, fornos de indução, sistemas de solda, prensas, guindastes, compressores, bombas, tornos, sistemas de galvanoplastia e eletrólise;

- $\quad$ grande quantidade de equipamentos eletrônicos e de informática;

- $\quad$ utilização de grande quantidade de lâmpadas de descarga.

$\mathrm{Na}$ maioria dos exemplos citados, o fator de potência da instalação é deteriorado devido à demanda considerável de potência reativa, em relação à demanda de potência ativa.

Nos motores e transformadores, por exemplo, a demanda de potência reativa é semelhante, quer em baixa ou plena carga, o mesmo não acontecendo com a demanda de potência ativa, que é diretamente proporcional à carga mecânica nos motores e à demanda elétrica da carga para os transformadores. Dessa forma, quando operam em vazio esses equipamentos são responsáveis por reduzir o fator de potência da instalação.

Já em aparelhos de refrigeração, aparelhos de ar condicionado e nos equipamentos industriais mencionados, a demanda elevada de potência reativa é inerente ao seu princípio de funcionamento, devido à presença de compressores, motores e geração de calor por indução magnética.

No caso de cargas de informática, o baixo fator de potência geralmente tem relação direta com a presença de componentes eletrônicos que geram correntes distorcidas (harmônicas de corrente) embora também possa ser demonstrado que boa parte desses 
equipamentos apresenta um fator de potência de deslocamento ligeiramente adiantado, configurando um comportamento capacitivo.

$\mathrm{Na}$ iluminação com lâmpadas de descarga de gás, o tipo de reator utilizado para a excitação do composto gasoso determina o caráter indutivo ou capacitivo do conjunto.

Os reatores eletromagnéticos, considerados de primeira geração, utilizam como principal componente um indutor, elemento responsável por gerar a tensão necessária à ignição da lâmpada e controlar os níveis de corrente e tensão nos seus terminais após sua entrada em funcionamento. Em reatores eletromagnéticos de lâmpadas fluorescentes cujos circuitos não apresentam mecanismo de compensação, o fator de potência situa-se em torno de 0,50 (indutivo), resultando em uma demanda de potência reativa até 1,7 vezes maior que a de potência ativa (HOFMANN; SCHLABBACH; JUST, 2012).

Com o advento dos reatores eletrônicos, considerados mais modernos e eficientes, os antigos reatores eletromagnéticos estão praticamente extintos do mercado de lâmpadas fluorescentes de baixa potência, destinadas à iluminação interna. Entretanto, para lâmpadas de descarga de gás de maior potência, destinadas à iluminação externa, os reatores eletromagnéticos ainda são largamente utilizados por sua maior resistência a flutuações da rede ou a intempéries, além do que a potência dos reatores eletrônicos está limitada a cerca de $150 \mathrm{~W}$.

Grande parte dos reatores eletrônicos para lâmpadas fluorescentes tubulares disponíveis no mercado contêm em seus circuitos um conversor boost, responsável pela correção do fator de potência, elevando-o a valores muito próximos da unidade (HOFMANN; SCHLABBACH; JUST, 2012). O mesmo não acontece com as lâmpadas fluorescentes compactas, cujos reatores eletrônicos incorporados geralmente apresentam fator de potência igual ou menor a 0,70. Em ambos os casos, o comportamento do conjunto reator/lâmpada é predominantemente capacitivo.

As principais implicações de um baixo fator de potência, do ponto de vista do consumidor, são as perdas elétricas na rede interna, devido à maior corrente exigida para alimentar a carga e a possibilidade do pagamento por excedentes de reativos.

Utilizando-se o exemplo da indústria pode-se afirmar, segundo Starosta (2009, p.419) que

as perdas em processos industriais relativas a problemas com consumo de energia reativa e qualidade de energia tendem a ser mais importantes e consideráveis que as 
próprias cobranças de excedente de energia reativa (multas) pelas concessionárias devido ao baixo fator de potência que este consumo de reativos possa causar.

Cálculos presentes na literatura (HOFMANN; SCHLABBACH; JUST, 2012), realizados para uma planta industrial de médio porte com demanda de potência ativa de cerca de $130 \mathrm{~kW}$ demonstram alguns dos efeitos dessas perdas. Se a planta for alimentada por um cabo de quatro vias de $120 \mathrm{~mm}^{2}$ e operar 2.400 horas por ano, com fator de potência 0,79 , as perdas ôhmicas anuais chegam a $60 \mathrm{kWh}$ por metro de cabo. Realizando-se a correção do fator de potência para 1,00 essas perdas são reduzidas a $37 \mathrm{kWh}$ por metro de cabo.

Já do ponto de vista do sistema elétrico, os efeitos associadas ao trânsito de potência reativa são diversos. Considerando-se um sistema trifásico de geração, transmissão e distribuição equilibrado, a corrente de linha, $I_{l}$, para transportar uma potência ativa fixa, $P$, sob uma tensão de linha, $U_{l}$, (valores eficazes), é inversamente proporcional ao fator de potência de deslocamento $\cos \varphi_{l}$ como mostra a equação (42).

$$
I_{l}=\frac{P}{\sqrt{3} \cdot U_{l} \cdot \cos \varphi_{l}}
$$

As perdas ôhmicas, $P_{\Omega}$, nesse sistema, por sua vez, são diretamente proporcionais ao quadrado de $I_{l}$, como mostra a equação (43). O termo $R_{l}$ representa a resistência elétrica dos condutores de fase, o que evidencia que as perdas por aquecimento são diretamente proporcionais ao comprimento da linha.

$$
P_{\Omega}=3 . I_{l}^{2} \cdot R_{l}
$$

Combinando-se as duas equações anteriores chega -se à equação (44), que expressa $P_{\Omega}$ em função de $\cos \varphi_{l}$.

$$
P_{\Omega}=\frac{P^{2} \cdot R_{l}}{U^{2} \cdot \cos ^{2} \varphi_{l}}
$$

A equação (44) denota que, para atender determinada demanda fixa por potência ativa, esse sistema elétrico teria as menores perdas possíveis para um fator de potência unitário. Caso essa condição não possa ser satisfeita, verifica-se que as perdas aumentam na proporção inversa do quadrado do fator de potência. Também pode-se notar que esse efeito é tanto mais intenso quanto maior for o comprimento da linha e que a única alternativa para reduzir $P_{\Omega}$ 
quando não se consegue corrigir o fator de potência é diminuindo o valor de $R_{l}$ aumentando a bitola dos condutores, o que eleva os custos do sistema.

Há outras preocupações decorrentes de um baixo fator de potência, como a necessidade de geração de reativos para atendimento da demanda e a ocupação, nos fios, de espaço que seria destinado à distribuição de potência ativa (MORÓN, 2009). Adicionalmente, um fator de potência deteriorado pode vir a provocar sobrecarga em cabos e transformadores, quedas ou elevações de tensão e desgaste em dispositivos de proteção e manobra (CREDER, 2007; HOFMANN; SCHLABBACH; JUST, 2012).

\subsection{Teoria da correção do fator de potência}

Considerando-se um circuito monofásico e que apenas cargas lineares estejam presentes, a correção do fator de potência, também chamada de compensação da energia reativa, pode ser realizada de acordo com o esquema ilustrado na figura 7 .

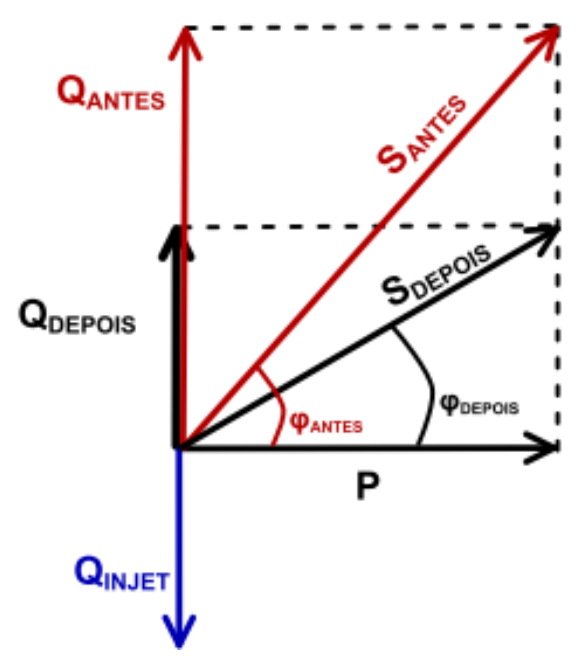

Figura 7- Correção do fator de potência para cargas lineares

Para se facilitar a análise geométrica do problema, optou-se por uma representação vetorial do triângulo das potências, igualando-se os valores absolutos das potências aos respectivos módulos dos vetores $\mathbf{Q}, \mathbf{S}$ e $\mathbf{P}$ associados.

O objetivo do procedimento de compensação ilustrado na figura 7 , neste caso, é a redução do ângulo $\varphi$ de defasagem entre a tensão e a corrente para um valor menor ou igual a 
$23,07^{\circ}$, que é aquele correspondente ao fator de potência de referência 0,92 . Como a carga é considerada linear, o fator de potência global do circuito é igual ao fator de potência de deslocamento, de acordo com a equação (18). A compensação pode ser feita injetando-se, na carga, determinada quantidade de potência reativa $\mathrm{Q}_{\mathrm{INJET}}$, que pode ser encontrada através da equação (45) a seguir,

$$
Q_{I N J E T}=P\left[\sqrt{\frac{1}{\left(F P_{A N T E S}\right)^{2}}-1}-\sqrt{\frac{1}{\left(F P_{D E P O I S}\right)^{2}}-1}\right]
$$

onde $\mathrm{P}$ é a potência ativa demandada pela carga, $F P_{\text {ANTES }}$ é o fator de potência supostamente deteriorado e $F P_{D E P O I S}$ o fator de potência desejado após a correção.

Se o fator de potência global do circuito desejado for igual ao valor de referência 0,92 , QINJET pode ser facilmente calculada por meio da equação (46).

$$
Q_{\text {INJET }}=P\left[\sqrt{\frac{1}{\left(F P_{\text {ANTES }}\right)^{2}}-1}-0,295\right]
$$

Caso a instalação elétrica possua cargas não-lineares o procedimento de correção do fator de potência pode ser melhor ilustrado por meio da figura 8 .

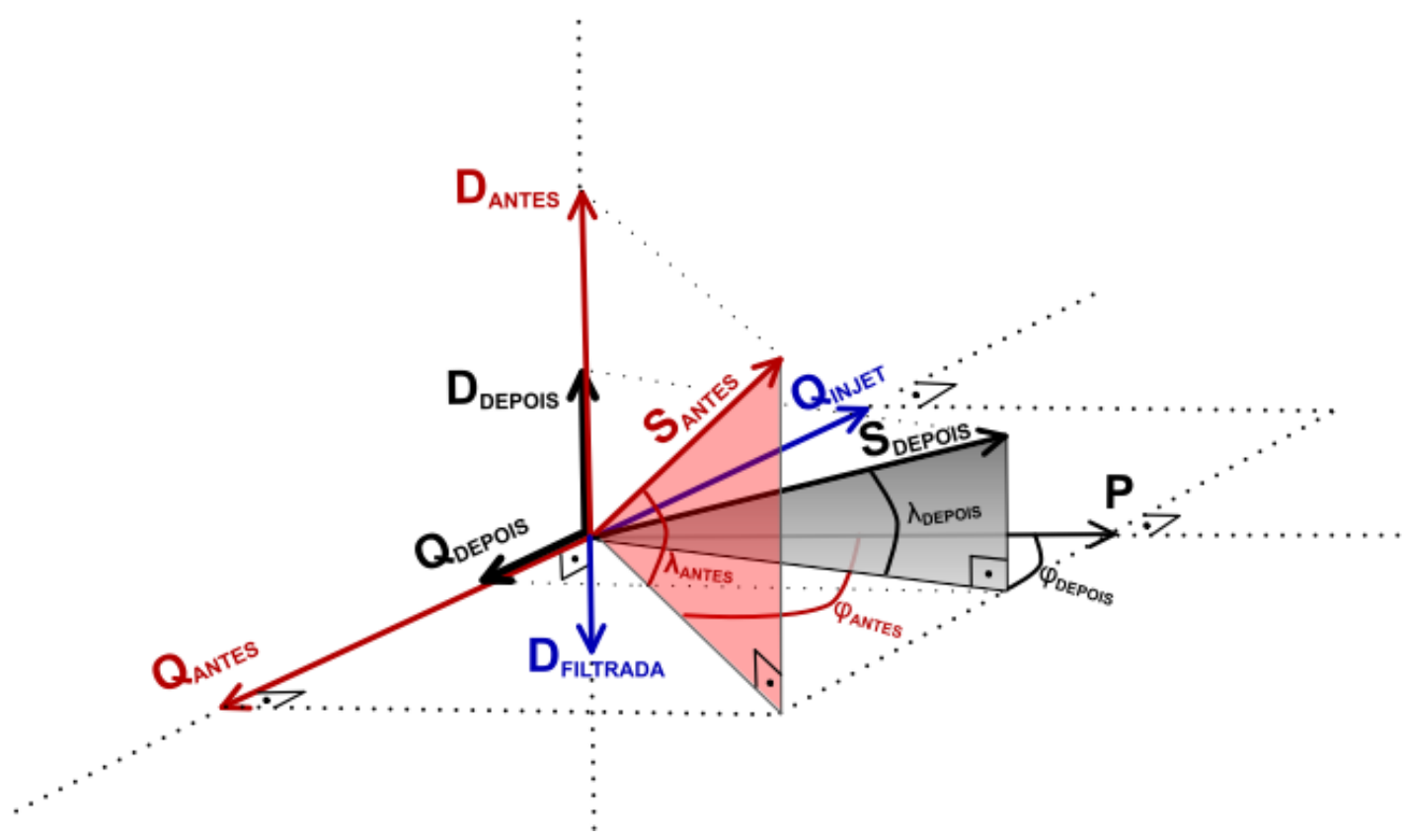

Figura 8- Correção do fator de potência para cargas não-lineares

Aqui também optou-se por uma representação vetorial. Os valores absolutos das 
potências correspondem aos módulos dos respectivos vetores $\mathbf{Q}, \mathbf{S}, \mathbf{P}$ e $\mathbf{D}$ associados. As considerações seguintes também referem-se a um circuito monofásico.

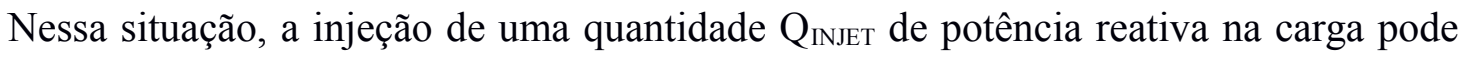
até aumentar o fator de potência de deslocamento $\cos \varphi$, inclusive fazendo-o chegar à unidade, se $\mathrm{Q}_{\mathrm{INJET}}$ for igual a $\mathrm{Q}_{\text {ANTES. }}$ Mas, de acordo com a equação (19), o fator de potência global do circuito FP ainda assim ficará condicionado a um fator $\cos \lambda$, referente à potência de distorção harmônica. Dessa forma, paralelamente à injeção da potência reativa, poderá ser necessária a filtragem das componentes harmônicas de corrente (ou parte delas) para se chegar ao fator de potência global do circuito desejado, o que equivale a reduzir de uma

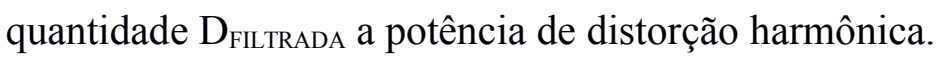

Esse conjunto de procedimentos tem como objetivo reduzir tanto o ângulo $\varphi$ quanto o ângulo $\lambda$, o que equivale, na figura 8 , a deixar a extremidade do vetor $\mathbf{S}$ o mais próximo possível da extremidade do vetor $\mathbf{P}$. O fator de potência global do circuito será igual a 1 se e somente se os vetores $\mathbf{S}$ e $\mathbf{P}$ forem coincidentes.

Suponha-se que toda a demanda por potência reativa da carga tenha sido compensada, o que equivale a se ter o ângulo $\varphi_{D E P O I S}=0$ na figura 8 , mas que o fator de potência global do circuito ainda se encontre deteriorado devido à distorção harmônica de corrente. A potência de distorção a ser filtrada, a fim de se obter o valor mínimo de referência 0,92 para FP, é dada pela equação (47).

$$
D_{\text {FILTRADA }}=P\left[\sqrt{\frac{1}{\left(F P_{\text {ANTES }}\right)^{2}}-\frac{1}{\left(\cos \varphi_{\text {ANTES }}\right)^{2}}}-0,295\right]
$$

onde $\mathrm{FP}_{\mathrm{ANTES}} \mathrm{e} \cos \varphi_{\text {ANTES }}$ são os fatores de potência global e de deslocamento, respectivamente, antes de qualquer correção.

Supõe-se, portanto, que se disponha de um equipamento capaz de medir, antes da correção, não apenas o fator de potência de deslocamento mas também o fator de potência global do circuito, sendo este último determinado pela combinação das equações (19) a (21).

Quando se tem um circuito bifásico ou trifásico, tecnicamente é recomendável se fazer a correção do fator de potência em cada fase, de forma a garantir o uso eficiente da energia em todas as malhas. Assim, minimizam-se possíveis efeitos indesejados relacionados às demandas de potência reativa e de distorção harmônica em todos os equipamentos alimentados.

Há que se dizer, porém, que para efeitos de tarifação por excedentes de reativos, a 
legislação não impõe a aferição por fase do fator de potência, mas sim para a instalação elétrica como um todo.

Após a correção do fator de potência de uma instalação elétrica, verifica-se uma redução de um fator $\delta p$ (em porcentagem) nas perdas ôhmicas, dado pela equação 48 .

$$
\delta p=\left[1-\left(\frac{F P_{\text {ANTES }}}{F P_{\text {DEPOIS }}}\right)^{2}\right] \times 100
$$

Ocorre, também, um aumento $\delta c$ (em porcentagem) na capacidade do sistema, dado pela equação 49 .

$$
\delta c=\left[1-\left(\frac{F P_{\text {ANTES }}}{F P_{\text {DEPOIS }}}\right)\right] \times 100
$$

\subsection{Técnicas convencionais de correção do fator de potência}

Existem basicamente duas técnicas convencionais para a correção do fator de potência: a utilização de máquinas síncronas e o emprego de capacitores.

As máquinas síncronas, quando superexcitadas, podem fornecer energia reativa. Elas podem trabalhar tanto movendo algumas cargas, como bombas e compressores (operando com fator de potência entre 0,8 e 1,0 adiantado) ou então trabalhar em vazio (com fator de potência praticamente nulo). Neste último caso, essas máquinas operam exclusivamente para fornecer potência reativa ao sistema e, por isso, recebem o nome de compensadores síncronos.

A utilização de máquinas síncronas na indústria com a dupla função de mover cargas e fornecer potência reativa só é viável economicamente quando grandes cargas mecânicas, superiores a $200 \mathrm{CV}$, são acionadas por longos períodos de tempo, superiores a 8 horas diárias (STAROSTA, 2009).

Por isso, o método mais difundido para a compensação de reativos é a utilização de capacitores, pois em geral é o mais econômico e permite maior flexibilidade de aplicação (STAROSTA, 2009). A correção do fator de potência pode ser feita de forma localizada, instalando-se os capacitores em paralelo com as cargas que demandam muita potência reativa ou então de forma global, colocando-os no quadro geral ou junto a transformadores.

As figuras 9 e 10 ajudam a ilustrar o princípio de funcionamento deste método. 

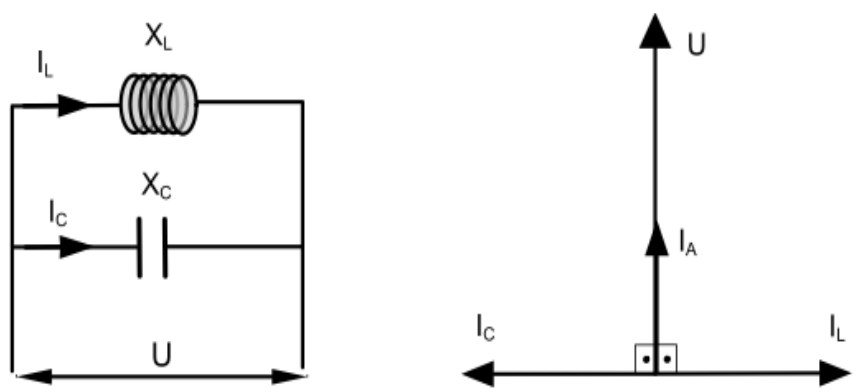

Figura 9- Representação fasorial da tensão e das correntes em um circuito LC Fonte: Adaptado de Hofmann et al. (2012)

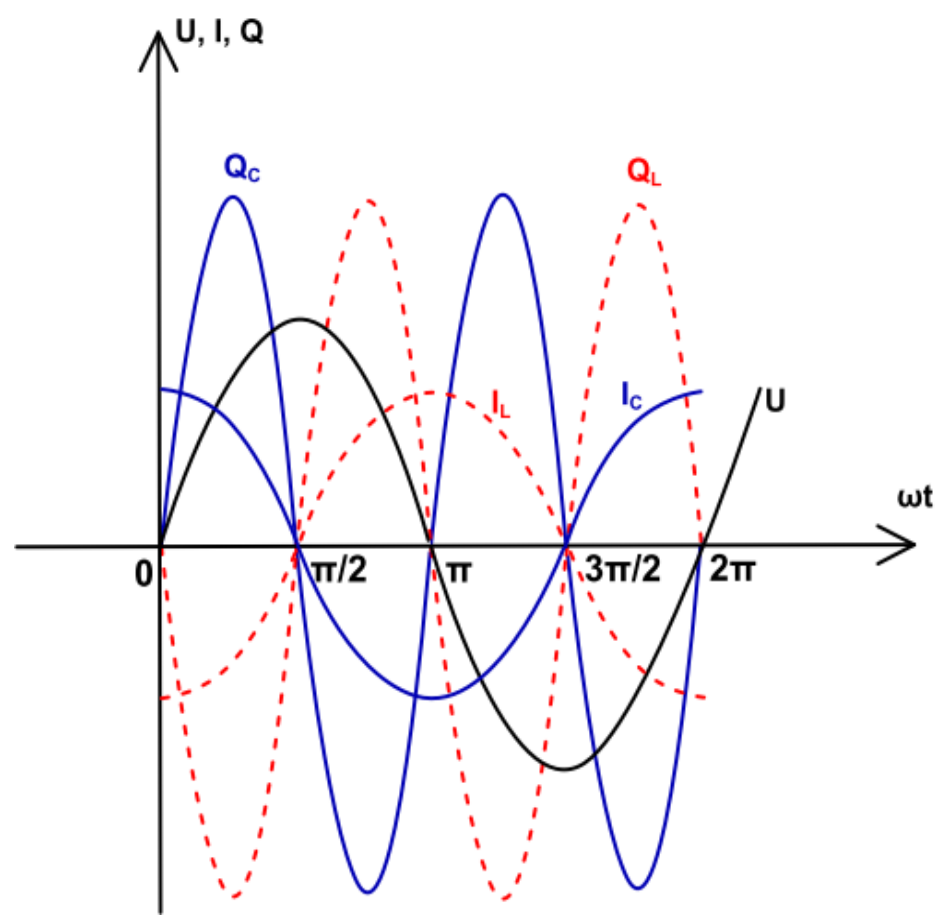

Figura 10-Trocas de potência reativa no circuito LC

Fonte: Adaptado de Hofmann et al. (2012).

A primeira imagem representa uma situação ideal em que um capacitor foi ligado em paralelo com um indutor e o respectivo diagrama fasorial da tensão $U$ nos terminais do conjunto e das correntes $I_{C}$ e $I_{L}$ que percorrem os dois elementos. Já a segunda imagem representa graficamente, além das três grandezas citadas, as potências reativas $\begin{array}{llll}Q_{C} & \text { e } & Q_{L}\end{array}$ no capacitor e no indutor no domínio do tempo. 
Considerou-se, inicialmente, que as reatâncias $X_{L}$ e $X_{C}$ são iguais. O fasor da figura 9 representa a corrente associada à potência ativa decorrente das perdas ôhmicas no circuito, por exemplo as que ocorrem nas bobinas e no núcleo do indutor.

Pode-se notar, tanto pelo diagrama fasorial quanto pelo gráfico, que a corrente no indutor está atrasada de $90^{\circ}$ com relação à tensão, ao passo que a corrente no capacitor está adiantada de $90^{\circ}$ em relação à tensão. Isso implica que quando a corrente no capacitor é positiva, a corrente no indutor tem a mesma intensidade, porém é negativa. Nota-se, adicionalmente, que no primeiro quarto de ciclo, o indutor fornece potência reativa ao capacitor ( $Q_{L}<0$ e $Q_{C}>0$ ), que a devolve no quarto seguinte $\left(\begin{array}{ccc}Q_{L}>0 & \text { e } & Q_{C}<0\end{array}\right)$ e assim sucessivamente.

Esses fatos revelam que o capacitor armazena temporariamente, na forma de energia potencial elétrica, a energia magnética que o indutor necessita para criar o campo magnético intrínseco. Esse procedimento produz um efeito benéfico à instalação elétrica e ao próprio sistema elétrico, pois elimina a necessidade de que a demanda por potência reativa do indutor seja suprida o tempo todo pela concessionária, reduzindo-se assim as perdas ôhmicas e aumentando-se a capacidade do sistema. Por isso, quando se diz que o capacitor "gera" potência reativa ou então que ele é uma "fonte" de potência reativa, deve-se entendê-lo como um reservatório local de energia reativa.

Finalmente, ainda em relação às figuras 9 e 10, percebe-se que a corrente líquida do conjunto é nula no caso em que as reatâncias são iguais. Caso as reatâncias fossem diferentes, a corrente residual $I_{R}$ que circularia pela rede em um dado instante, referente à potência reativa resultante, seria dada pela equação 50 .

$$
I_{R}=I_{L}-I_{C}
$$

$\mathrm{Na}$ prática, os capacitores são acondicionados em gabinetes, formando associações capazes de fornecer desde alguns kvar até centenas de kvar, denominadas bancos de capacitores. Esses bancos podem ser fixos (quando não há nenhum controle) ou automatizados (quando há o controle em tempo real do fator de potência). Quanto maior a sofisticação dos mecanismos de controle e proteção fornecidos junto com o banco, maior o investimento inicial em $\mathrm{R} \$ / \mathrm{kvar}$.

A correção do fator de potência através de capacitores envolve uma série de cuidados, no que se recomenda sempre a consulta a um profissional ou empresa especializada. Por 
exemplo, deve-se dimensionar corretamente a capacidade do banco e se escolher corretamente a sua localização, visando-se maximizar os ganhos econômicos. Além disso, se não houver um dispositivo que desligue o banco no período noturno, pode-se incorrer em excedentes de reativos de natureza capacitiva, como discorrido na próxima seção.

Adicionalmente, a presença de cargas não lineares na instalação elétrica implica na possibilidade da ocorrência da ressonância harmônica após a instalação dos capacitores, colocando-se em risco o próprio banco e demais equipamentos da carga. As reatâncias capacitivas e indutivas da carga formam um circuito LC com uma frequência de ressonância $\mathrm{f}_{r} \quad$ característica, dada pela equação (51):

$$
\mathrm{f}_{r}=\frac{1}{2 \pi} \times \sqrt{\frac{1}{L C}}
$$

onde L e C são a indutância e a capacitância do circuito, respectivamente.

Segundo Creder (2007, p. 286),

a frequência de ressonância da maioria dos circuitos se estabelece na faixa de $\mathrm{kHz}$. Como normalmente não existem fontes de corrente de frequência tão elevada, a ressonância nesta condição não constitui um problema. Entretanto, ao se instalar um banco de capacitores para a correção do fator de potência em circuitos com cargas não-lineares, a frequência de ressonância se reduz, podendo criar uma condição de ressonância com as correntes harmônicas geradas.

E, segundo Starosta (2009, p. 430),

como consequência da ressonância, correntes harmônicas circularão pelos capacitores, causando ainda acréscimo de corrente na rede de alimentação e sobretensões exageradas. Na situação de ressonância, todos os componentes da rede (fonte, carga e capacitores) correm riscos de danos irreversíveis, sendo a situação mais favorável aquela em que os capacitores são desconectados do circuito, quer pela atuação do dispositivo de proteção (dos capacitores) ou mesmo pela queima dos próprios capacitores.

Visando-se atenuar os efeitos da ressonância harmônica, é altamente recomendável a instalação de reatores antirressonantes em série com os capacitores. Essa medida aumenta a impedância no ramo que liga o capacitor à rede elétrica, reduzindo a frequência de ressonância do circuito para um valor inferior àquele correspondente à corrente harmônica a 
ser evitada e que, naturalmente, não coincida com o de outros harmônicos.

\subsection{Regulamentação dos excedentes de reativos no Brasil}

A cobrança por excedentes de reativos, no Brasil, é regulamentada pela Resolução Normativa (RN) ANEEL No 414/2010 (AGÊNCIA NACIONAL DE ENERGIA ELÉTRICA, 2010), modificada posteriormente pela RN ANEEL No 569/2013 (AGÊNCIA NACIONAL DE ENERGIA ELÉTRICA, 2013). As regras que são apresentadas a seguir valem exclusivamente para consumidores do grupo A (tensão maior ou igual a $2,3 \mathrm{kV}$ ), pois os consumidores do grupo B ficaram isentos dessa cobrança após a RN ANEEL Nº 569/2013.

A legislação citada fixa um valor mínimo de referência, $\mathrm{f}_{R}$, igual a 0,92 para o fator de potência (indutivo ou capacitivo). Assim, sempre que o fator de potência da UC (medido de hora em hora ou calculado para o período de faturamento) for inferior a 0,92 , o consumidor paga tanto pela energia reativa quanto pela demanda de potência reativa excedentes (tarifação binômia).

Caso a UC possua equipamento de medição apropriado para registrar valores horários, as fórmulas para a obtenção dos valores $E_{\mathrm{RE}}$ e $D_{\mathrm{RE}}(p)$ (em reais), correspondentes à energia elétrica e à demanda de potência reativa excedentes por posto tarifário, respectivamente, são dadas pelas equações (52) e (53).

$$
\begin{gathered}
E_{\mathrm{RE}}=\sum_{T=1}^{\mathrm{n} 1}\left[E E A M_{T} \times\left(\frac{\mathrm{f}_{R}}{\mathrm{f}_{T}}-1\right)\right] \times V R_{E R E} \\
\left.D_{\mathrm{RE}}(p)=\underset{\mathrm{T}=1}{\operatorname{MA} 2}\left(P A M_{T} \times \frac{\mathrm{f}_{R}}{\mathrm{f}_{T}}\right)-P A F(p)\right] \times V R_{D R E}
\end{gathered}
$$

$\mathrm{Na}$ equação (52), $\quad E E A M_{T}$ é o montante de energia elétrica ativa (em MWh) e $\mathrm{f}_{T}$ é o fator de potência, ambos medidos a cada intervalo $\mathrm{T}$ de 1 hora. $\mathrm{O}$ termo $V R_{E R E}$ é o valor de referência da tarifa de energia aplicável ao subgrupo B1 (em R $\$ / M W h$ ). O valor de n1 corresponde ao número de horas do período de faturamento.

$\mathrm{Na}$ equação (53), $\quad P A M_{T}$ equivale à demanda de potência ativa medida a cada 1 
hora, $\quad P A F(p)$ é a demanda de potência ativa faturável em cada posto tarifário $\quad p \quad$ (em $\mathrm{kW})$ e $V R_{D R E}$ corresponde à tarifa de demanda de potência (em $\mathrm{R} \$ / \mathrm{kW}$ ) para o horário fora de ponta, referente aos subgrupos do grupo A e na modalidade tarifária horária azul. O valor de $\mathrm{n} 2$ corresponde ao número de horas por posto tarifário. A função MAX determina o valor máximo do produto entre parênteses, em cada posto tarifário $\mathrm{p}$.

É importante se frisar que, para a apuração dos valores de $E_{\mathrm{RE}}$ e $D_{\mathrm{RE}}(p)$, segundo a RN ANEEL $\mathrm{N}^{\circ}$ 414/2010, apenas os valores de $\mathrm{f}_{T}$ inferiores a 0,92 capacitivo (das 23h30min às 6h30min) ou inferiores a 0,92 indutivo (nos demais horários) devem ser considerados.

Se, por outro lado, a UC não possuir equipamento de medição apropriado para registrar valores horários, as fórmulas para a obtenção dos valores, em reais, correspondentes à energia elétrica reativa excedente $E_{\mathrm{RE}}$ à da demanda de potência reativa excedente $D_{\mathrm{RE}}$ são dadas pelas equações (54) e (55), respectivamente.

$$
\begin{gathered}
E_{\mathrm{RE}}=E E A M \times\left(\frac{\mathrm{f}_{R}}{\mathrm{f}_{M}}-1\right) \times V R_{E R E} \\
D_{\mathrm{RE}}=\left(P A M \times \frac{\mathrm{f}_{R}}{\mathrm{f}_{M}}-P A F\right) \times V R_{D R E}
\end{gathered}
$$

Na equação (54), EEAM é o montante de energia elétrica ativa (em MWh) e $\mathrm{f}_{M}$ é o fator de potência médio, ambos determinados a cada período de faturamento.

Por fim, na equação (55), PAM equivale à demanda de potência ativa e $P A F$ é a demanda de potência ativa faturável, ambas também determinadas durante o período de faturamento.

\subsection{Quantificação do recurso solar}

A intensidade da radiação solar incidente sobre uma superfície coletora depende de uma série de fatores, como a geometria Terra-Sol, a espessura e composição química da camada atmosférica atravessada pelo raios solares, as condições meteorológicas locais, a inclinação e a orientação azimutal da superfície (PINHO; GALDINO, 2014), entre outros. 
A última referência traz os detalhes da influência de cada um dos elementos citados, bem como os instrumentos de medição da radiação solar e métodos para sua estimativa, no que se recomenda aos leitores menos familiarizados uma consulta prévia a esse material.

A ênfase desta seção é a definição e a interpretação de duas grandezas físicas muito utilizadas na Engenharia de Sistemas Fotovoltaicos e que aparecem diversas vezes ao longo do trabalho.

Uma delas é a irradiância, $G$, definida como a potência radiante (radiação solar) incidente em uma superfície, por unidade de área, de acordo com a equação (56):

$$
G=\frac{P_{\mathrm{IN}}}{A}
$$

onde $P_{\mathrm{IN}}$ é a potência instantânea incidente e A a área da superfície irradiada. Normalmente a irradiância é expressa em $\mathrm{W} / \mathrm{m}^{2}$ ou $\mathrm{kW} / \mathrm{m}^{2}$.

A título de exemplo, a figura 11 mostra duas curvas de irradiância obtidas nas dependências do IEE-USP, utilizando-se o sistema de aquisição de dados descrito em detalhes no Capítulo 2. Uma delas foi obtida em um dia nublado e a outra em um dia de céu limpo, em intervalos de 1 minuto, em uma mesma semana de inverno.

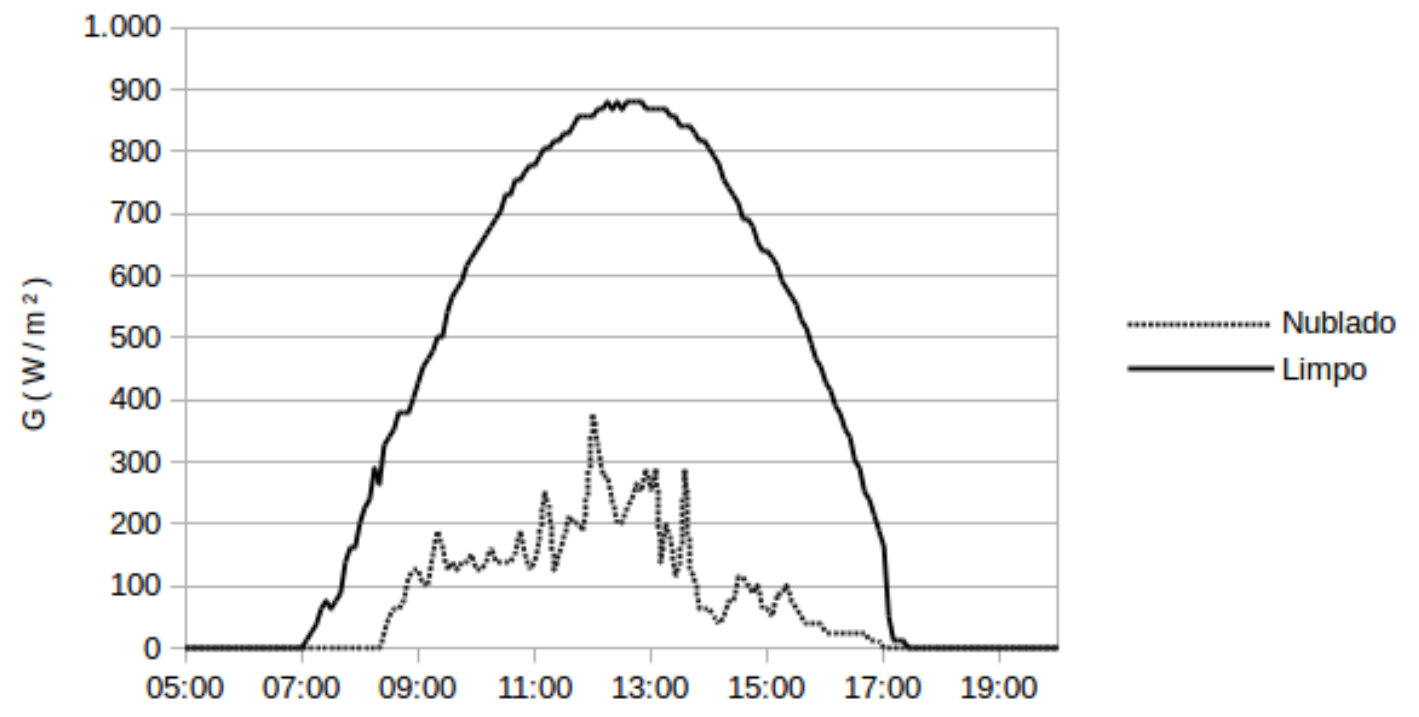

Figura 11- Irradiância para céu nublado e céu limpo

No dia de céu limpo, nota-se menores valores de irradiância no início da manhã e final da tarde e um pico um pouco antes das 13h00. Essa variação diária da irradiância é 
consequência da massa de ar, que também é variável ao longo do dia, na proporção inversa do cosseno do ângulo zenital do Sol (PINHO; GALDINO, 2014). Quanto maior a massa de ar, maior a interferência dos fenômenos da absorção e do espalhamento que a atmosfera exerce sobre os raios solares.

No dia nublado, além da influência da referida massa de ar, nota-se também a interferência da nebulosidade no valor da irradiância (o maior valor registrado no dia foi menor que $400 \mathrm{~W} / \mathrm{m}^{2}$, valor que seria atingido facilmente nas primeiras horas da manhã, caso o dia fosse ensolarado).

A segunda grandeza é a irradiação, $H$, definida como a energia solar incidente sobre uma superfície coletora ao longo de um intervalo de tempo T, por unidade de área. Como a energia pode ser escrita como a integral da potência incidente em relação ao tempo, a equação (57) expressa o valor de $H$.

$$
H=\frac{1}{A} \int_{T} P_{\mathrm{IN}} d t
$$

Combinando-se as equações (56) e (57), pode-se interpretar a irradiação como sendo numericamente igual à área sob a curva da irradiância.

Dessa forma, observando-se a figura 12 , nota-se que a área cinza equivale à diferença entre a energia captada no dia de céu limpo e no dia de seu nublado, por unidade de área

$\left(H_{\text {Limpo }}-H_{\text {Nublado }}\right)$. A área branca corresponde à irradiação no dia nublado e a soma das duas áreas é equivalente à irradiação no dia de céu limpo.

Normalmente, a irradiação é expressa em $\mathrm{kWh} / \mathrm{m}^{2}$.Também é comum, na literatura, a menção à irradiação diária, mensal ou anual sobre uma superfície, como em $5 \mathrm{kWh} / \mathrm{m}^{2}$.dia, $150 \mathrm{kWh} / \mathrm{m}^{2}$.mês ou $1.825 \mathrm{kWh} / \mathrm{m}^{2}$.ano. Ela é o principal indicador da disponibilidade de recurso solar em determinada localidade.

Para se conhecer a energia solar, $E_{\text {IN }}$, incidente sobre a superfície, ao longo do intervalo $\mathrm{T}$, basta multiplicar a irradiação pela área total, como na equação (58). Geralmente essa energia é expressa em kWh.

$$
E_{\mathrm{IN}}=H . A
$$




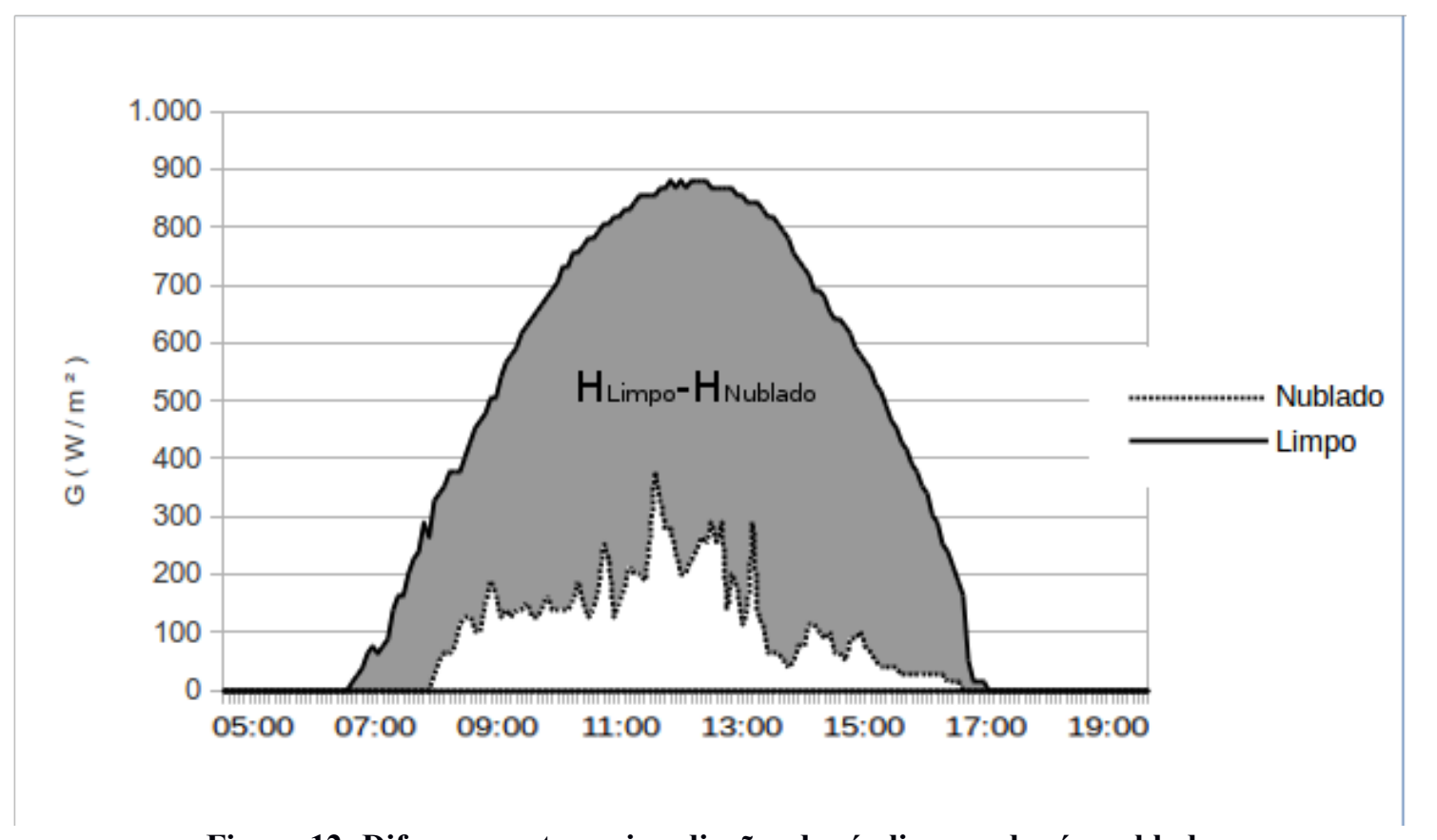

Figura 12- Diferença entre as irradiações de céu limpo e de céu nublado

\subsection{Indicadores de desempenho de um SFCR}

Os principais componentes de um SFCR são o gerador fotovoltaico (composto pelos módulos, nos quais ocorre a conversão da energia solar incidente em eletricidade) e o inversor, equipamento eletrônico responsável pela conversão da energia elétrica em c.c. proveniente do gerador em energia elétrica em c.a.

As perdas elétricas nesses dois elementos são as mais significativas para o sistema como um todo e decorrem de uma série de fatores. Nos módulos, estão relacionadas principalmente à temperatura de operação, sujeira e à dispersão entre os próprios módulos, enquanto que, no inversor, elas decorrem do seguimento do ponto de máxima potência do gerador e da conversão c.c.-c.a. propriamente dita (ZILLES et al., 2012).É importante destacar que também ocorrem perdas nas conexões e nos cabos, especialmente quando estes últimos são subdimensionados.

É possível avaliar o desempenho do sistema como um todo, através da utilização de três indicadores bastante difundidos na literatura de Engenharia de Sistemas Fotovoltaicos, por exemplo na última referência logo acima.

O primeiro deles é a produtividade do sistema, $Y_{F}$, também conhecida como final yield, definida como a razão entre a energia elétrica entregue à carga em um intervalo de 
tempo T e a potência nominal $P_{N}$ do gerador. Escrevendo-se essa energia como a integral da potência $P_{A C}$ na saída do inversor em relação ao tempo, tem-se a equação (59).

$$
Y_{F}=\frac{1}{P_{N}} \int_{T} P_{A C} d t
$$

Embora $Y_{F}$ tenha dimensão de tempo, é comum expressá-lo em $\mathrm{kWh} / \mathrm{kW}_{\mathrm{p}}$.

O segundo indicador é o fator de capacidade, $C_{F}$, definido como a razão entre a energia elétrica efetivamente entregue à carga em um intervalo de tempo T e a energia elétrica teórica que o sistema entregaria caso operasse na potência nominal durante esse mesmo intervalo de tempo, conforme a equação (59).

$$
C_{F}=\frac{1}{P_{N} \cdot T} \int_{T} P_{A C} d t
$$

O fator de capacidade é um parâmetro adimensional, geralmente expresso em porcentagem.

Finalmente, o último indicador que se deseja definir é o rendimento global do sistema, $P R$, também conhecido como performance ratio. Ele pode ser escrito como na equação (61), onde $G_{0}=1.000 \mathrm{~W} / \mathrm{m}^{2}$ é a irradiância de referência, utilizada nas condições padrão de testes de módulos fotovoltaicos.

$$
P R=\frac{Y_{F}}{H / G_{0}}
$$

O desempenho global também é uma grandeza adimensional geralmente expressa em porcentagem. O numerador da equação (61), já definido anteriormente, pode ser interpretado como o tempo teórico de operação do sistema na potência nominal do gerador, de forma a produzir toda a energia entregue à carga no intervalo de tempo T. Já o denominador, conhecido na literatura estrangeira como reference yield, $Y_{R}$, ou horas de sol pleno, $h_{S P}$, na literatura brasileira, corresponde ao tempo teórico que seria obtido caso toda a irradiação incidente na superfície coletora ocorresse sob uma irradiância fixa em $1.000 \mathrm{~W} / \mathrm{m}^{2}$.

Os três índices apresentados anteriormente têm a sua importância específica. No caso de $C_{F}$, o cálculo do custo de geração fotovoltaica. Já $Y_{F}$ permite realizar diversas 
comparações entre dois sistemas fotovoltaicos, pois normaliza a produção efetiva de energia elétrica em relação à potência instalada. Finalmente, através de $P R$ pode-se comparar o desempenho efetivo de um sistema fotovoltaico com o máximo desempenho teórico possível, podendo-se assim avaliar as perdas globais do sistema.

\subsection{Custo de geração de um SFCR}

O cálculo do custo de geração fotovoltaica, $C_{G}$, segue a métrica utilizada em qualquer outro projeto de geração de energia elétrica, na qual é feita uma análise de ciclo de vida do empreendimento, levando-se em conta os investimentos iniciais, I, os gastos com operação e manutenção, o fator de capacidade, $C_{F}$, da planta e a taxa de desconto, $r$. A equação (62) (ZILLES; OLIVEIRA, 1999) traz a relação entre esses parâmetros.

$$
C_{G}=\left[\frac{r(1+r)^{n}}{(1+r)^{n}-1}+O \& M\right] \times \frac{I}{8,76 \cdot C_{F}}
$$

A taxa de desconto, $r$, e o termo $O \& M$, referente à taxa de operação e manutenção, são adimensionais e expressos em porcentagem, assim como $C_{F}$. O valor de $I$ é tomado em $\mathrm{R} \$ / \mathrm{kW}_{\mathrm{p}}$. Dessa forma, o valor de $C_{G}$ fica expresso em $\mathrm{R} \$ / \mathrm{MWh}$.

\subsection{Controle de potência em inversores para SFCR}

A figura 13 mostra a topologia básica de um inversor monofásico do tipo fonte de tensão (VSI ou voltage source inverter) e sem transformador. No diagrama, a energia elétrica c.c. proveniente do gerador fotovoltaico GFV é armazenada temporariamente no capacitor $\mathrm{C}$ e depois entregue ao conversor c.c.-c.a. de ponte completa formada pelas chaves $S_{1}$ a $S_{4}$ que, neste caso, são do tipo IGBT (insulated gate bipolar transistor). Operando em uma frequência de chaveamento entre 5 e $20 \mathrm{kHz}$ e utilizando modulação por largura de pulso (PWM), o conversor gera uma onda de tensão que, após filtrada nos indutores $\mathrm{L}_{1}$ e $\mathrm{L}_{2}$, toma um formato senoidal (SCHMIDT; BURGER; SCHMID, 2011). 


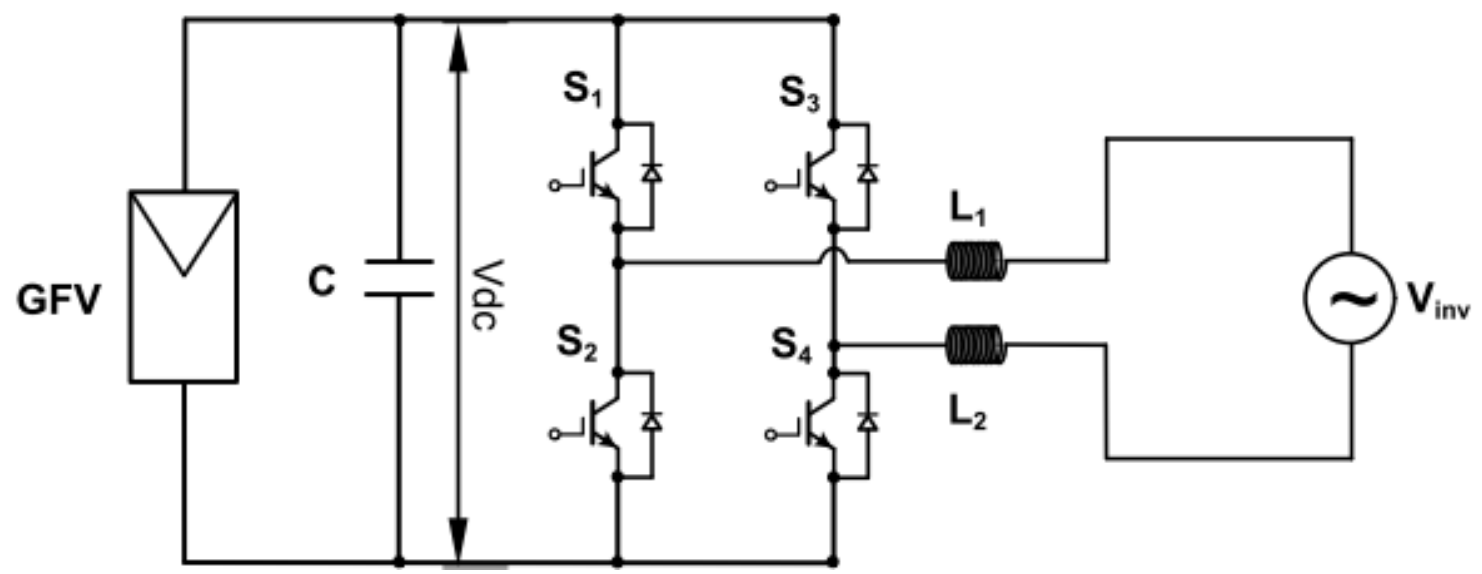

Figura 13-Topologia básica de um inversor monofásico sem transformador

Fonte: Adaptado de Schmidt, Burger e Schmid (2011)

Se esse inversor é conectado diretamente à rede elétrica, tem-se o circuito equivalente da figura 14, na qual o inversor e a rede podem ser considerados duas fontes com tensões senoidais dadas por $v_{i n v}$ e $v_{\text {rede }}$, respectivamente, e $X_{L}$ é a reatância de acoplamento equivalente, geralmente indutiva.

\section{$\mathbf{X}_{\mathrm{L}}$}

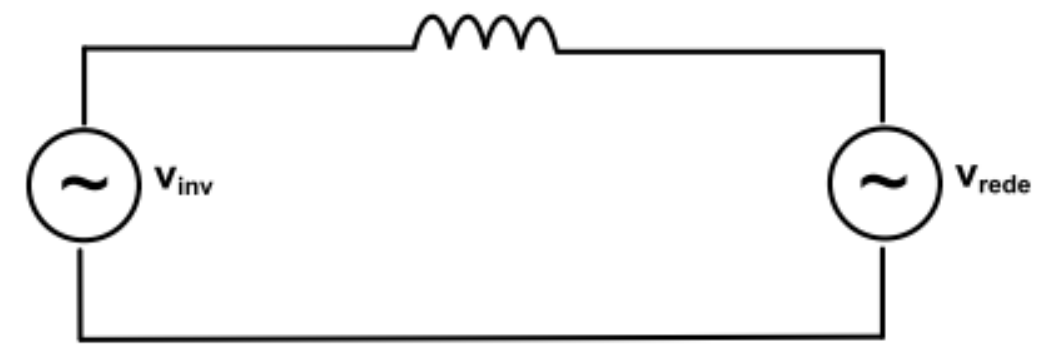

Figura 14-Circuito equivalente no acoplamento do inversor à rede

Se $V_{i n v}$ e $V_{\text {rede }}$ são os valores eficazes de $v_{i n v}$ e $v_{\text {rede, }}$, respectivamente, e $\delta$ é o ângulo de defasagem entre as duas ondas de tensão, pode-se determinar os fluxos de potência ativa $P$ e reativa $Q$ do inversor para a rede elétrica (ou vice-versa) através das equações (63) e (64) (HASSAINE et al., 2014; ALBUQUERQUE et al., 2010; NAYAR; ISLAM; SHARMA, 2001). 


$$
\begin{gathered}
P=\frac{V_{\text {inv }} \cdot V_{\text {rede }}}{X_{L}} \cdot \sin \delta \\
Q=\frac{V_{\text {rede }}}{X_{L}} \cdot\left(V_{\text {inv }} \cos \delta-V_{\text {rede }}\right)
\end{gathered}
$$

Nota-se, pela análise das equações (63) e (64), que se o inversor possuir um mecanismo de controle capaz de obter $\delta$ e $V_{\text {rede }}$ em um dado instante, ele pode variar a troca de potência ativa e/ou reativa com a rede em um instante posterior, alterando a amplitude, $V_{i n v}$, da onda de tensão por ele gerada, o ângulo de defasagem, $\delta$, ou ambos simultaneamente.

Se outras topologias de inversores VSI fossem utilizadas no lugar do exemplo da figura 13 (por exemplo, com inversores com transformador ou de múltiplos estágios de conversão c.c./c.c.), os princípios de transferência de potência do inversor para a rede ou viceversa seriam os mesmos.

Para que o inversor disponha de uma tensão trifásica em sua saída, pode-se utilizar uma ponte com 6 IGBTs em vez de 4, conforme mostra a figura 15 .

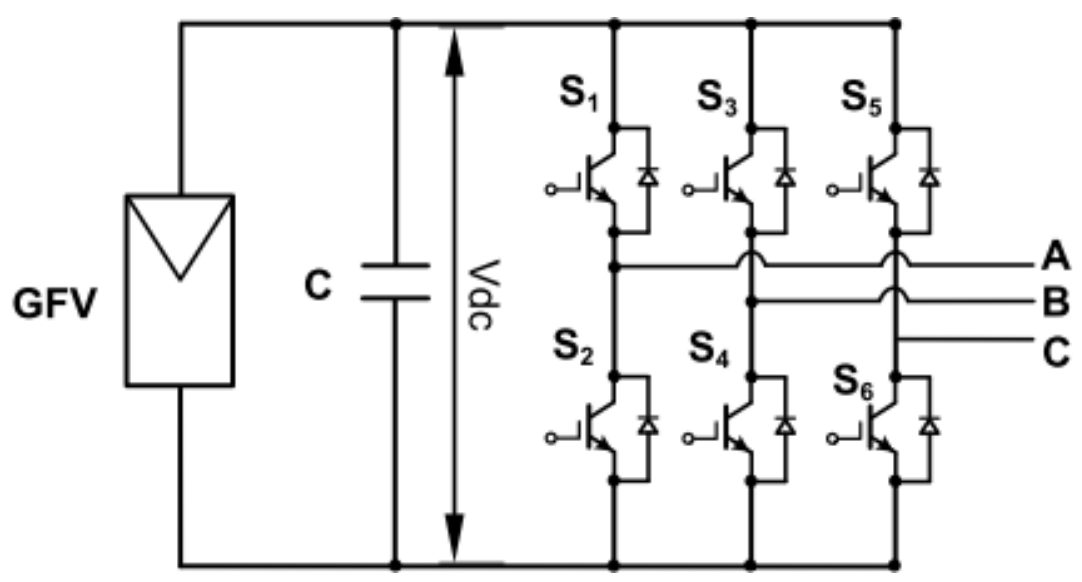

Figura 15-Topologia básica de um inversor trifásico sem transformador 


\subsection{Abordagem metodológica}

Para se atacar o problema levantado em condições reais de operação, foi realizado um estudo de caso de um sistema fotovoltaico conectado indiretamente à rede elétrica pública, no quadro geral de um edifício comercial com perfil de prédio público, pertencente a um complexo que configura uma UC do grupo A (tensão de fornecimento igual a $13,8 \mathrm{kV}$ ). Porém, tanto a alimentação proveniente da rede quanto aquela fornecida pelo sistema fotovoltaico são entregues ao prédio em baixa tensão $(220 \mathrm{~V})$, através do uso de transformadores.

O estudo da interação entre a carga, o sistema fotovoltaico e a rede elétrica, no que tange aos fluxos de potência ativa e reativa, deu-se através de uma abordagem empírica. Essa experiência encontra-se descrita com riqueza de detalhes ainda neste capítulo, de forma que aqui pretende-se apenas fornecer uma visão geral do aparato utilizado e das grandezas medidas e analisadas.

O sistema fotovoltaico utilizado no estudo é composto por 5 subsistemas, cada um contendo um gerador fotovoltaico de potência nominal 15,6 kWp e um inversor de $12,5 \mathrm{~kW}$ de potência ativa nominal.

Inicialmente, foi traçado um perfil da carga, para um dia típico de verão e outro de inverno, através de dados disponibilizados pelo PUFE (Programa Usos Finais da Energia) do IEE-USP, de medições realizadas diretamente no quadro geral do prédio e verificações in loco. Em seguida, foram programados três conjuntos de ensaios constantes da tabela 1.

O primeiro conjunto permitiu avaliar o comportamento do sistema fotovoltaico em condições distintas de disponibilidade de recurso solar, quando ele opera no modo convencional, que é aquele em que apenas potência ativa é gerada. Analisou-se basicamente os efeitos da temperatura sobre o gerador fotovoltaico, a eficiência do inversor, as perdas nos cabos e no rebaixamento de tensão e a taxa de desempenho global do sistema (performance ratio). Para se garantir a confiabilidade dos resultados, utilizou-se nos testes dos EAGS dois subsistemas que operavam de forma independente, porém em condições teoricamente idênticas. 
Tabela 1- Descrição do conjunto de ensaios realizados

\begin{tabular}{|c|c|c|}
\hline Nome do conjunto de ensaios & Sigla & Objetivos \\
\hline Ensaios de avaliação geral do sistema & EAGS & $\begin{array}{l}\text { Monitorar o funcionamento do sistema } \\
\text { fotovoltaico no modo de operação } \\
\text { padrão do inversor (fator de potência } \\
\text { unitário), para diferentes condições } \\
\text { climáticas. A duração desse conjunto foi } \\
\text { de } 2 \text { dias não subsequentes (um dia } \\
\text { ensolarado e outro nublado), utilizando } \\
\text {-se } 2 \text { subsistemas operando de forma } \\
\text { independente e em condições } \\
\text { teoricamente idênticas. }\end{array}$ \\
\hline Ensaios de compensação de reativos & ECR & $\begin{array}{l}\text { Monitorar as curvas de demanda de } \\
\text { potência ativa, reativa e aparente, bem } \\
\text { como do fator de potência, obtidos a } \\
\text { partir do medidor eletrônico da entrada } \\
\text { da edificação, para duas situações } \\
\text { distintas: um dia útil com a carga } \\
\text { indutiva e o sistema fotovoltaico } \\
\text { operando com fator de potência unitário } \\
\text { e outro dia útil com o sistema } \\
\text { fotovoltaico entregando potência ativa e } \\
\text { reativa simultaneamente, essa última } \\
\text { com vistas a suprir localmente a } \\
\text { demanda por reativos e evitar a cobrança } \\
\text { de excedentes. A duração desse conjunto } \\
\text { foi de } 4 \text { dias, sendo } 2 \text { duplas de dias } \\
\text { subsequentes. }\end{array}$ \\
\hline $\begin{array}{l}\text { Ensaios de avaliação dos modos } \\
\text { capacitivo e indutivo }\end{array}$ & EAMCI & $\begin{array}{l}\text { Verificar se ao operar nos modos } \\
\text { capacitivo e indutivo, obedecidos os } \\
\text { limites de potência reativa fixados na } \\
\text { norma NBR } 16149: 2013 \text {, o inversor } \\
\text { mantém o desempenho que teria se } \\
\text { operasse no modo padrão ou se sua } \\
\text { capacidade de entregar potência ativa } \\
\text { fica prejudicada. Esse grupo de testes } \\
\text { ocorreu em três dias consecutivos de céu } \\
\text { limpo e com níveis de irradiância muito } \\
\text { semelhantes, utilizando-se um mesmo } \\
\text { subsistema, que operou com fator de } \\
\text { potência unitário no primeiro dia, } \\
\text { capacitivo no segundo dia e indutivo no } \\
\text { terceiro dia. }\end{array}$ \\
\hline
\end{tabular}


Os ensaios aconteceram exclusivamente no inverno, período em que demanda por potência ativa do prédio é menor que no verão, quando há uso intensivo do ar-condicionado, visando amenizar a carga térmica do prédio. Adicionalmente, como será descrito em detalhes adiante, constatou-se que o perfil da carga é predominantemente capacitivo no inverno, tornando-se levemente indutivo apenas quando há uma grande quantidade de aparelhos de condicionamento ambiental ligados simultaneamente.

Por isso, para levar a cabo o segundo conjunto de ensaios, limitou-se a potência ativa entregue pelo sistema fotovoltaico, visando-se aproximar ao máximo as curvas de geração e demanda, ao mesmo tempo em que se forçou um comportamento indutivo da carga.

Isso foi conseguido da seguinte forma: para limitar a potência entregue pelo sistema fotovoltaico, utilizou-se apenas 1 subsistema para entregar potência ativa (SUBSISTEMA 1), dos cinco disponíveis. Já para forçar um comportamento indutivo da carga, colocou-se o inversor de um segundo subsistema para trabalhar subexcitado (SUBSISTEMA 2), demandando uma quantidade fixa de potência reativa da rede mas sem gerar potência ativa, como se fosse mais um equipamento que compõe a carga. Devido ao resultado da superposição das curvas de potência reativa da carga em seu estado natural e deste inversor subexcitado, o comportamento global do conjunto, monitorado a partir do medidor da entrada da edificação, tornou-se predominantemente indutivo.

Como descrito na tabela 1, no primeiro dia, o inversor do SUBSISTEMA 1 trabalhou com fator de potência unitário, a fim de se evidenciar o problema da degradação do fator de potência medido na entrada do prédio relatado, na Introdução. No segundo dia, configurou-se esse inversor para trabalhar superexcitado, gerando potência ativa e reativa simultaneamente, de forma a suprir localmente a demanda por reativos e deixar de obtê-los a partir da rede elétrica. Esse procedimento foi realizado duas vezes, mudando-se apenas os níveis de excitação dos inversores.

Finalmente, o terceiro grupo de ensaios foi realizado em três dias subsequentes de céu limpo, sem nuvens praticamente durante todo o período. Ele foi necessário, pois, caso ficasse constatada a capacidade de se compensar reativos utilizando-se o inversor do SUBSISTEMA 1, dever-se-ia averiguar se a geração de potência reativa, obedecidos os limites da norma NBR 16149:2013, não afeta a produção de potência ativa, comparativamente à situação em que o inversor operasse com fator de potência unitário. A referida norma permite que esse modelo de inversor entregue ou demande, em termos de reativos, um valor numericamente igual a 43,5\% da sua potência ativa nominal (ASSOCIAÇÃO BRASILEIRA DE NORMAS TÉCNICAS, 2013)- cerca de 5,4 kvar ). A dúvida é pertinente pois, caso a produção de 
potência ativa seja afetada de forma significativa, isso gera impactos no tempo de retorno do investimento.

Os dados obtidos através dos equipamentos de aquisição encontram-se descritos abaixo. Os intervalos de aquisição mencionados são os menores possíveis disponíveis para cada equipamento (datalogger, placa de aquisição ou medidor eletrônico).

A cada 1 minuto foram registrados:

a) a irradiância no plano do gerador fotovoltaico;

b) a temperatura de operação dos módulos e a temperatura ambiente;

c) a corrente, a tensão e a potência disponíveis nas duas entradas c.c. do inversor;

d) a potência e a energia ativas na saída c.a. do inversor;

A cada 5 minutos foram registrados:

e) as potências e as energias ativa e reativa entregues no ponto de conexão;

f) as potências e as energias ativa e reativa demandadas pela carga;

g) as potências e as energias ativa e reativa fornecidas (ou absorvidas) pela rede;

h) a tensão entre cada fase e o neutro no ponto de conexão do sistema fotovoltaico, que é o quadro geral da UC e no secundário do alimentador;

i) o fator de potência medido no ponto de conexão (quadro geral) e no ponto de entrada do fornecimento.

\subsection{Sistema fotovoltaico de $78 \mathrm{kWp}$ sobre o prédio da Administração do IEE - USP}

A figura 16 apresenta um diagrama unifilar da planta estudada, a qual encontra-se descrita detalhadamente nesta seção e na próxima.

Essa usina é uma das quatro plantas que fazem parte do Projeto de P\&D ANEEL $N^{\circ}$ 0068-0029/2011, denominado "Desenvolvimento de Competências e Avaliação de Arranjos Técnicos e Comerciais em Geração Distribuída com Sistemas Fotovoltaicos Conectados à Rede", cujo escopo prevê a instalação de 0,5 MWp nas dependências da USP de São Paulo, capital. 
Fileira 1

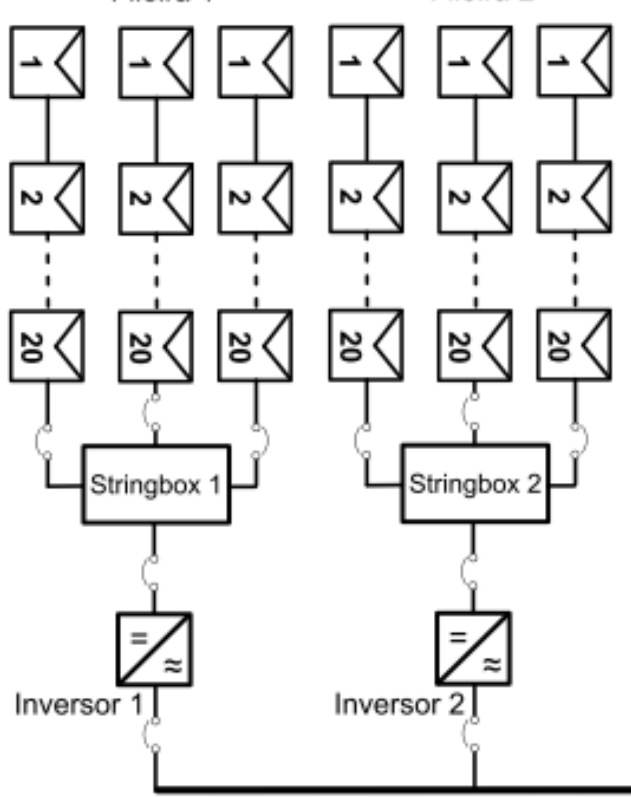

Barramento AC $380 \mathrm{~V}$
Fileira 3

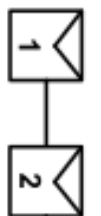

i
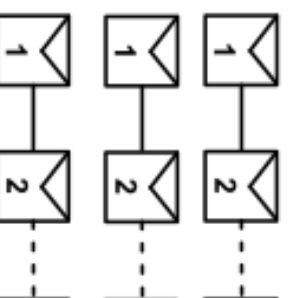
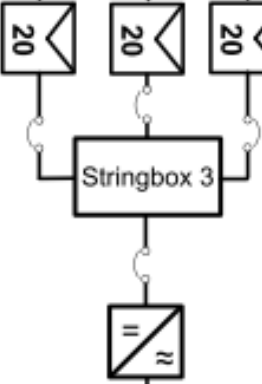

Inversor 3

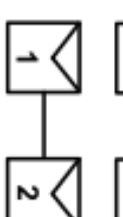

Fileira 4
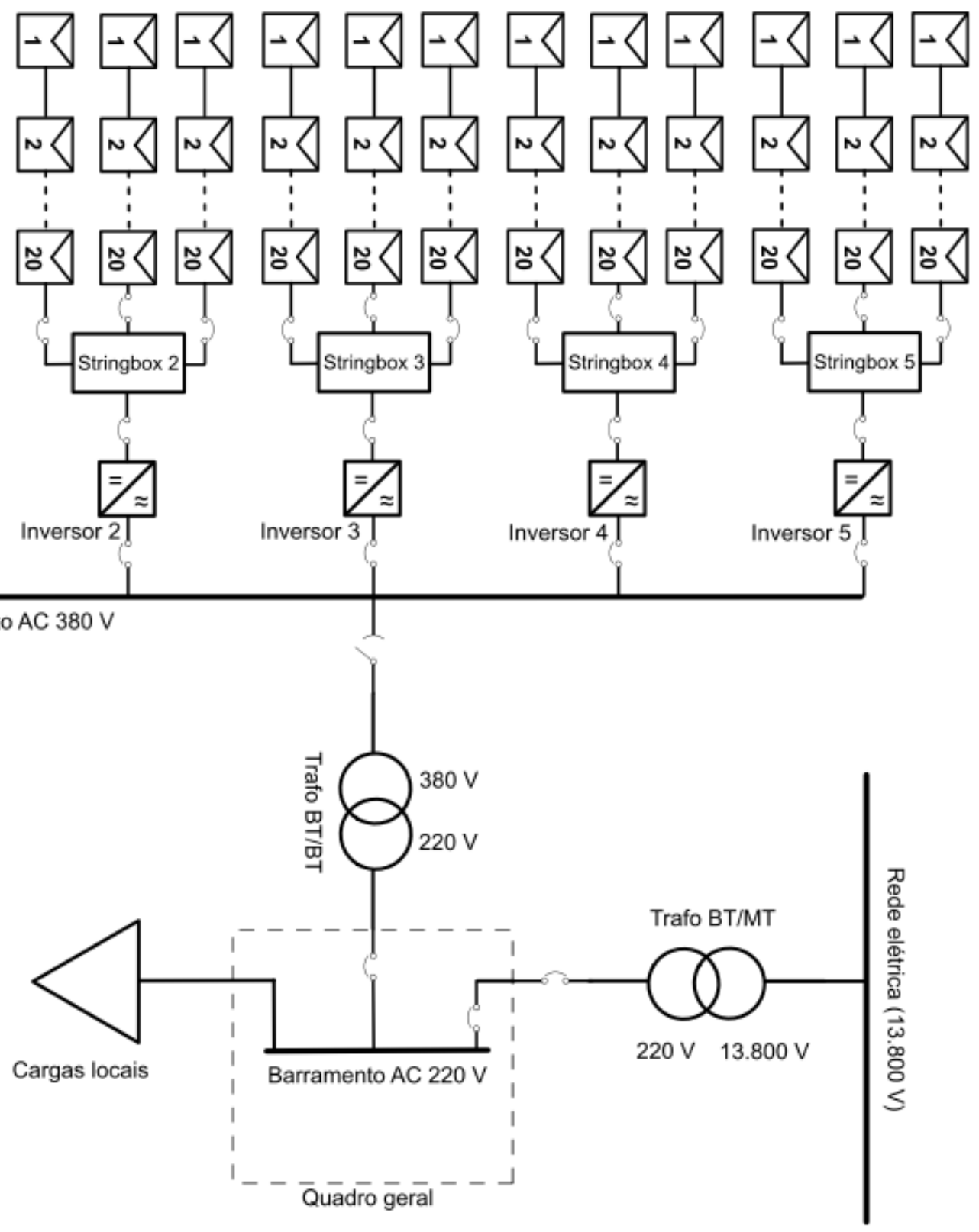

Figura 16- Diagrama unifilar das instalações elétricas do sistema CRPV

O gerador fotovoltaico, de $78 \mathrm{kWp}$, está instalado sobre o telhado do prédio da Administração do IEE - USP e pode ser visualizado na figura 17.

A concepção da planta foi fiel ao conceito BAPV (Building Adapted PV), cuja tradução para o português significa sistema fotovoltaico adaptado à edificação. Ou seja, o sistema foi instalado sobre uma construção preexistente e, por isso, teve que se adaptar ao projeto arquitetônico do prédio.

Dessa forma, a fixação dos módulos ao telhado deu-se através da aplicação de uma 
estrutura de alumínio cujas bases são constituídas de perfis em U, perfeitamente adaptáveis ao contorno arredondado das telhas, com um impacto mínimo sobre elas. Os detalhes da estrutura são mostrados na figura 18 .

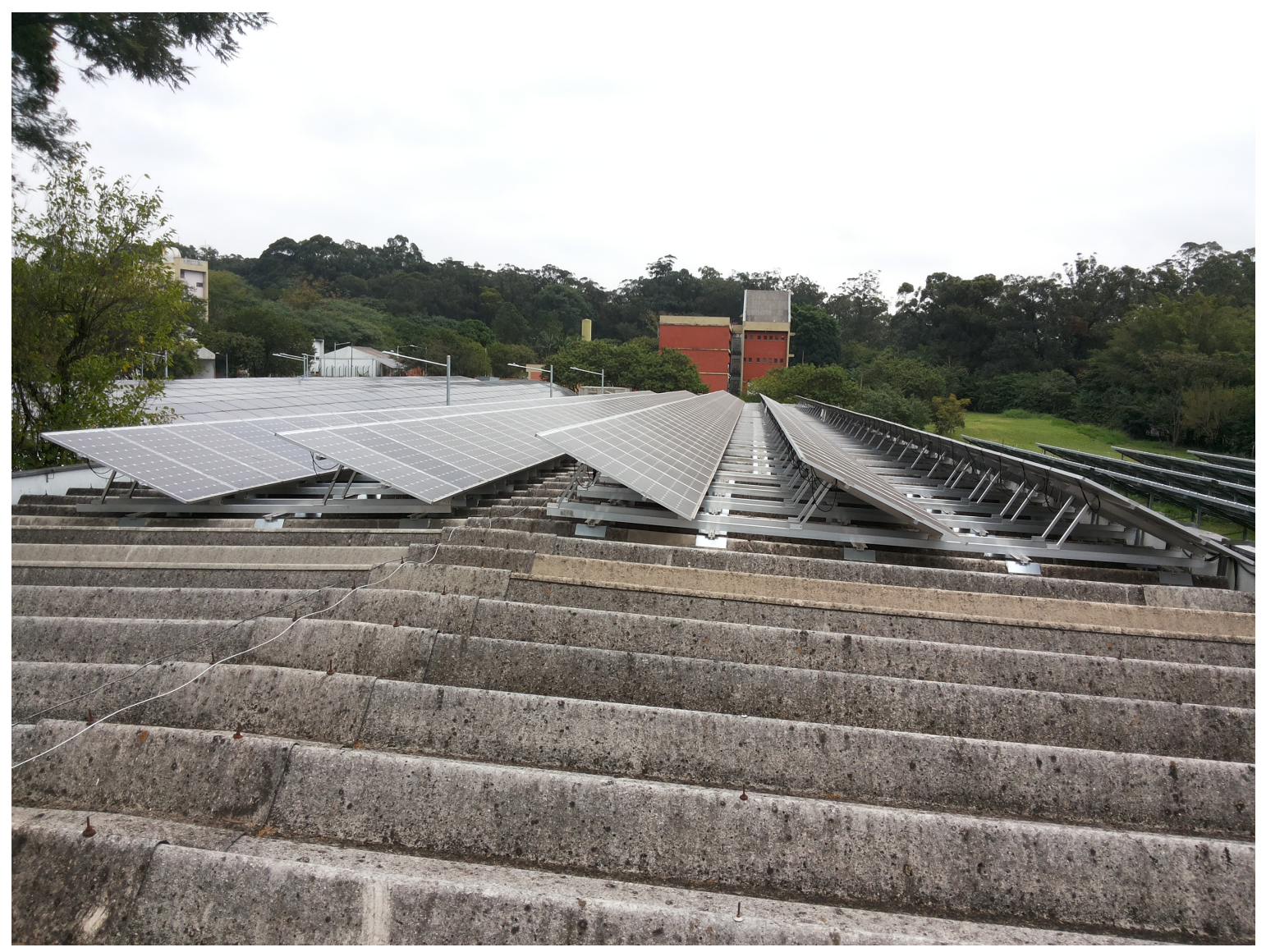

Figura 17 - Gerador fotovoltaico de 78 kWp sobre o edifício da Administração do IEE - USP
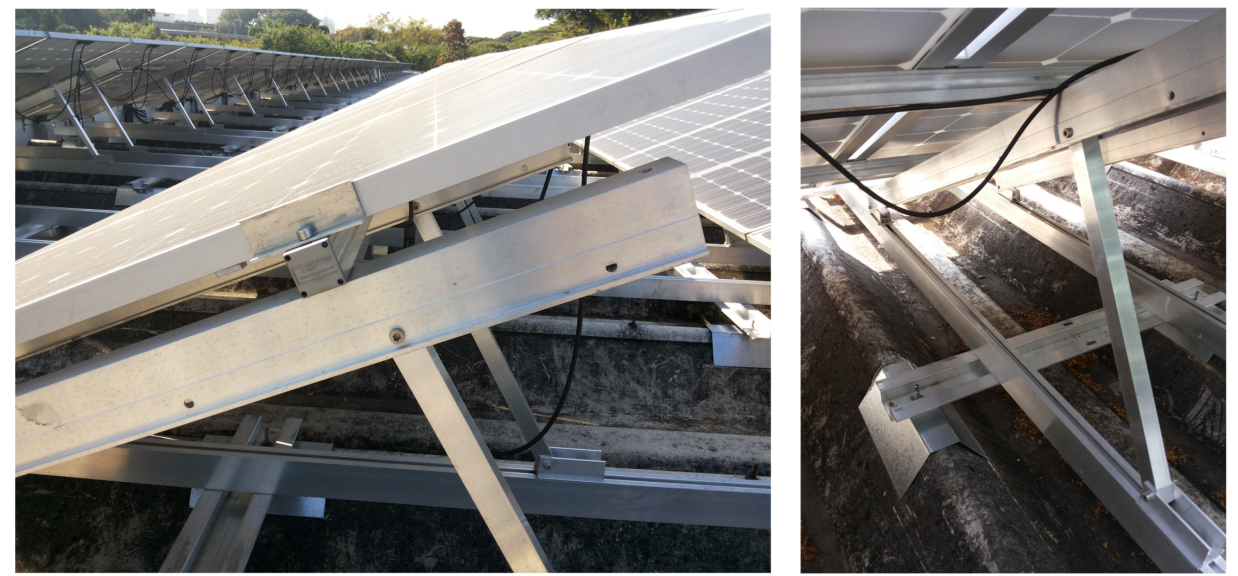

Figura 18- Detalhes da fixação dos arranjos de módulos fotovoltaicos ao telhado 
O gerador é composto de 5 fileiras de módulos de silício monocristalino, modelo $S W$ 260 mono, de $260 \mathrm{Wp}$, do fabricante SOLAR WORLD. Cada fileira contém 60 módulos, totalizando $15,6 \mathrm{kWp}$ por subsistema e $78 \mathrm{kWp}$ para a planta toda.

Para cada fileira há um quadro conhecido como stringbox, no interior do qual são realizadas as conexões elétricas dos arranjos. Nele também encontram-se dispositivos de seccionamento, proteção e de aquisição de dados do lado c.c.

Desse quadro partem os cabos que alimentam as entradas c.c. de um inversor trifásico de 12,5 kW nominais, modelo AURORA TRIO PVI 12.5-TL-OUTDS, do fabricante POWER$O N E$. O principal diferencial deste modelo é a presença de um mecanismo de controle de reativos incorporado (limitado à potência aparente máxima de 13,8 kVA).

Cada inversor conta com dois seguidores de ponto de máxima potência independentes, que são denominados, ao longo do trabalho, SPMP1 e SPMP2.

As figuras 19 e 20 apresentam, respectivamente, as fotografias do inversor e da stringbox de uma das fileiras. Como se pode observar, ambos estão abrigados sob os próprios módulos, também sobre o telhado.

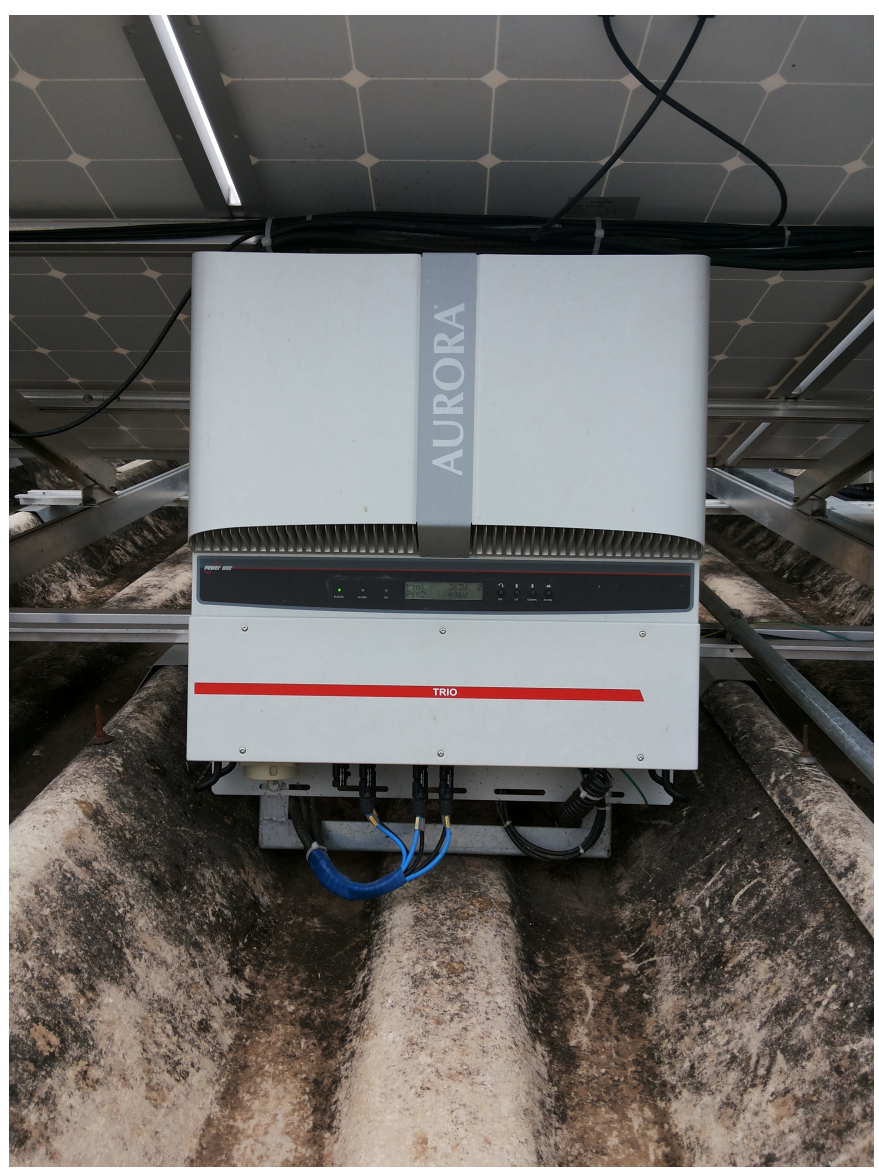

Figura 19-Inversor AURORA TRIO PVI 12.5-TL-OUTDS 


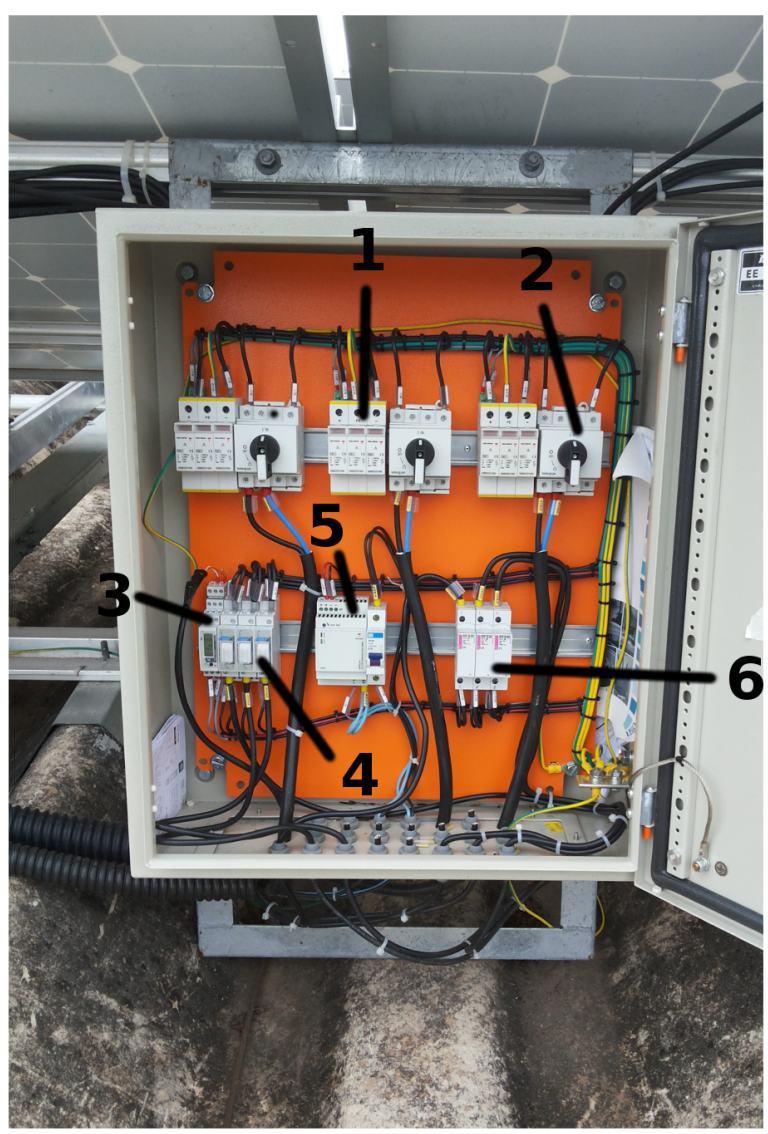

\section{LEGENDA:}

\section{1- Proteção contra surtos}

\section{2- Chave seccionadora}

\section{3- Datalogger Modbus}

4- Fusíveis c.c. do polo +

5- Fonte de alimentação

6- Fusíveis c.c. do polo -

Figura 20- Detalhes dos componentes de uma stringbox

A figura 21 traz um diagrama de blocos do inversor. No canto superior esquerdo, notase a presença de duas entradas c.c. (IN1 e IN2), sendo uma para cada seguidor do ponto de máxima potência (SPMP1 e SPMP2). Em cada entrada c.c. podem ser conectadas até 2 strings, o que pode ser identificado, por exemplo, através da presença dos terminais IN1.1 (+) e IN1.1 (-) e IN1.2 (+) e IN1.2 (-).

Após ser armazenada temporariamente em um banco de capacitores tipo bulk, a energia c.c. é convertida em c.a. pelo IGBT. O filtro acoplado à saída deste último componente tem a função de dar um aspecto senoidal à forma de onda de tensão na saída do inversor.

O circuito de controle possui um microprocessador responsável por diversas tarefas, dentre as quais modelar a forma de onda na saída do inversor em função das características da rede e de parâmetros eventualmente enviados a ele por telecomando (por exemplo, no caso de correção do fator de potência). 


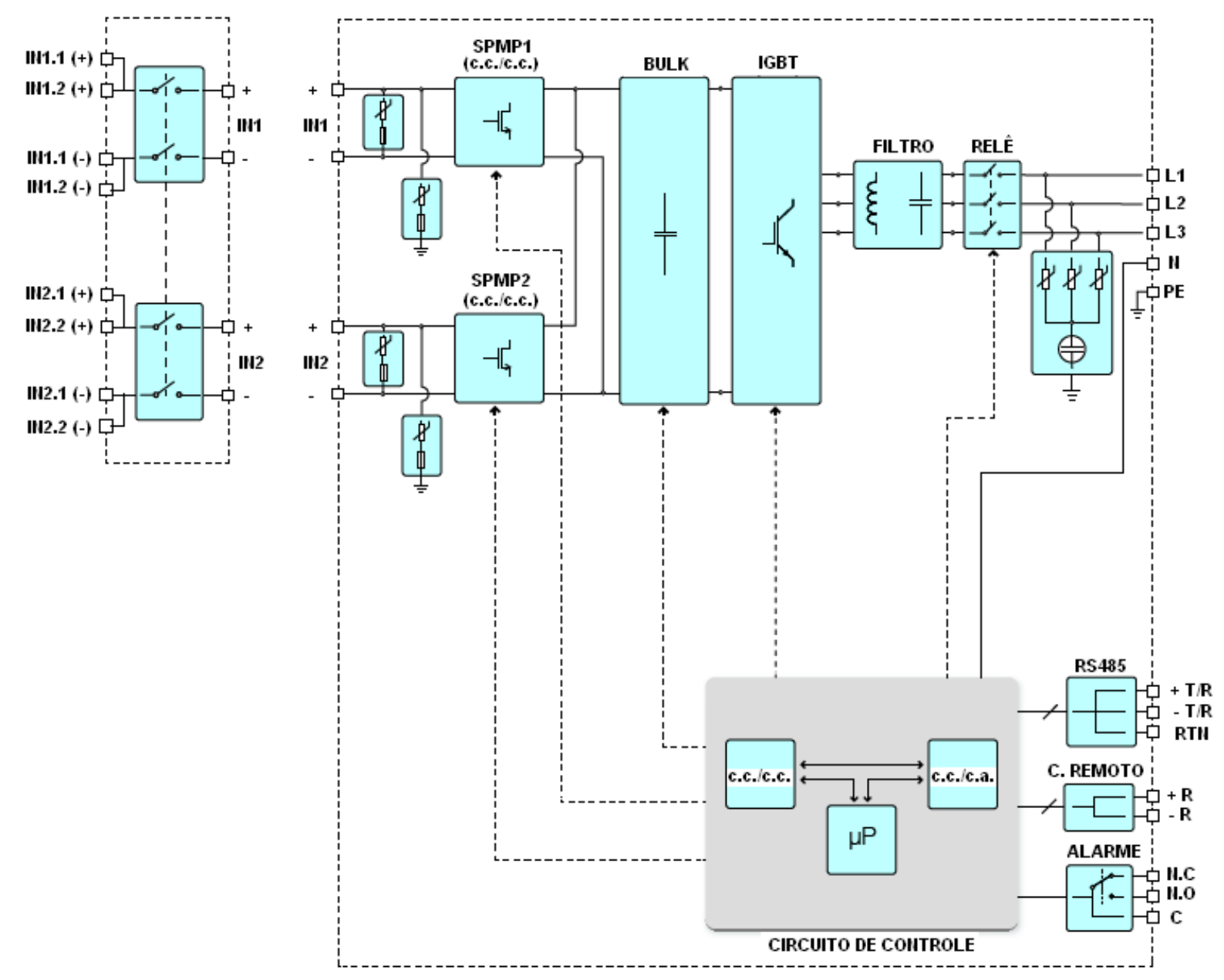

Figura 21-Diagrama de blocos do inversor AURORA PVI 12.5-TL-OUTD-S

A tabela 2 apresenta um resumo das especificações técnicas do inversor. Quando o fator de potência é igual a 1, o inversor entrega apenas potência ativa, a qual é limitada a 12,5 $\mathrm{kW}$. Porém, como esse valor é numericamente inferior à potência aparente máxima, que é de 13,8 kVA, existe um lastro de potência que pode ser utilizado no controle de reativos, sem afetar a potência ativa nominal. Isso permitiria, por exemplo, programar o inversor para, além de ser capaz de entregar os $12,5 \mathrm{~kW}$ nominais, despachar ou demandar potência reativa simultaneamente (seja fixando o fator de potência em um valor não inferior a 0,9 ou então a potência reativa em um valor não superior a 5,8 kvar).

Também é possível configurar o fator de potência até o valor mínimo de 0,8 ou então a potência reativa em um valor máximo de 8,3 kvar mas, a partir de um fator de potência inferior a 0,9 ou de uma potência reativa superior a 5,8 kvar,, a produção de potência ativa será prejudicada, de forma que o inversor será incapaz de processar, concomitantemente com 
a potência reativa, os $12,5 \mathrm{~kW}$ nominais.

Tabela 2-Especificações do inversor AURORA PVI 12.5-TL-OUTD-S

\begin{tabular}{|c|c|}
\hline Característica & Valores/descrição \\
\hline Faixa de tensões c.c. de operação & $250 \mathrm{~V}$ a $850 \mathrm{~V}$ \\
\hline Tensão c.c. ótima de operação & $580 \mathrm{~V}$ \\
\hline Máxima corrente c.c. por SPMP & $18 \mathrm{~A}$ \\
\hline Faixa de tensões c.a. de operação & $320 \mathrm{~V}$ a $480 \mathrm{~V}$ \\
\hline Máxima corrente c.a. & $20 \mathrm{~A}$ \\
\hline Faixa de frequências de operação & $57 \mathrm{~Hz}$ a $63 \mathrm{~Hz}$ \\
\hline Potência ativa nominal & $12,5 \mathrm{~kW}$ \\
\hline Eficiência máxima & $97,8 \%$ \\
\hline Potência aparente máxima & $13,8 \mathrm{kVA}$ \\
\hline Tipos de controle de reativos disponíveis & $\begin{array}{l}\text { 1- fator de potência fixo } \\
\text { 2- potência reativa fixa } \\
\text { 3- fator de potência variável em função } \\
\text { da potência ativa } \\
\text { 4- potência reativa variável em função } \\
\text { da tensão no ponto de acoplamento. }\end{array}$ \\
\hline $\begin{array}{l}\text { Fator de potência mínimo sem comprometimento } \\
\text { da potência ativa nominal }\end{array}$ & 0,9 (indutivo ou capacitivo) \\
\hline $\begin{array}{l}\text { Potência reativa máxima sem comprometimento } \\
\text { da potência ativa nominal }\end{array}$ & $\pm 5,8$ kvar \\
\hline Fator de potência mínimo* & 0,8 (indutivo ou capacitivo) \\
\hline Potência reativa máxima** & $\pm 8,3$ kvar \\
\hline
\end{tabular}

* Ao operar com fator de potência inferior a 0,9 o inversor tem sua potência ativa nominal diminuída.

** Embora a potência aparente máxima do equipamento seja de 13,8 kVA, o fabricante limita a potência reativa do inversor em $\pm 8,3$ kvar.

Como a tensão fase/fase na saída do inversor é de $380 \mathrm{~V}$, enquanto a alimentação da carga é feita com uma tensão de $220 \mathrm{~V}$ fase/fase, foi necessária a utilização de um transformador $380 \mathrm{~V} / 220 \mathrm{~V}$, de capacidade $75 \mathrm{kVA}$. Esse transformador e o painel de conexões e proteção, que recebe os cabos do lado c.a. dos 5 inversores, estão acondicionados em um abrigo de alvenaria em frente ao prédio da Administração e são mostrados na figura 22. Os detalhes do painel podem ser vistos na figura 23. 

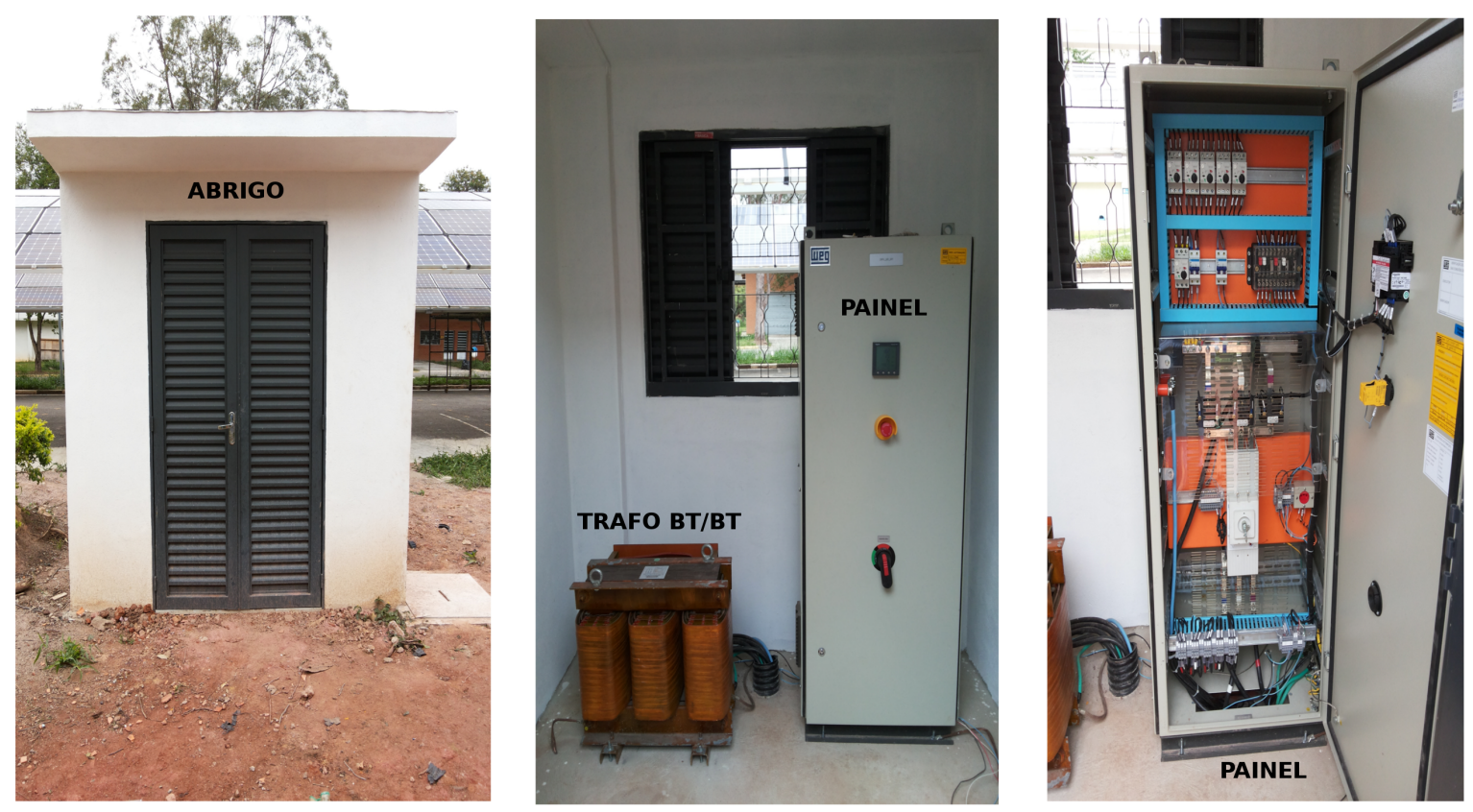

Figura 22- Abrigo contendo transformador de $75 \mathrm{kVA}(380 \mathrm{~V} / 220 \mathrm{~V})$ e painel de proteção

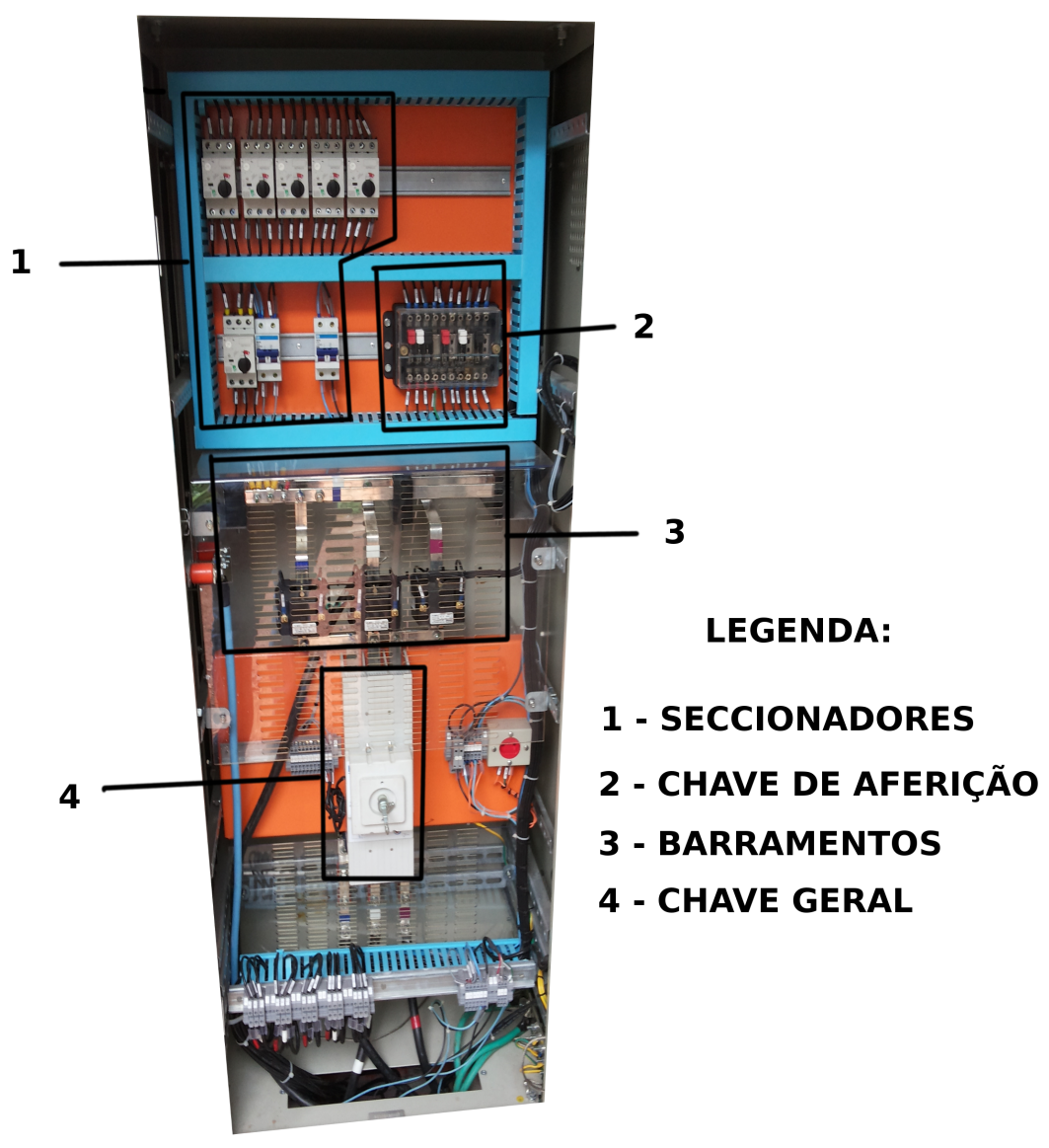

Figura 23-Detalhes do painel de proteção do sistema CRPV 
A figura 24 apresenta as vistas superior e traseira do transformador de $380 \mathrm{~V} / 220 \mathrm{~V}$, do fabricante COOTRANS. Trata-se de um transformador trifásico, de capacidade $75 \mathrm{kVA}$, do grupo de conexão Dd0 (delta/delta com defasagem de $0^{\circ}$ ). Esse equipamento opera a seco, possui nível de isolamento de $1 \mathrm{kV}$, grau de proteção IP00, e a elevação média de temperatura de seus enrolamentos em relação à temperatura ambiente, na potência máxima, é de $105{ }^{\circ} \mathrm{C}$. Ele atende a norma NBR 10295/2011 (transformadores de potência secos).

Os diagramas elétrico e vetorial, extraídos diretamente da etiqueta do produto, encontram-se na figura 25.
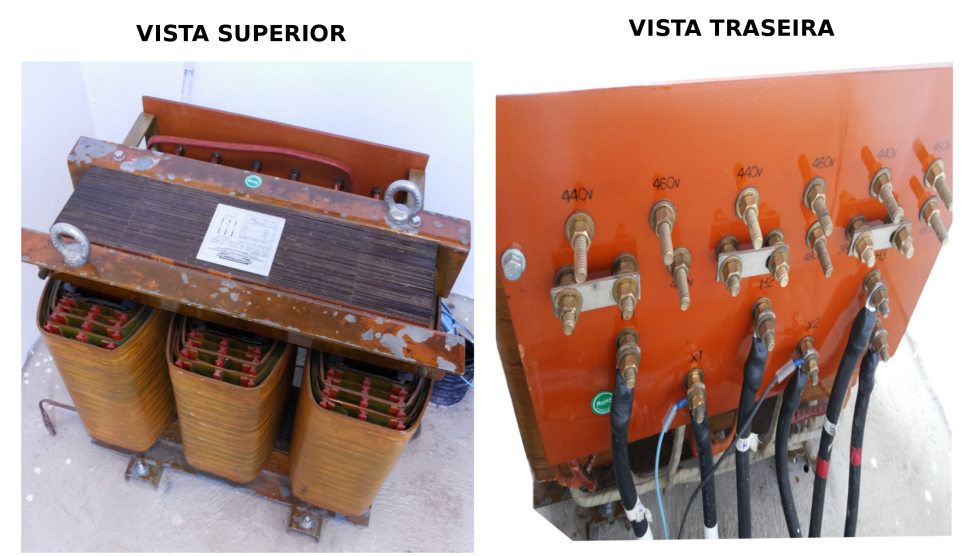

Figura 24- Vistas superior e traseira do transformador de $380 \mathrm{~V} / 220 \mathrm{~V}$

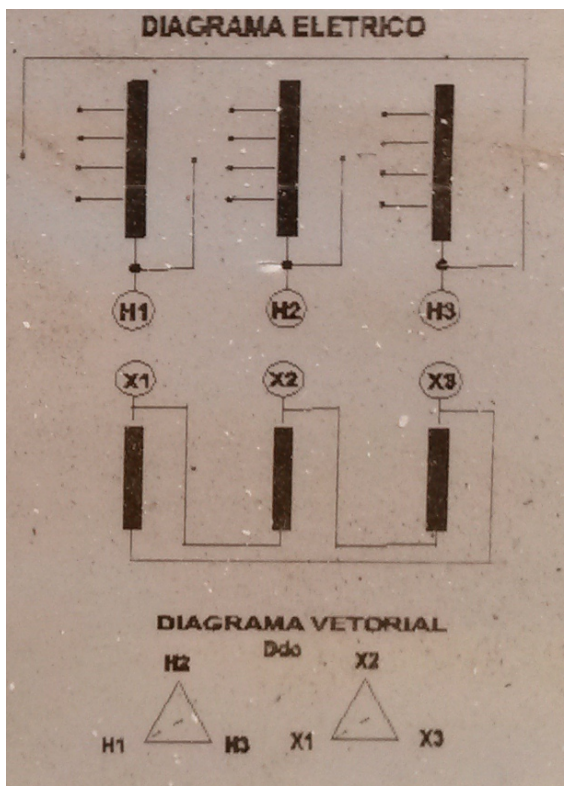

Figura 25-Diagramas elétrico e vetorial do transformador de $380 \mathrm{~V} /$ $220 \mathrm{~V}$ 
A principal vantagem da configuração delta/delta desse transformador, sendo o lado primário alimentado por uma fonte trifásica equilibrada, que é o sistema fotovoltaico, é minimização de problemas referentes ao $3^{\circ}$ harmônico.

\subsection{Instalações elétricas}

A carga é alimentada em baixa tensão (220 V fase/fase) pelo sistema fotovoltaico e/ou pela rede elétrica através de dois circuitos trifásicos independentes, acoplados aos barramentos do quadro geral da edificação.

Um deles provém do transformador de $13.800 \mathrm{~V} / 220 \mathrm{~V}$ presente no cubículo da figura 26, de capacidade $75 \mathrm{kVA}$, cujo primário está ligado fisicamente à subestação do IEE por meio de uma linha subterrânea, e cujo secundário está ligado diretamente aos barramentos do quadro geral do edifício da Administração. No lado direito da imagem, pode-se ver o detalhe do compartimento de baixa tensão.
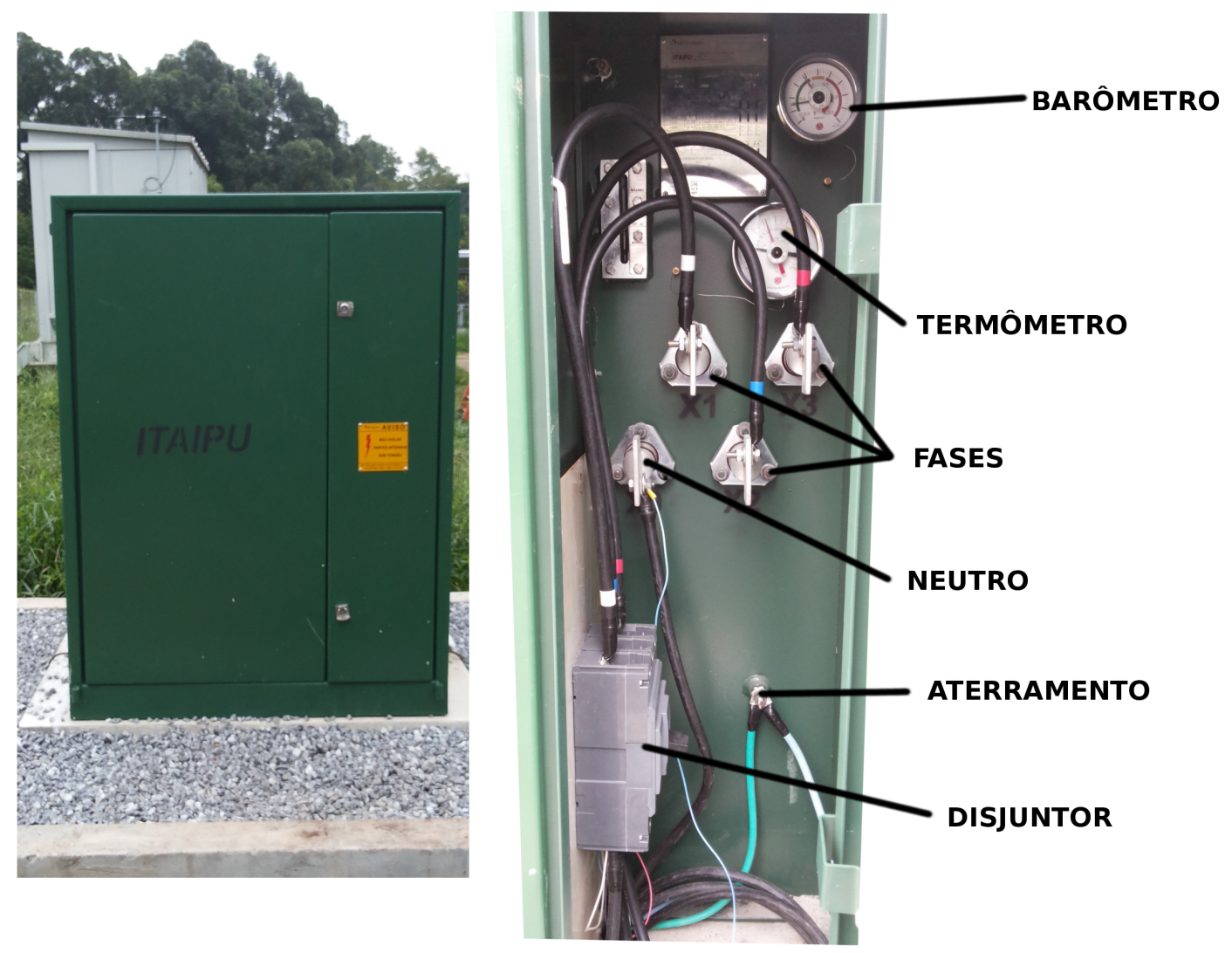

Figura 26- Transformador de 75 kVA (13.800 V / 220 V) 
Este circuito é composto por 6 cabos, sendo 3 cabos de $95 \mathrm{~mm}^{2}$ (um para cada fase), 1 cabo de $70 \mathrm{~mm}^{2}$ (para o condutor neutro), 1 cabo de $50 \mathrm{~mm}^{2}$ e 1 cabo de $35 \mathrm{~mm}^{2}$ (esses dois últimos para o aterramento).

O segundo conjunto de cabos parte de dentro do abrigo de alvenaria apresentado anteriormente na figura 22 e é composto por 4 condutores de $70 \mathrm{~mm}^{2}$. Três desses cabos correspondem às fases que saem do secundário do transformador de $380 \mathrm{~V} / 220 \mathrm{~V}$. O quarto cabo liga o neutro do quadro geral ao painel dentro do abrigo de alvenaria e serve basicamente para permitir a alimentação de alguns dispositivos do painel em $110 \mathrm{~V}$ (a tensão fase/fase na saída do transformador do abrigo é de 220 V). Esses 4 cabos também estão ligados diretamente aos barramentos do quadro geral, o qual é mostrado em detalhes na figura 27.

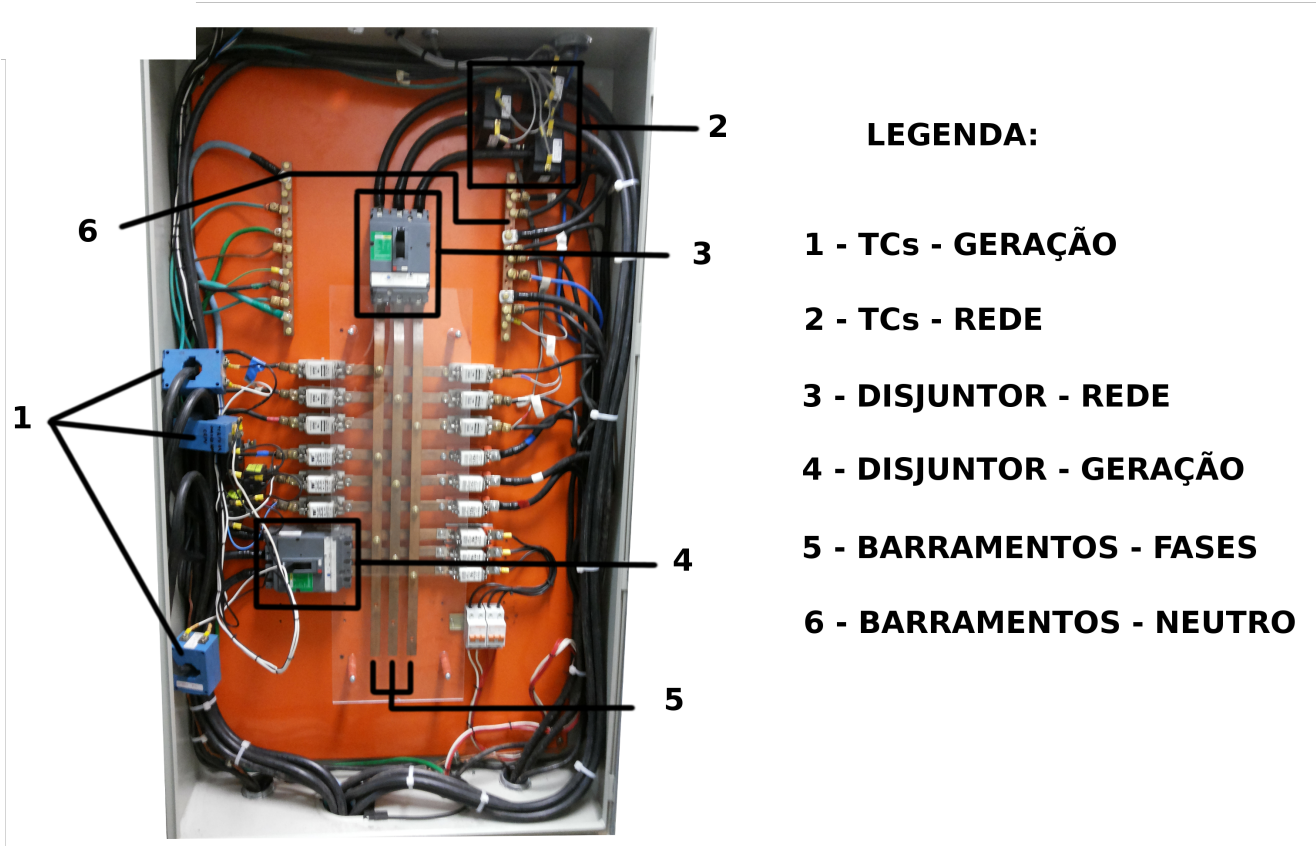

Figura 27-Quadro geral do prédio da Administração do IEE-USP

Do lado de fora do prédio, os dois circuitos estão embutidos em eletrodutos de PVC flexíveis de 4", subterrâneos e independentes, os quais terminam em uma caixa de passagem, também do lado externo. No seu trajeto da caixa de passagem para o quadro geral, os circuitos foram embutidos em canaletas metálicas de $100 \mathrm{~mm}$ por $50 \mathrm{~mm}$, independentes e com aberturas de ventilação (figura 28). 


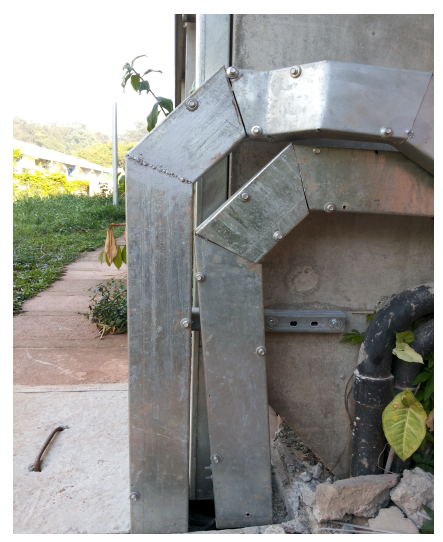

Figura 28- Canaletas metálicas com circuitos independentes seguindo para o quadro geral

Um outro circuito importante que deve ser destacado é aquele que supre o primário do transformador de $380 \mathrm{~V} / 220 \mathrm{~V}$ com a energia proveniente do lado c.a. dos 5 inversores. De cada inversor partem 3 cabos de $4 \mathrm{~mm}^{2}$, sendo um para cada fase. Esses 15 condutores seguem por uma canaleta metálica de $100 \mathrm{~mm}$ por $50 \mathrm{~mm}$ que passa por cima do telhado e pelo lado externo da parede até a caixa de passagem (figura 29), de onde seguem por um eletroduto de PVC flexível de 4" até os barramentos do painel que se encontra dentro do abrigo de alvenaria, onde também está conectado o primário do referido transformador
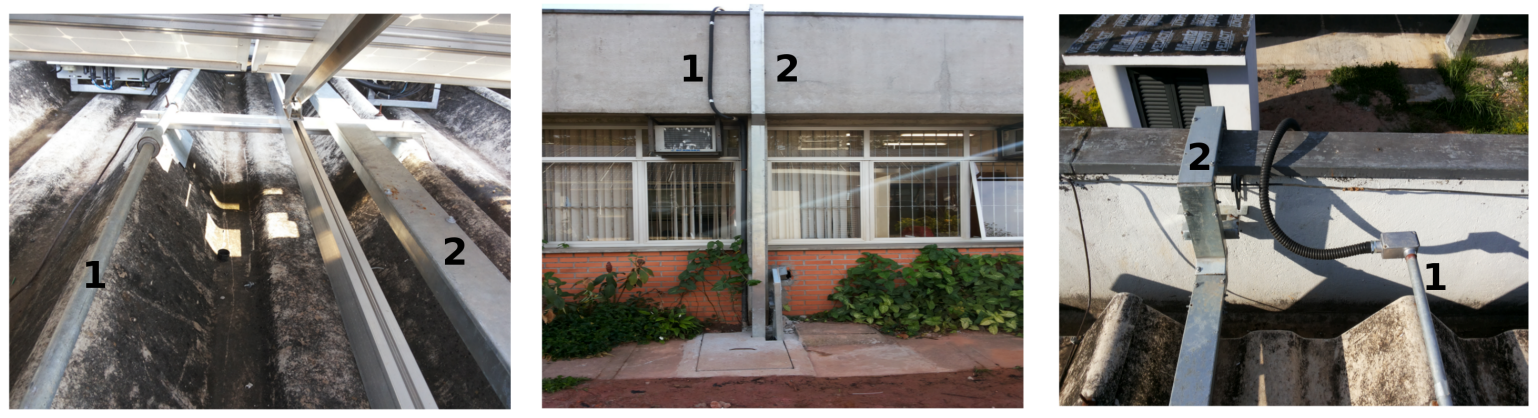

\section{LEGENDA:}

\section{1 - CABOS DE COMUNICAÇÃO}

2 - CABOS DE ENERGIA

Figura 29- Circuitos de comunicação e de energia provenientes dos 5 inversores 
No que tange aos fluxos de potência ativa, as fileiras de módulos 1 a 5 alimentam os 5 inversores, que entregam energia em $380 \mathrm{~V}$ fase/fase aos barramentos no interior do painel do abrigo de alvenaria. Do painel a energia segue para o transformador rebaixador de $380 \mathrm{~V}$ para $220 \mathrm{~V}$ e deste para o quadro geral do prédio. Quando a energia produzida pelo sistema fotovoltaico é suficiente para alimentar o prédio e ainda há excedentes, no transformador BT/MT (baixa tensão para média tensão ou vice-versa) o sentido da corrente é da carga para a rede (sentido reverso) e, quando a produção fotovoltaica é insuficiente ou nula, o sentido da corrente é da rede para a carga (sentido direto).

Já em relação aos fluxos de potência reativa, o sentido dependerá do comportamento instantâneo da carga e dos inversores (caráter indutivo ou capacitivo) e dos volumes de reativos envolvidos. A título de exemplo, se num dado instante a carga apresenta comportamento indutivo e exige 3,0 kvar, ao passo que os inversores apresentam comportamento capacitivo e entregam juntos 4,0 kvar, será observado um fluxo de 1,0 kvar no sentido da carga para a rede elétrica (sentido reverso). Caso os inversores entregassem apenas 2,0 kvar, seria observado um fluxo de 1,0 kvar da rede elétrica para a carga (sentido direto).

Finalmente, observa-se que o prédio da Administração possui um outro sistema fotovoltaico, de aproximadamente $11 \mathrm{kWp}$ (MACÊDO; ZILLES, 2009), que esteve desligado durante os ensaios e, por isso, não tem suas instalações elétricas descritas neste trabalho.

\subsection{Sistema de aquisição de dados}

O foco desta seção é apresentar os equipamentos e softwares utilizados na aquisição de dados durante os ensaios realizados.

O datalogger analógico modelo MYPCLAB, do fabricante NOVUS (parte inferior esquerda da figura 30) amostrou e gravou a cada 1 minuto, em um notebook, os dados provenientes do módulo de referência (para determinação indireta da irradiância, por meio da tensão no resistor shunt ligado à saída do módulo), de um termopar tipo T (para a temperatura dos módulos) e de um sensor de temperatura ambiente. A precisão do equipamento é de \pm 20 $\mathrm{mV}$ para a tensão no resistor, de $\pm 2{ }^{\circ} \mathrm{C}$ para a temperatura dos módulos e de $\pm 1,5^{\circ} \mathrm{C}$ para a temperatura ambiente. 
MÓDULO DE REFERÊNCIA
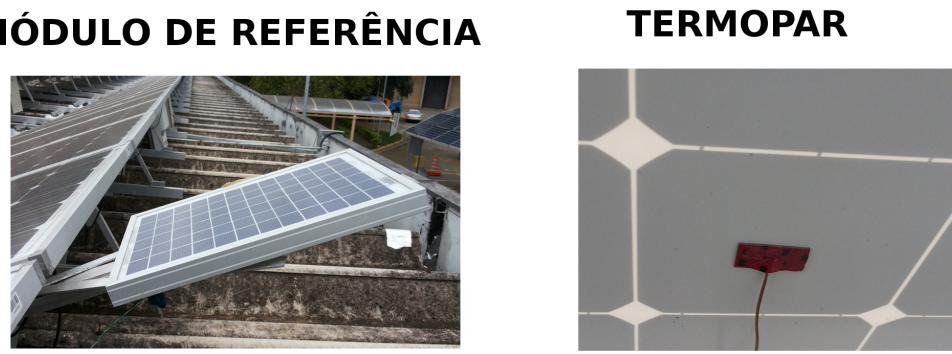

SENSOR DE TEMPERATURA AMBIENTE

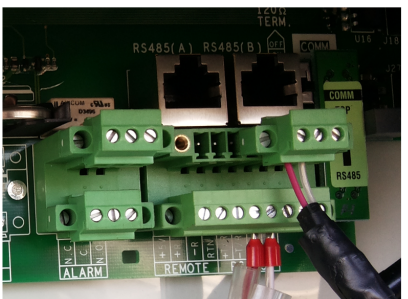

PLACA RS485

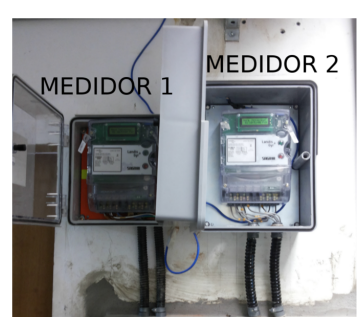

MEDIDORES DE ENERGIA

DATALOGGER

Figura 30- Equipamentos utilizados para aquisição de dados

A configuração do MYPCLAB, bem como a exportação dos dados registrados foi feita através de software de mesmo nome, cuja interface pode ser vista na figura 31.

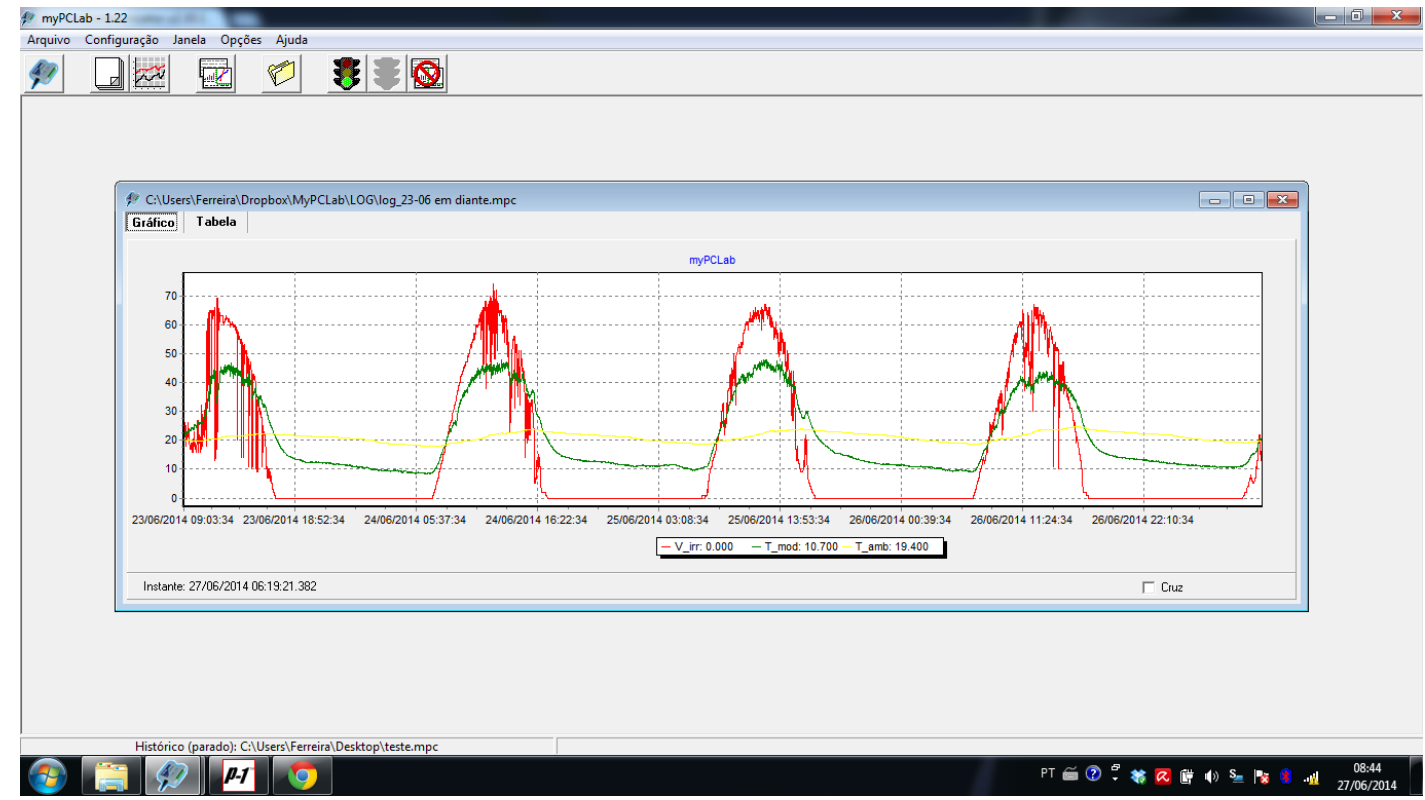

Figura 31-Interface do software MYPCLAB 
O inversor conta com um mecanismo de aquisição de dados incorporado (são monitoradas as grandezas elétricas: tensão, corrente, potência e energia dos lados c.a. e c.c.). Durante os ensaios, os dados foram acessados através da placa de comunicação RS-485 da figura 30 e gravados também a cada 1 minuto no mesmo notebook.

Os parâmetros do inversor, inerentes ao controle de potência reativa, foram configurados também através da placa RS-485, utilizando-se o software AURORA MANAGER LITE (figura 32). Já o monitoramento das grandezas elétricas e a gravação no computador foram realizados através do software AURORA COMMUNICATOR (figura 33).

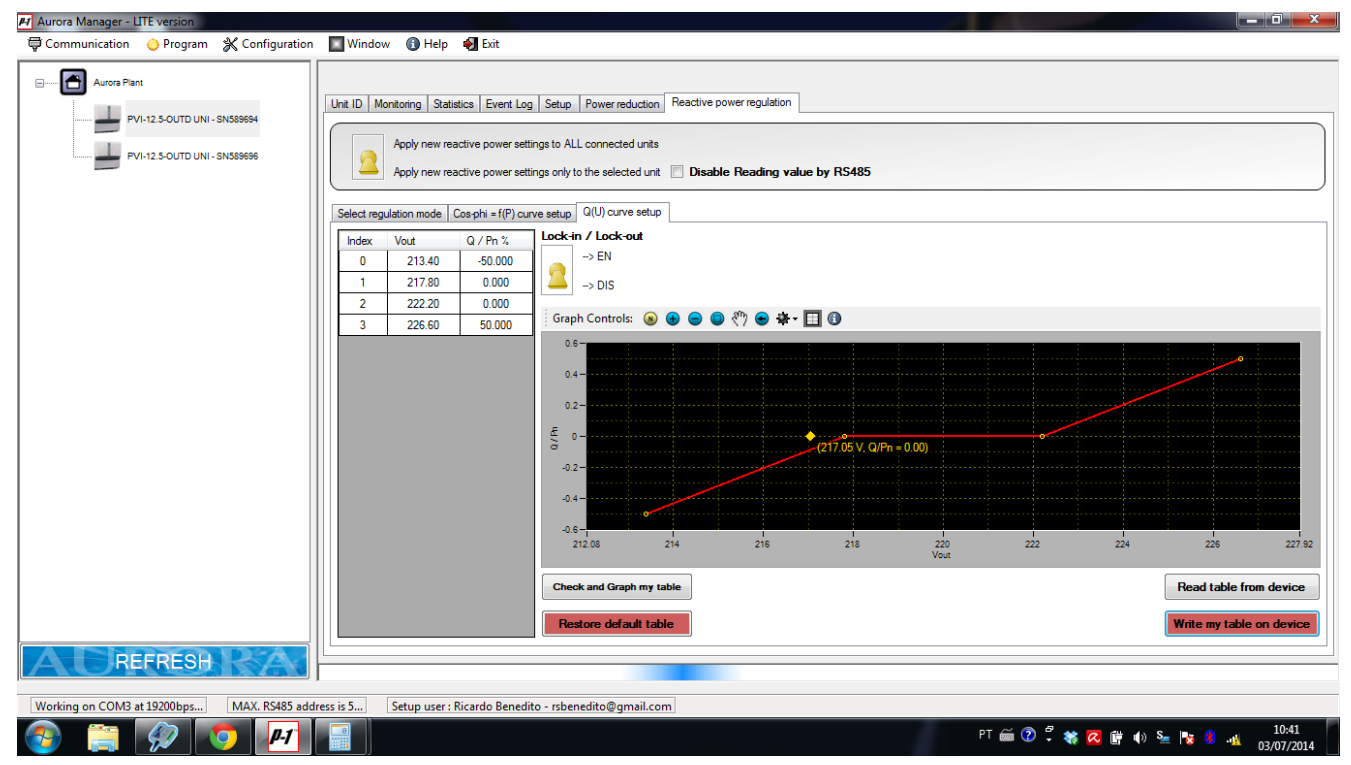

Figura 32- Interface do software Aurora Manager Lite

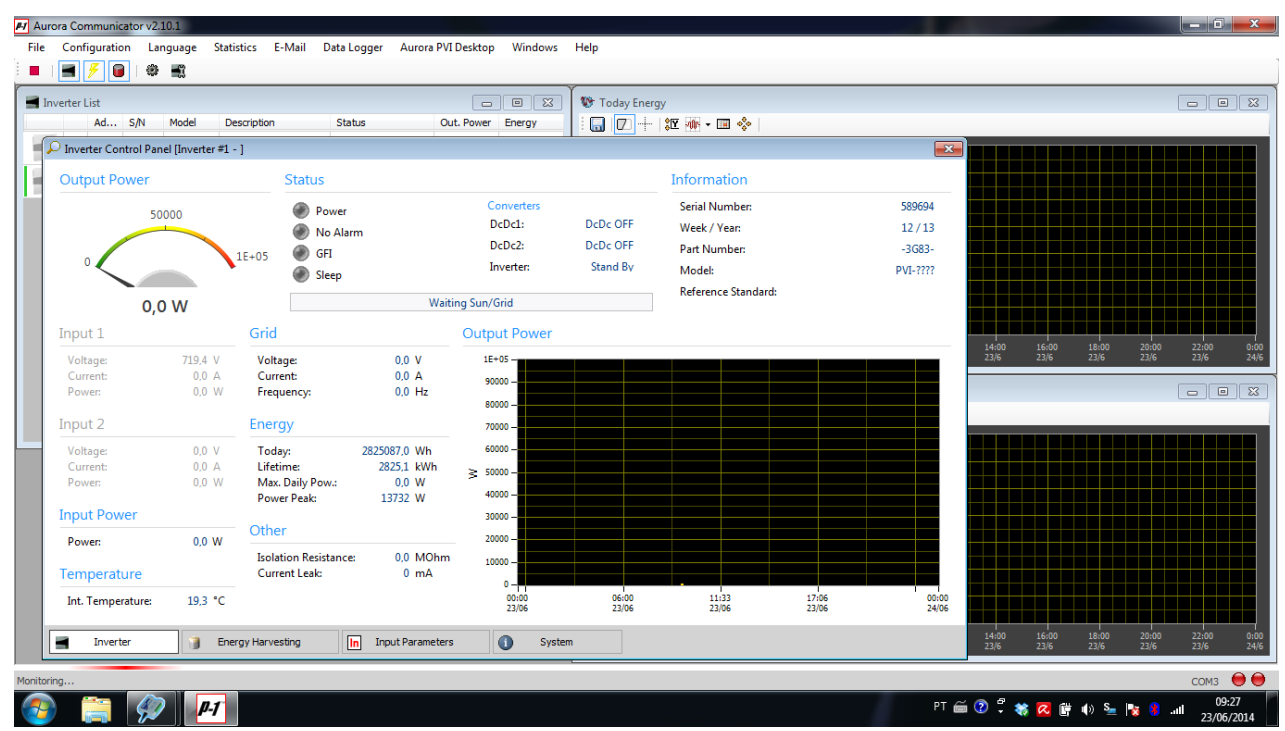

Figura 33- Interface do software Aurora Communicator 
A vantagem da comunicação RS-485 do inversor é que todos os inversores do sistema podem formar uma rede, o que permite realizar alterações em diversos exemplares de forma simultânea. Para a ligação física entre a placa RS-485 e o notebook foi utilizado um cabo de par trançado blindado e um conversor RS-485 para USB.

É importante destacar que as medições do lado c.a. realizadas pelo mecanismo interno do inversor referem-se apenas a corrente, tensão, potência e energia ativas entregues em 380 $\mathrm{V}$, ou seja, antes de passar pelo transformador de $380 \mathrm{~V} / 220 \mathrm{~V}$ (portanto, não englobam reativos e as perdas no rebaixamento de tensão pelo transformador). Dessa forma, elas foram utilizadas apenas para estimar o desempenho do inversor.

A figura 34 mostra esquematicamente o sistema de aquisição de dados das grandezas elétricas dos lados c.c. e c.a. dos inversores, da irradiância e da temperatura dos módulos e ambiente.

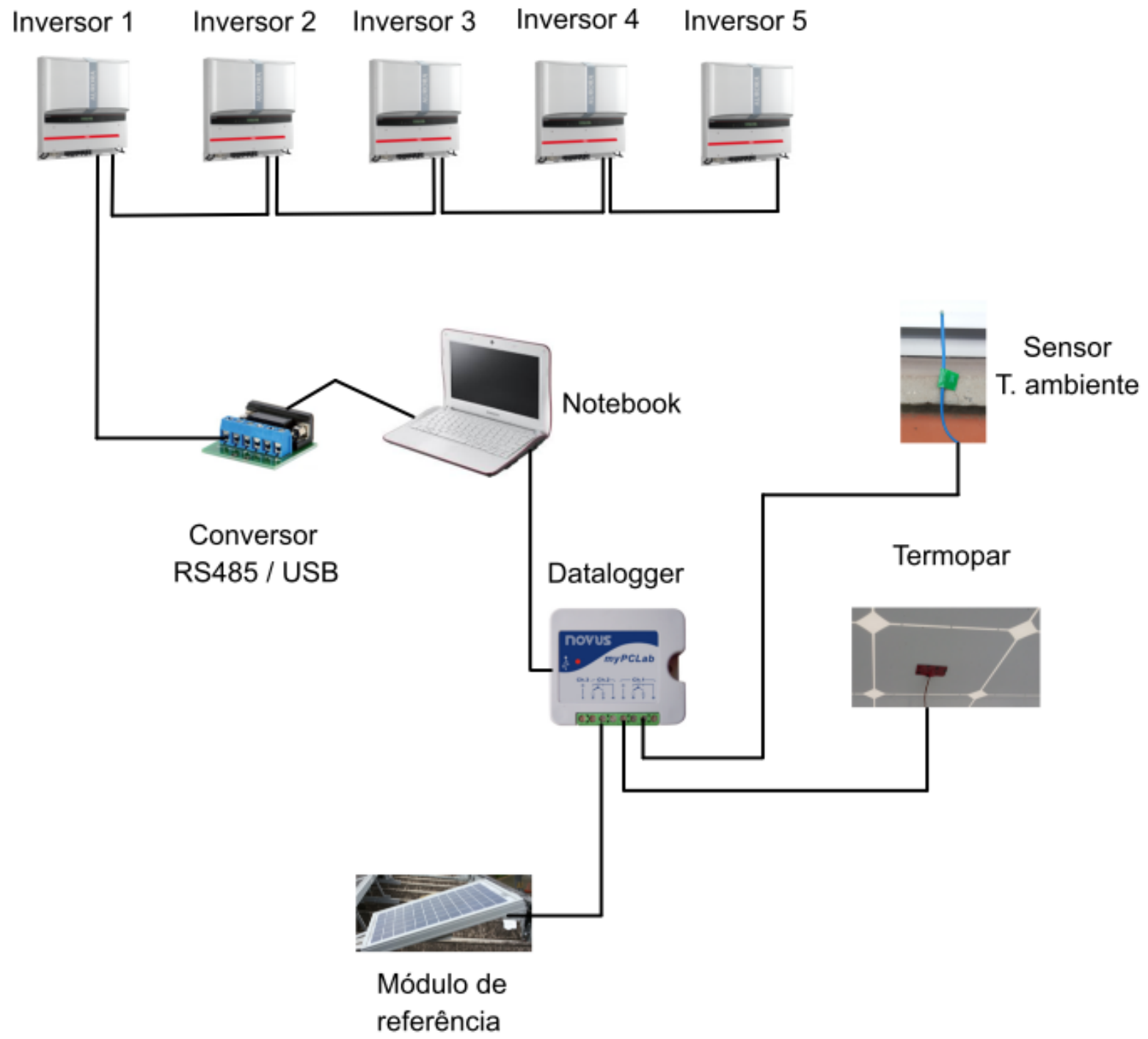

Figura 34- Sistema de aquisição dados dos inversores, de irradiância e de temperatura 
Para se estudar o balanço energético da edificação, considerando-se os fluxos de potência ativa e reativa no quadro geral, foram utilizados 2 exemplares do medidor eletrônico de energia modelo $S A G A 1000$, do fabricante $L A N D I S+G Y R$, sendo um deles para o circuito trifásico proveniente do sistema fotovoltaico (MEDIDOR 1) e o outro para o circuito alimentador, também trifásico, ligado à rede elétrica (MEDIDOR 2). Comparando-se os fluxos de potência e energia registrados pelos dois medidores, foi possível obter algebricamente os mesmos dados relativos à carga, sem a necessidade da instalação de medidores adicionais para essa finalidade.

Os medidores apresentam memória de massa para 21 canais, acessível fisicamente através de um cabo óptico específico adquirido junto ao fabricante. A interface do software PLAWIN, utilizado para configurar os medidores, acessar e exportar os dados gravados pode ser vista na figura 35 .

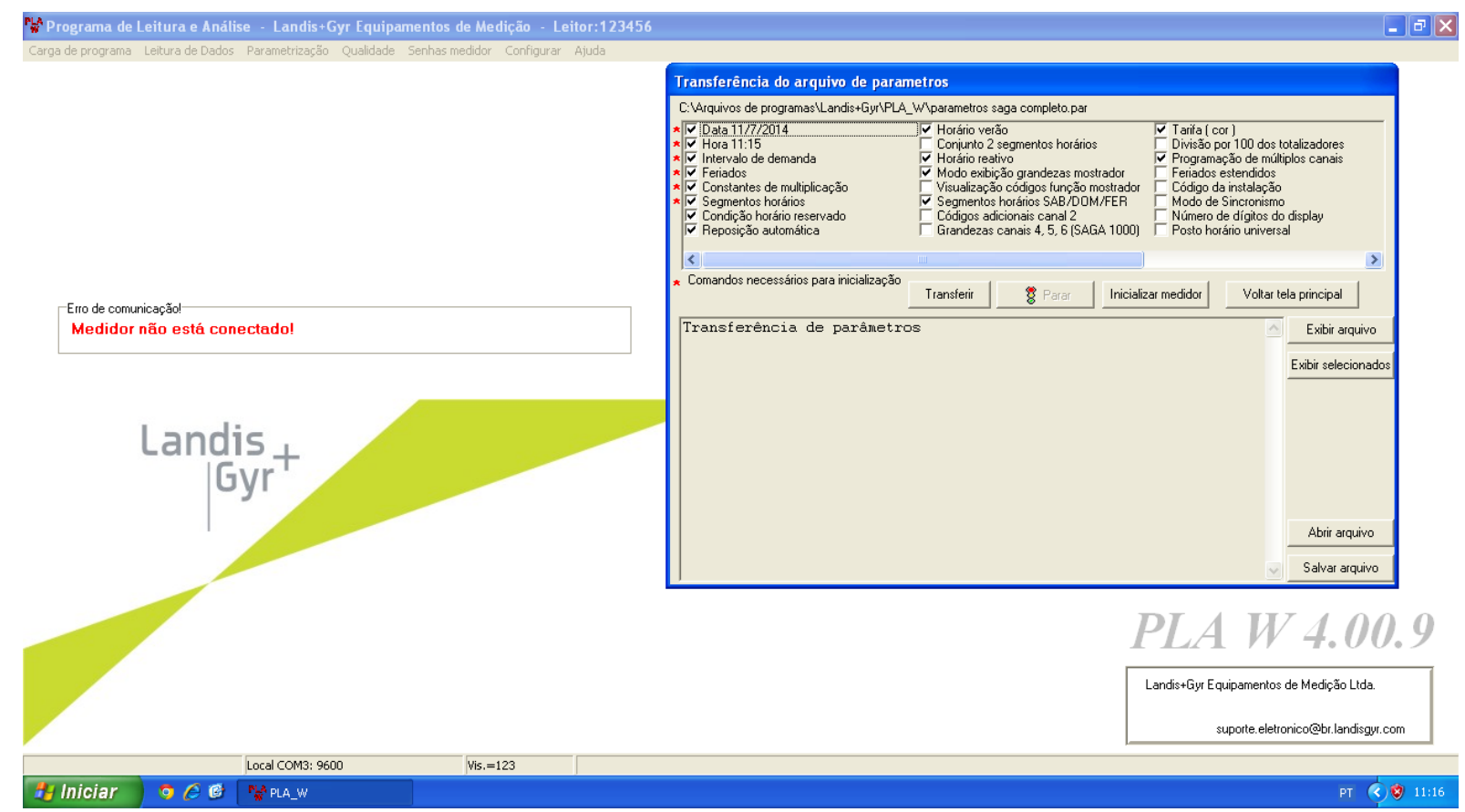

Figura 35- Interface do software PLAWIN

O SAGA 1000 mede em quatro quadrantes e atende às normas ABNT NBR14519, NBR14520 e NBR14522 e às exigências de medição e comunicação da Câmara Comercializadora de Energia (CCEE) e do Operador Nacional do Sistema (ONS). As grandezas elétricas medidas são: energia ativa e reativa totais nos sentidos direto e reverso, potência ativa e reativa totais nos sentidos direto e reverso, fator de potência global, tensão 
por fase (média e máxima, em relação ao neutro), corrente por fase, distorção harmônica de tensão por fase e distorção harmônica de corrente por fase.

Os dois medidores foram fixados na parede, logo acima do quadro geral. De cada medidor partem 10 cabos de $1,5 \mathrm{~mm}^{2}$, sendo 4 ligados diretamente aos barramentos do quadro geral, para medição de tensão e distorção harmônica de tensão, e 6 ligados a TCs (transformadores de corrente), para medição indireta da corrente em cada fase e outras grandezas relacionadas.

A figura 36 mostra esquematicamente as ligações realizadas.

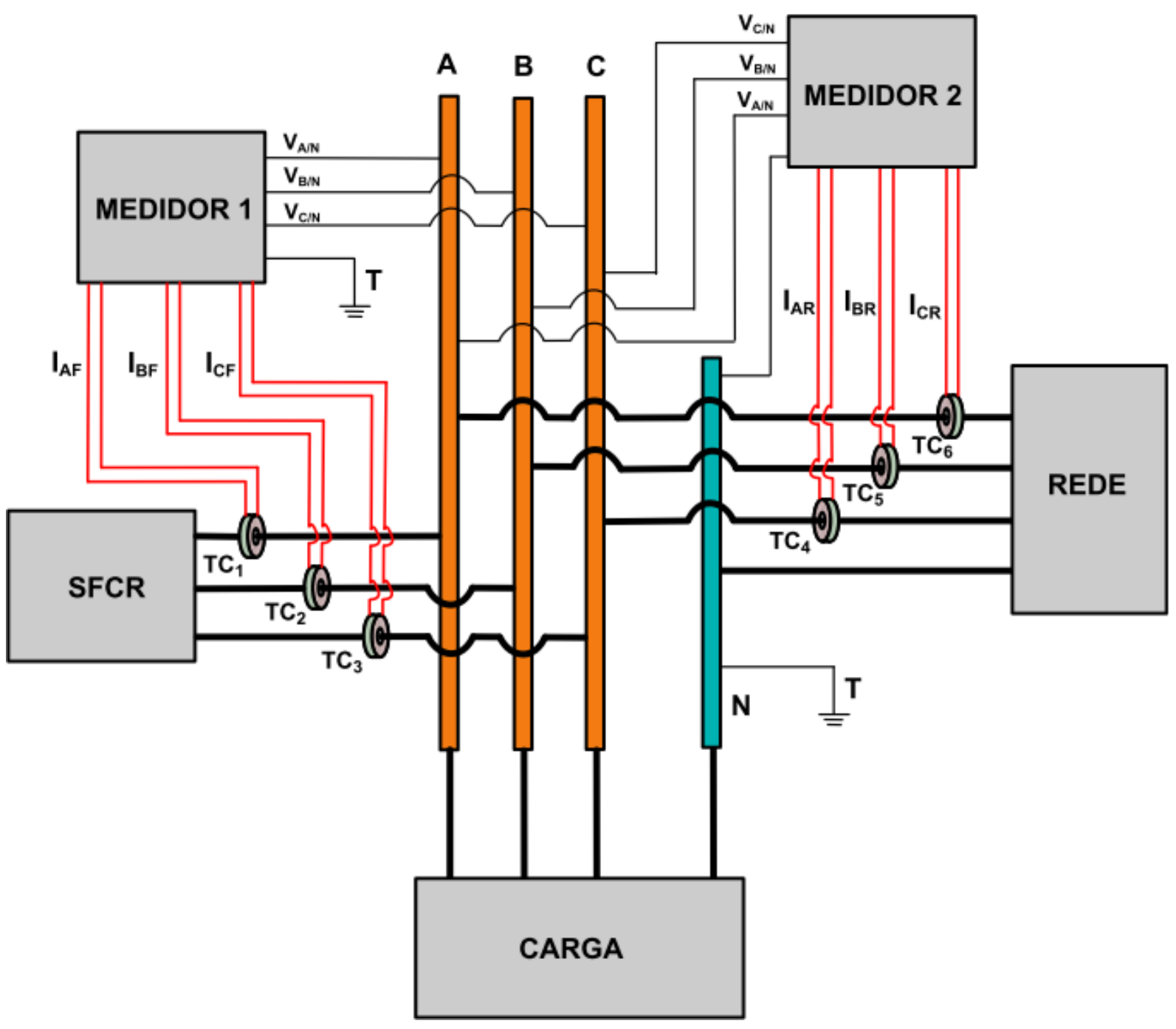

Figura 36-Ligação dos medidores de energia elétrica no quadro geral

$\mathrm{Na}$ ilustração, procurou-se representar em laranja os barramentos relativos às fases (A, B e C) e em azul o barramento relativo ao neutro (N), o qual encontra-se aterrado. Esses 
elementos estão visíveis na fotografia real do quadro geral da figura 27 , apresentada anteriormente neste capítulo.

Os TCs de 1 a 3 , instalados nas fases do circuito em delta proveniente do sistema fotovoltaico, são do modelo 4NC-0624, do fabricante SIEMENS. Já os TCs de 4 a 6 , instalados nas fases do circuito em Y que vem da rede elétrica, são do modelo $K R-174$, do fabricante $K R O N$. A relação de transformação de todos os TCs utilizados é de 300-5 A e a exatidão de $0,6 \%$.

Ainda sobre a figura 36 , os termos $\mathrm{I}_{\mathrm{AF}}, \mathrm{I}_{\mathrm{BF}}$ e $\mathrm{I}_{\mathrm{CF}}$ referem-se às correntes no secundário dos TCs de 1 a 3 , enquanto os termos $I_{\mathrm{AR}}, \mathrm{I}_{\mathrm{BR}} \mathrm{e} \mathrm{I}_{\mathrm{CR}}$ referem-se às correntes no secundário dos TCs de 4 a 6 . Os termos $\mathrm{V}_{\mathrm{A} / \mathrm{N}}, \mathrm{V}_{\mathrm{B} / \mathrm{N}}$ e $\mathrm{V}_{\mathrm{C} / \mathrm{N}}$ dizem respeito às tensões entre as fases (dos circuitos ou dos barramentos) e o neutro, no ponto de acoplamento.

Os dados da memória de massa dos medidores são integralizados e registrados em intervalos mínimos de 5 minutos, sendo então essa a configuração utilizada nos ensaios.

Um terceiro SAGA 1000, denominado MEDIDOR 3, foi instalado dentro do abrigo de alvenaria, com o objetivo específico de registrar a tensão e a distorção harmônica de tensão nas 3 fases ligadas ao secundário do transformador de $13.800 \mathrm{~V} / 220 \mathrm{~V}$. A ligação física entre os terminais do transformador e o medidor se deu através de um cabo de 4 vias de $1,5 \mathrm{~mm}^{2}$.

Desejava-se, com essa medida, registrar possíveis diferenças de potencial entre o secundário do referido transformador e o quadro geral, posto que há uma distância de aproximadamente 60 metros entre eles, resultando em uma resistência elétrica de $0,011 \Omega$ em cada condutor de fase, a $20^{\circ} \mathrm{C}$, valor que tende a aumentar com a temperatura do condutor. Essa informação não é determinante na presente pesquisa, mas poderá ser útil em outros trabalhos.

\subsection{Perfil da carga}

Como foi citado no início deste capítulo, a caracterização inicial da carga se deu através de dois procedimentos distintos: a utilização dos resultados da pesquisa do PUFE e a medição no quadro geral do prédio, utilizando-se medidores de energia.

O edifício em questão tem um perfil de prédio público com funções administrativas e funciona de segunda a sexta-feira, das $08 \mathrm{~h} 00$ às $18 \mathrm{~h} 00$. A tabela 3 apresenta os principais equipamentos utilizados no local. 
Tabela 3-Equipamentos elétricos do prédio da Administração do IEE-USP

\begin{tabular}{ccc}
\hline Equipamentos & Quantidade & $\begin{array}{c}\text { Potência nominal total } \\
(\mathbf{k W})\end{array}$ \\
\hline Ar-condicionado & 23 & 49,5 \\
Impressoras & 28 & 11,1 \\
Lâmpadas & 304 & 10,6 \\
fluorescentes & 35 & 5,6 \\
Computadores & 4 & 2,8 \\
Fotocopiadoras & 10 & 1,7 \\
Ventiladores & 1 & 1,5 \\
Máquina de café & 1 & 0,9 \\
Forno de micro-ondas & 5 & 0,8 \\
Refrigeradores & 1 & 0,8 \\
Switch de rede & 1 & 0,5 \\
Cafeteira & 5
\end{tabular}

Fonte: PUFE - IEE-USP.

Os equipamentos de uso contínuo e intenso e que, portanto, representam melhor a demanda do prédio, são os de iluminação e de informática. Os equipamentos de refrigeração são usados continuamente mas são de pequeno porte, sendo que dois deles são do tipo frigobar. Os aparelhos de ar condicionado e ventiladores, embora possuam juntos $61 \%$ da potência nominal total, são utilizados apenas em momentos de elevada temperatura ambiente. Apenas nos meses quentes o seu uso se torna contínuo. Os demais itens, além de possuírem potência pequena, são utilizados de forma esporádica.

Com o sistema fotovoltaico desligado e utilizando-se o MEDIDOR 2 descrito anteriormente, foram levantadas as curvas de demanda por potência ativa e demanda de potência reativa do prédio da Administração, para um dia típico de final de verão e para um dia de inverno. Os gráficos estão presentes nas figuras 37 e 38 e correspondem aos dias 19/03/2014 e 24/06/2013, respectivamente.

No que tange à potência ativa, nota-se uma demanda muito semelhante, no verão ou no inverno, para as primeiras e últimas horas do expediente. Porém, no verão, com a elevação considerável da temperatura ambiente ao longo do dia, a demanda sobe drasticamente devido ao uso intensivo dos aparelhos de ar condicionado. 


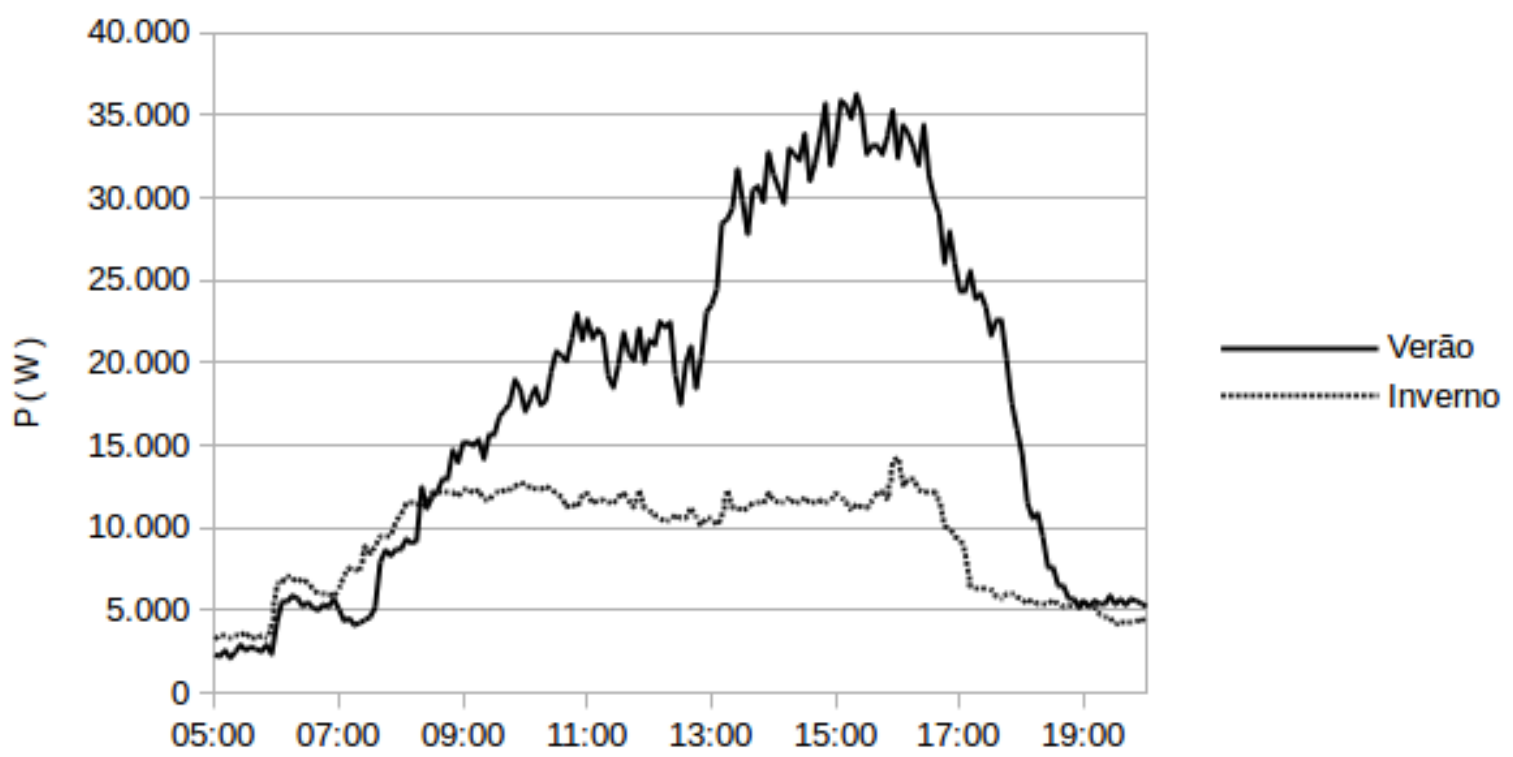

Figura 37- Demanda de potência ativa do prédio da Administração

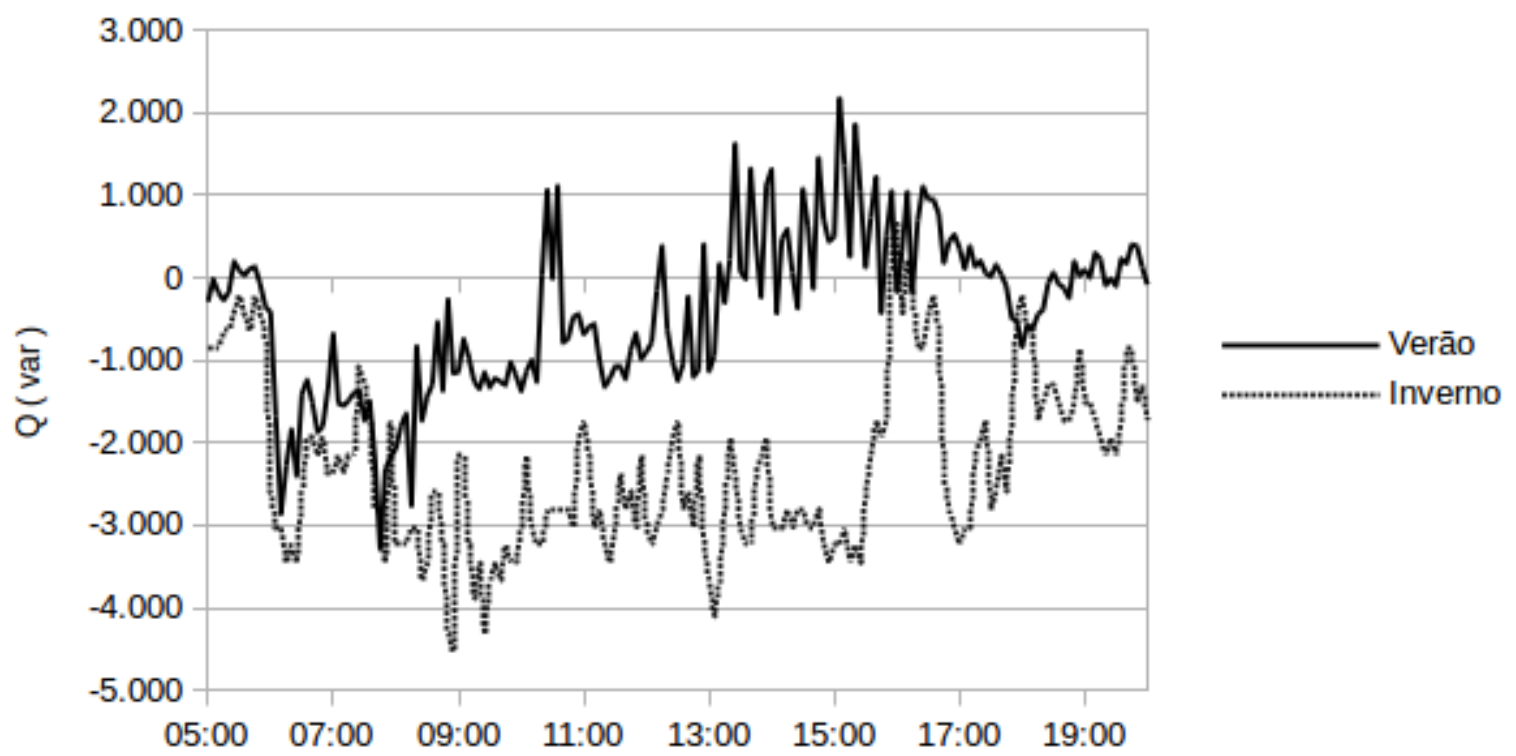

Figura 38- Demanda de potência reativa do prédio da Administração

Já em relação à potência reativa, o sinal positivo indica que a rede elétrica fornece reativos ao prédio (comportamento indutivo da carga) e o sinal negativo indica que o prédio injeta reativos na rede (comportamento capacitivo da carga).

Nota-se, analisando-se as figuras 37 e 38, que o comportamento do prédio é predominantemente capacitivo, se não houver o uso intensivo de aparelhos de ar 
condicionado, e indutivo quando muitos desses aparelhos são ligados simultaneamente.

A figura 39 mostra o fator de potência medido na entrada do prédio da Administração, para os mesmos dias de referência das figuras 37 e 38 .

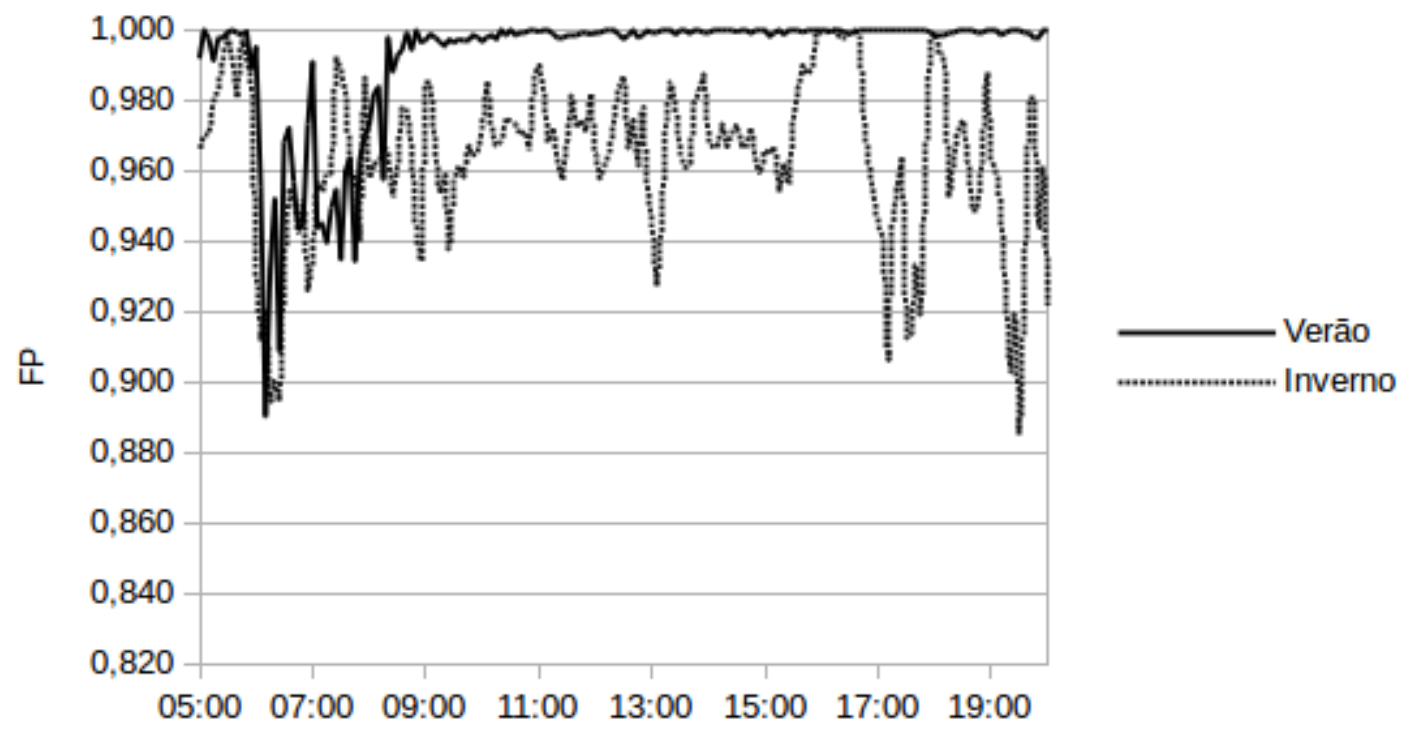

Figura 39-Fator de potência do prédio da Administração

No inverno ou no verão, o fator de potência tem valor maior que o fator de potência de referência 0,92 na maior parte do dia, ficando abaixo deste valor em curtos períodos das horas iniciais ou finais de expediente, quando a demanda de potência ativa é menor.

A principal constatação proveniente das figuras 37, 38 e 39 é a de que o perfil natural da carga não tenderia a gerar um problema de excedentes de reativos, caso toda a demanda por potência ativa fosse suprida exclusivamente pela rede elétrica. Deve-se destacar que, mesmo nos momentos em que o fator de potência mostra-se menor que 0,92 , o perfil da carga é capacitivo, não gerando cobrança. Nos momentos em que o perfil da carga é predominantemente indutivo (tardes quentes de verão, devido ao uso do ar-condicionado), o fator de potência estará sempre próximo da unidade, pois o aumento na demanda por reativos é acompanhado pelo consumo de potência ativa.

Assim, demonstra-se que uma eventual deterioração do fator de potência do prédio da Administração tem relação direta com o problema levantado na Introdução e não com os equipamentos que compõem a carga. 


\subsection{O método e suas limitações}

O método, que é essencialmente experimental, está amparado na confiabilidade dos equipamentos e procedimentos utilizados. Os primeiros atendem a normas nacionais e internacionais emitidas por organismos de reconhecida credibilidade, tais como IEC (International Electrotechnical Commission), INMETRO (Instituto Nacional de Metrologia, Qualidade e Tecnologia), CCEE (Câmara Comercializadora de Energia Elétrica) e ABNT (Associação Brasileira de Normas Técnicas). Os procedimentos que se referem às instalações elétricas do arranjo experimental, estão de acordo com a norma ABNT NBR5410, a qual é referência obrigatória no Brasil. Já aqueles referentes à coleta e tratamento dos dados experimentais encontram-se consolidados na literatura.

As principais limitações da metodologia proposta decorrem de atrasos no cronograma de implementação do sistema fotovoltaico. Uma delas é a ausência de um monitoramento em tempo real do fator de potência na entrada da edificação para que o mecanismo de compensação de reativos do inversor trabalhe sob demanda. Embora o modelo de inversor utilizado permita a alteração remota do fator de potência (ou da quantidade fixa de potência reativa entregue), isso deve ser feito por um dispositivo de controle externo, capaz de obter o fator de potência da carga e enviar um telecomando ao inversor através de software supervisório.

Outra limitação de caráter temporal é o período relativamente curto em que os ensaios foram realizados. Para se estabelecer uma estratégia de compensação de reativos otimizada para a edificação estudada, há a necessidade de um monitoramento de longo prazo das curvas de potência ativa e reativa, a fim de se acompanhar as variações do perfil da carga ao longo de, pelo menos, um ano completo.

O estudo também não permite avaliar outras possibilidades de uso do mecanismo de controle de reativos do inversor, além da eliminação da cobrança de excedentes de reativos. Por exemplo, o controle de tensão e a prestação de serviços ancilares à concessionária.

No ensaio de compensação de reativos realizado não foi abordada a questão da filtragem da potência de distorção, causada por cargas não lineares, a qual contribui para a diminuição do fator de potência global da instalação. Conforme mencionado no Capítulo 1, a injeção de reativos, que foi a ação implementada, permite corrigir apenas o fator de potência de deslocamento.

Outro aspecto não contemplado pelo método é a possibilidade de a compensação de 
reativos pelo inversor do sistema fotovoltaico ocasionar o problema de ressonância também citado no Capítulo 1, a exemplo do que é comum ocorrer com a implementação de bancos de capacitores.

Por fim, não foi possível inferir se a utilização do mecanismo de controle de reativos tem algum impacto na vida útil dos inversores. 


\section{RESULTADOS E DISCUSSÃO}

\subsection{Resultados dos ensaios de avaliação geral do sistema (EAGS)}

\subsection{1 - Tempo aberto}

A figura 40 mostra a curva de irradiância do primeiro dia do primeiro bloco de testes descritos na tabela 1 do Capítulo 2. Já a figura 41 traz a potência c.a. na saída dos inversores dos subsistemas 1 e 2 utilizados nos ensaios.

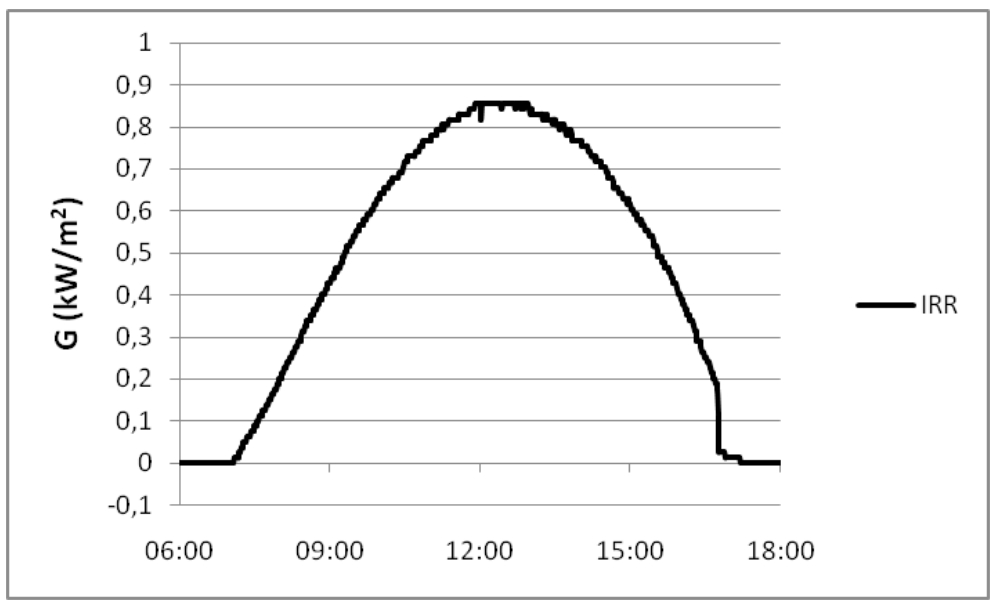

Figura 40-Irradiância - EAGS (ensolarado)

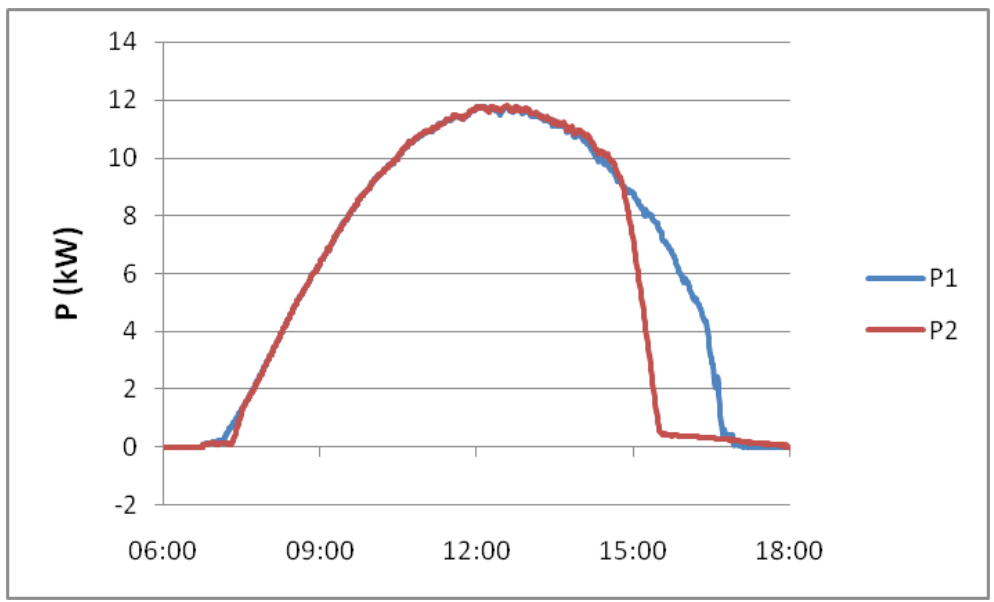

Figura 41-Potência na saída do inversor- EAGS (ensolarado) 
Observa-se que foi um dia de céu limpo de inverno e a leve assimetria notada no fim de tarde tem relação com a presença de obstáculos no poente dessa época de inverno (prédios no entorno da USP e árvores de grande porte).

Chama a atenção a queda no desempenho do inversor 2 a partir das $15 \mathrm{~h} 00$ (antes desse horário os dois subsistemas apresentam produções parelhas). Subindo-se no telhado por volta deste horário, descobriu-se que o problema tem relação com o sombreamento das fileiras 2 em diante, provocado pelas fileiras pregressas, conforme a figura 42 .

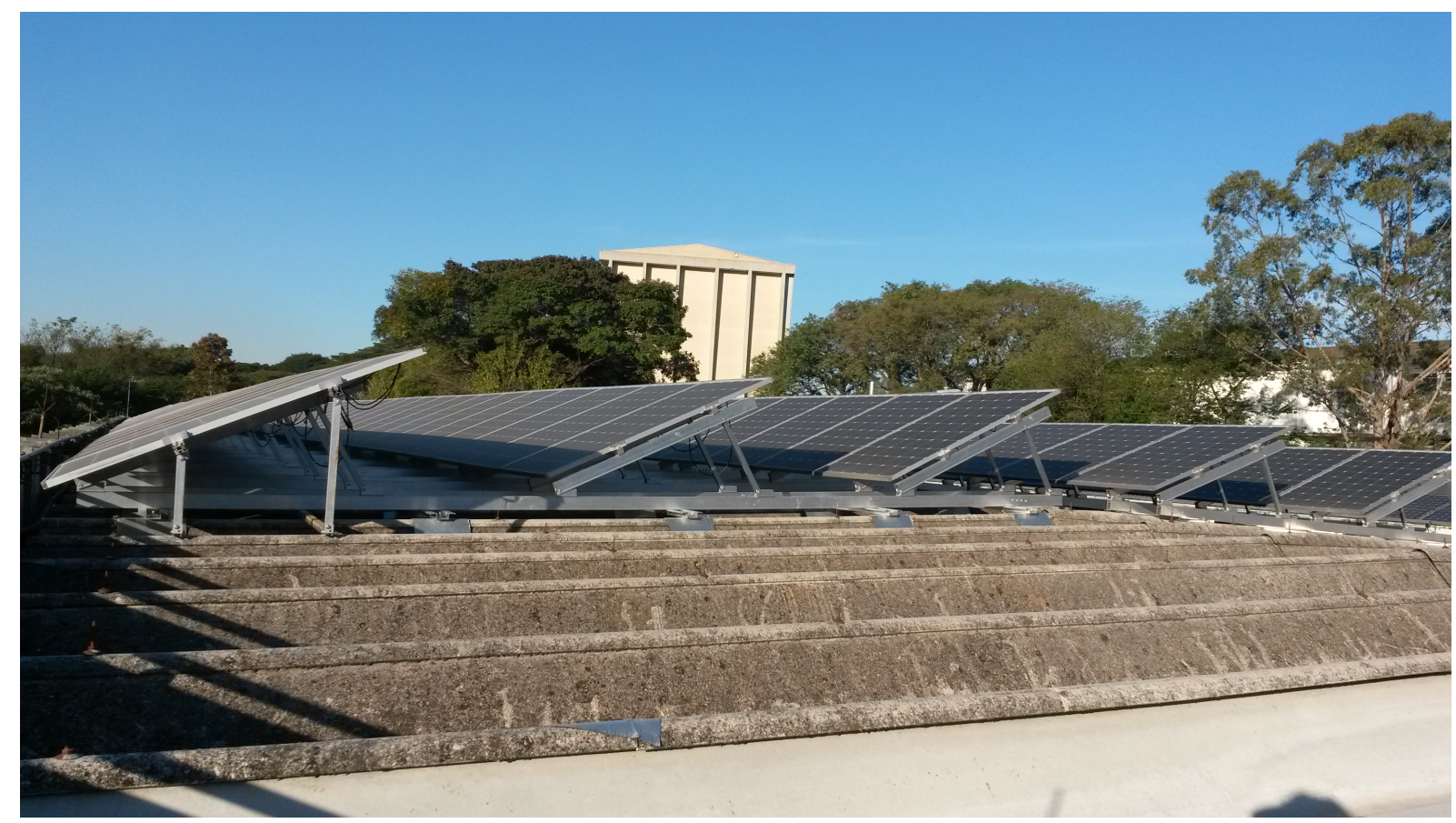

Figura 42- Sombreamento das fileiras 2 a 5 no período da tarde - estação inverno

A produção das fileiras sombreadas cai drasticamente devido à disposição vertical dos módulos, a qual foi necessária para melhor aproveitamento do espaço sobre o telhado. Uma vez que os três arranjos de células em série de cada módulo têm uma ou mais células sombreadas simultaneamente, a produção de todo o módulo é afetada.

O tipo de módulo utilizado na usina apresenta 60 células ligadas em série, separadas em 3 arranjos de 20 células, cada um deles em paralelo com um diodo de bypass, conforme ilustrado na figura 43.

Caso não haja nenhuma célula sombreada, os três arranjos operam normalmente e a potência na saída do módulo é a máxima possível para as condições de irradiância e temperatura de célula naquele instante. 


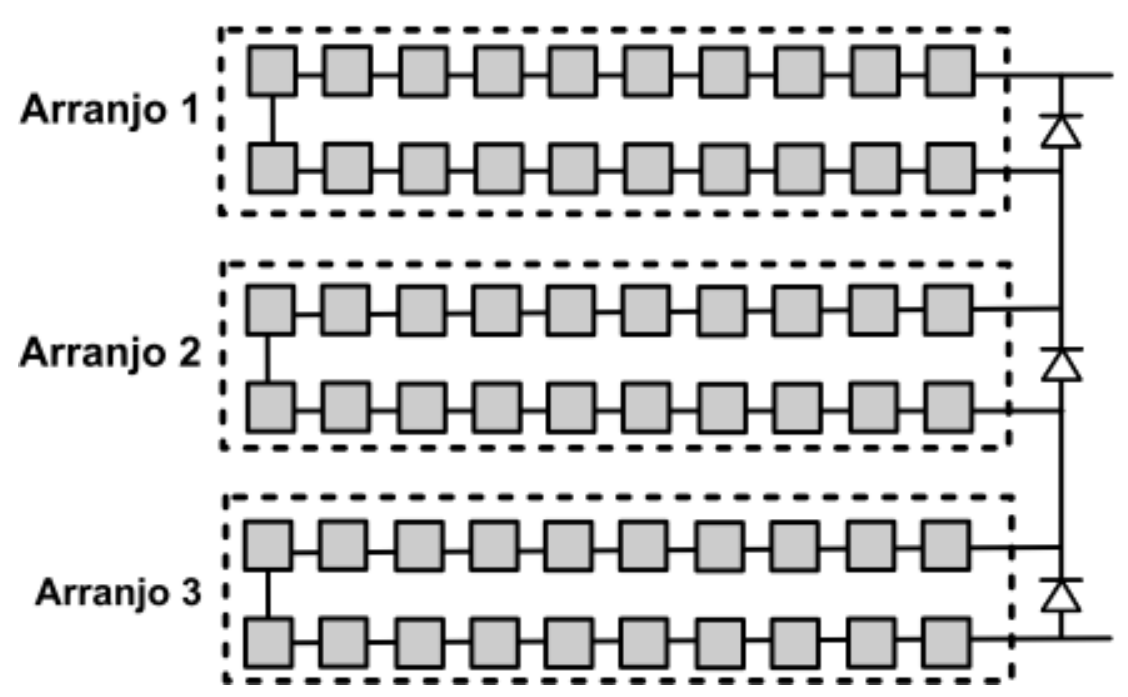

Figura 43- Disposição das células dos módulos SUNMODULE 260

Caso haja sombreamento parcial do módulo devido às fileiras anteriores e a sua disposição seja horizontal, a atuação dos diodos permite que os arranjos não afetados pela sombra possam continuar funcionais. Por exemplo, na figura 44, o arranjo 3 deixa de produzir energia elétrica, mas os arranjos 1 e 2 continuam a gerar eletricidade, posto que o diodo em paralelo com o arranjo 3 oferece um caminho alternativo à passagem da corrente elétrica.

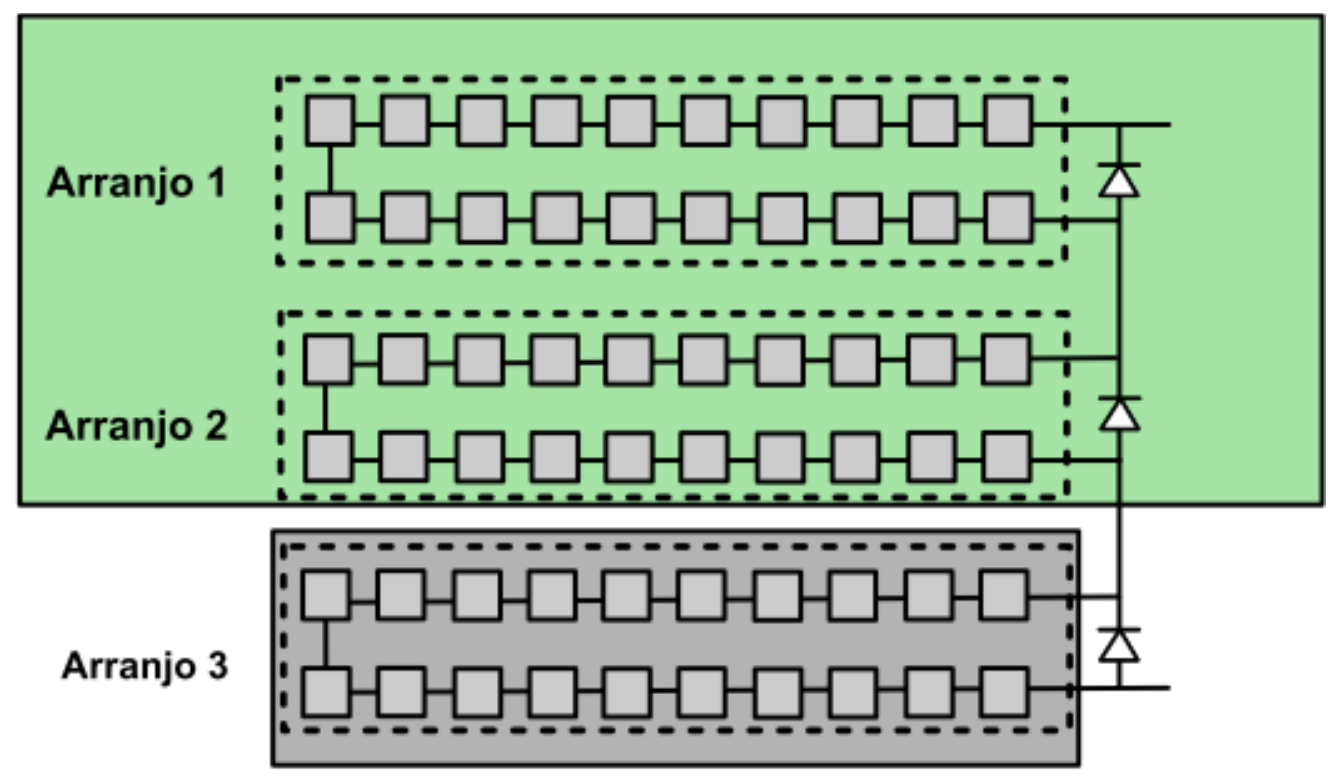

SOMBRA

Figura 44-Sombreamento com o módulo disposto na horizontal 
Se, por outro lado, a disposição do módulo for vertical, a probabilidade de o sombreamento afetar a produtividade do módulo aumenta sobremaneira. Por exemplo, na figura 45 os 3 arranjos são afetados simultaneamente, de forma que eles deixam de produzir energia elétrica.
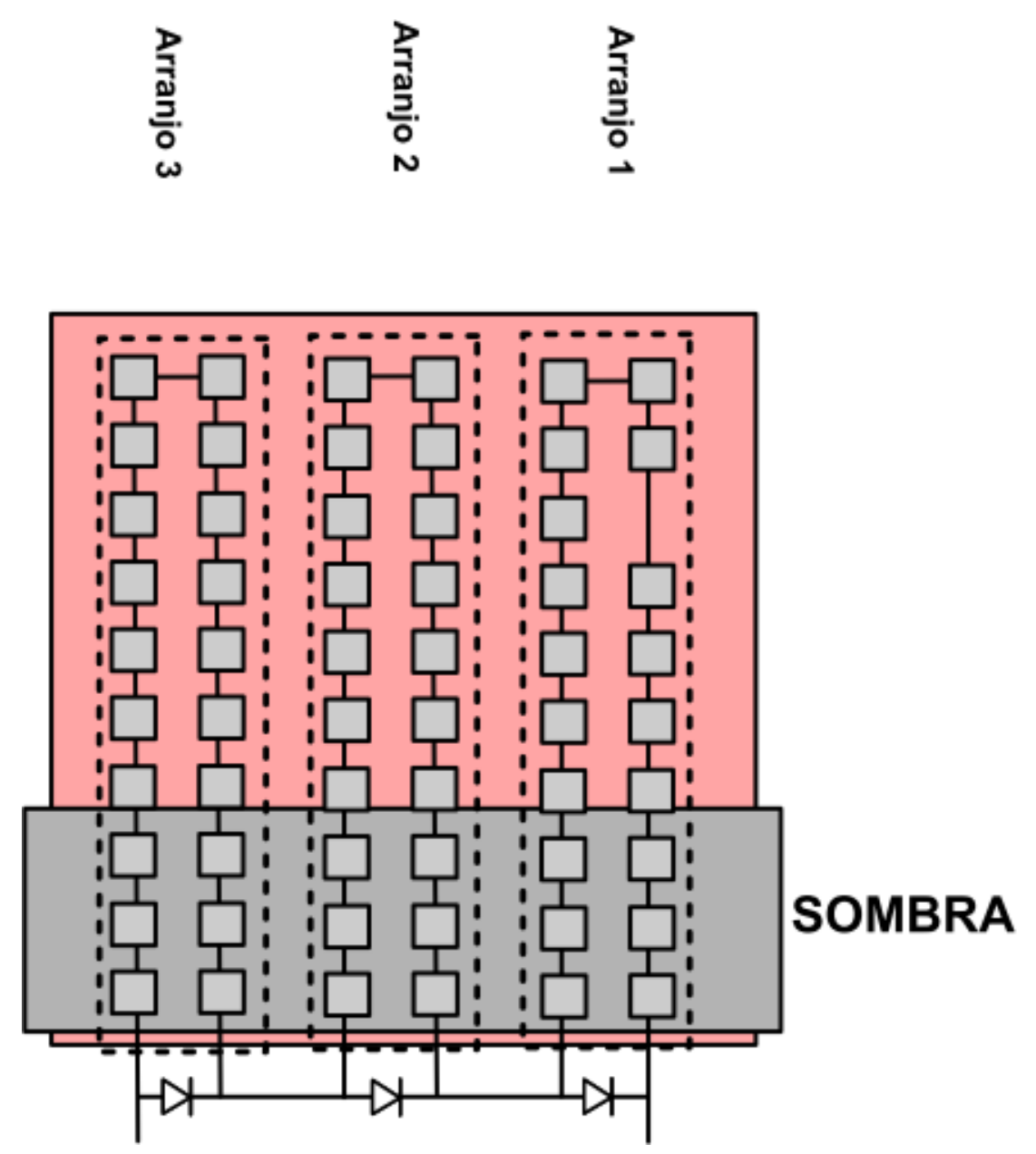

Figura 45- Sombreamento com o módulo disposto na vertical.

As figuras 46 e 47 apresentam a eficiência dos inversores 1 e 2, respectivamente, em função do carregamento, com base nos dados do sistema de aquisição interno do inversor. Analisando-se as figuras, nota-se que, a partir de um carregamento de $20 \%$, o inversor trabalha com elevadas eficiências (em torno de 97\%). 


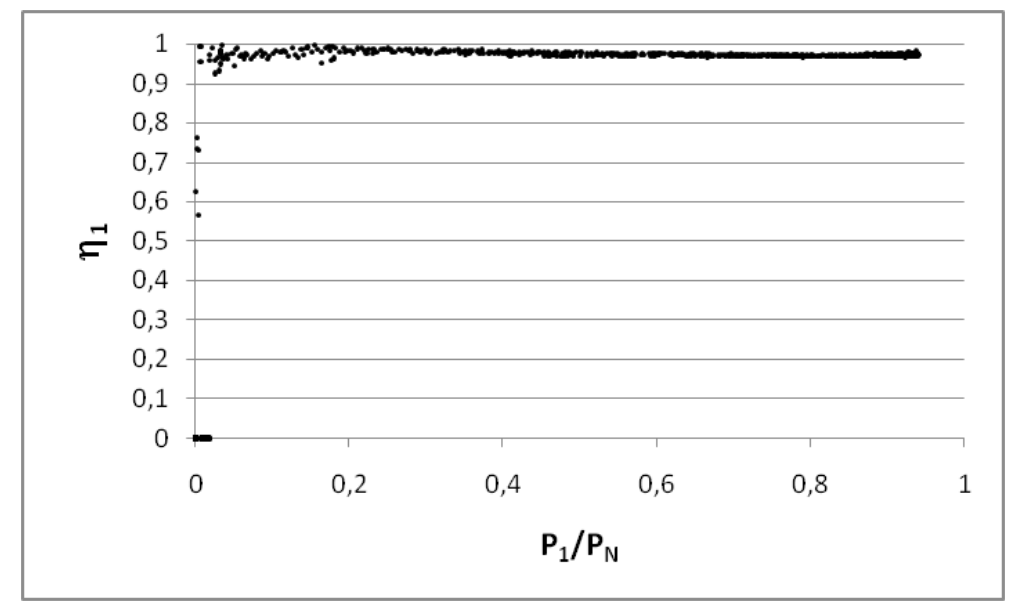

Figura 46-Eficiência do inversor 1 - EAGS (ensolarado)

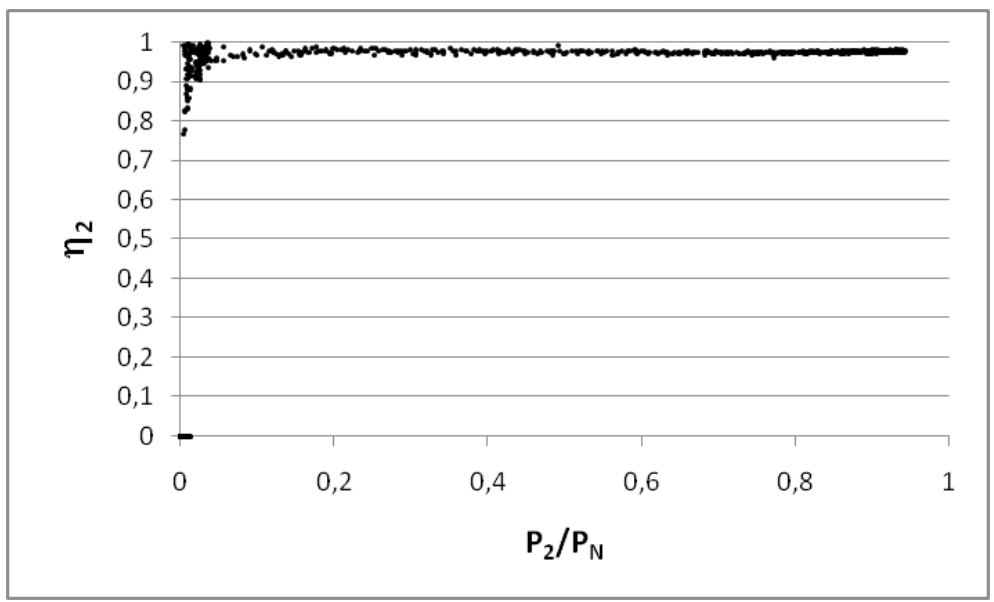

Figura 47- Eficiência do inversor 2 - EAGS (ensolarado)

Verificou-se, então, a curva de eficiência fornecida pelo fabricante $A B B$ (antiga POWER-ONE), a qual pode ser vista na figura 48. De acordo com ela, a eficiência depende, além do carregamento, da tensão c.c. na entrada do inversor, sendo que maiores eficiências são atingidas para tensões entre $580 \mathrm{~V}$ e $750 \mathrm{~V}$. Para tensões inferiores a $360 \mathrm{~V}$ a eficiência tende a ser ligeiramente menor, especialmente para carregamentos superiores a $60 \%$. A eficiência ótima para esse modelo de inversor, segundo o fabricante, ocorreria para uma tensão de entrada de $580 \mathrm{~V}$ e carregamento a partir de $20 \%$. 


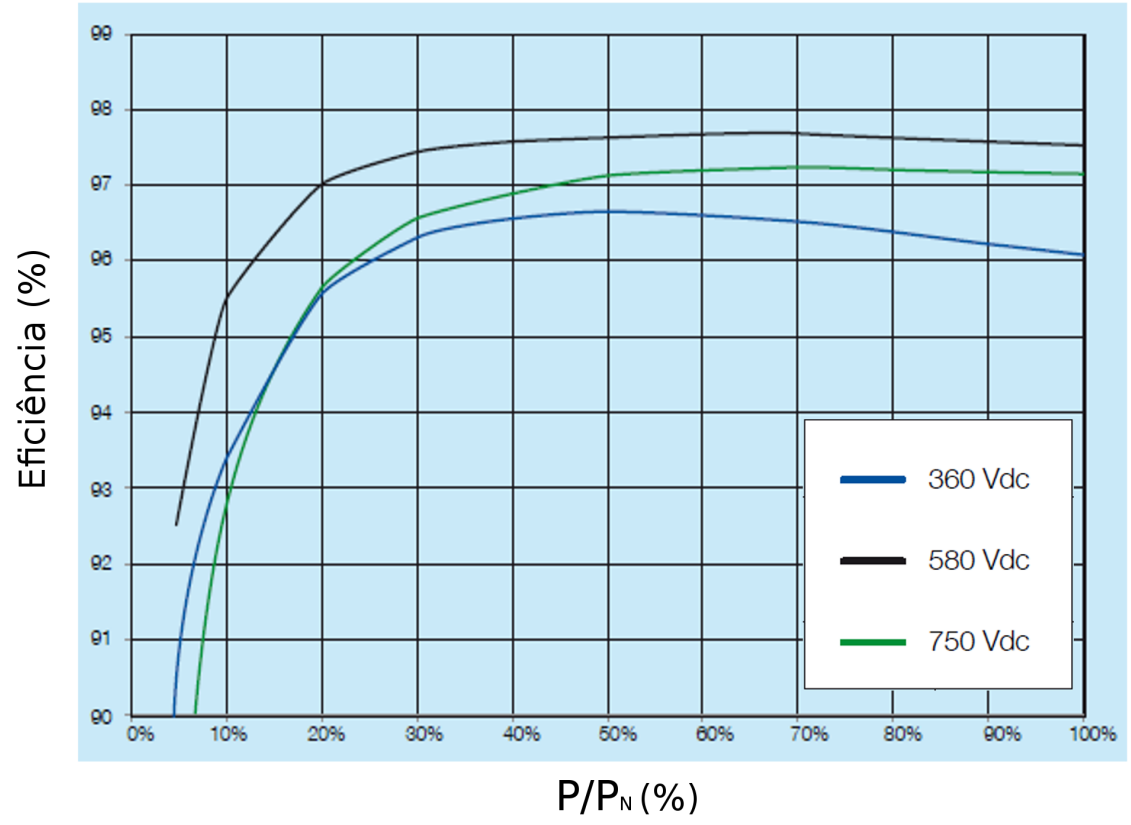

Figura 48- Curva de eficiência do inversor Aurora PVI 12.5 TL-OUTD.

Fonte: ABB

Em seguida, analisou-se a tensão na entrada c.c. do SPMP1 e do SPMP2 para cada inversor (inversor 1 nas figuras 49 e 50 e inversor 2 nas figuras 51 e 52). Em todos os casos, nota-se que o inversor trabalha com tensões de entrada entre $550 \mathrm{~V}$ e $650 \mathrm{~V}$ na maior parte do tempo, o que, com base na curva de eficiência da figura 48, corrobora com os valores de eficiência mostrados nas figuras 46 e 47 ).

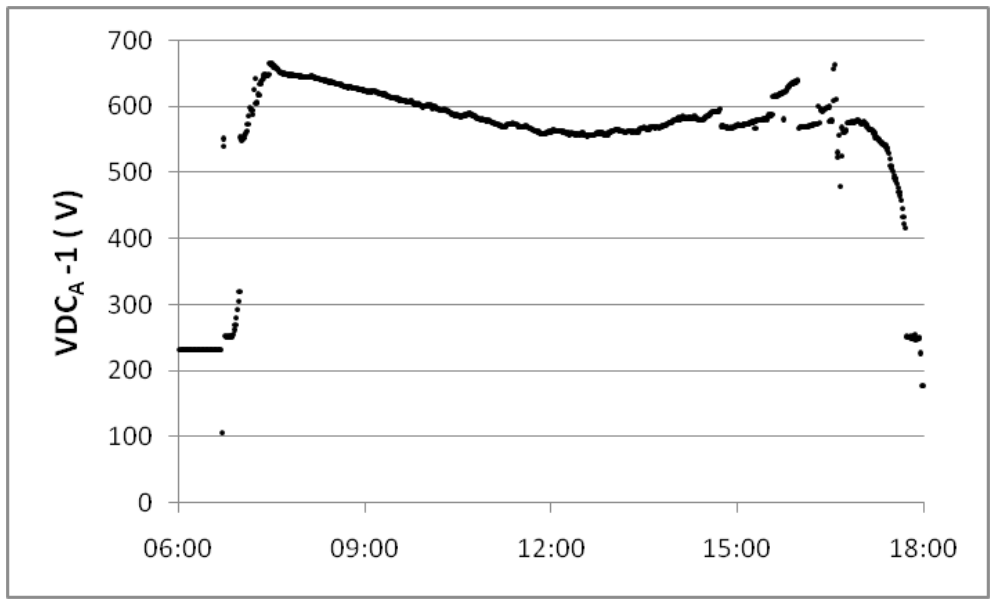

Figura 49-Tensão de entrada SPMP1/INV 1 - EAGS (ensolarado) 


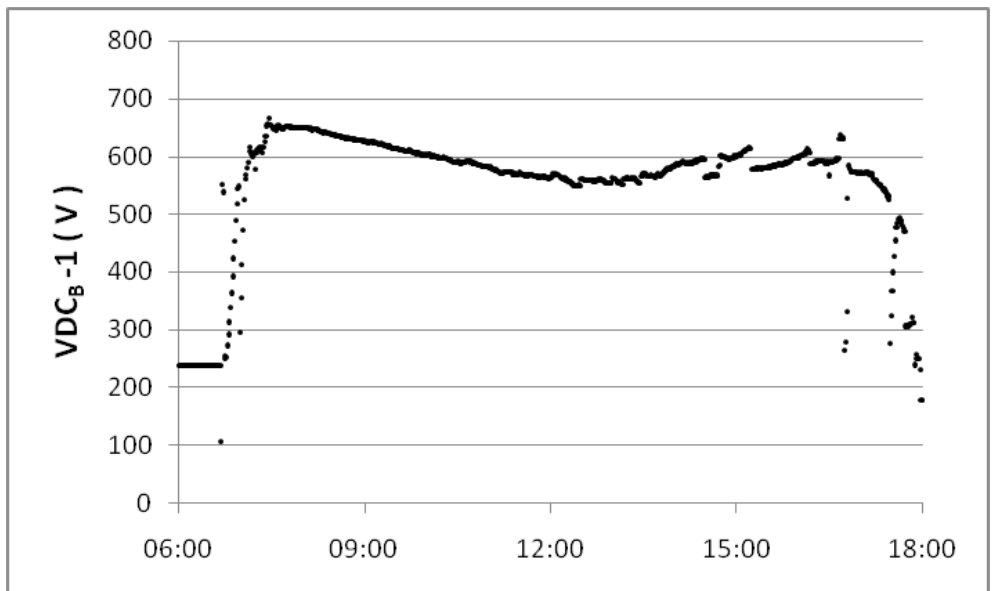

Figura 50- Tensão de entrada SPMP2/INV 1 - EAGS (ensolarado)

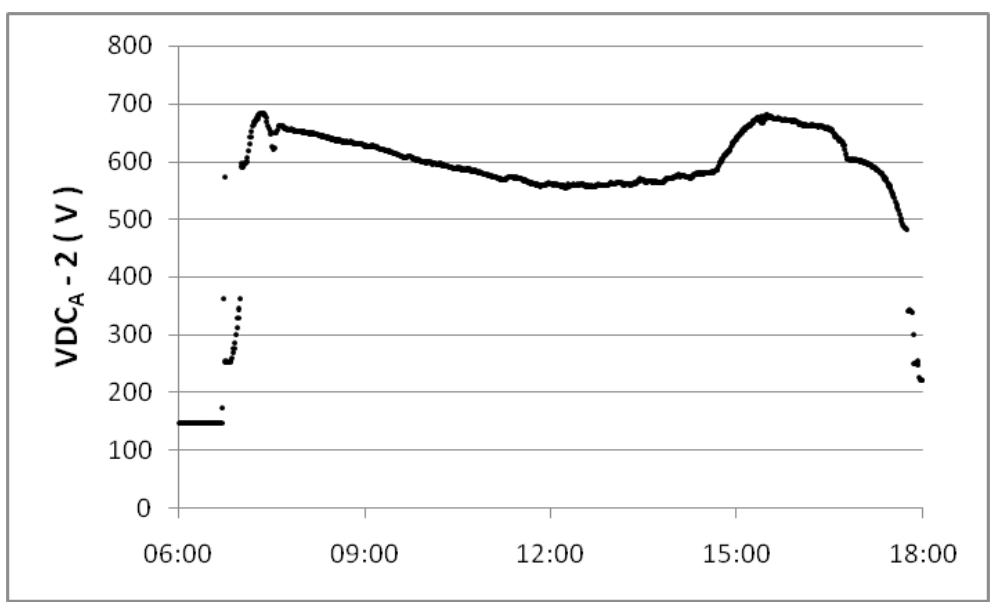

Figura 51- Tensão de entrada SPMP1/INV 2 - EAGS (ensolarado)

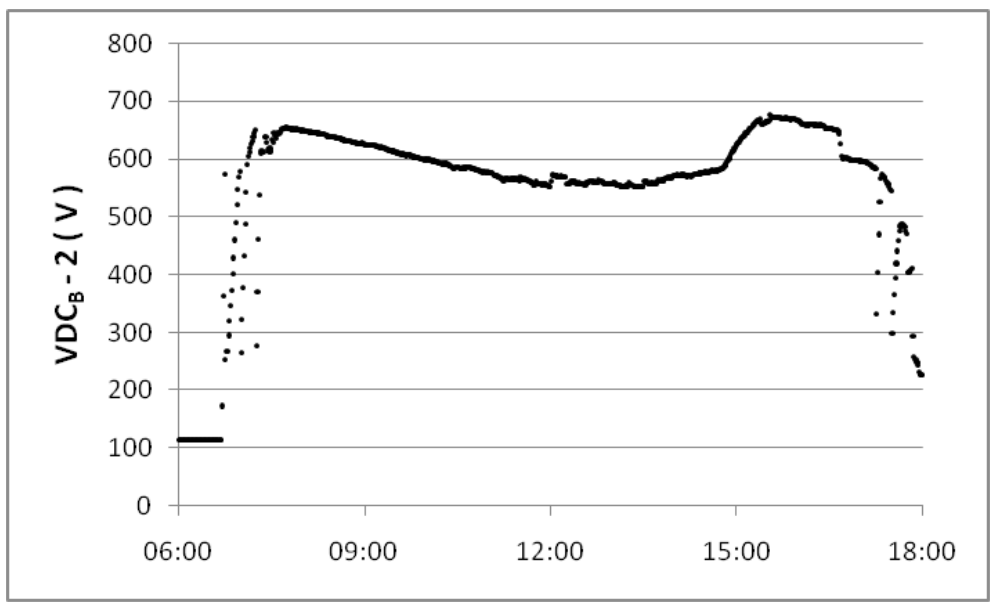

Figura 52- Tensão de entrada SPMP2/INV 2 - EAGS (ensolarado) 
Pode-se observar, nas figuras 51e 52, que um dos efeitos do sombreamento sobre a segunda fileira é a elevação abrupta da tensão nas entradas c.c. do inversor 2 (notável a partir das 15h00).

A potência nominal dos módulos fotovoltaicos é estabelecida, historicamente, com base nas chamadas condições padrão, que são irradiância de $1 \mathrm{~kW} / \mathrm{m}^{2}$, distribuição espectral correspondente a uma massa de ar igual a 1,5 e temperatura de célula de $25{ }^{\circ} \mathrm{C}$, condições que dificilmente ocorrem na operação em campo, levando a uma diferença significativa entre a potência nominal e a potência de fato entregue pelos módulos (ZILLES et al., 2012).

A figura 53 a seguir mostra a temperatura dos módulos, no primeiro dia de ensaios. A figura 54 é uma cópia da figura 40, que mostra a irradiância, e está sendo reapresentada com a finalidade de facilitar a análise subsequente.

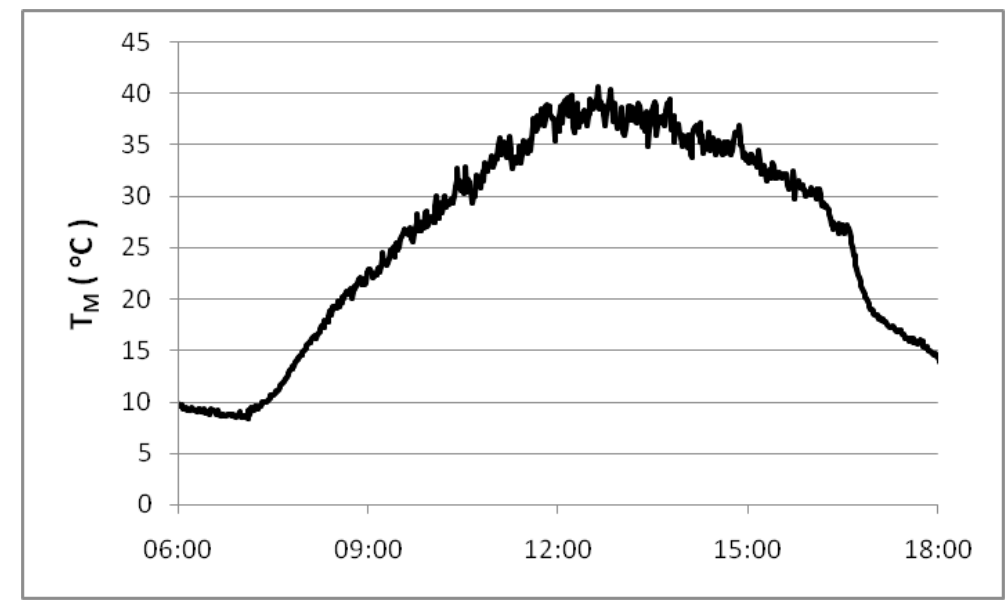

Figura 53-Temperatura dos módulos - EAGS (ensolarado)

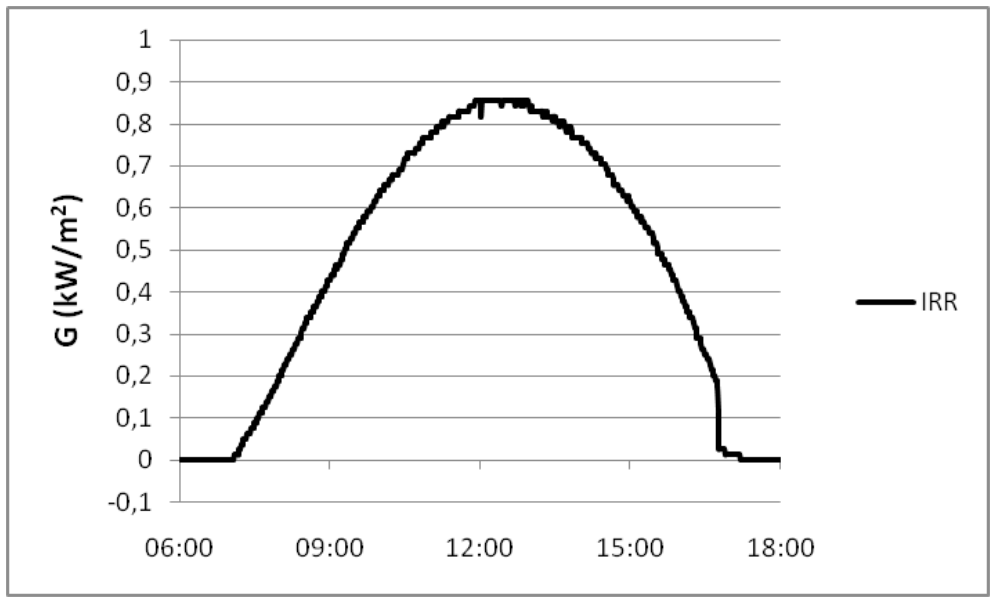

Figura 54- Cópia da figura 40- Irradiância - EAGS (ensolarado) 
Conhecendo-se o coeficiente de temperatura do ponto de máxima potência, $\gamma_{m p}$, pode-se calcular a máxima potência, $P_{m p}$, do gerador fotovoltaico em função da irradiância, $G_{t}$, no plano do gerador e da temperatura de célula $\left(\mathrm{em}{ }^{\circ} \mathrm{C}\right.$ ), conforme a equação (65) (MACÊDO, 2006; ZILLES et al., 2012; PINHO; GALDINO, 2014). Os termos $P_{F V}^{0}$ e $G_{0}$ correspondem à potência nominal do gerador fotovoltaico e à irradiância padrão, respectivamente.

$$
P_{m p}=P_{F V}^{0} \frac{G_{t}}{G_{0}}\left[1-\gamma_{m p}\left(T_{C}-25^{o} C\right)\right]
$$

Multiplicando-se a equação anterior pela eficiência de seguimento do ponto de máxima potência $\eta_{S P M P}$ e pela eficiência de conversão c.c.-c.a., $\eta_{C O N V}$, obtém-se a equação (66), capaz de expressar de forma satisfatória a potência na saída do inversor.

$$
P_{\text {saida }}=P_{F V}^{0} \frac{G_{t}}{G_{0}}\left[1-\gamma_{m p}\left(T_{C}-25^{\circ} C\right)\right] \eta_{S P M P} \eta_{C O N V}
$$

Utilizando-se os valores $P_{F V}^{0}=60 \times 0,260 \mathrm{~W}$ e $\gamma_{m p}=0,45 \% /{ }^{\circ} \mathrm{C}$ fornecidos pelo fabricante dos módulos, $\quad \eta_{S P M P}=95 \%$ (estimado) e $\quad \eta_{C O N V}=97 \%$ (obtido experimentalmente e fornecido pelo fabricante), foram obtidas as curvas calculadas para a potência na saída do inversor, as quais são apresentadas nas figuras 55 e 56, junto às curvas medidas.

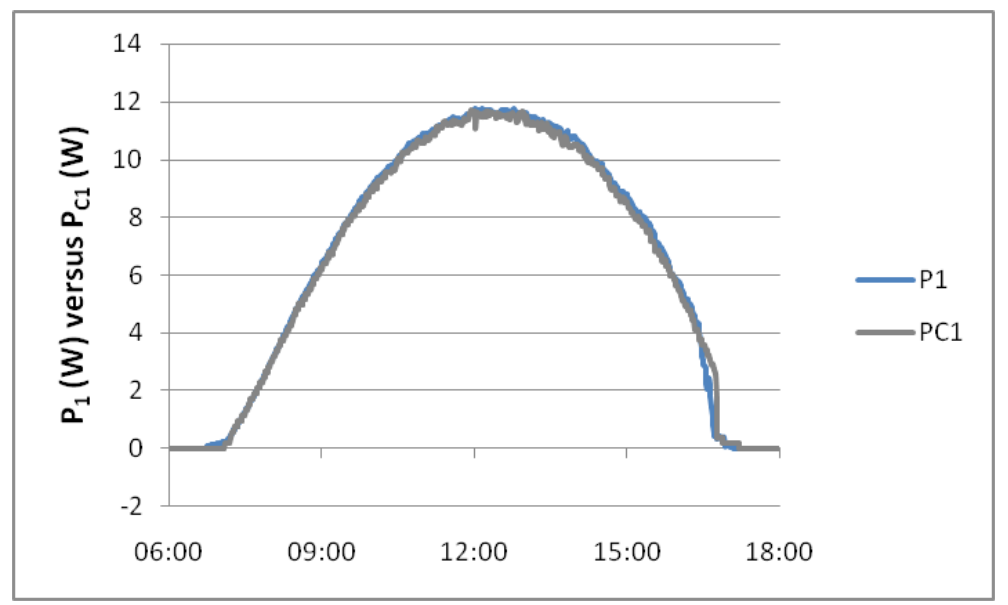

Figura 55-Potências medida (P) e calculada $(P C)$ para o inversor 1 EAGS (ensolarado) 


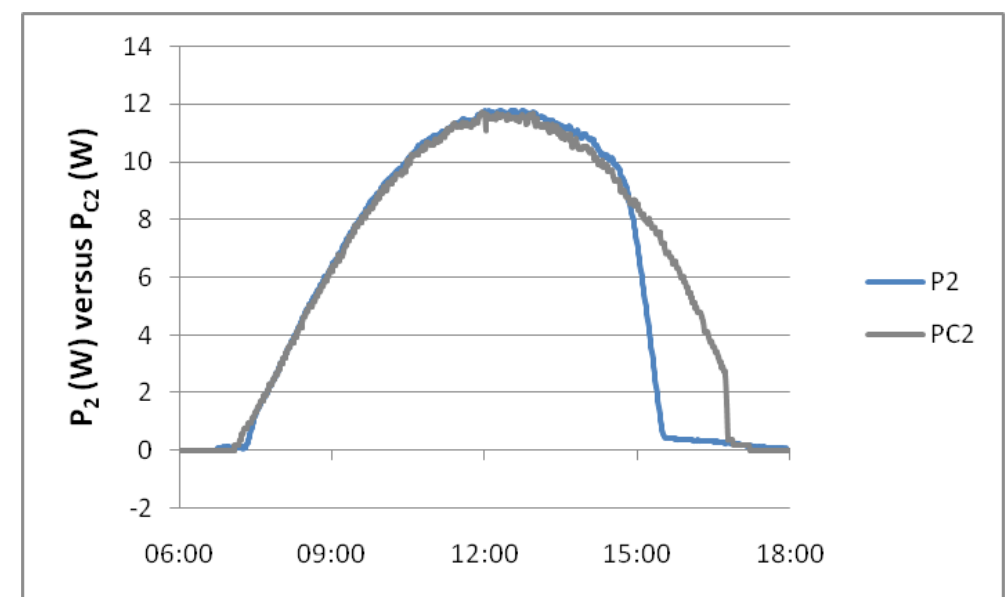

Figura 56-Potências medida (P) e calculada (PC) para o inversor 2 EAGS (ensolarado)

Observa-se a boa concordância entre os valores medidos e calculados, exceto para o inversor 2 no período da tarde, devido ao problema do sombreamento do gerador, já relatado. Assim, o SUBSISTEMA 1, que não é afetado pela sombra, parece operar em consonância com o que dele era esperado para as condições ambientais a que as tecnologias envolvidas estão sujeitas, ao menos em um dia ensolarado.

A tabela 4 resume os indicadores de desempenho para os dois sistemas, obtidos na saída do inversor e no ponto de conexão.

Tabela 4-Resumo dos indicadores de desempenho - EAGS (ensolarado)

\begin{tabular}{|c|c|c|c|c|c|c|}
\hline Inversor & $\begin{array}{c}E_{\text {saída }} \\
(k W h)\end{array}$ & $\begin{array}{c}E_{\text {p.conexão }} \\
(\mathbf{k W h})\end{array}$ & $\begin{array}{c}P_{\text {saída }} \\
(\%)\end{array}$ & $\begin{array}{c}\text { PR }_{\text {STCsaída }} \\
\text { (\%) }\end{array}$ & $\begin{array}{c}P_{\text {p.conexão }} \\
(\%)\end{array}$ & $\begin{array}{c}\text { PR }_{\text {STCp.conexão }} \\
(\%)\end{array}$ \\
\hline 1 & 78,2 & - & 90,1 & 93,4 & - & \\
\hline 2 & 70,5 & - & 81,3 & 84,2 & - & \\
\hline Ambos & 148,7 & 137,8 & 85,5 & 88,9 & 79,4 & 82,3 \\
\hline
\end{tabular}

O sombreamento afetou a produtividade na saída do inversor 2 em cerca de $10 \%$ $(70,5 \mathrm{kWh}$ frente a 78,2 kWh do inversor 1). Nota-se também perdas da ordem de $7,1 \%$ entre a saída dos inversores e a entrega da energia no ponto de conexão (quadro geral), as quais ocorrem no processo de rebaixamento da tensão de $380 \mathrm{~V}$ para $220 \mathrm{~V}$ pelo transformador e no cabeamento dos circuitos que ligam o telhado ao quadro. 


\subsection{2 - Tempo nublado}

A figura 57 mostra a irradiância medida em um dia nublado com poucas aberturas de sol e a figura 58 a respectiva curva de geração fotovoltaica (na saída do inversor).

O problema referente ao sombreamento do gerador do SUBSISTEMA 2 ficou menos evidente neste caso, mas ainda é perceptível a partir das $15 \mathrm{~h} 00$.

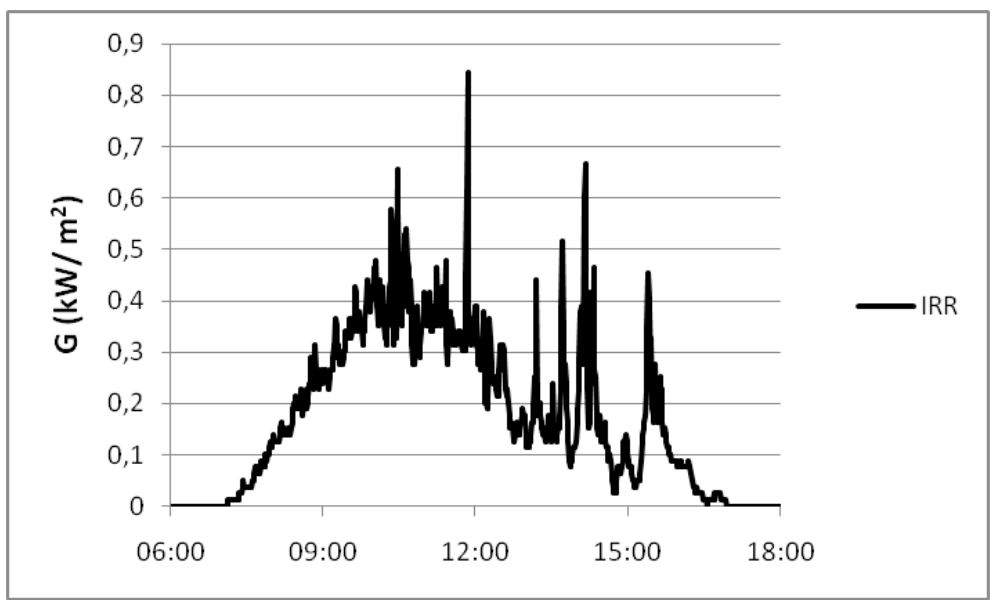

Figura 57-Irradiância - EAGS (nublado)

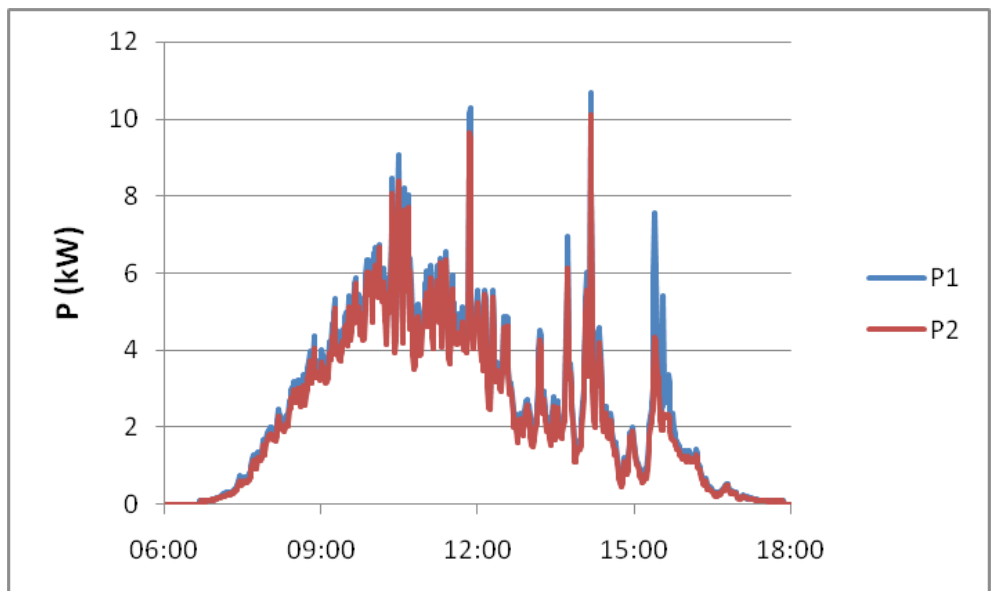

Figura 58- Potência na saída do inversor - EAGS (nublado)

As eficiências obtidas experimentalmente para os dois inversores são mostradas nas figuras 59 e 60. Foram observadas eficiências elevadas (acima de 95\%), mesmo com o 
carregamento máximo na ordem de 50\%.

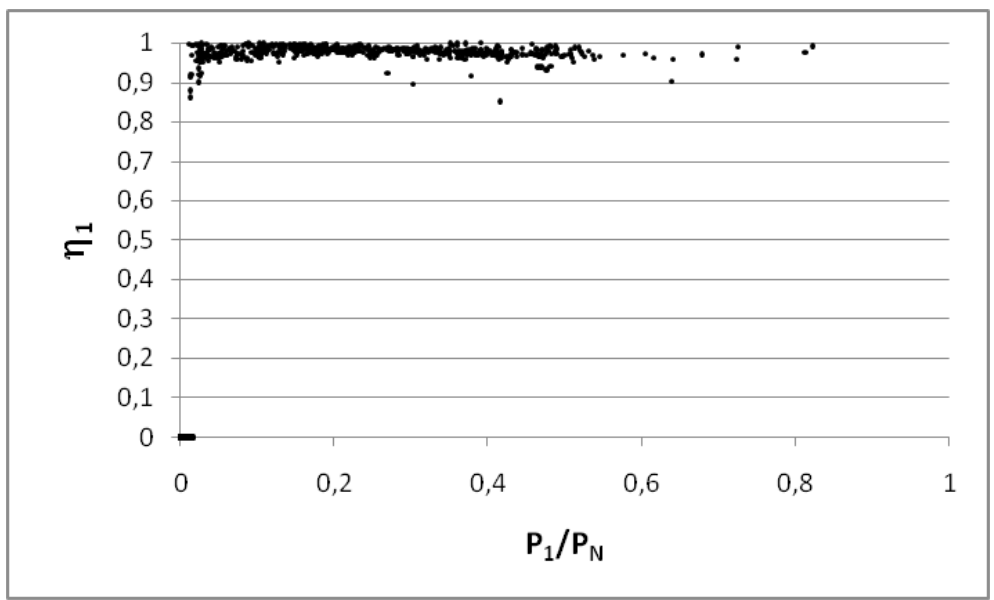

Figura 59-Eficiência do inversor 1 - EAGS (nublado)

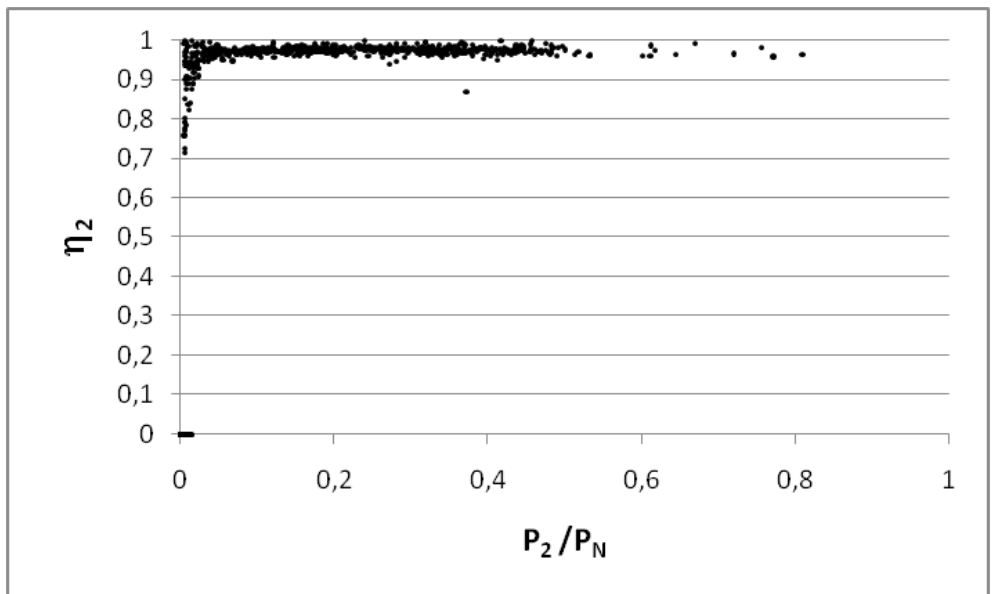

Figura 60-Eficiência do inversor 2 - EAGS (nublado)

Novamente, procurou-se confrontar as duas curvas anteriores com aquela fornecida pelo fabricante (figura 48 ) e com as curvas que expressam a tensão na entrada c.c. de cada SPMP (figuras 61 e 62 para o inversor 1 e figuras 63 e 64 para o inversor 2).

A tensão de trabalho tanto no SPMP1 e do SPMP2 esteve próxima de $600 \mathrm{~V}$ na maior parte do tempo para os dois inversores, de forma que os valores de eficiência obtidos experimentalmente estão de acordo com aqueles previstos para os níveis de carregamento observados. 


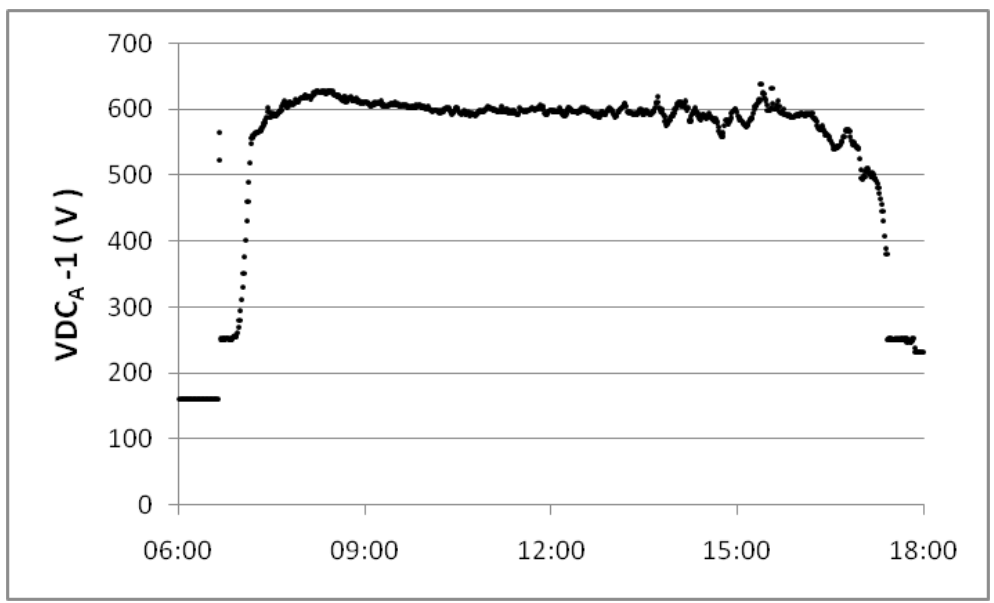

Figura 61- Tensão de entrada SPMP1/INV 1-EAGS (nublado)

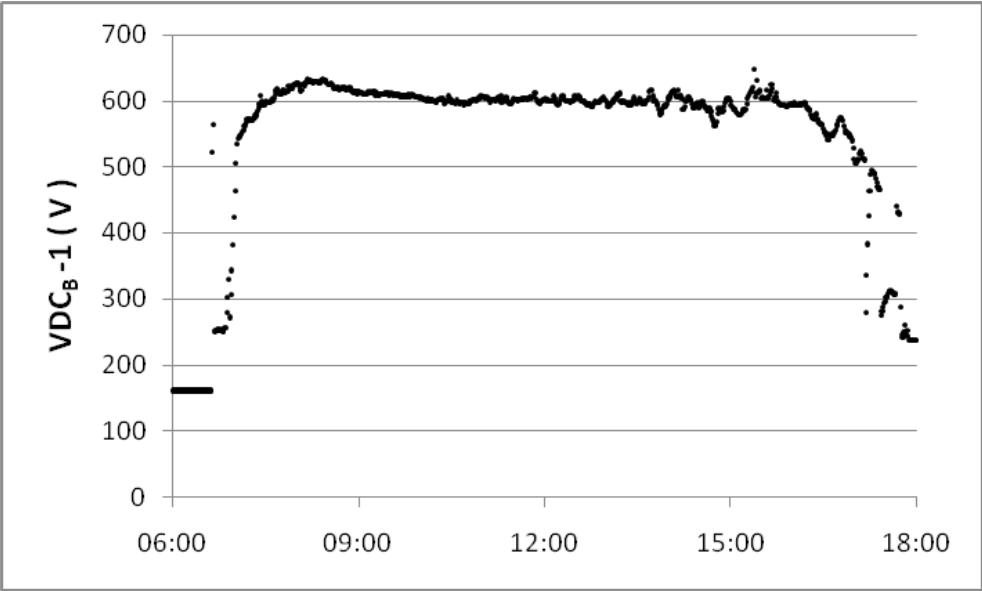

Figura 62-Tensão de entrada SPMP2/INV 1 - EAGS (nublado)

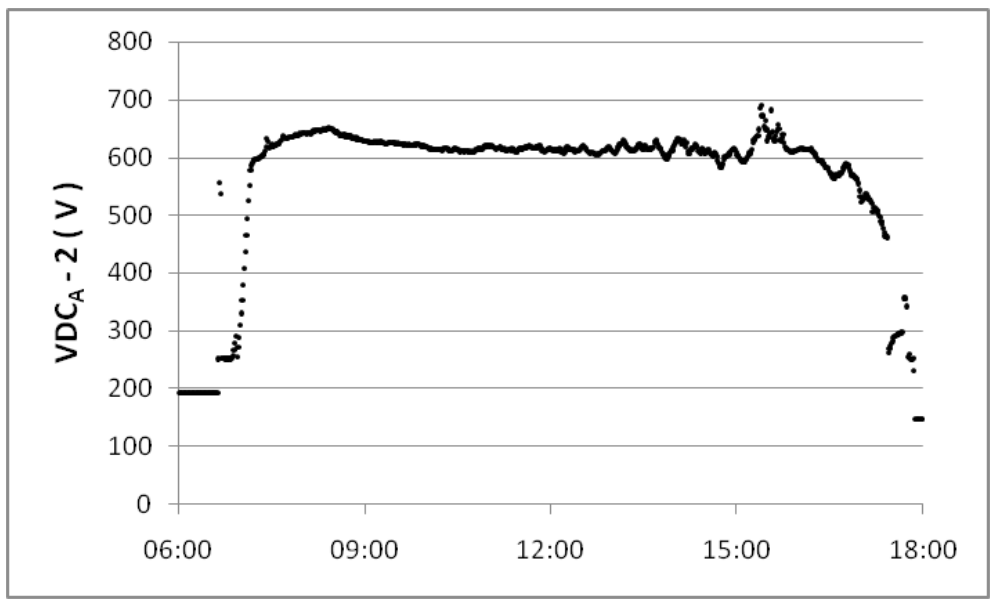

Figura 63-Tensão de entrada SPMP1/INV 2 - EAGS (nublado) 


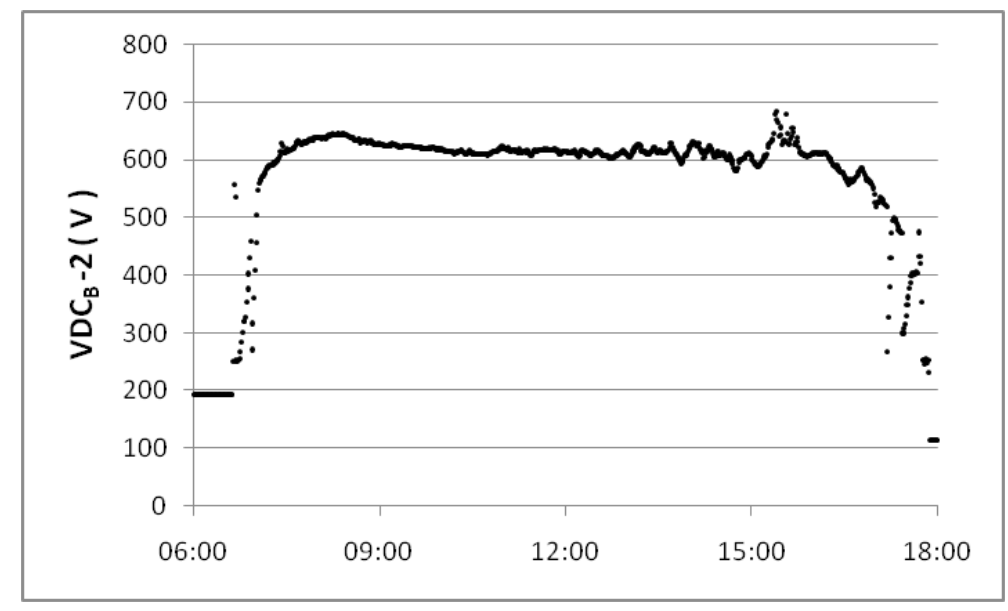

Figura 64-Tensão de entrada SPMP2/INV 2 - EAGS (nublado)

A figura 65, por seu turno, mostra o comportamento da temperatura do gerador fotovoltaico sob tempo encoberto. Notadamente, os menores níveis de irradiância (figura 66, que é uma cópia da figura 57), comparativamente ao dia ensolarado, implicaram em menor aquecimento dos módulos.

Da mesma forma, como os valores instantâneos de potência convertida de c.c. para c.a. no dia nublado foram menores que no dia ensolarado, as temperaturas internas dos inversores também apresentaram-se menores, para os mesmos horários do dia ensolarado.

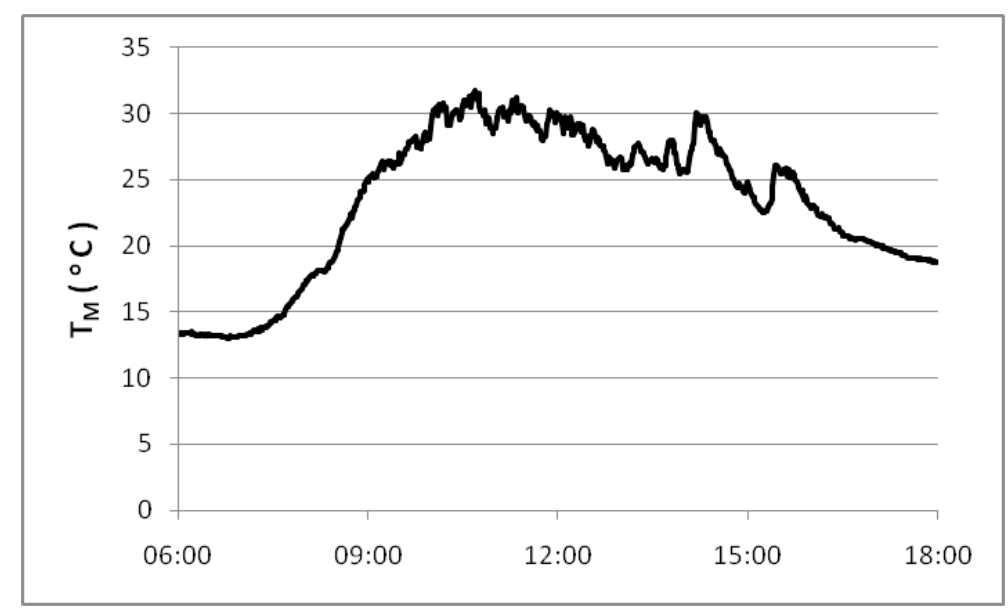

Figura 65-Temperatura dos módulos - EAGS (nublado) 


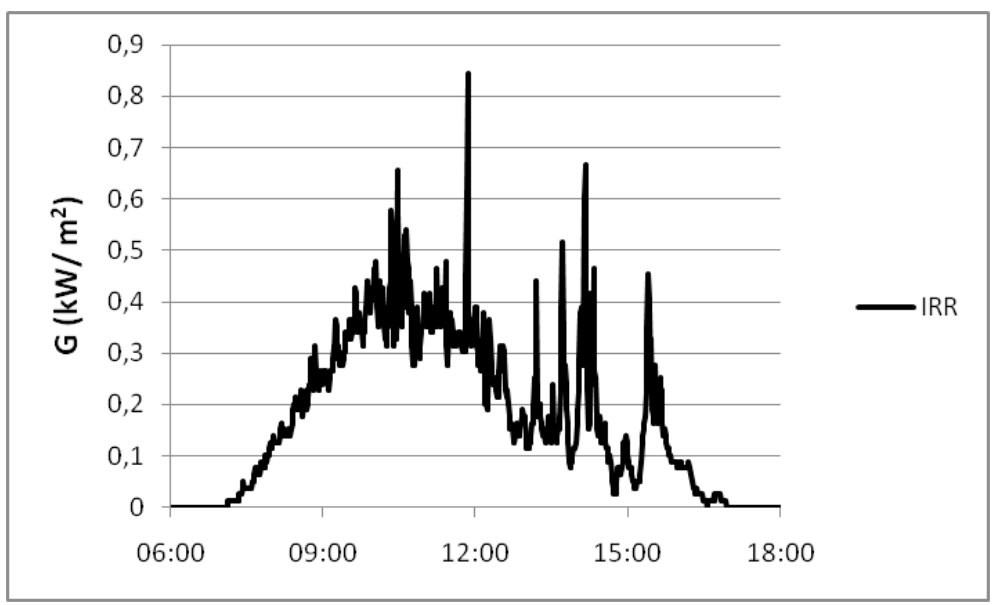

Figura 66- Cópia da figura 57 - Irradiância - EAGS (nublado)

As curvas da potência de saída dos inversores medidas e calculadas (figuras 67 e 68) novamente mostram boa concordância, evidenciando a aderência da equação (66) mesmo em dias nublados (exceto na figura 68 a partir das $15 \mathrm{~h} 00$, devido ao sombreamento da fileira 2 ).

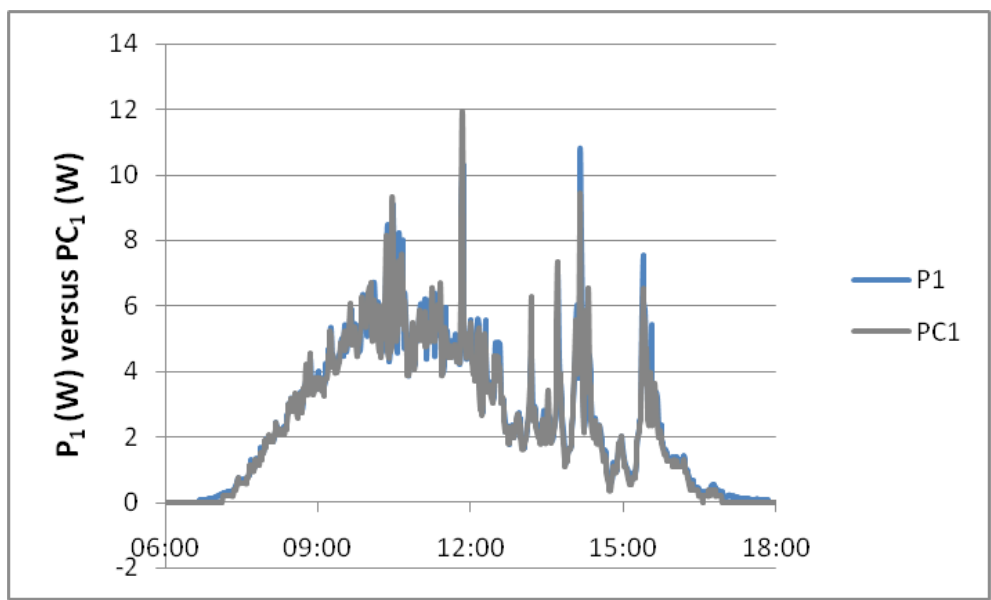

Figura 67-Potências medida (P) e calculada (PC) para 0 inversor 1 EAGS (nublado) 


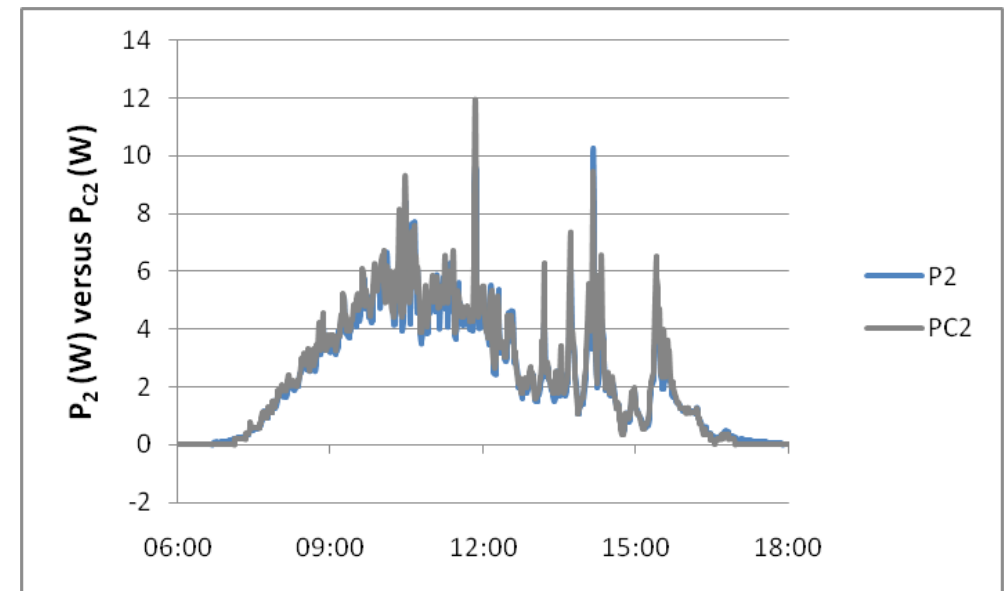

Figura 68-Potências medida (P) e calculada (PC) para o inversor 2 EAGS (nublado)

Para se finalizar a análise deste primeiro bloco de ensaios, a tabela 5 resume os indicadores de desempenho para os dois sistemas, obtidos na saída do inversor e no ponto de conexão, no dia nublado.

Tabela 5-Resumo dos indicadores de desempenho - EAGS (ensolarado)

\begin{tabular}{ccccccc}
\hline Inversor & $\begin{array}{c}\mathbf{E}_{\text {saída }} \\
(\mathbf{k W h})\end{array}$ & $\begin{array}{c}\mathbf{E}_{\text {p.conexão }} \\
\mathbf{( k W h )}\end{array}$ & $\begin{array}{c}\mathbf{P R}_{\text {sáda }} \\
\mathbf{( \% )}\end{array}$ & $\begin{array}{c}\mathbf{P R}_{\text {STCsaída }} \\
\mathbf{( \% )}\end{array}$ & $\begin{array}{c}\mathbf{P R}_{\text {p.conexão }} \\
\mathbf{( \% )}\end{array}$ & $\begin{array}{c}\mathbf{P R}_{\text {STCp.conexão }} \\
\mathbf{( \% )}\end{array}$ \\
\hline 1 & 31,1 & - & 94,6 & 95,0 & - & \\
2 & 28,4 & - & 86,4 & 86,5 & - & \\
Ambos & 59,5 & 51,1 & 90,6 & 91,5 & 77,8 & 78,6 \\
\hline
\end{tabular}

Nota-se que, embora a produtividade dos dois subsistemas tenha sido menor, o valor de PR na saída do inversor atingiu valores elevados comparativamente ao dia ensolarado, especialmente no SUBSISTEMA 1. Esse fato tem relação com as baixas temperaturas dos módulos, as quais ficaram muito próximas do valor padrão de $25^{\circ} \mathrm{C}$ boa parte do dia. Por outro lado, observou-se uma queda no valor de PR medido no ponto de conexão, o que se explica pelo fato de as perdas no transformador de rebaixamento de $380 \mathrm{~V}$ para $220 \mathrm{~V}$ serem na sua maior parte fixas (algo entre 8,4 kWh e 10,9 kWh diários) o que, proporcionalmente, impacta mais o PR para o dia nublado. 


\subsection{Resultados dos ensaios de compensação de reativos (ECR)}

\subsection{1 - Dias 1 e 2 - Nível de excitação de 8 kvar}

Como foi descrito no Capítulo 2, neste bloco de ensaios o inversor do SUBSISTEMA 1 trabalhou com fator de potência unitário no primeiro dia (1) e passou a gerar potência ativa e reativa no segundo dia (2), ao passo que o inversor do SUBSISTEMA 2 só foi utilizado para forçar um comportamento indutivo da carga, que é naturalmente capacitiva nessa época do ano. É importante salientar que o inversor do SUBSISTEMA 2 esteve subexcitado e, portanto, demandando potência reativa durante todos os ensaios deste último bloco, mudando-se apenas o seu nível de excitação, o qual foi parametrizado inicialmente em +8 kvar indutivo.

Uma premissa importante é a de que o problema da cobrança por excedente de reativos, que poderia afetar o tempo de retorno do empreendimento fotovoltaico, torna-se relevante apenas no período diurno e quando a carga é indutiva, pois mesmo que o fator de potência da UC fosse menor que 0,92, mas capacitivo, não seriam cobrados excedentes de reativos no período diurno, mas apenas em um período de 6 horas consecutivas compreendidas entre $23 \mathrm{~h} 00$ e $06 \mathrm{~h} 00$. Dessa forma, estudou-se a compensação de reativos apenas para o caso em que a carga apresenta um comportamento indutivo.

As figuras 69 e 70 mostram as irradiâncias e a potências geradas pelo inversor do SUBSISTEMA 1 nos dois primeiros dias do segundo bloco de ensaios.

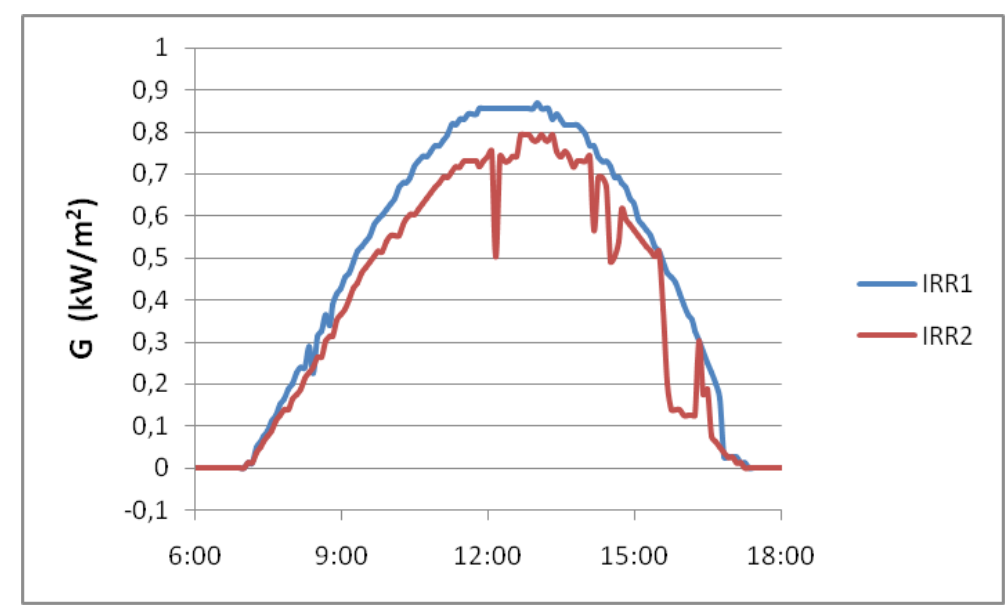

Figura 69-Irradiância - ECR (dias 1 e 2) 


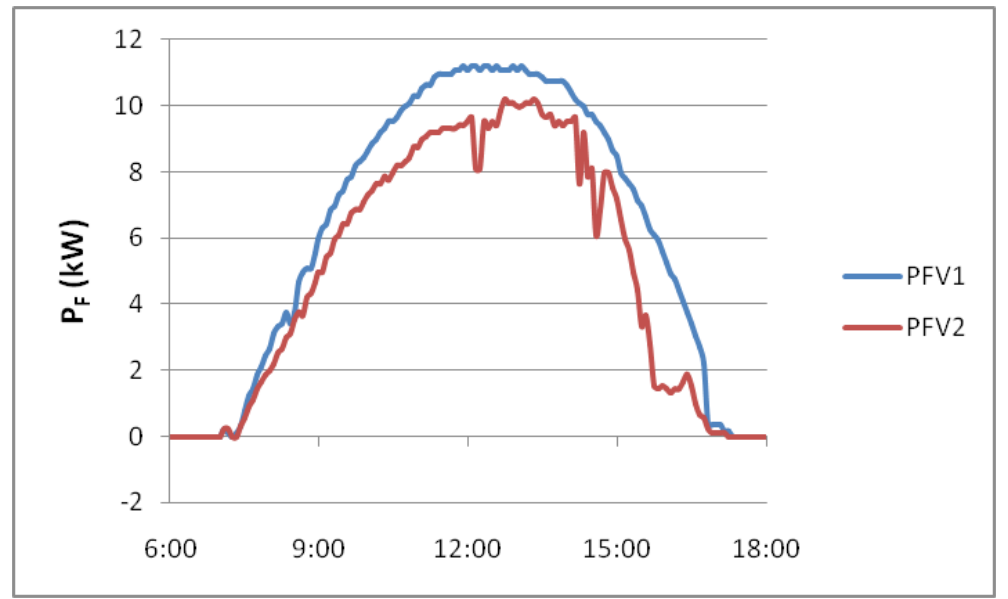

Figura 70-Potência gerada - ECR (dias 1 e 2)

A produção do SUBSISTEMA 1 foi um pouco inferior no dia 2, mas, pela análise das duas figuras anteriores, isso tem relação com os diferentes níveis de irradiância nos dois dias de testes e não com o fato de no segundo dia o subsistema ter gerado potência ativa e reativa concomitantemente (essa hipótese é testada apropriadamente no próximo bloco de ensaios).

A figura 71 traz uma importante informação referente à potência ativa demandada pela carga, independentemente da fonte supridora (rede ou sistema fotovoltaico) nos dias 1 e 2 . Nota-se que, a despeito de haver alguns picos de consumo em momentos específicos no segundo dia, na maior parte do tempo o perfil de consumo nos dois dias é muito semelhante.

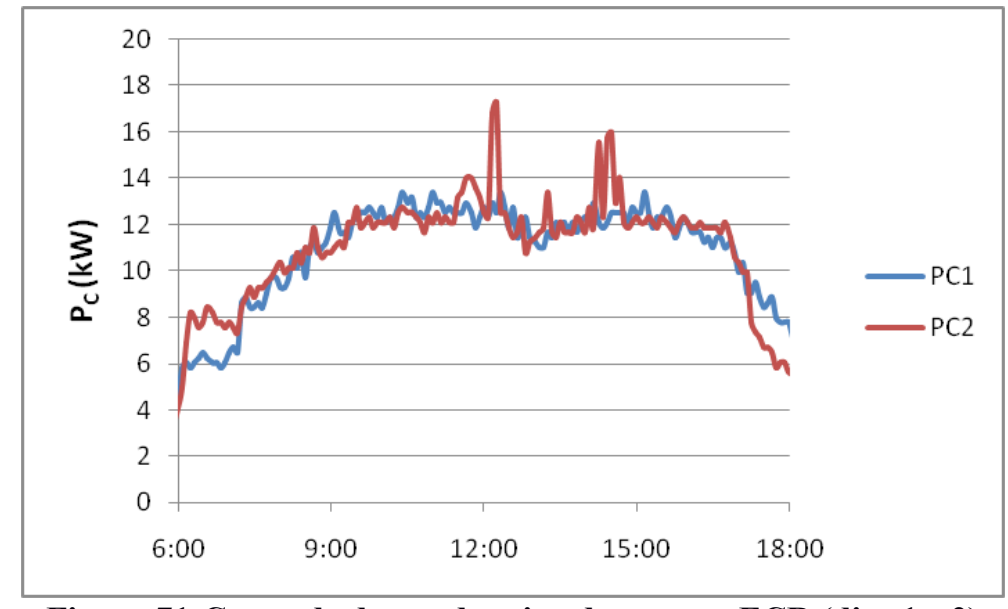

Figura 71-Curva de demanda ativa da carga - ECR (dias 1 e 2)

A figura 72 apresenta a curva de demanda líquida $\mathrm{P}_{\mathrm{L}}$, que é aquela efetivamente registrada pelo medidor eletrônico na entrada do prédio. 


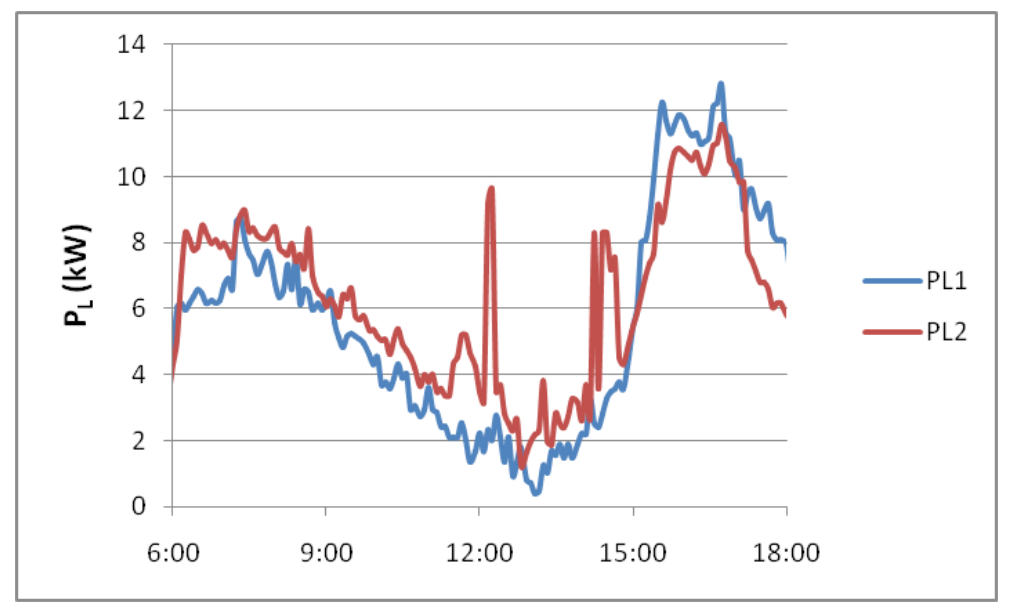

Figura 72-Curva de demanda ativa líquida - ECR (dias 1 e 2)

A diferença entre os aspectos das curvas, quando se compara as figuras 71 e 72, reside no fato de que parte da demanda da carga é suprida pelo sistema fotovoltaico, o que provoca a depressão da curva da potência proveniente da rede elétrica, especialmente quando os níveis de irradiância são mais elevados. Para corroborar essa informação apresenta-se, na figura 73, o consumo líquido horário de energia elétrica.

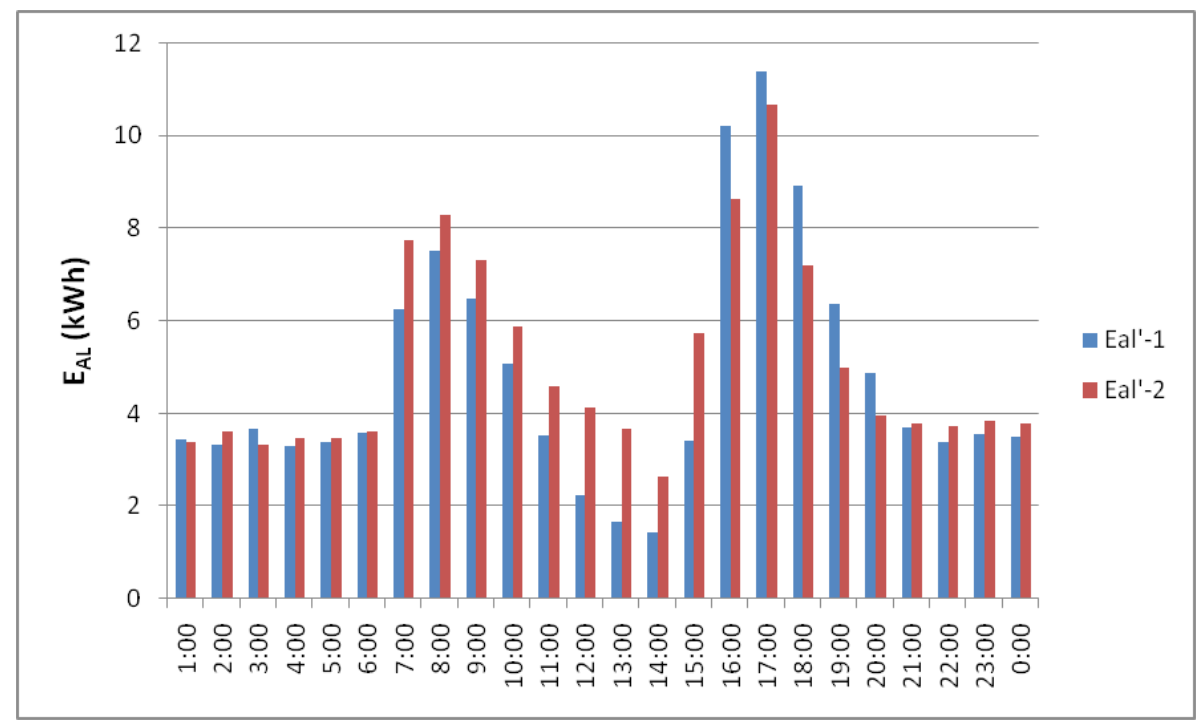

Figura 73-Consumo líquido horário de energia ativa - ECR (dias 1 e 2)

O gráfico presente na figura 74 é um dos mais importantes desta seção. Ele mostra a curva de demanda reativa líquida nos dois dias de ensaios. Visivelmente, a carga apresentava um comportamento indutivo no primeiro dia (valores predominantemente positivos de $\mathrm{Q}_{\mathrm{L}}$ ), que muda para levemente capacitivo no segundo dia, após a ação de compensação de reativos 
implementada.

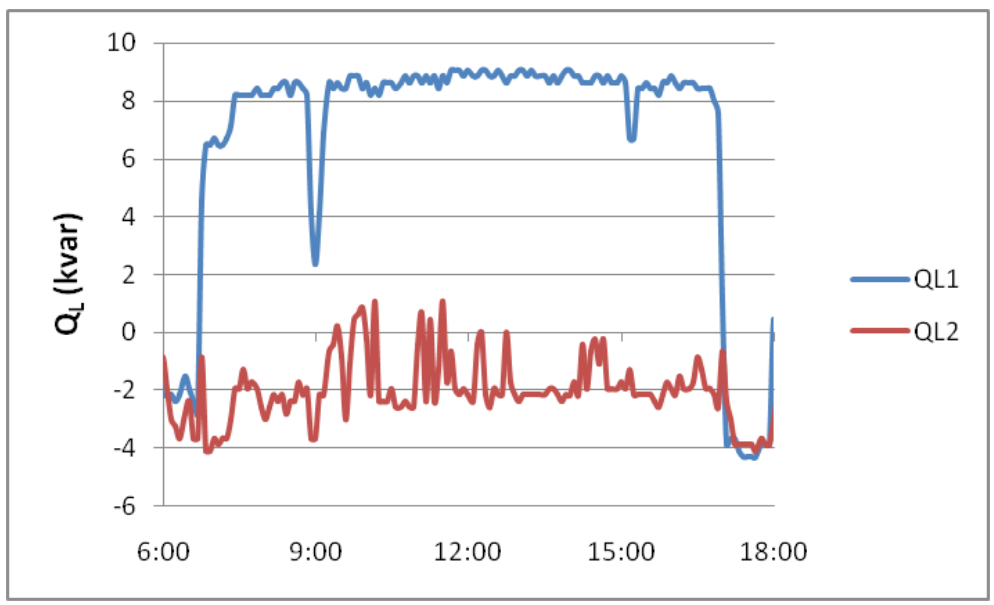

Figura 74-Curva de demanda reativa líquida - ECR (dias 1 e 2)

$\mathrm{Na}$ imagem da figura 75 fica evidenciado o problema da degradação do fator de potência FP da UC, quando esta possui sistema próprio de geração distribuída. A curva cinza, denominada FPEF1, refere-se ao fator de potência efetivo da instalação, que seria aquele medido caso a demanda por potência ativa fosse suprida exclusivamente pela rede elétrica. Como foi utilizado um nível de excitação elevado para o inversor do SUBSISTEMA 2 (cerca de +8 kvar), o fator de potência seria relativamente baixo (da ordem de 0,82 indutivo) mas estável ao longo do dia. Porém, como a maior parte da demanda por potência ativa é suprida pelo sistema fotovoltaico, o fator de potência registrado pelo equipamento da concessionária apresenta-se deteriorado, como se nota na depressão apresentada pela curva azul, denominada FP1.

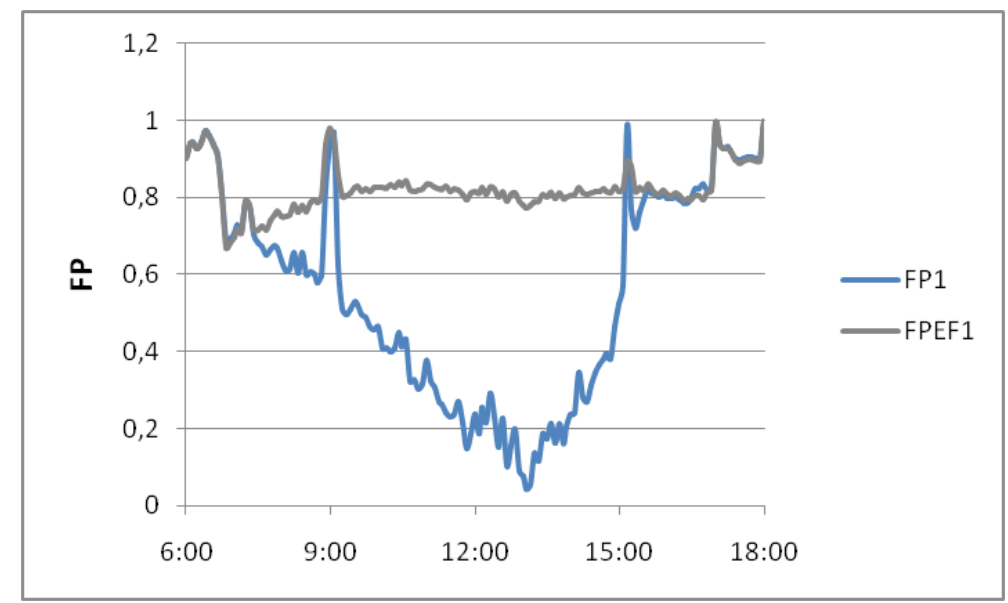

Figura 75-Fator de potência (5 em 5 min) - ECR (dia 1) 
No segundo dia, quando se programou o inversor do SUBSISTEMA 1 para gerar potência ativa e reativa simultamente, de forma a suprir localmente a demanda por reativos, o medidor da entrada do prédio registrou valores do fator de potência bem superiores, como se pode notar pela curva FP2 da figura 76.

Novamente, a curva cinza, denominada FPEF2, que representaria o fator de potência medido caso toda a potência ativa fosse suprida pela concessionária, mostra que está havendo um uso eficiente da energia elétrica, pois o fator de potência efetivo da instalação é estável e, neste caso, os valores atingidos beiram a unidade na maior parte do dia.

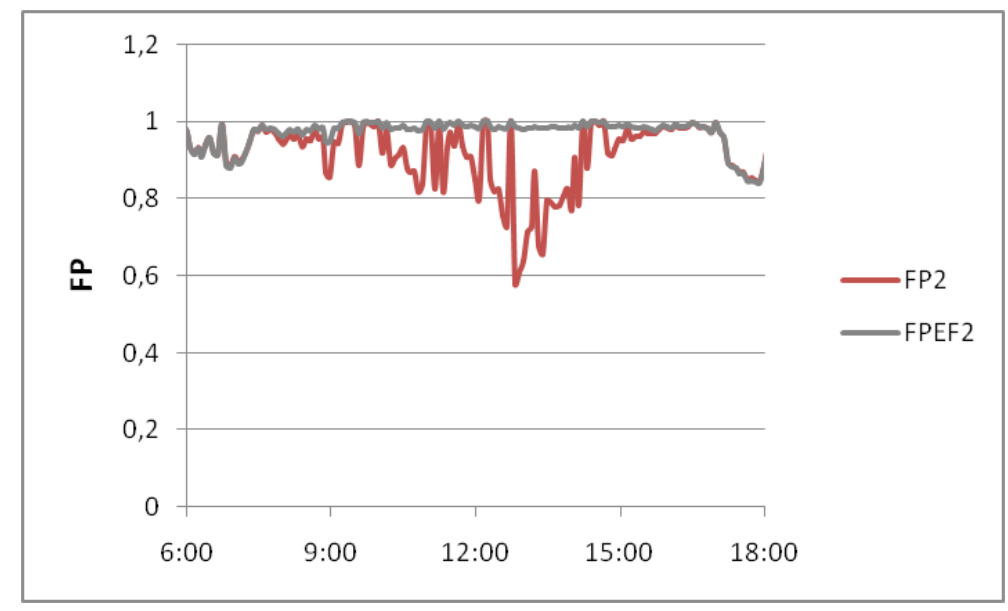

Figura 76-Fator de potência (5 em 5 min) - ECR (dia 2)

Para efeitos de tarifação por excedente de reativos, a medição do fator de potência é feita de hora em hora; por isso a figura 77 deve ser analisada cuidadosamente.

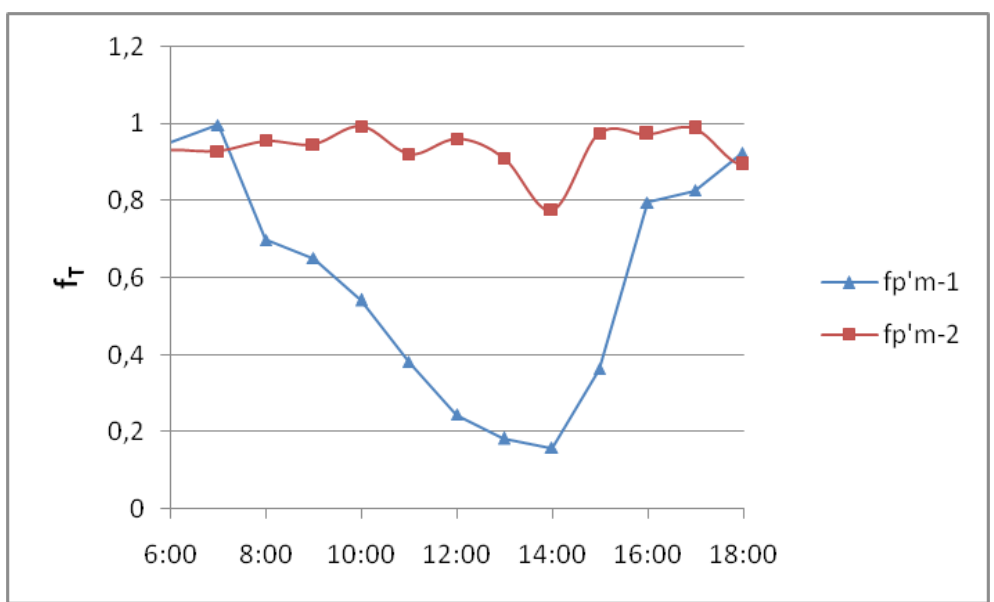

Figura 77- Fator de potência (1 em 1 hora) - ECR (dias 1 e 2) 
Pode-se notar que se conseguiu estabilizar o fator de potência medido pela concessionária e, a despeito de o fator de potência ter apresentado valores inferiores a 0,92 em alguns horários (por exemplo, próximo das 14h00), ele apresentava caráter levemente capacitivo, o que não incorre em cobrança por excedente de reativos para o horário.

A figura 78 é importante para a compreensão da eficácia da ação de compensação implementada. Ela apresenta, de hora em hora e em reais, os valores correspondentes à energia reativa excedente no dia 1 , totalizando $\mathrm{R} \$ 16,60$. No dia 2 , com a mudança do perfil da carga para levemente capacitivo, a cobrança pela energia reativa excedente seria nula. Nessa análise, não foi considerada a cobrança pela demanda reativa excedente, $D_{\mathrm{RE}}$.

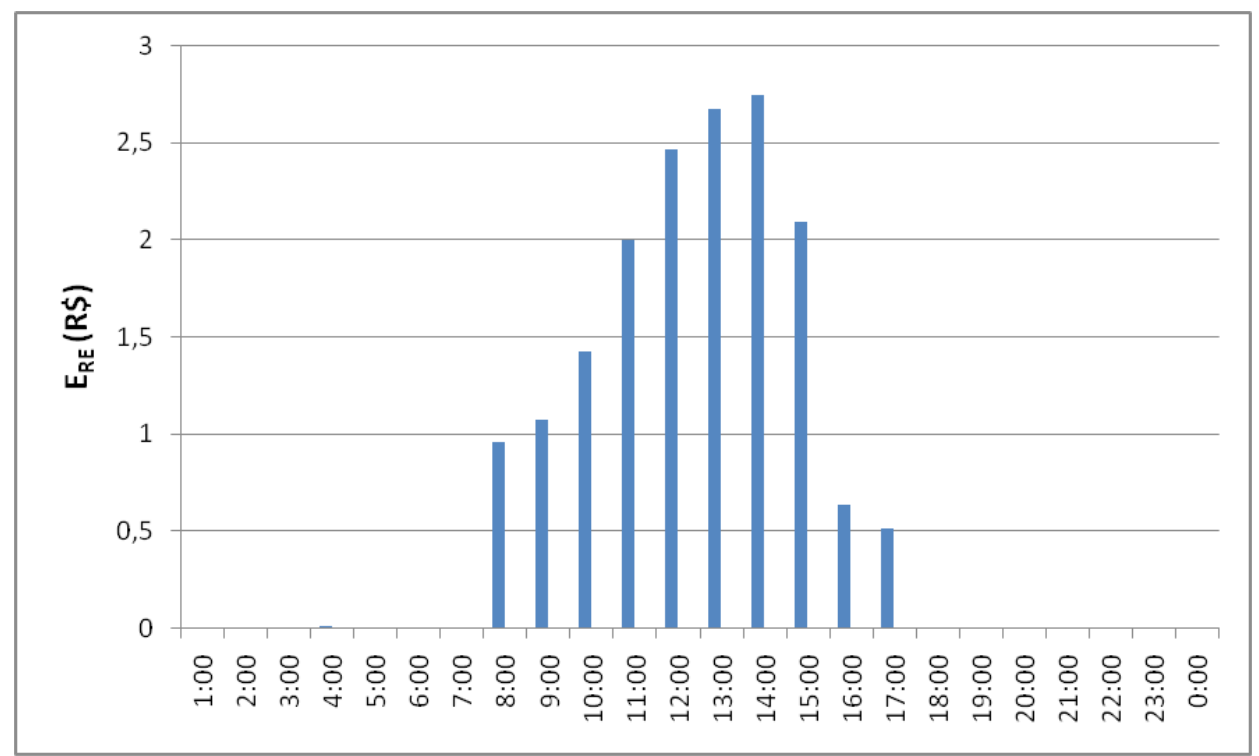

Figura 78- Energia reativa excedente - ECR - dia 1

Finalmente, ao se analisar a última figura desta seção, que é a de número 79, percebese que a ação de compensação aumentou a capacidade do sistema supridor da concessionária no segundo dia, o que pode ser notado quando se analisa a potência aparente que trafega entre o alimentador e o prédio, notavelmente inferior no segundo dia, embora já se tenha demonstrado que as demandas por potência ativa da carga nos dois dias eram muito semelhantes. 


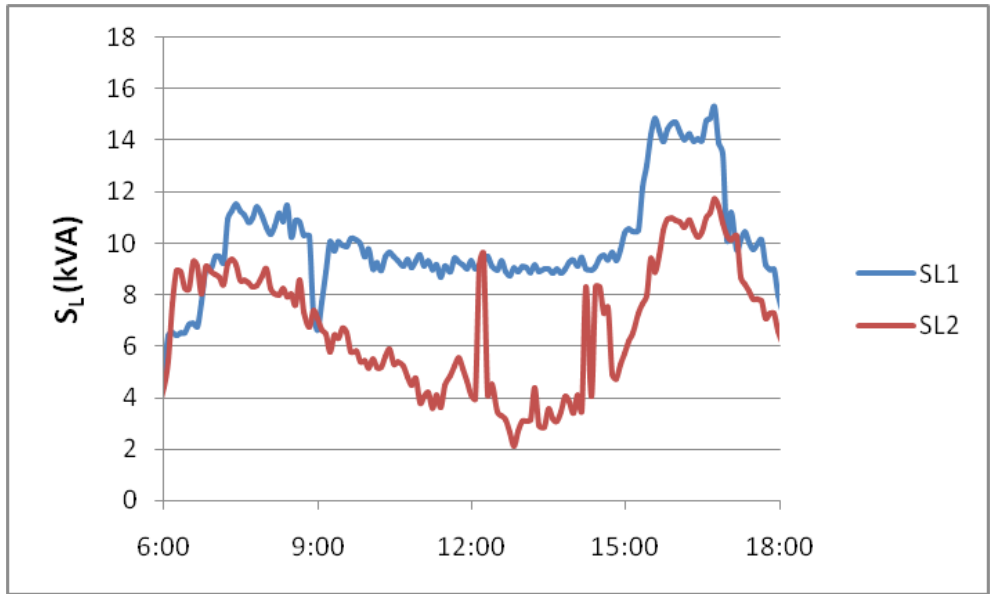

Figura 79-Potência aparente - ECR (dias 1 e 2)

\subsection{2 - Dias 3 e 4 - Nível de excitação de 4 kvar}

Os procedimentos descritos na seção anterior foram repetidos em mais dois dias consecutivos, que são chamados dias 3 e 4 (com um intervalo de 6 dias para os testes anteriores, pois houve uma interrupção nos ensaios devido ao mau tempo). Porém, diminuiuse o nível de excitação dos inversores para 4 kvar.

As figuras 80 e 81 mostram, respectivamente, as irradiâncias e as potências geradas pelo SUBSISTEMA 1 nos dias 3 e 4.

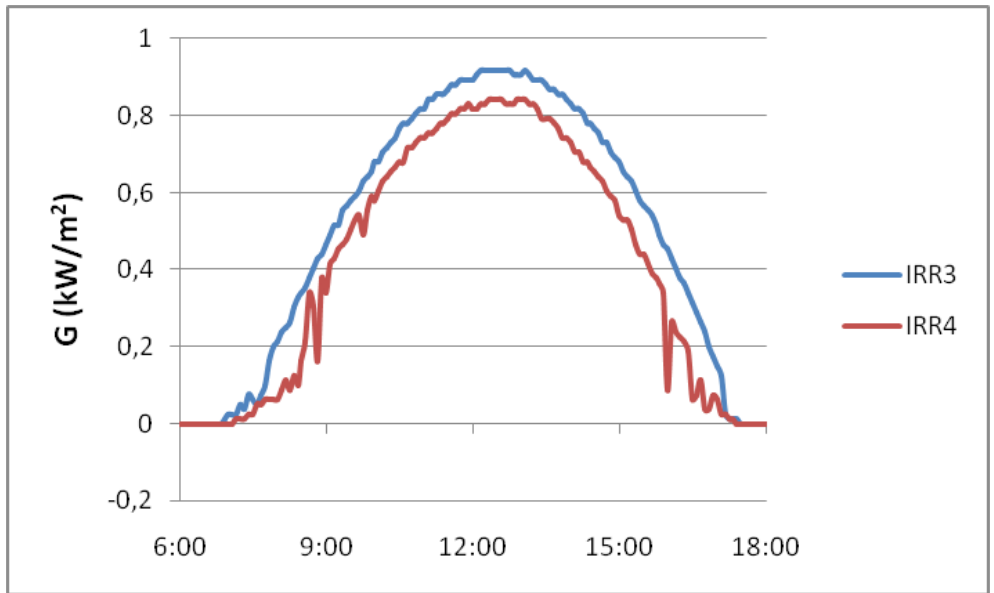

Figura 80-Irradiância - ECR (dias 3 e 4) 


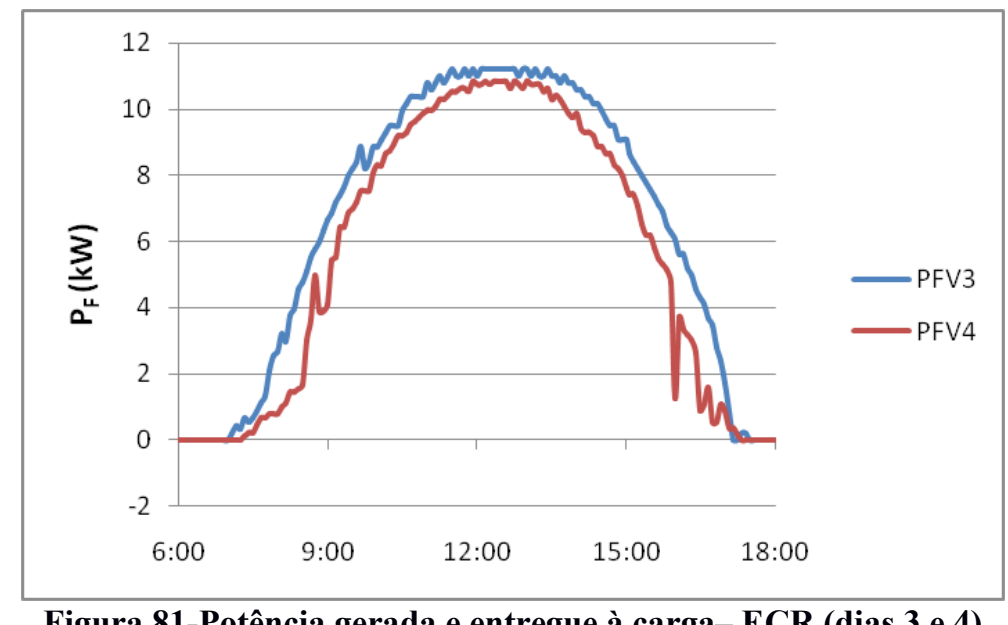

Figura 81-Potência gerada e entregue à carga- ECR (dias 3 e 4)

A exemplo dos testes anteriores, não se conseguiu perfís idênticos de irradiância nos dias 3 e 4. Porém a produção do sistema fotovoltaico pode ser considerada satisfatória nos dois dias, no que se refere ao objetivo de demonstrar a viabilidade da ação de compensação que é demonstrada na sequência.

Mais importante que essa pequena diferença na produção fotovoltaica nos dias 3 e 4 é o fato de que as curvas de demanda da carga $\mathrm{P}_{\mathrm{C}}$ (figura 82) e da demanda líquida $\mathrm{P}_{\mathrm{L}}$ (figura 83) são novamente semelhantes, como também ocorreu nos dias 1 e 2.

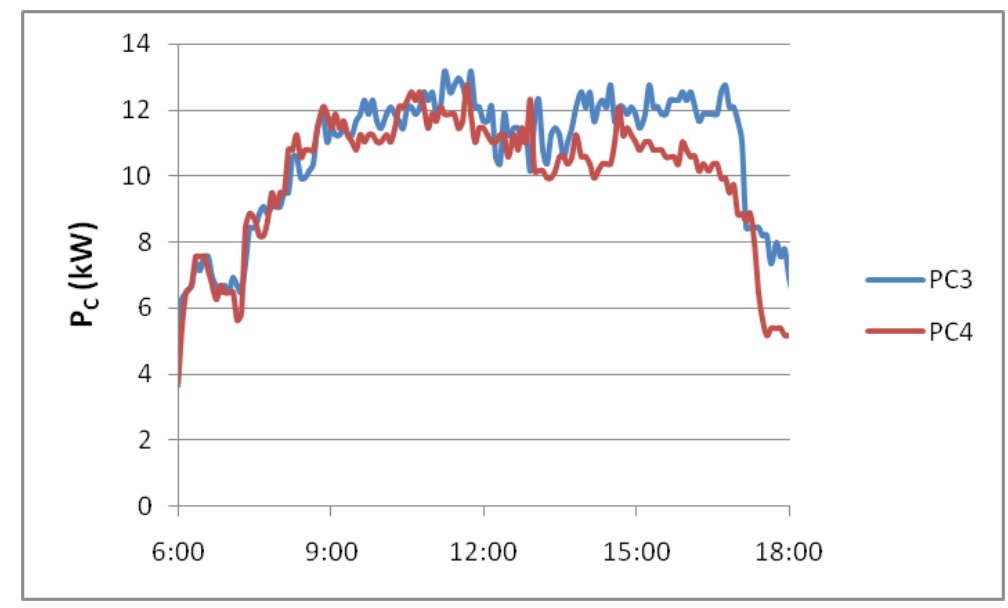

Figura 82-Curva de demanda ativa da carga - ECR (dias 3 e 4) 


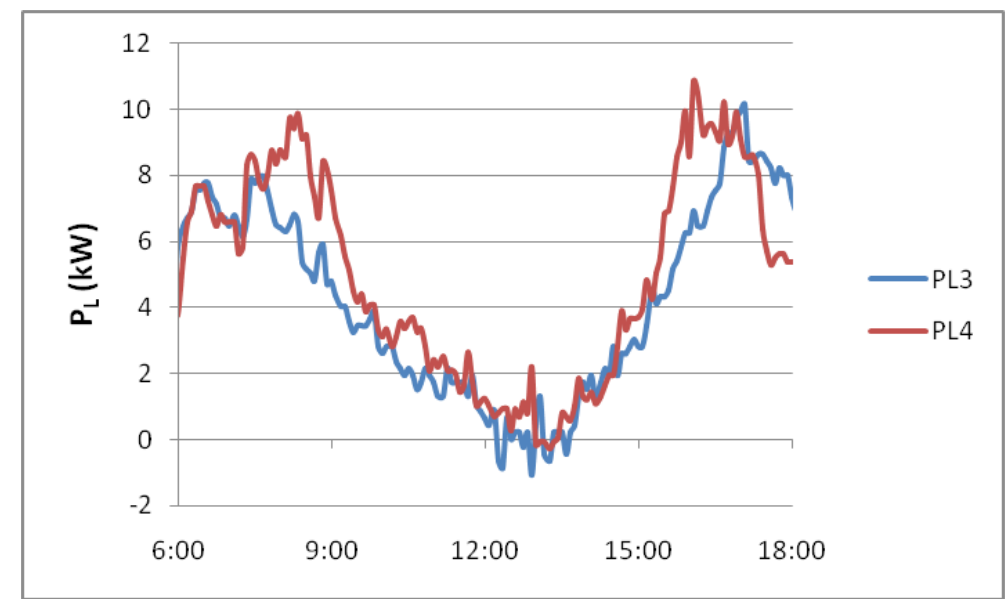

Figura 83-Curva de demanda ativa líquida - ECR (dias 3 e 4)

Um detalhe importante é que a depressão na curva da potência líquida foi mais acentuada nos dias 3 e 4 que nos dias 1 e 2, havendo inclusive momentos com exportação de pequenas quantidades de energia ativa para a rede elétrica, como no período próximo às 13 h00 do dia 3. A figura 84 ajuda a ilustrar esse fato.

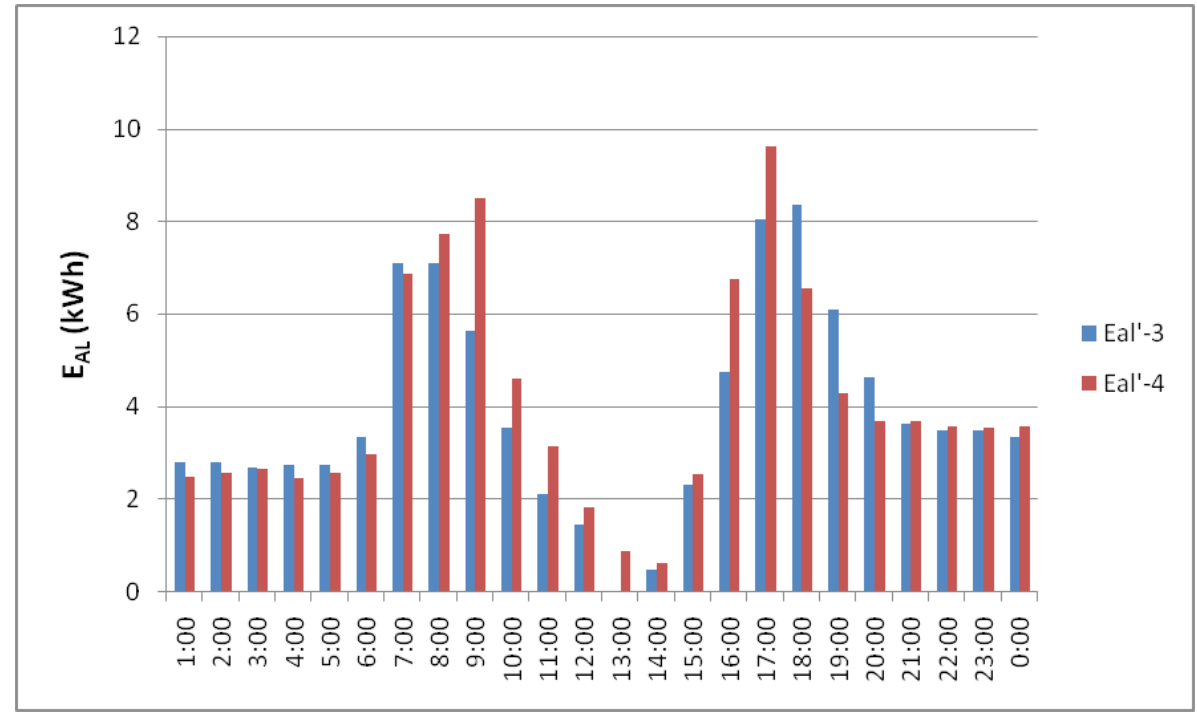

Figura 84-Consumo líquido horário de energia ativa - ECR (dias 3 e 4)

Ao se analisar as curvas de demanda reativa líquida $Q_{L}$ nos dias 3 e 4, nota-se novamente a predominância de um comportamento indutivo no dia 3 e um comportamento majoritariamente capacitivo no dia 4, demonstrando-se novamente os efeitos compensatórios inerentes à injeção de potência reativa pelo SUBSISTEMA 1 no dia 4, o que não ocorreu no dia 3. 


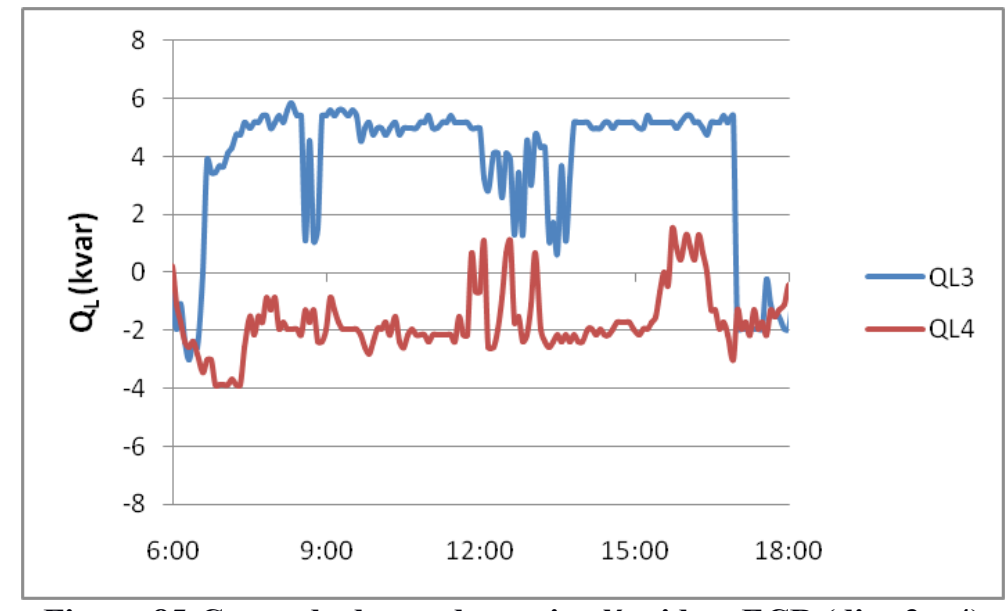

Figura 85-Curva de demanda reativa líquida - ECR (dias 3 e 4)

Da figura 86, observa-se que, mesmo apresentando um caráter indutivo no dia 3, o fator de potência efetivo expresso através da curva FPEF3 manteve-se em níveis elevados (acima de 0,92) na maior parte do tempo, diferindo, portanto, da situação identificada na seção anterior, quando no dia 1 a subexcitação exagerada do inversor do SUBSISTEMA 2 provocou um impacto maior no fator de potência. Porém, como é conhecido, quando a medição é feita a partir do medidor da entrada do prédio o fator de potência apresenta-se deteriorado, como se pode notar pela curva FP3 da figura 86. Como o suprimento de energia ativa pela rede elétrica é praticamente nulo (ou até negativo) nos horários de maior produção solar, a depressão da curva do fator de potência torna-se ainda mais acentuada que aquela verificada no dia 1.

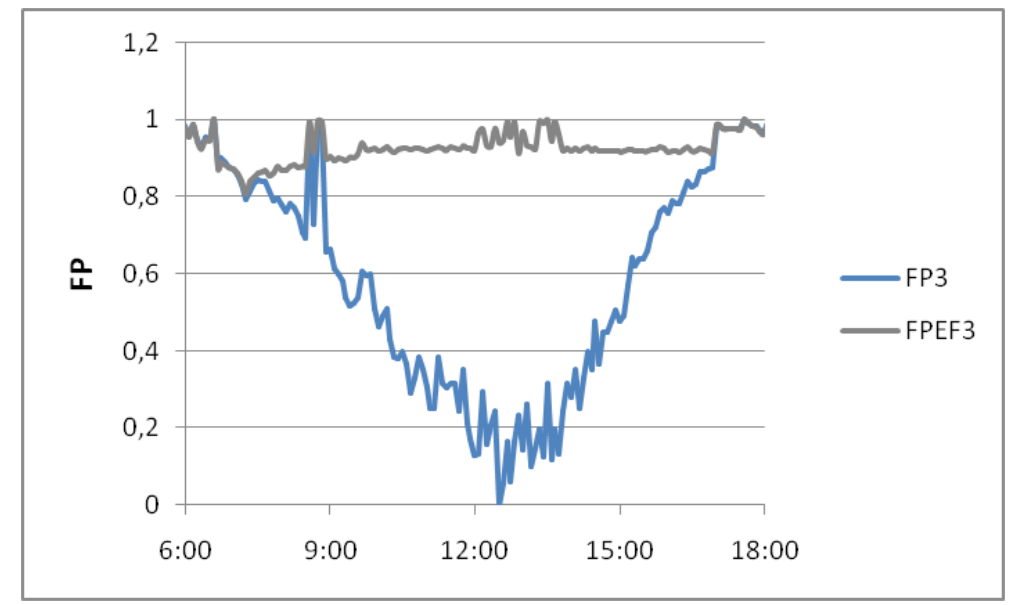

Figura 86-Fator de potência (5 em 5 min) - ECR (dia 3) 
Ao se analisar agora o fator de potência medido na entrada do prédio no dia 4 (curvas FP4 da figura 87 e fp'm - 4 da figura 88), pode-se julgar erroneamente que a ação compensatória do dia 4 não teve eficácia.

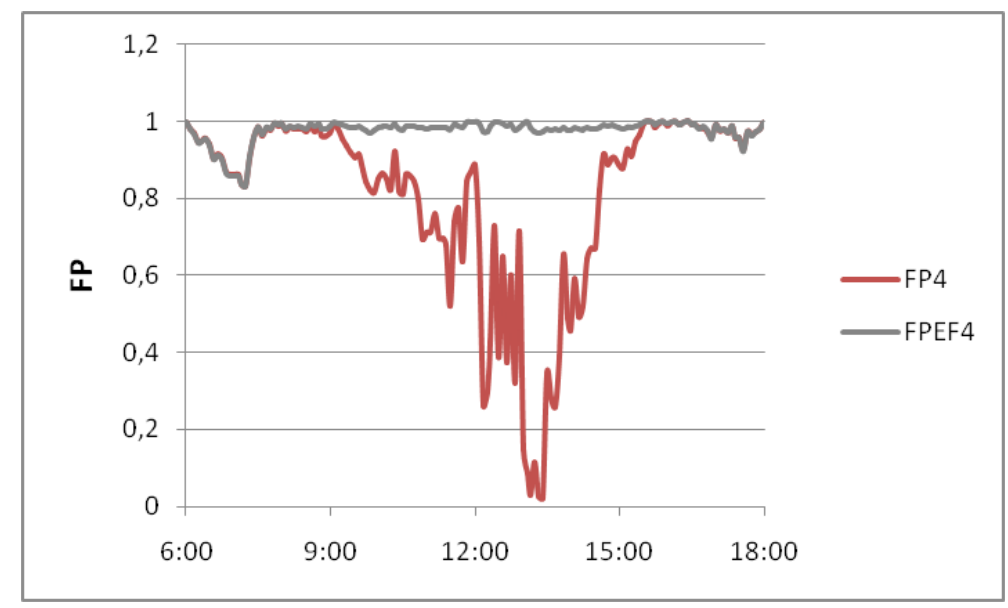

Figura 87-Fator de potência (5 em 5 min) - ECR (dia 4)

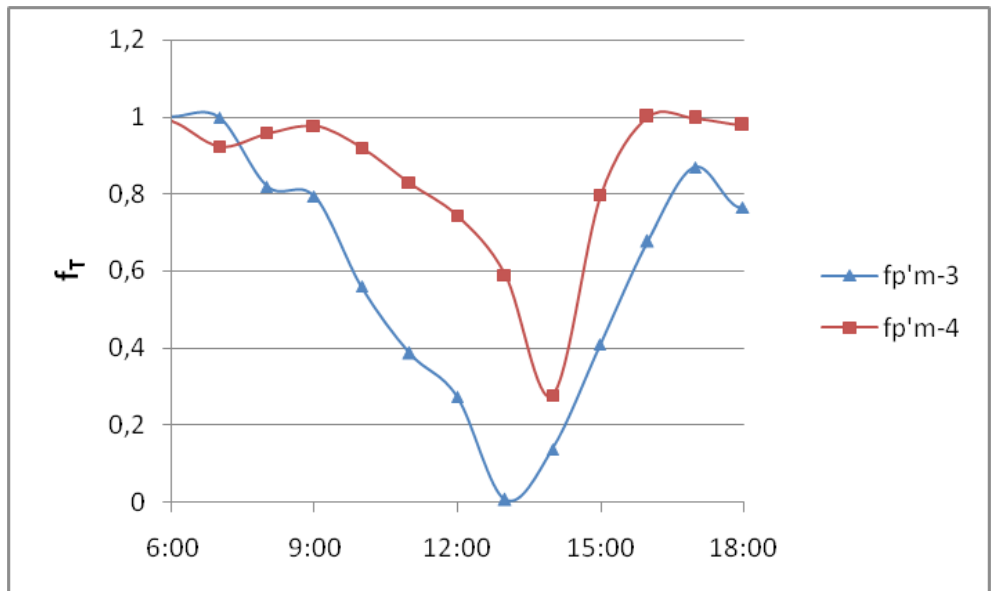

Figura 88-Fator de potência (1 em 1 hora) - ECR (dias 3 e 4)

Essa interpretação poderia surgir caso se analisassem apenas as curvas do fator de potência antes e depois da correção, pois não se conseguiu manter o fator de potência no dia 4, medido a partir da entrada do prédio, próximo do valor de referência.

Porém, quando se analisa o impacto da ação de compensação na curva de energia reativa excedente $E_{R E}$, verifica-se uma economia de cerca de $R \$ 8,40$, referente ao valor que seria pago caso nenhuma ação compensatória fosse implementada no dia 4. A figura 89 mostra os valores, em reais, referentes à energia reativa excedente de hora em hora. 


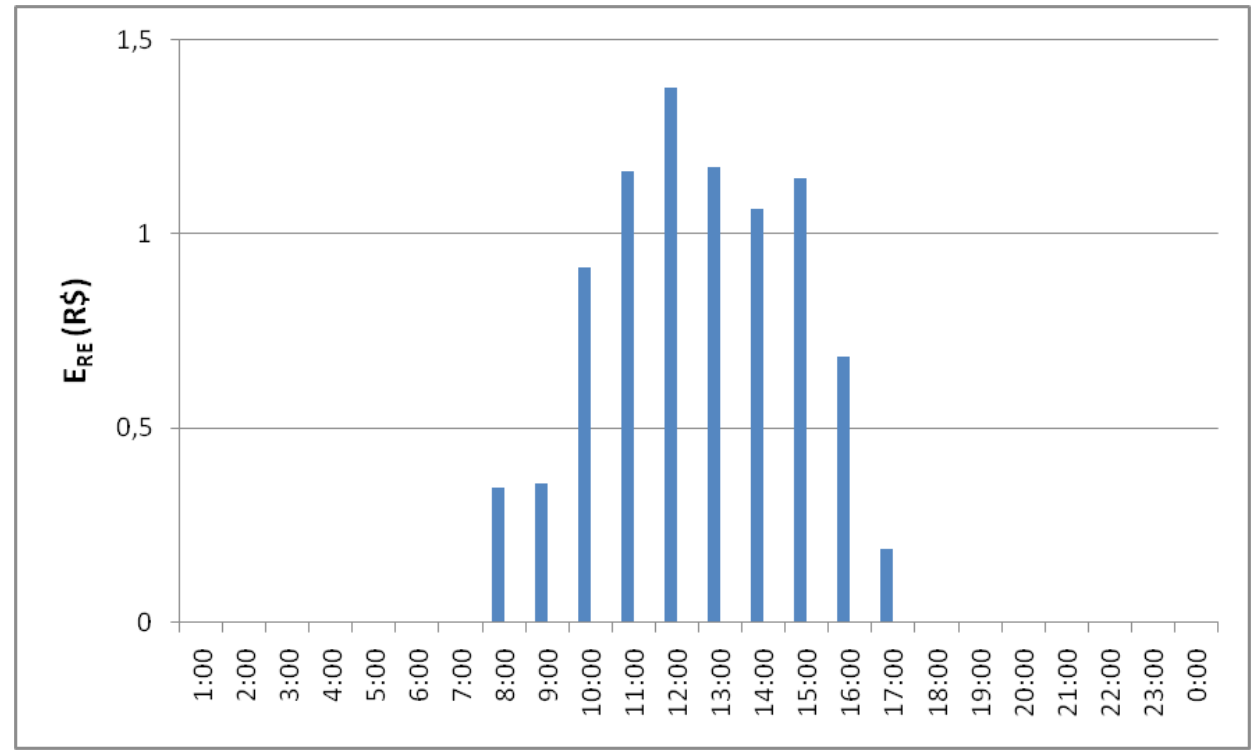

Figura 89- Energia reativa excedente - ECR (dia 3)

Do ponto de vista elétrico, os baixos valores de fator de potência apresentados, mesmo após a compensação de reativos, se analisados isoladamente, poderiam sugerir um uso ineficiente do sistema elétrico. Porém, ao se verificar a curva da potência aparente que trafega entre o alimentador da concessionária e a entrada do prédio, nota-se novamente a liberação de capacidade do sistema após a ação corretiva (dia 4), a exemplo do que já havia ocorrido no dia 2.

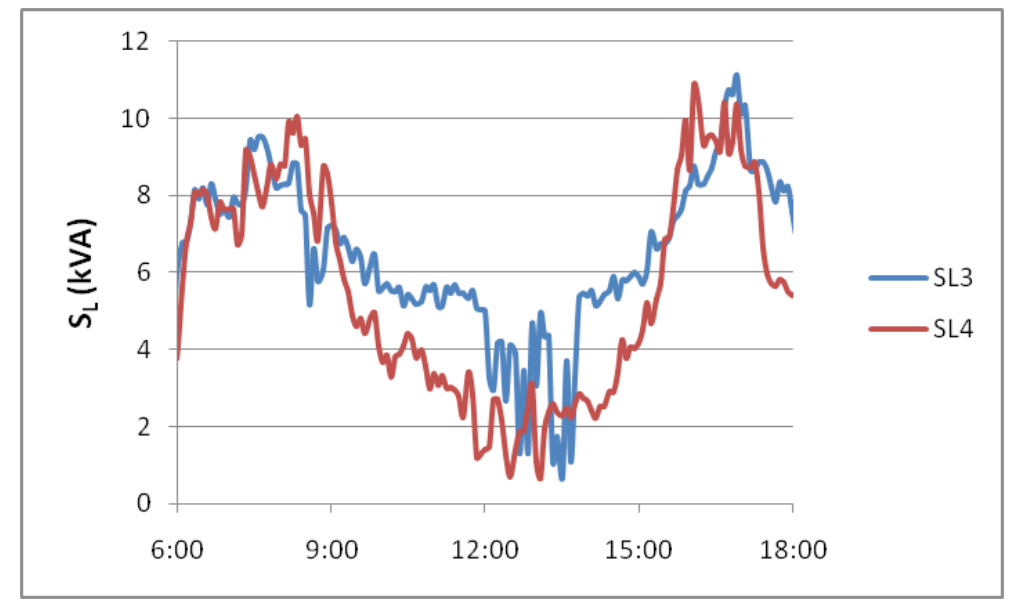

Figura 90-Potência aparente - ECR (dias 3 e 4)

Pode-se complementar essa afirmação com a análise da curva FPEF4 da figura 87, 
quando fica evidente que se toda a potência ativa exigida pela carga fosse suprida pela concessionária, o fator de potência medido pelo seu medidor no dia 4 ficaria estável e próximo da unidade praticamente o dia todo, o que indica que os níveis de energia reativa injetada na rede não são considerados prejudiciais ao sistema.

\subsection{Resultados dos ensaios de avaliação dos modos capacitivo e indutivo (EAMCI)}

Os resultados dos ensaios de compensação de reativos mostraram-se promissores ao minimizarem a cobrança pela energia reativa excedente que se verificaria caso nenhuma ação compensatória fosse implementada, além de outros benefícios, como a liberação de capacidade no sistema elétrico.

Mas, uma vez que o inversor está limitado pela potência aparente máxima que é capaz de processar, uma pergunta que necessita de resposta é: qual o impacto do fornecimento de energia reativa sobre a produção de energia ativa e, consequentemente, ao tempo de retorno do investimento no sistema fotovoltaico?

Para responder a essa pergunta é que programou-se o terceiro bloco de ensaios, no qual o inversor do SUBSISTEMA 1 foi monitorado por três dias consecutivos de céu limpo, estando configurado no modo normal (fator de potência unitário) no primeiro dia, no modo capacitivo no segundo dia (entregando uma quantidade fixa de potência reativa igual ao limite estabelecido na NBR 16149:2013 para esse modelo de inversor) e no modo indutivo no terceiro dia (demandando uma quantidade fixa de potência reativa também igual ao limite da NBR 16149:2013). Os resultados dos testes são apresentados a seguir.

\subsection{1 - Modo normal versus modo capacitivo}

A figura 91 mostra as curvas de irradiância obtidas nos dois dias consecutivos em que o inversor do SUBSISTEMA 1 foi testado nos modos normal e capacitivo, respectivamente. As curvas têm um aspecto ligeiramente diferente, com momentos em que uma se sobressai em relação à outra, em termos da radiação solar incidente no plano do gerador. 
Entretanto, o mesmo se aplica às curvas da potência gerada $\mathrm{P}_{\mathrm{FV}}$, conforme se observa na figura 92, de forma que o pequeno incremento do recurso solar no segundo dia foi acompanhado de um acréscimo proporcional de produtividade, de forma que o desempenho do sistema foi praticamente idêntico durante os dois dias.

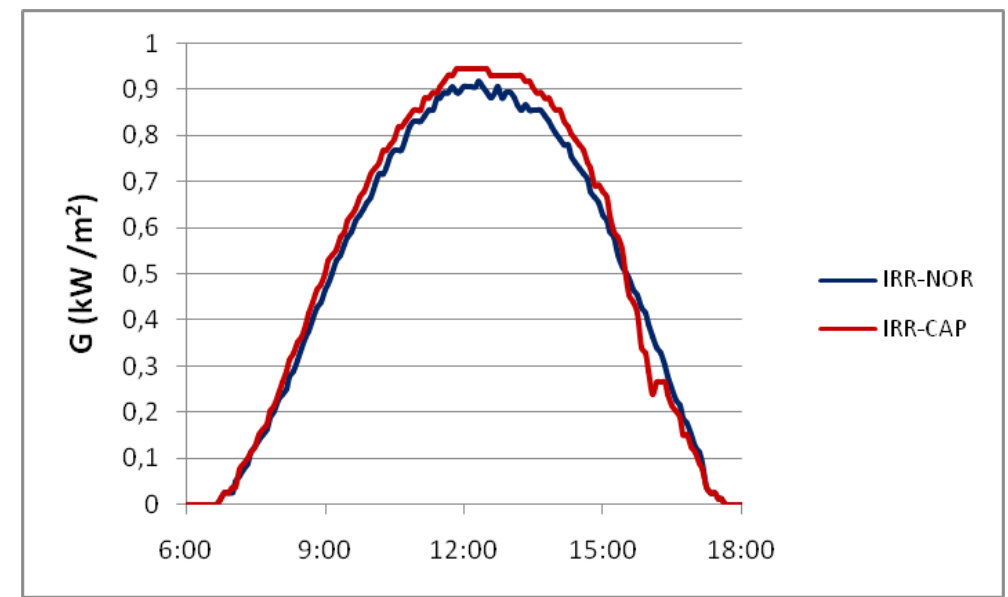

Figura 91-Irradiância - EAMCI (normal versus capacitivo)

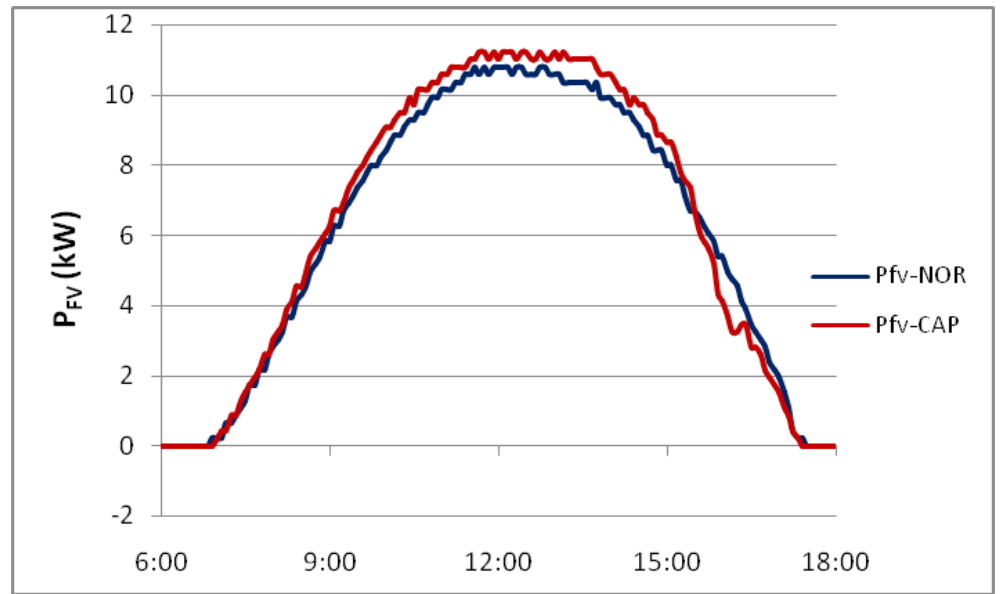

Figura 92- Potência ativa na saída do inversor- EAMCI (normal versus capacitivo)

Os valores numéricos dos resultados obtidos encontram-se na tabela 6. Optou-se por fornecer os resultados para a energia entregue no ponto de conexão e, portanto, os números já consideram as perdas no rebaixamento de tensão pelo transformador e no cabeamento dos circuitos que conectam os equipamentos do telhado ao quadro geral. 
Tabela 6-Resumo dos indicadores de desempenho - EAMCI (normal versus capacitivo)

\begin{tabular}{ccccc}
\hline Teste & $\mathbf{H}\left(\mathbf{k W h} / \mathbf{m}^{\mathbf{2}}\right)$ & $\mathbf{E}_{\text {p.conexão }}(\mathbf{k W h})$ & $\mathbf{P R}_{\text {p.conexão }}(\mathbf{\%})$ & PR $_{\text {STCp.conexão }}(\mathbf{\%})$ \\
\hline Normal & 5,95 & 73,6 & 79,3 & 86,0 \\
Capacitivo & 6,17 & 76,2 & 79,2 & 85,6 \\
\hline
\end{tabular}

A figura 93 mostra o comportamento da temperatura dos módulos nos dois dias de ensaios.

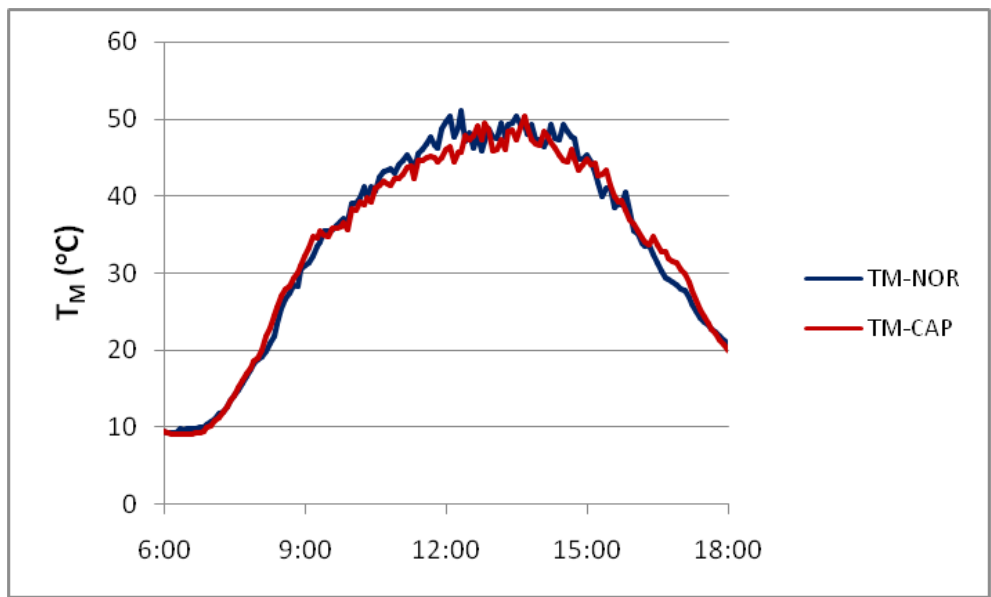

Figura 93-Temperatura dos módulos - EAMCI (normal versus capacitivo)

De posse dos dados de temperatura e da irradiância no plano do gerador, realizou-se uma pequena modificação no modelo matemático representado pela equação (66) deste capítulo, que foi basicamente a inserção do parâmetro $\eta_{T R}$, referente às perdas já citadas no transformador rebaixador e no cabeamento até o quadro geral, chegando-se à equação (67) para a potência entregue no ponto de conexão.

$$
P_{p . \text { conexão }}=P_{F V}^{0} \frac{G_{t}}{G_{0}}\left[1-\gamma_{m p}\left(T_{C}-25^{\circ} C\right)\right] \eta_{S P M P} \eta_{C O N V} \eta_{T R}
$$

Adotando-se o valor $\eta_{T R}=0,93$ (obtido experimentalmente - ver tabela 4 da seção 3.1.1 ) e mantendo-se os demais parâmetros idênticos aos da referida seção, foram obtidas as curvas calculadas, PC-NOR e PC-CAP, para os dois dias consecutivos, as quais foram plotadas com as respectivas curvas medidas nas figuras 94 e 95. 


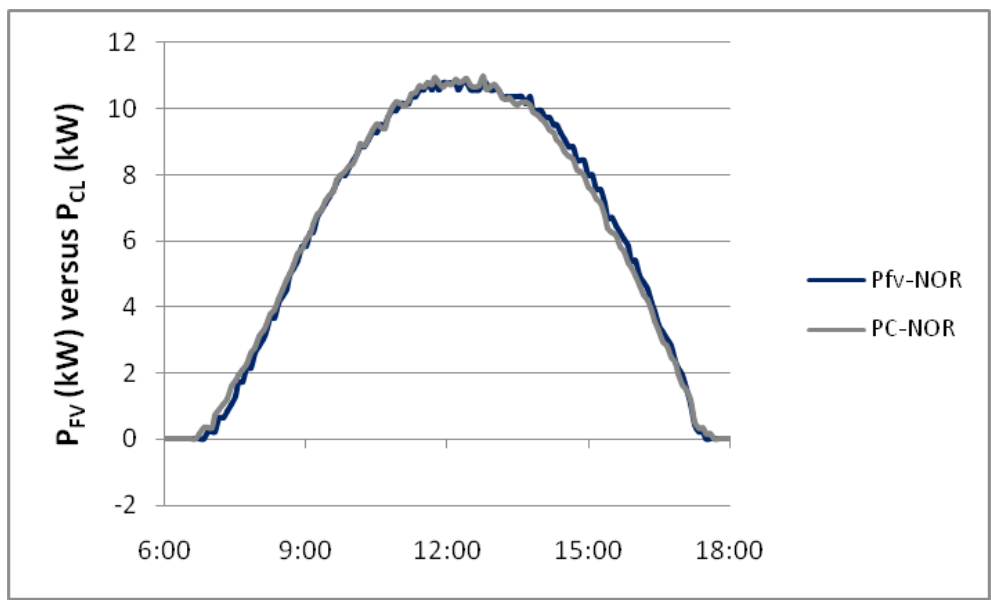

Figura 94-Potências medida (Pfv) e calculada (PC) - EAMCI (normal)

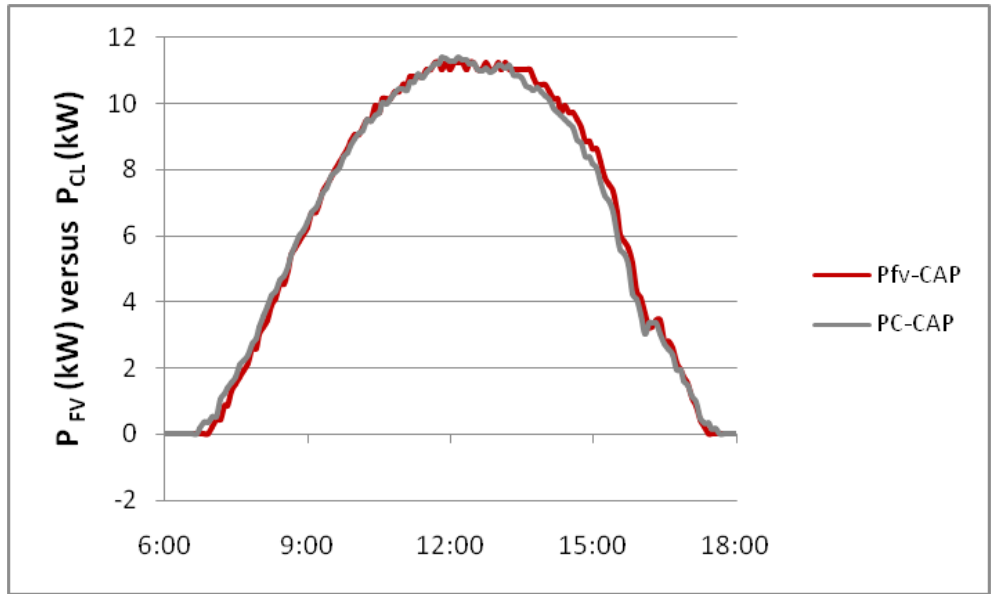

Figura 95-Potências medida (Pfv) e calculada (PC) - EAMCI (capacitivo)

Observa-se, nos dois gráficos anteriores, que a produção nos dois dias esteve de acordo com aquela prevista teoricamente para as condições ambientais e para as tecnologias de conversão empregadas. Essa análise comprova, assim, que o inversor não tem sua produção de potência ativa afetada se a produção de potência reativa estiver dentro dos limites estabelecidos na NBR 16149:2013.

Para atestar que o inversor de fato forneceu potência reativa no segundo dia, foram construídos os gráficos das figuras 96 e 97, que mostram, respectivamente, as curvas de potência reativa $\mathrm{Q}_{\mathrm{FV}}$ e aparente $\mathrm{S}_{\mathrm{FV}}$ nos modos normal e capacitivo. Percebe-se que o SUBSISTEMA 1, que teoricamente deveria ter sua curva de potência reativa próxima de zero quando operando no modo normal, apresenta uma demanda mínima de reativos, que está entre 0,5 e 0,8 kvar, que deve estar associada à magnetização do transformador rebaixador. 


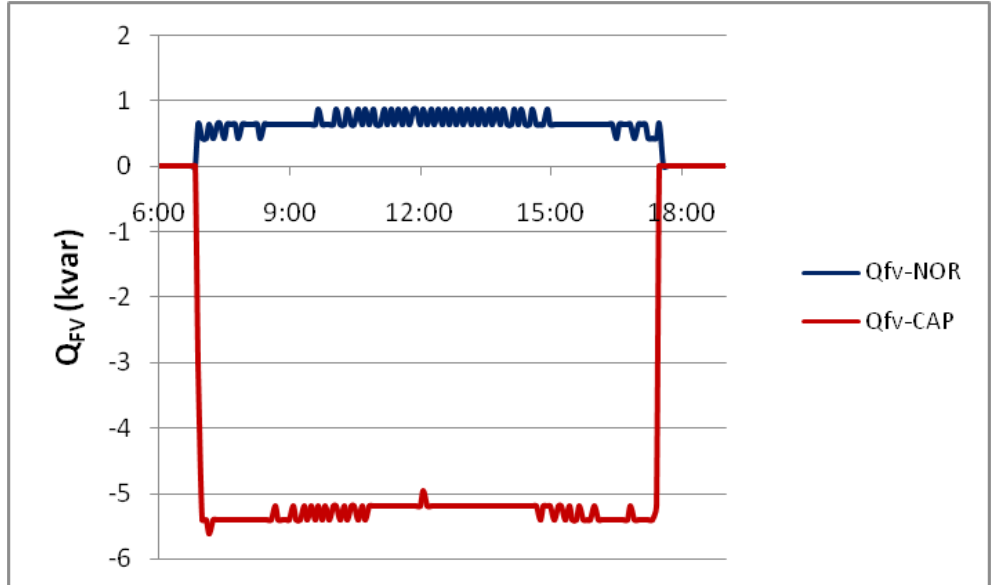

Figura 96- Potência reativa na saída do inversor - EAMCI (normal versus capacitivo)

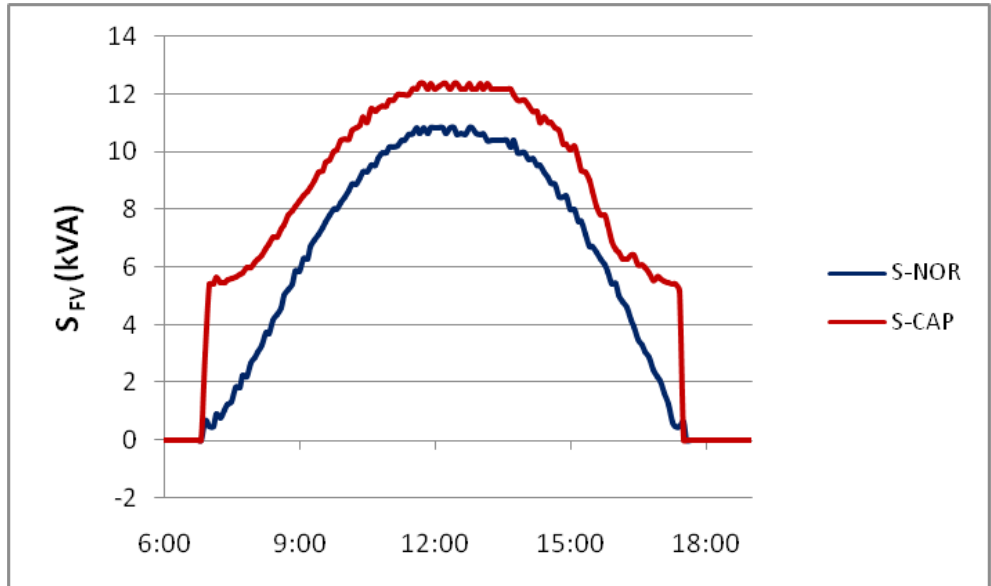

Figura 97-Potência aparente na saída do inversor - EAMCI (normal versus capacitivo)

É interessante notar o comportamento do fator de potência do sistema fotovoltaico nos modos normal e capacitivo (figuras 98 e 99, respectivamente). O sistema opera com fator de potência muito próximo da unidade, quando no modo normal. Já no ensaio no modo capacitivo, como a potência reativa entregue pelo sistema foi fixada, o fator de potência varia ao longo do dia. Nesse caso, como o fator de potência do sistema fotovoltaico aumenta à medida que potência ativa entregue pelo sistema também aumenta, o formato da figura 99 acompanha a geração solar. 


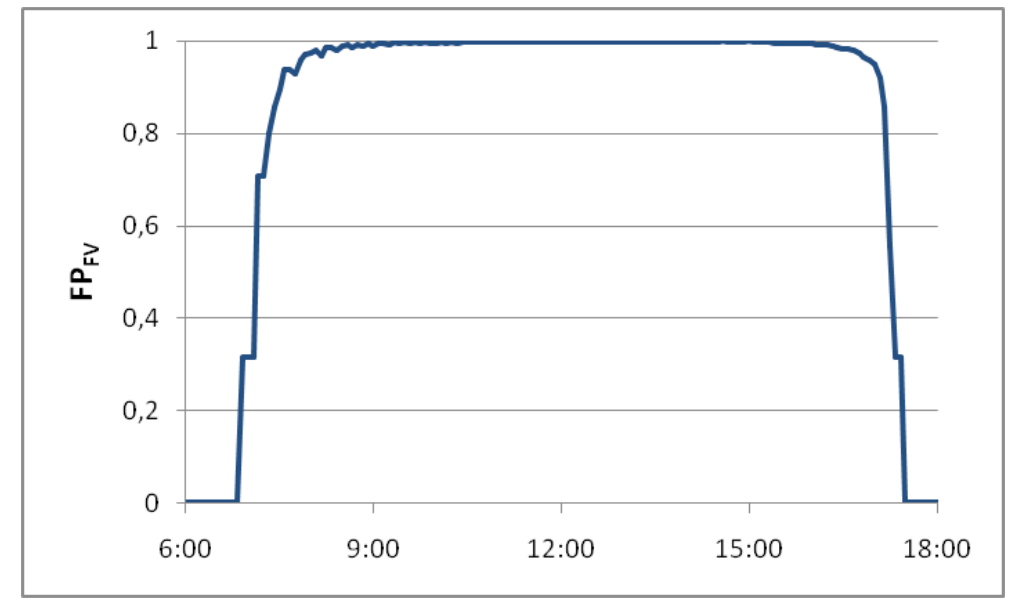

Figura 98- Fator de potência do sistema fotovoltaico no modo normal

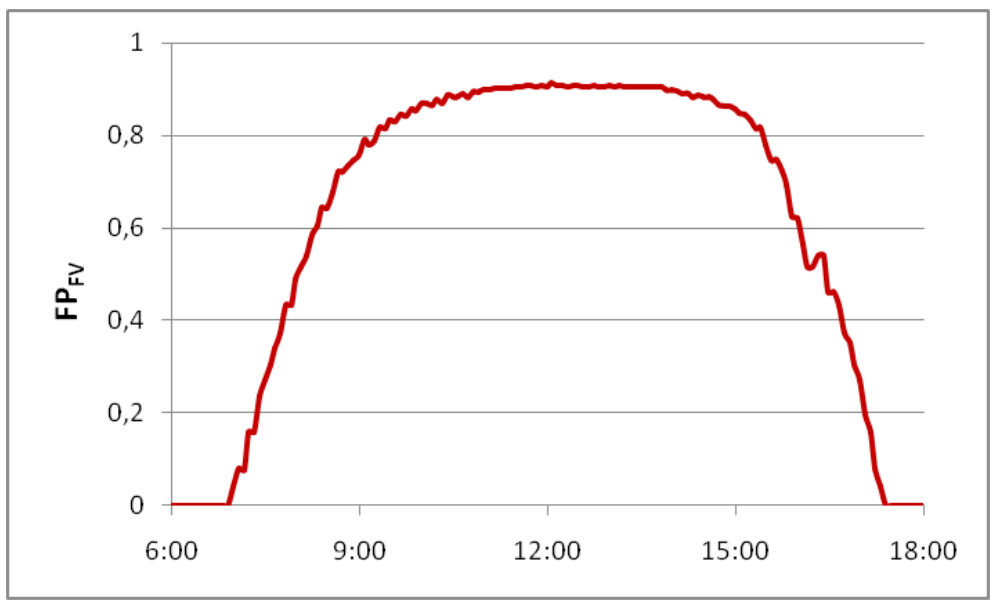

Figura 99-Fator de potência do sistema fotovoltaico no modo capacitivo

Um detalhe importante é que os testes dos modos normal e capacitivo mostrados logo acima foram feitos em um sábado e um domingo consecutivos, dias não úteis para o prédio da Administração do IEE-USP. Esse fato criou uma ótima oportunidade para se avaliar os impactos da produção de reativos pelo inversor na tensão no ponto de conexão e também no secundário do alimentador da rede elétrica, visto que nos fins de semana o perfil de consumo do prédio é sempre muito parecido (se fossem realizados em dias úteis, os testes não seriam capazes de distinguir os impactos provocados pelo sistema fotovoltaico daqueles provocados pela carga, que é muito dinâmica durante o horário comercial).

As figuras 100 a 102 apresentam as curvas de demanda de potência ativa da carga para 
os seguintes dias, respectivamente: dia do ensaio em modo normal, dia do ensaio em modo capacitivo e um outro dia de final de semana com o sistema fotovoltaico (SFV) desligado, utilizado apenas como referência.

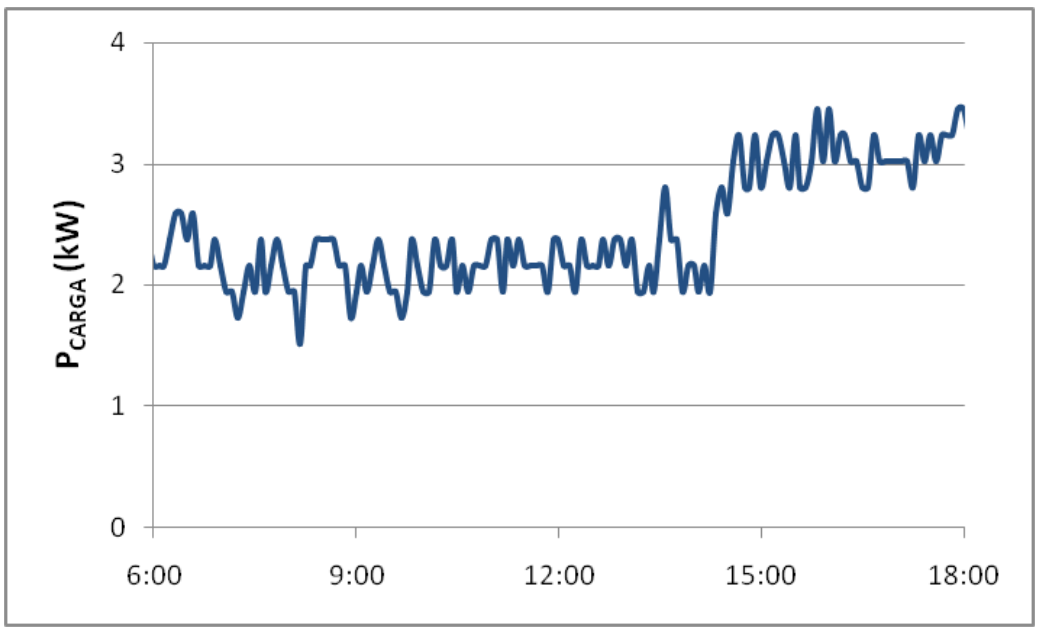

Figura 100- Curva de potência ativa da carga - modo normal

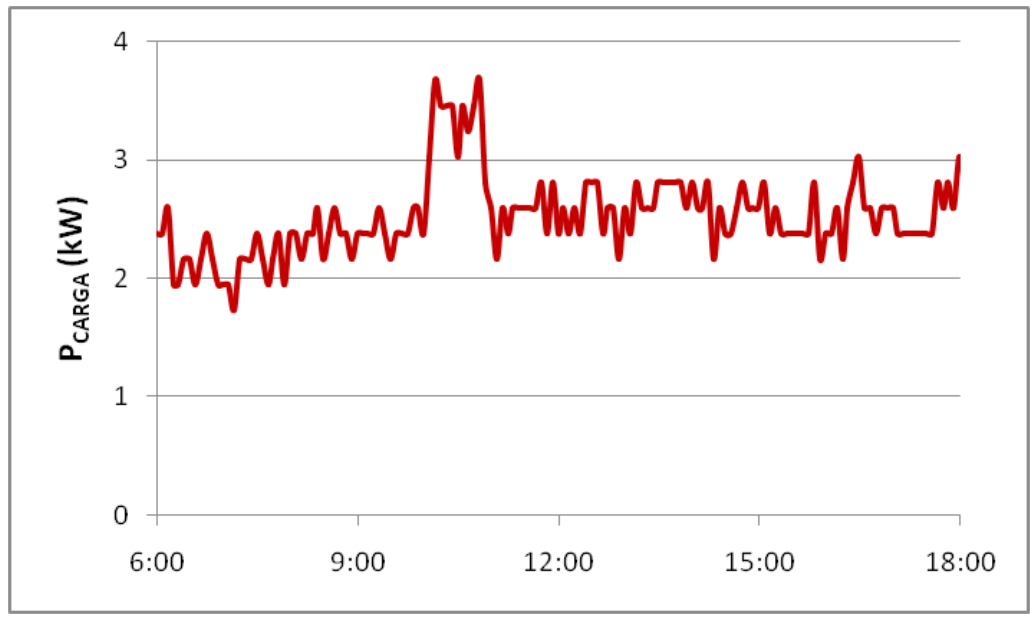

Figura 101-Curva de potência ativa da carga - modo capacitivo

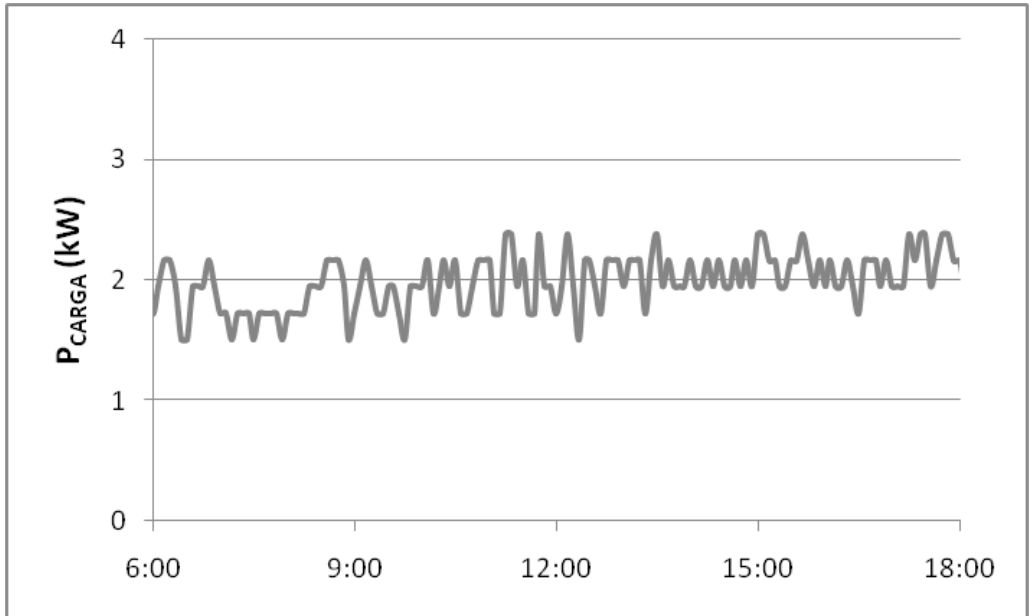

Figura 102-Curva de potência ativa da carga - SFV desligado 
Nota-se que, nesses três dias, na maior parte do tempo a potência ativa demandada ficou entre $2 \mathrm{~kW}$ e $3 \mathrm{~kW}$, um valor bastante inferior ao que seria observado em um dia útil.

As curvas de demanda de potência reativa da carga, para os mesmos três dias, podem ser vistas nas figuras 103 a 105.

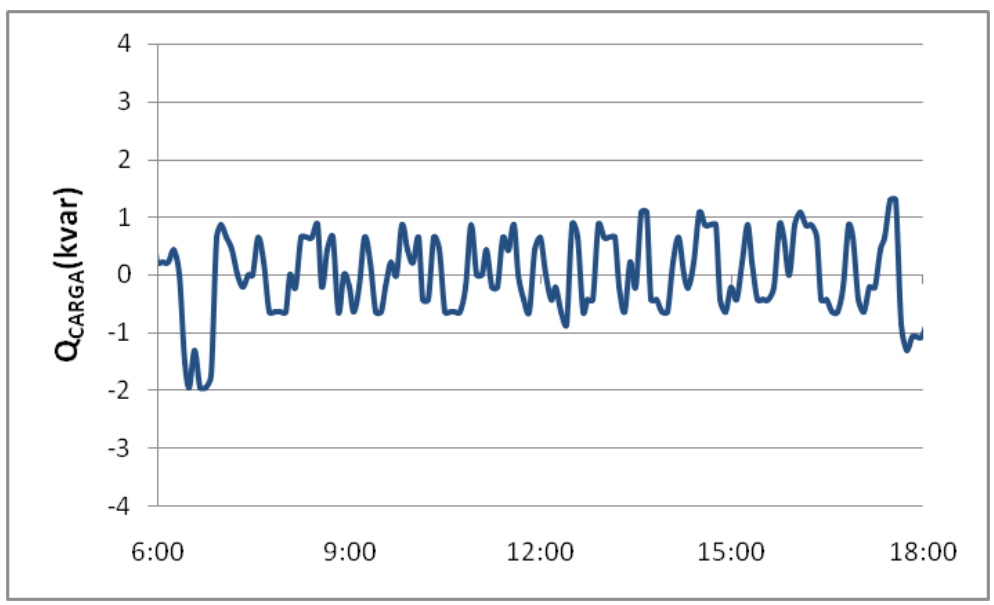

Figura 103- Curva de potência reativa da carga -modo normal

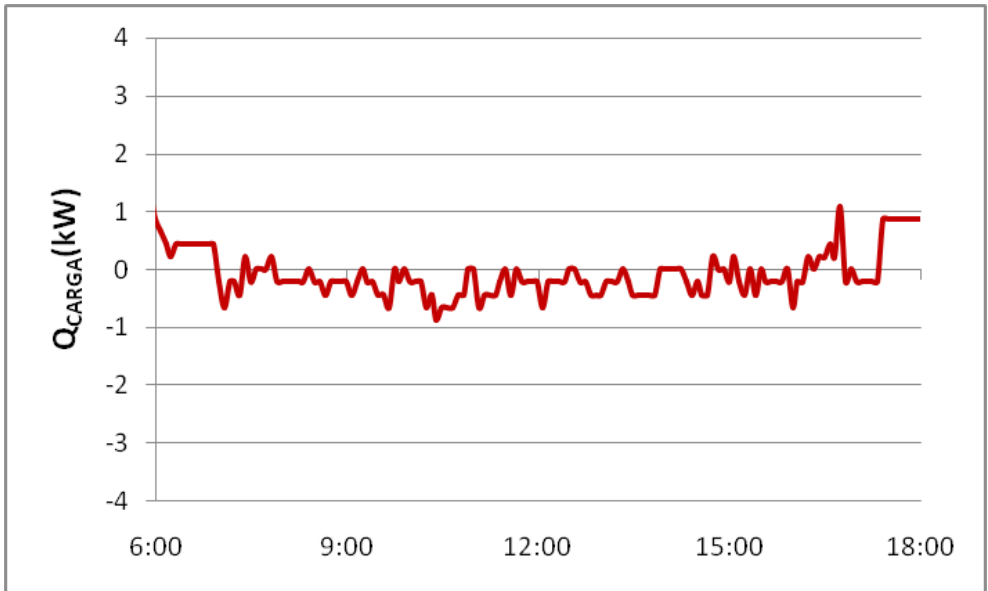

Figura 104-Curva de potência reativa da carga -modo capacitivo

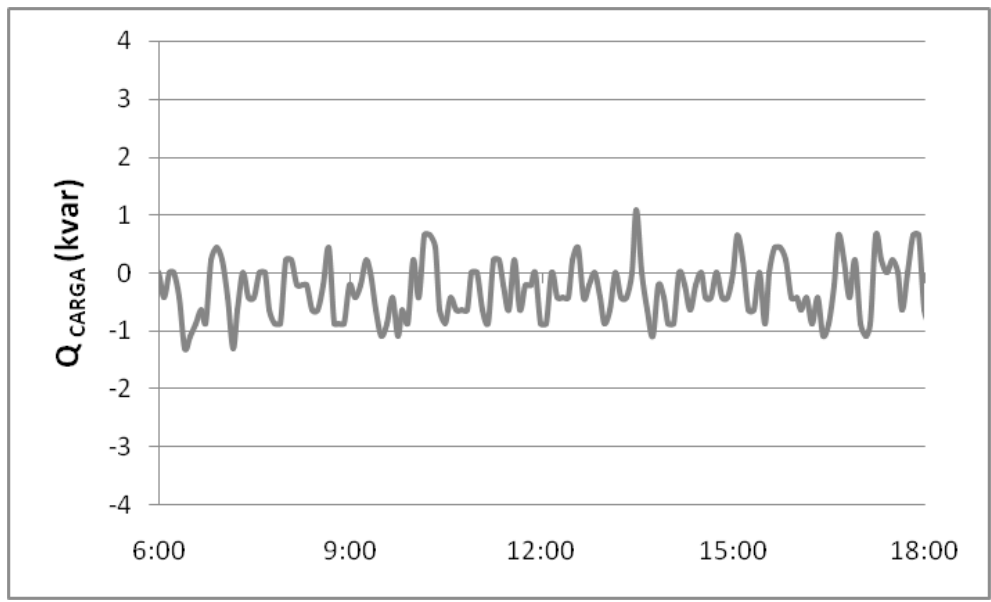

Figura 105-Curva de potência reativa da carga - SFV desligado 
Novamente, as três curvas apresentam um aspecto semelhante, com uma demanda relativamente pequena de reativos, comparativamente a um dia útil, com um perfil oscilando entre capacitivo e indutivo ao longo do dia.

Uma vez que ficou comprovada a semelhança entre as curvas de demanda de potência ativa e reativa da carga, nos três dias analisados, pode-se finalmente avaliar possíveis impactos, em termos de tensão, decorrentes da injeção de reativos pelo inversor do sistema fotovoltaico.

As figuras 106 a 108 apresentam as curvas das tensões entre cada fase e o neutro, nos três dias.

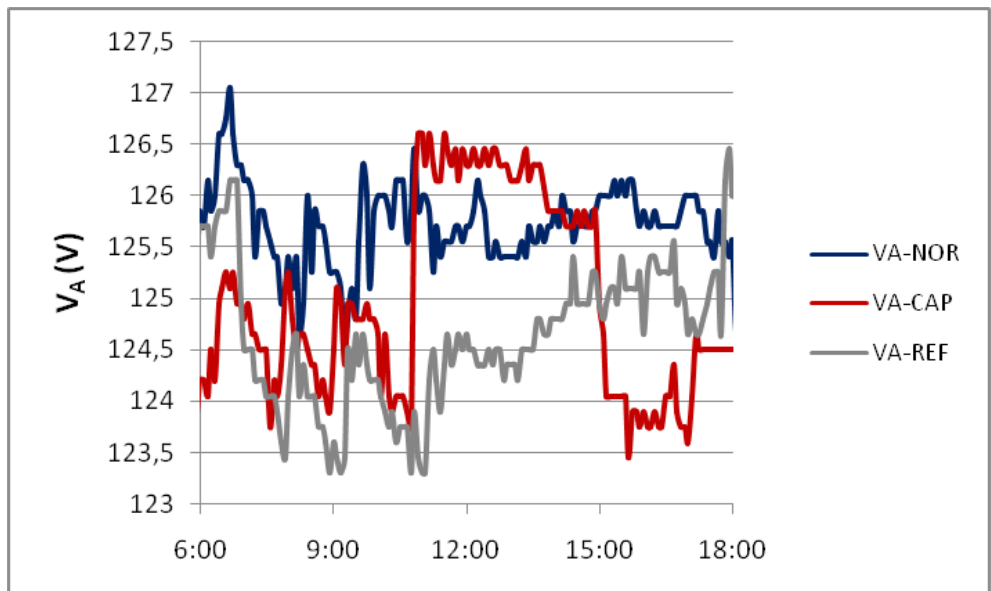

Figura 106- Tensão fase A/neutro no ponto de conexão - (normal versus capacitivo)

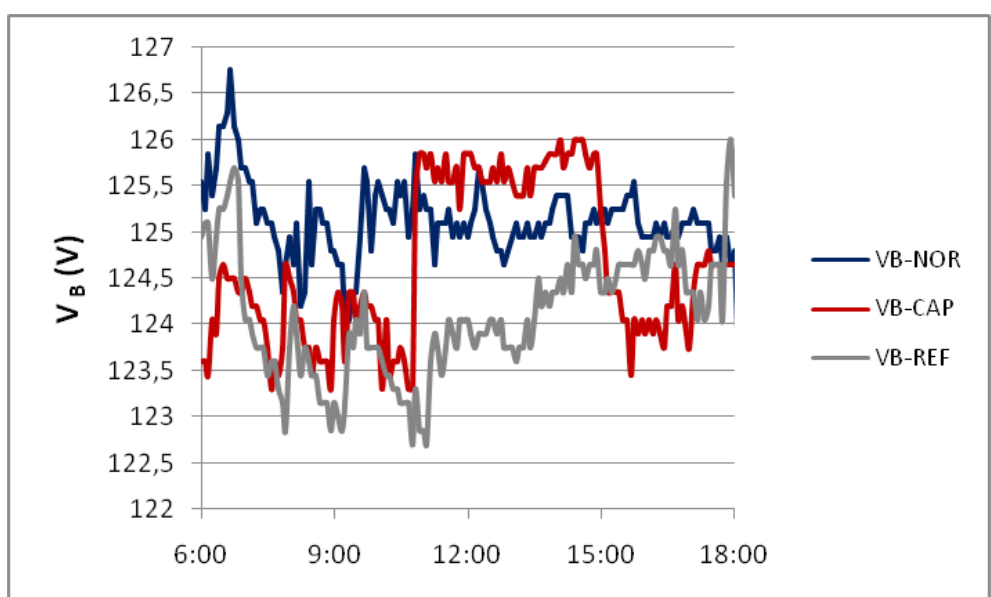

Figura 107-Tensão fase $B$ /neutro no ponto de conexão - (normal versus capacitivo) 


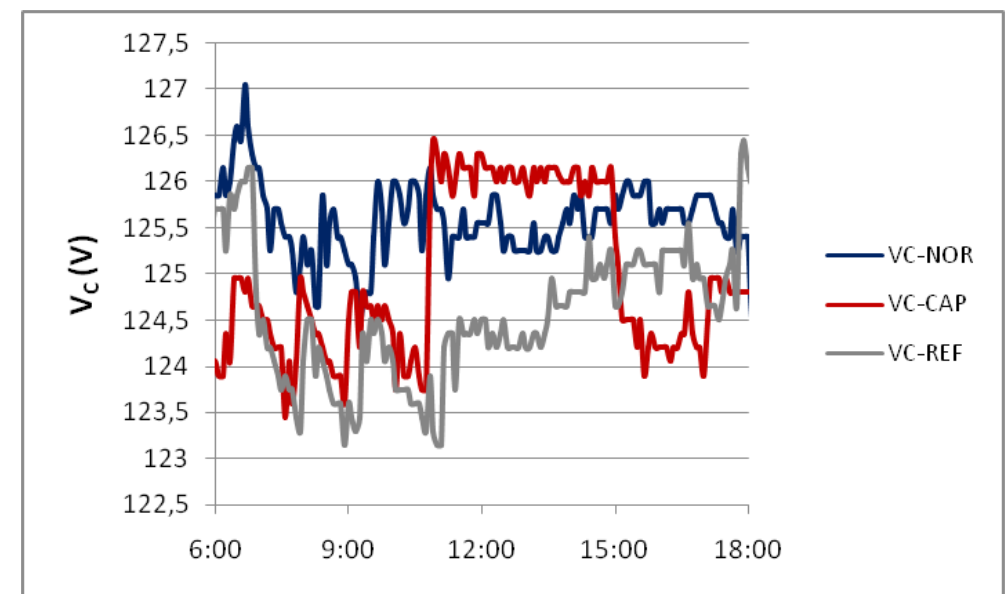

Figura 108-Tensão fase C/neutro no ponto de conexão - (normal versus capacitivo)

A operação do sistema fotovoltaico, mesmo que no modo normal, provoca uma pequena elevação de tensão no ponto de conexão, da ordem de $1 \mathrm{~V}$. Se ele estiver no modo capacitivo, essa elevação é distintamente maior - cerca de $2 \mathrm{~V}$. Porém, esses valores são irrisórios em termos de impactos sobre o sistema elétrico, quando se considera apenas uma UC cujas instalações elétricas estejam corretamente dimensionadas e cujo inversor atenda a norma brasileira de qualificação de inversores, como é o caso do sistema analisado.

As figuras 109 a 111 trazem as mesmas curvas, porém obtidas a partir do medidor ligado ao secundário do transformador alimentador da concessionária, nas quais se pode notar a mesma hierarquia dos níveis de tensão verificados no ponto de conexão, porém com uma diferença para menos de cerca de $0,5 \mathrm{~V}$, a qual deve estar associada a uma queda de tensão natural esperada para um percurso de cerca de 60 metros de cabos entre o secundário do transformador alimentador e o quadro geral.

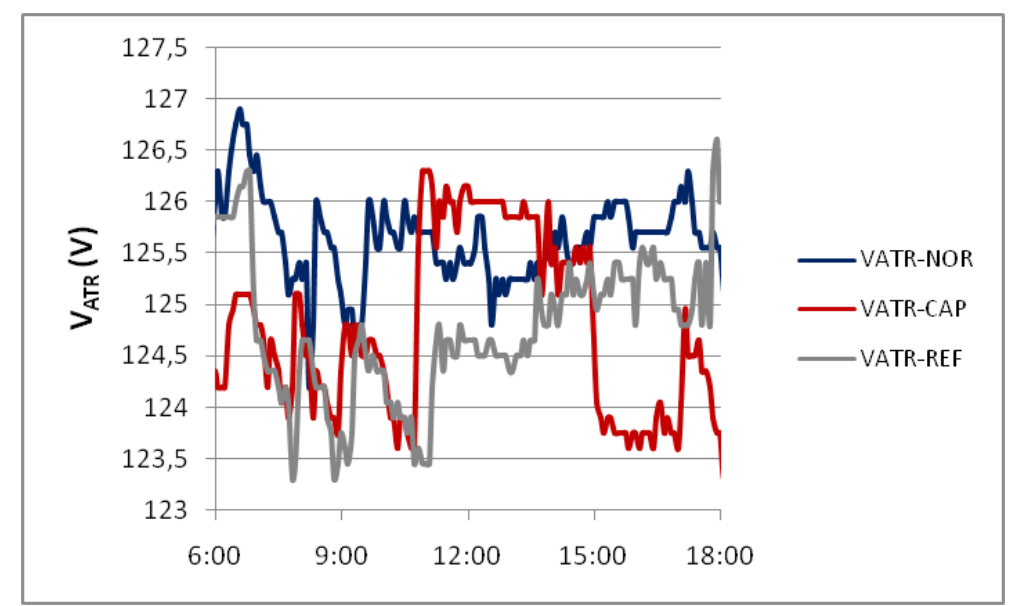

Figura 109-Tensão fase A/neutro no transformador - (normal versus capacitivo) 


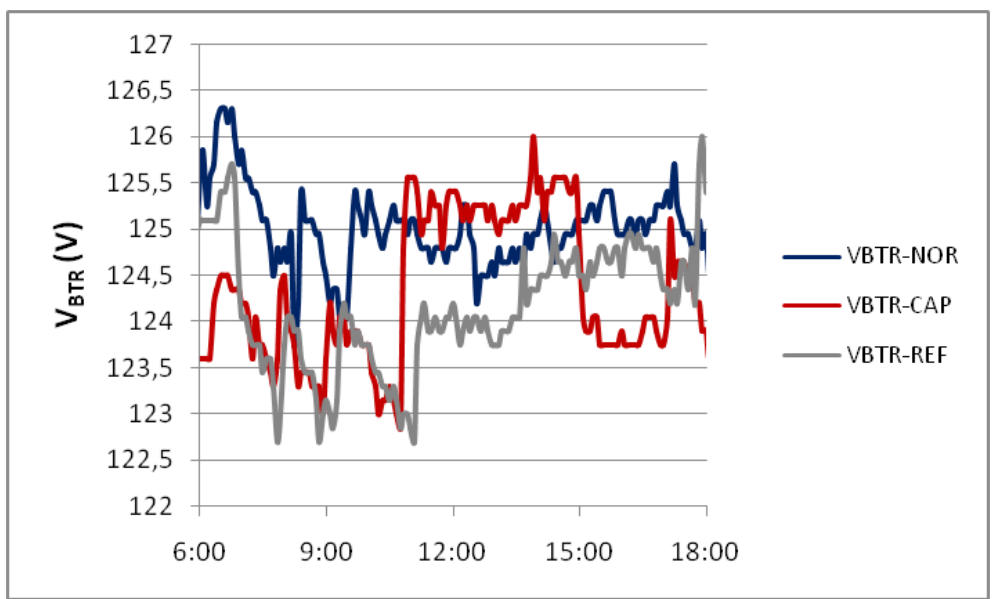

Figura 110-Tensão fase B/neutro no transformador - (normal versus capacitivo)

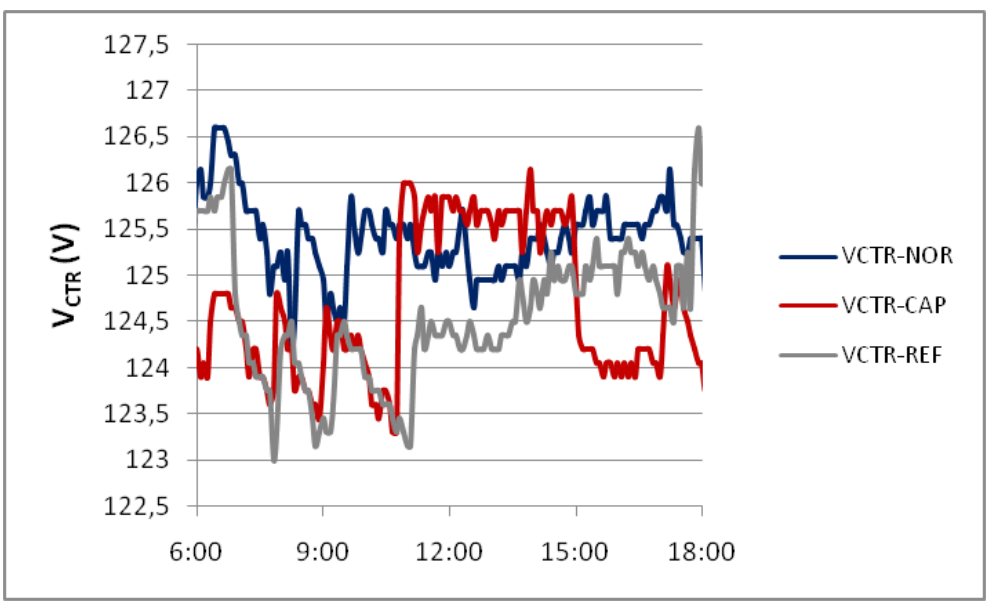

Figura 111-Tensão fase C/neutro no transformador - (normal versus capacitivo)

\subsection{2 - Modo normal versus modo indutivo}

Quando foram comparados os modos normal e indutivo, os resultados obtidos, em termos de desempenho, também foram muito semelhantes.

Na figura 112 pode-se ver que os níveis de irradiância estiveram muito próximos, assim como a figura 113 denota que a produção do sistema fotovoltaico nos dois dias de testes foi muito semelhante. 


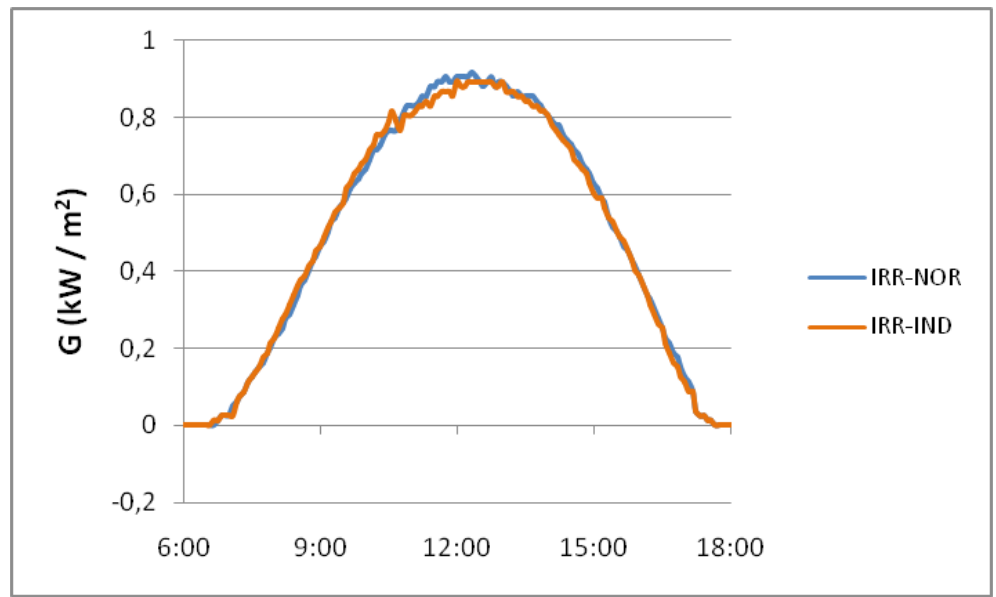

Figura 112-Irradiância - EAMCI (normal versus indutivo)

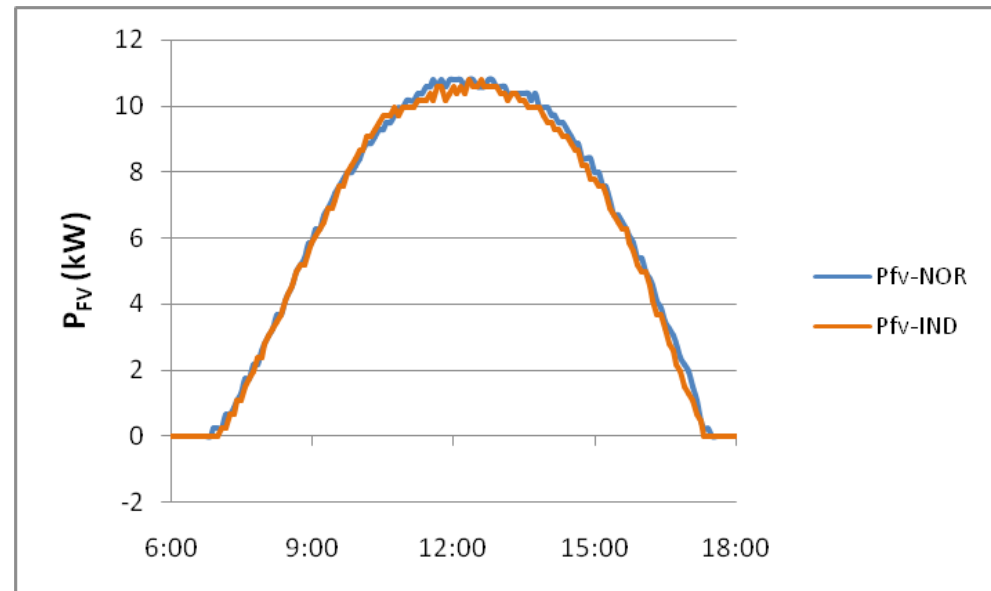

Figura 113-Potência ativa na saída do inversor- EAMCI (normal versus indutivo)

Em termos numéricos, a tabela 6 resume os indicadores de desempenho obtidos no teste comparativo.

Tabela 7-Resumo dos indicadores de desempenho - EAMCI (normal versus indutivo)

\begin{tabular}{ccccc}
\hline Teste & $\mathbf{H}\left(\mathbf{k W h} / \mathbf{m}^{2}\right)$ & $\mathbf{E}_{\text {p.conexão }}(\mathbf{k W h})$ & $\mathbf{P R}_{\text {p.conexão }}(\mathbf{\%})$ & PR $_{\text {STCp.conexão }}(\mathbf{\%})$ \\
\hline Normal & 5,95 & 73,6 & 79,3 & 86,0 \\
Indutivo & 5,91 & 71,9 & 78,0 & 84,5 \\
\hline
\end{tabular}

Aqui também se procurou avaliar os efeitos da temperatura de operação dos módulos sobre a produtividade do sistema. As curvas da figura 114 ilustram que os módulos operaram 
com temperatura ligeiramente superior quando se fez o teste no modo indutivo, comparativamente ao dia do teste no modo normal, devido às condições ambientais. Essa condição não foi verificada ao longo de todo o dia, mas sim na maior parte dele. É provável que essa tenha sido a causa da pequena diferença de 1,3\% em termos de desempenho notada na tabela anterior.

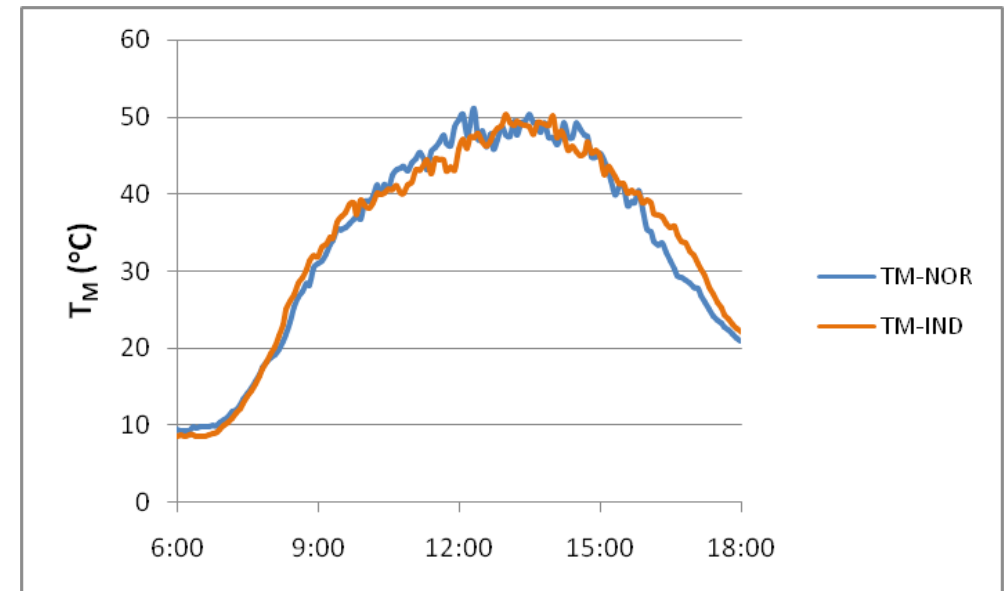

Figura 114-Temperatura dos módulos - EAMCI (normal versus indutivo)

De fato, ao se aplicar o mesmo modelo teórico da equação (67) para esse dia de testes, obtém-se uma excelente concordância entre os valores de potência calculados e medidos (figura 115).

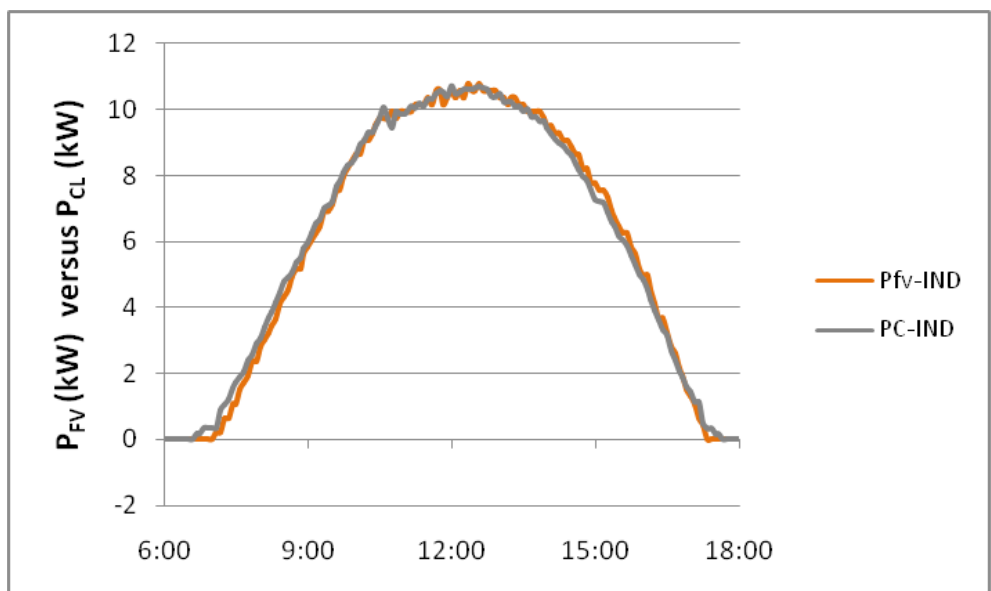

Figura 115-Potências medida (Pfv) e calculada (PC) - EAMCI (indutivo)

Mantendo-se a sequência apresentada na seção anterior, são apresentadas a seguir as 
curvas de potência reativa (figura 116) e de potência aparente (figura 117), no modo indutivo.

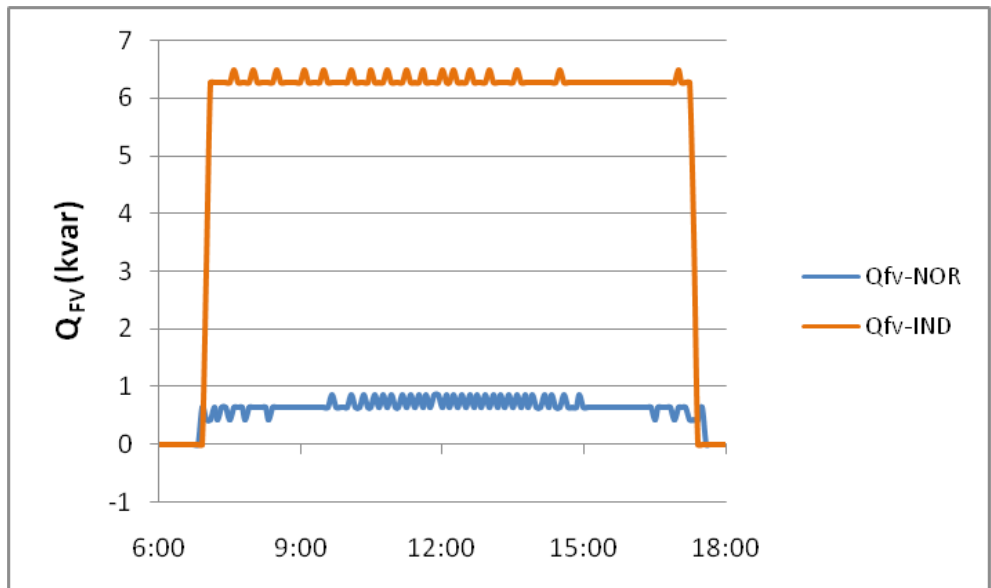

Figura 116-Potência reativa na saída do inversor - EAMCI (normal versus indutivo)

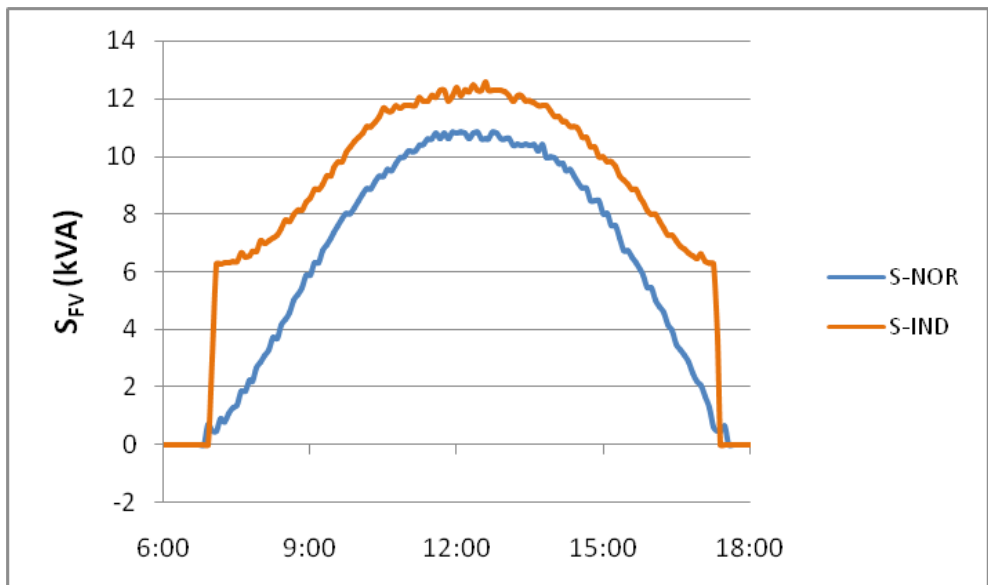

Figura 117-Potência aparente na saída do inversor - EAMCI (normal versus indutivo)

O ensaio para o modo indutivo apresentado logo acima foi realizado na segunda-feira subsequente aos dois ensaios anteriores, de forma que não seria conveniente comparar os impactos sobre a tensão no ponto de conexão e no secundário do alimentador para os modos normal e indutivo, pelo motivo já exposto anteriormente. Teoricamente, a operação no modo indutivo acarretaria em uma diminuição da tensão, mas essa afirmação carece de comprovação experimental.

Para efeito ilustrativo, as curvas seguintes, que foram obtidas fora do contexto deste bloco de ensaios, permitem ratificar a afirmação anterior. As curvas 118 e 119 foram obtidas em um domingo de céu praticamente limpo, no qual o mesmo inversor do SUBSISTEMA 1 
operava no modo indutivo, porém com o fator de potência fixo em 0,9 (e não com a potência reativa fixa, como no ensaio anterior).

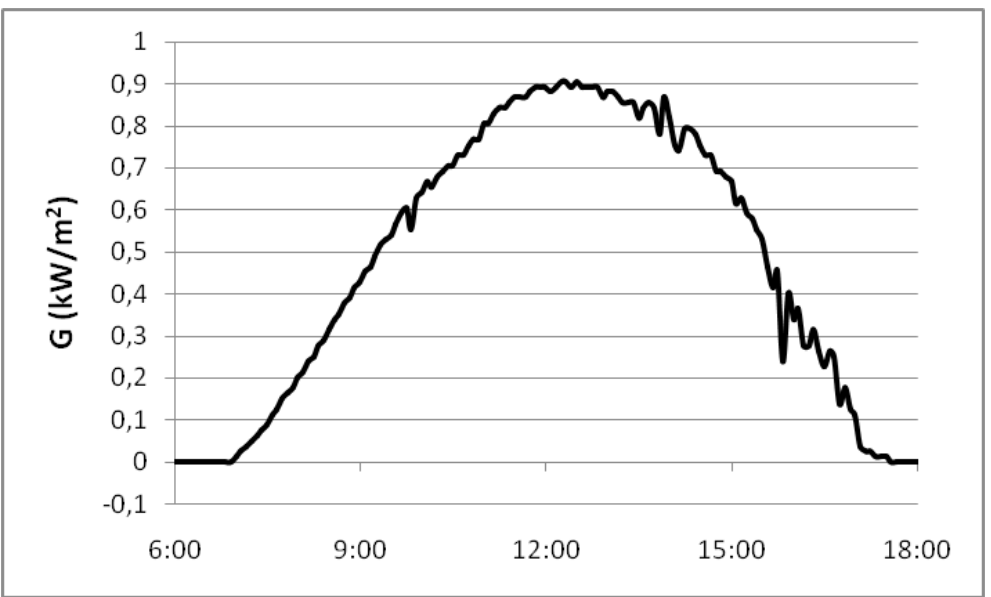

Figura 118-Irradiância - Domingo (indutivo)

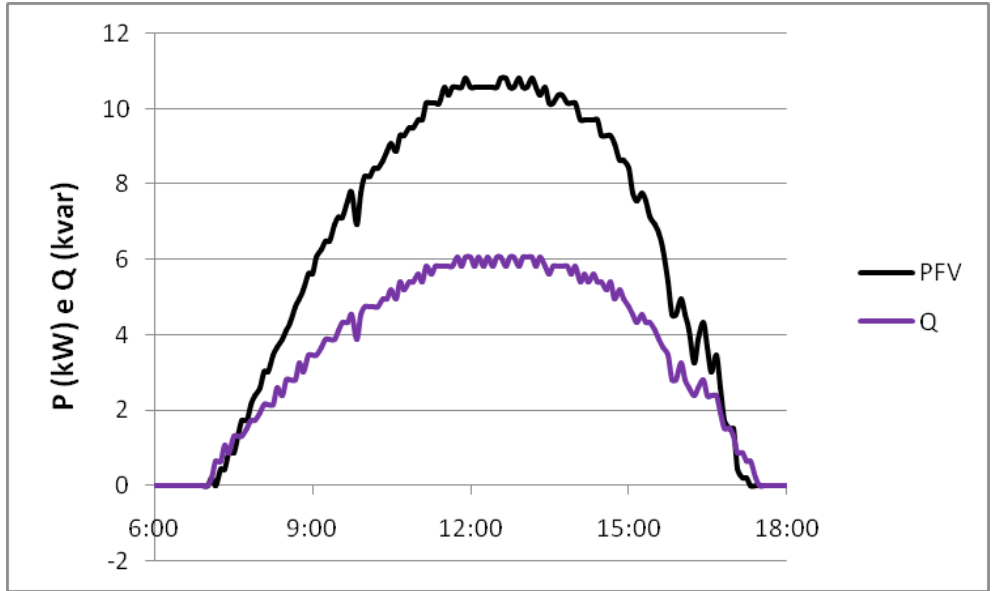

Figura 119-Potências ativa e reativa - Domingo (indutivo)

As curvas das figuras 120 a 122 apresentam as tensões entre as fases e o neutro no ponto de conexão ao longo desse dia. Novamente, para efeito comparativo, utilizou-se a mesma curva de referência da comparação entre os modos normal e capacitivo (seção 3.3.1).

Especialmente nos períodos de maior irradiância, quando a demanda de reativos pelo inversor aumenta proporcionalmente, verifica-se uma diminuição de cerca de $1,0 \mathrm{~V}$ no ponto de conexão, que não chega a ser preocupante quando se considera uma única UC, cujo sistema fotovoltaico atenda aos valores normativos.

Enfim, os ensaios desta última seção comprovaram que também no modo indutivo não se verifica uma perda significativa de produtividade do sistema fotovoltaico ou algum 
impacto relevante sobre o sistema elétrico, embora se descarte a possibilidade de algum consumidor operar seu sistema nesse modo, correndo o risco de arcar com os excedentes de reativos previstos em lei, no horário comercial.

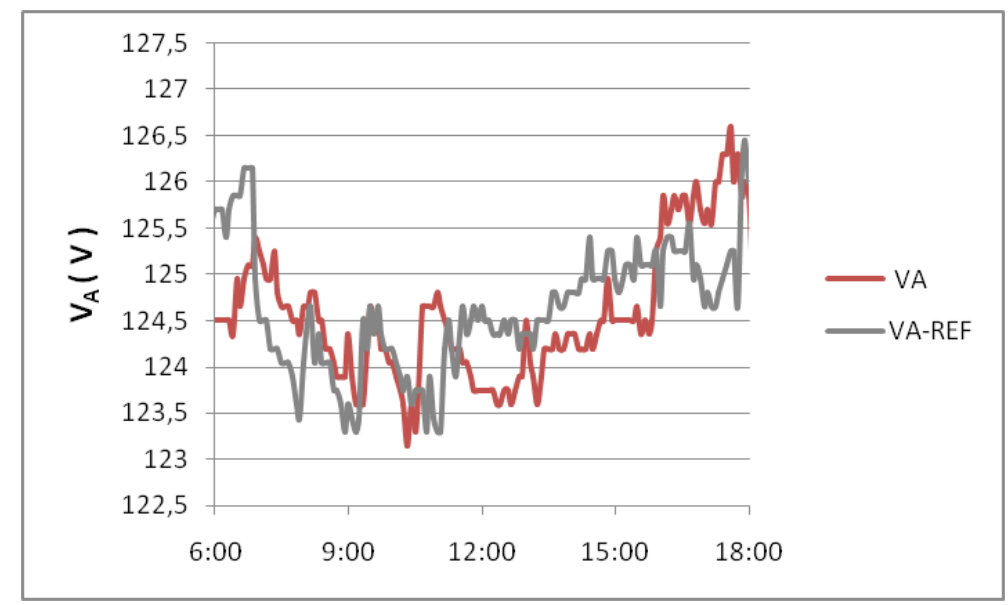

Figura 120-Tensão fase A/neutro - Domingo (indutivo)

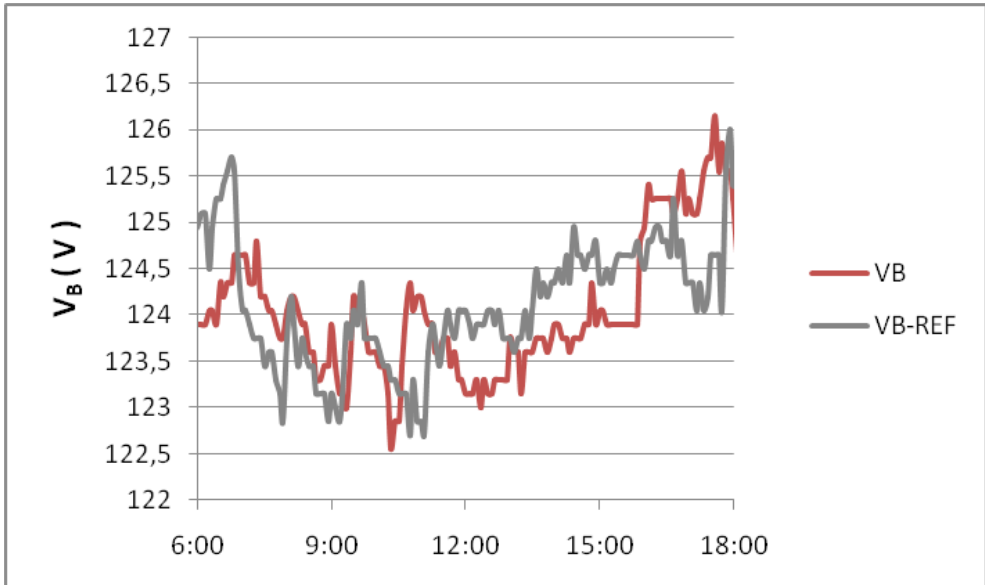

Figura 121-Tensão fase B/neutro - Domingo (indutivo)

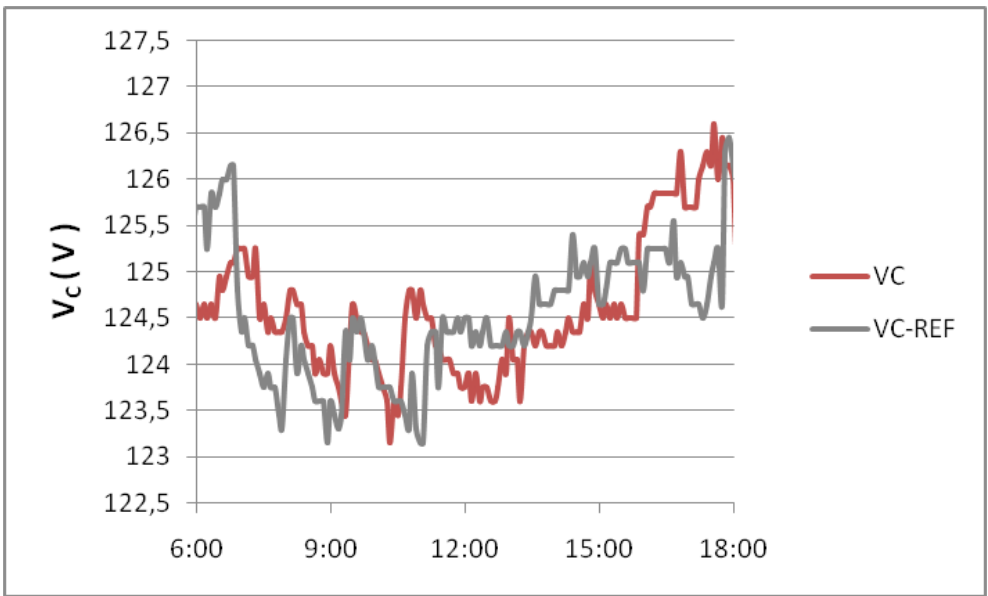

Figura 122-Tensão fase C/neutro - Domingo (indutivo) 


\section{CONCLUSÕES}

O estudo demonstrou que o fornecimento de potência reativa pelo inversor, concomitantemente com a produção de energia ativa, minimizou o problema da cobrança de energia reativa excedente, pois o perfil da carga, do ponto de vista do medidor da entrada do prédio, mudou de fortemente indutivo para levemente capacitivo. Os resultados também indicam alguns benefícios, ao sistema elétrico, da compensação de reativos pelo inversor, como a liberação de capacidade no sistema.

$\mathrm{Na}$ análise comparativa do desempenho do inversor nos modos normal, capacitivo e indutivo, demonstrou-se que a existência de um lastro de potência aparente é fundamental para que o equipamento possa entregar (ou demandar) a potência reativa necessária à correção do fator de potência, obedecidos os limites de injeção de reativos fixados em norma, sem comprometer a produção de potência ativa.

É possível inferir que, se houver interesse por parte da concessionária e anuência do proprietário da UC, é possível utilizar o controle de reativos para impactar a tensão no ponto de conexão ou mesmo em outros pontos da rede elétrica, seja aumentando-a ou diminuindo-a, nos casos em que isso se fizer necessário. Porém essa possibilidade carece de mais estudos sobre as quantidades de reativos necessárias e os respectivos impactos na vida útil dos equipamentos e na produtividade do sistema fotovoltaico.

$\mathrm{Na}$ etapa de revisão bibliográfica, constatou-se que a principal técnica convencional para compensação de reativos é a utilização de bancos de capacitores, a qual também poderia ser aplicada na resolução do problema da deterioração do fator de potência levantado na Introdução. Porém, a literatura aponta que esse tipo de solução não é trivial, pois são necessários diversos cuidados na sua utilização, como o uso de dispositivos externos de manobra e controle e de filtros antirressonantes. Assim, a instalação e monitoramento de bancos de capacitores exige a contratação de profissionais especializados e a aquisição de equipamentos de proteção e controle adequados, tornando o custo final de implementação muito maior que o dos próprios capacitores.

Esses custos podem ser evitados se for levado em conta que, no Brasil, é condição obrigatória para inversores com potência nominal superior a 3,0 $\mathrm{kW}$ a presença do controle de reativos, cabendo ao operador de rede definir quais os procedimentos que devem ser tomados para fazer um uso adequado e normatizado dessa funcionalidade. 
Uma solução teoricamente mais simples para o problema apresentado na Introdução, que é a mudança na forma de se medir o fator de potência em UCs com microgeração ou minigeração, ainda carece de regulamentação e, certamente, agregaria custos referentes à aquisição de medidores, adequação de processos e treinamento de pessoal que precisam ser conhecidos.

Dessa forma, os resultados da pesquisa indicam uma tendência a se considerar a compensação de reativos pelos inversores do sistema fotovoltaico a estratégia mais apropriada, até o presente momento, para lidar com a possibilidade da cobrança de excedentes de reativos causada pela aparente deterioração do fator de potência, medido no ponto de entrega, confirmando-se a hipótese inicial. 


\section{SUGESTÕES PARA TRABALHOS FUTUROS}

Em decorrência do alcance limitado dos resultados deste trabalho, são sugeridos os seguintes temas de pesquisa para trabalhos futuros:

- Construção e implementação de algoritmo e controlador externo para correção em tempo real do fator de potência de uma instalação através de inversores com mecanismo de controle de reativos;

- Controle de tensão, no ponto de conexão, através do uso de inversores com controle de reativos;

- Impacto do fornecimento de potência reativa na vida útil de inversores;

- Estudo da ressonância harmônica decorrente da compensação de reativos através de inversores;

- Utilização de plantas fotovoltaicas de médio porte com controle de reativos na prestação de serviços ancilares pelas distribuidoras de energia elétrica. 


\section{REFERÊNCIAS BIBLIOGRÁFICAS}

AGÊNCIA NACIONAL DE ENERGIA ELÉTRICA. Resolução Normativa No $\mathbf{4 1 4}$, de 9 de setembro de 2013: Estabelece as Condições Gerais de Fornecimento de Energia Elétrica de forma atualizada e consolidada. Brasília, 2013.

AGÊNCIA NACIONAL DE ENERGIA ELÉTRICA. Resolução Normativa No 569, de 23 de julho de 2013: Modifica a abrangência na aplicação do fator de potência para faturamento do excedente de reativos de unidades consumidoras e altera a Resolução Normativa $\mathrm{n}^{\mathrm{o}} .414$, de 9 de setembro de 2010. Brasília, 2013.

ALBUQUERQUE, F. L. et al. Photovoltaic solar system connected to the electric power grid operating as active power generator and reactive power compensator. Solar Energy, v. 84, n. 7, p. 1310-1317, jul. 2010.

ASSOCIAÇÃO BRASILEIRA DE NORMAS TÉCNICAS. NBR16149: Sistemas fotovoltaicos (FV) - Características da interface de conexão com a rede elétrica de distribuição. Rio de Janeiro, 2013.

BARBOSA, P. G. et al. Control strategy for grid-connected DC-AC converters with load power factor correction. Generation, Transmission and Distribution, IEE Proceedings-, v. 145, n. 5, p. 487-491, set. 1998.

BARRETO, G. et al. Circuitos de corrente alternada: fundamentos e prática. 1. ed. São Paulo: Oficina de Textos, 2012.

BELAIDI, R. et al. Shunt active power filter connected to a photovoltaic array for compensating harmonics and reactive power simultaneously. In: Fourth International Conference on Power Engineering, Energy and Electrical Drives (POWERENG), 2013, Turkey. Proceedings. Istanbul: IEEE, 2013. p.1482-1486.

BENEDITO, Ricardo da Silva. Caracterização da geração distribuída por meio de Sistemas fotovoltaicos conectados à rede, no Brasil, sob os aspectos técnico, econômico e regulatório. 2009. 108f. Dissertação (Mestrado em Ciências) - Programa de Pós- Graduação em Energia da Universidade de São Paulo, São Paulo, 2009.

BRAUN, M. Reactive Power supplied by PV Inverters-Cost-Benefit-Analysis. In: 22nd European Photovoltaic Solar Energy Conference (EU PVSEC), 2007, Italy. Proceedings. Milan:2007.

CAGNANO, A. et al. Can PV plants provide a reactive power ancillary service? A treat 
offered by an on-line controller. Renewable Energy, v. 36, n. 3, p. 1047 - 1052, 2011.

CHANG, C.-H. et al. Simplified Reactive Power Control for Single-Phase Grid-Connected Photovoltaic Inverters. IEEE Transactions on Industrial Electronics, v. 61, n. 5, p. 22862296, mai. 2014.

CHUNLING, L. et al. Power quality enhancement by means of a novel control method of a three-phase grid-connected photovoltaic system. In: Power Electronics and Motion Control Conference, 2009. China. Proceedings. Wuhan: IEEE, 2009. p. 2140-2142.

COTRIM, Ademaro Alberto. Conceitos fundamentais. In: COTRIM, A. A. M. B. Instalações elétricas. 5. ed. São Paulo: Pearson, 2009. Cap. 2, p. 29-65.

CREDER, Hélio. Correção do fator de potência e instalação de capacitores. In: CREDER, H. Instalações elétricas. 15. ed. Rio de Janeiro: Pearson, 2007. Cap.9, p. 269-291.

GHARAKHANY, R.; MOHAMADIAN, M.; VARJANI, A. Y. Reactive power compensation using Z-source based photovoltaic system. In: Power Energy Society General Meeting, 2009.Canada. Proceedings. Alberta:IEEE, 2009.

HAMROUNI, N.; JRAIDI, M.; CHÉRIF, A. New control strategy for 2-stage grid-connected photovoltaic power system. Renewable Energy, v. 33, n. 10, p. $2212-2221,2008$.

HAMZAOUI, I.; BOUCHAFAA, F.; HADJAMMAR, A. Investigation of the behavior of a three phase gridconnected photovoltaic system to control active and reactive power with DPC. Energy Procedia, v. 6, n. 0, p. 493 - 502, 2011.

HASSAINE, L. et al. Digital power factor control and reactive power regulation for gridconnected photovoltaic inverter. Renewable Energy, v. 34, n. 1, p. 315 - 321, 2009.

HASSAINE, L. et al. Power control for grid connected applications based on the phase shifting of the inverter output voltage with respect to the grid voltage. International Journal of Electrical Power \& Energy Systems, v. 57, n. 0, p. 250 - 260, 2014.

HOFMANN, W.; SCHLABBACH, J.; JUST, W. Reactive Power Compensation: A Practical Guide. [s.1.] John Wiley \& Sons, 2012.

KIM, S.; YOO, G.; SONG, J. A bifunctional utility connected photovoltaic system with power factor correction and UPS facility. In: Photovoltaic Specialists Conference, 1996. United 
States. Proceedings. Washington: IEEE, 1996. p 1363-1368.

LIBO, W.; ZHENGMING, Z.; JIANZHENG, L. A Single-Stage Three-Phase Grid-Connected Photovoltaic System With Modified MPPT Method and Reactive Power Compensation. IEEE Transactions on Energy Conversion, v. 22, n. 4, p. 881-886, dez. 2007.

LI, H. et al. Real and reactive power control of a three-phase single-stage PV system and PV voltage stability. In: Power and Energy Society General Meeting, 2012. United States. Proceedings. San Diego: IEEE, 2012. p. 1-8.

LIU, L. et al. A Cascaded Photovoltaic System Integrating Segmented Energy Storages With Self-Regulating Power Allocation Control and Wide Range Reactive Power Compensation. IEEE Transactions on Power Electronics, v. 26, n. 12, p. 3545-3559, dez. 2011.

MACÊDO, Wilson Negrão. Análise do fator de dimensionamento do inversor aplicado a sistemas fotovoltaicos conectados à rede. 2006. 183f. Tese (Doutorado em Energia) Programa de Pós-Graduação em Energia da Universidade de São Paulo, São Paulo, 2006.

MACÊDO, W. N.; ZILLES, R. Influence of the power contribution of a grid-connected photovoltaic system and its operational particularities. Energy for Sustainable Development, v. 13, n. 3, p. $202-211,2009$.

MARTI, P. et al. Distributed reactive power control methods to avoid voltage rise in gridconnected photovoltaic power generation systems. In: IEEE International Symposium on Industrial Electronics (ISIE), 2013. Taiwan. Proceedings. Taipei, 2013.

MORÓN, Juan Antonio. Compensación de potencia reactiva en líneas de distribución.In: MORÓN, J. A. Y. Sistemas Eléctricos de Distribución. Barcelona: Reverte, 2009. Cap. 7, p.190-216.

NAYAR, C. V.; ISLAM, S. M.; SHARMA, H. Power Electronics for Renewable Energy Sources.In: HASHID, M.H. Power Electronics Handbook. Canada: Academic Press, 2001. Cap. 23, p. 539-573.

NOROOZIAN, R.; GHAREHPETIAN, G. B. An investigation on combined operation of active power filter with photovoltaic arrays. International Journal of Electrical Power \& Energy Systems, v. 46, n. 0, p. 392 - 399, 2013.

PINHO, J.T. , (Org.); GALDINO, M. A. , (Org.). Manual de engenharia para sistemas fotovoltaicos. Rio de Janeiro: CRESESB, 2014. 
PINTO, A.; ZILLES, R. Reactive power excess charging in grid-connected PV systems in Brazil. Renewable Energy, v. 62, n. 0, p. 47 - 52, 2014.

RESHMA, K.; RAJESH, C. Harmonic and reactive power compensation in a grid connected PV system with source side control technique. International Journal of Emerging Technology and Advanced Engineering, v. 3, n. 9, p. 212-220, 2013.

SEO, H.R. et al. Harmonics and reactive power compensation method by grid-connected Photovoltaic generation system. In: International Conference on Electrical Machines and Systems (ICEMS), 2009. Japan. Proceedings. Tokio: IEEE, 2009.

SCHMIDT, H.; BURGER, B.; SCHMID, J. Power Conditioning for Photovoltaic Power Systems. In: LUQUE, H; HEGEDUS, S. Handbook of Photovoltaic Science and Engineering. 2.ed. Chennai: John Wiley \& Sons, 2011. Cap. 21, p.955-983.

STAROSTA, José. Compensação da energia reativa. In: COTRIM, A.M.B. Instalações elétricas. 5. ed. São Paulo: Pearson, 2009. Cap. 14, p. 419-434.

TSENGENES, G.; ADAMIDIS, G. Investigation of the behavior of a three phase gridconnected photovoltaic system to control active and reactive power. Electric Power Systems Research, v. 81, n. 1, p. 177-184, jan. 2011.

TURITSYN, K. et al. Local Control of Reactive Power by Distributed Photovoltaic Generators. In: International Conference on Smart Grid Communications (SmartGridComm), 2010. United States. Proceedings. Maryland: IEEE, 2010. p. 79-84.

TURITSYN, K. et al. Options for Control of Reactive Power by Distributed Photovoltaic Generators. Proceedings of the IEEE, v. 99, n. 6, p. 1063-1073, jun. 2011.

YU, H.; PAN, J.; XIANG, A. A multi-function grid-connected PV system with reactive power compensation for the grid. Solar Energy, v. 79, n. 1, p. 101 - 106, 2005.

ZILLES, R. et al. Sistemas fotovoltaicos conectados à rede elétrica. São Paulo: Oficina de Textos, 2012.

ZILLES, R.; OLIVEIRA, S. H. F. O Preço do Wp e o custo do kWh fornecido por sistemas interligados à rede elétrica. In: VIII Congresso Brasileiro de Energia, 1999. Anais. Rio de Janeiro, CBE, 1999. p 743-748. 